\title{
On the significance and predictability of geological parameters in the exploration for geothermal energy
}

\section{Dissertation}

zur Erlangung des mathematisch-naturwissenschaftlichen Doktorgrades

„Doctor rerum naturalium“

der Georg-August-Universität Göttingen

im Promotionsprogramm Geowissenschaften / Geographie der Georg-August-University School of Science (GAUSS)

vorgelegt von

Johanna Frederike Bauer

aus Konstanz 


\section{Betreuungsausschuss:}

\section{Prof. Dr. Jonas Kley}

Abteilung: Strukturgeologie und Geodynamik

Geowissenschaftliches Zentrum der Georg-August-Universität Göttingen

\section{Dr. David C. Tanner}

Sektion: Seismik und Potentialverfahren

Leibniz-Institut für Angewandte Geophysik (LIAG)

Prof. Dr. Inga Moeck

Sektion: Geothermik und Informationssysteme

Leibniz-Institut für Angewandte Geophysik (LIAG)

\section{Referenten:}

\section{Referent:}

2. Korreferentin

Korreferent:

\section{Prof. Dr. Jonas Kley}

Abteilung: Strukturgeologie und Geodynamik

Geowissenschaftliches Zentrum der Georg-August-Universität Göttingen

\section{Dr. David C. Tanner}

Sektion: Seismik und Potentialverfahren

Leibniz-Institut für Angewandte Geophysik (LIAG)

\section{Prof. Dr. Inga Moeck}

Sektion: Geothermik und Informationssysteme

Leibniz-Institut für Angewandte Geophysik (LIAG)

\section{Mitglieder der Prüfungskommission:}

- Prof. Dr. Jonas Kley Geowissenschaftliches Zentrum der Georg-August-Universität Göttingen

- Dr. David C. Tanner Leibniz-Institut für Angewandte Geophysik (LIAG)

- Prof. Dr. Inga Moeck Leibniz-Institut für Angewandte Geophysik (LIAG)

- Prof. Dr. Sharon Webb Geowissenschaftliches Zentrum der Georg-August-Universität Göttingen

- Dr. Bernd Leiss Geowissenschaftliches Zentrum der Georg-August-Universität Göttingen

- Dr. Elco Luijendijk Geowissenschaftliches Zentrum der Georg-August-Universität Göttingen 
"A man should look for what is,

and not for what he thinks should be"

Albert Einstein (1879 - 1955) 



\begin{abstract}
Sufficient reservoir permeability is essential to exploit heat resources for geothermal energy. Reliable prediction of permeability and in consequence flow rate in a deep geothermal reservoir is difficult to predict because subsurface data are rare. Since fracture density often increases around fault zones, fault-related reservoirs have become prime targets for exploration. However, this is not without risk, because fault-related permeability can vary greatly on the small scale.
\end{abstract}

My cumulative thesis is part of the AuGE Project (Aufschlussanalogstudien und ihre Anwendbarkeit in der Geothermischen Exploration), which aims to establish outcrop studies as an important part of geothermal exploration. My thesis is concerned with the predictability of geological parameters of fault zones based on outcrop studies within the Upper Rhine Graben (URG), an area that, due to its elevated geothermal gradient, is promising for geothermal energy. Additionally, I investigated the influence and interaction of the most relevant parameters for geothermal reservoir quality in a numerical sensitivity study.

I carried out fieldwork in faulted and unfaulted outcrops of Muschelkalk and Buntsandstein rocks. The results of these outcrop studies show that fault zones have the potential to increase flow rate by many orders of magnitude. My co-workers and I found that a relationship exists between the permeability of the fault zones and lithological parameters, but also that fault permeability is heterogeneous even within the same lithology. Quantification of these observations was, however, not possible.

To test transferability of the data collected at the surface to depth, these results were compared with data from a nearby well. The study shows that certain petrological properties are comparable, but key parameters, such as petrophysical properties and fracture-system parameter, are not. The latter are responsible for the fluid flow rate and therefore extrapolation of outcrop data to depth would lead to misjudgement of the reservoir characteristics.

Subsequently, I modelled the fluid and heat transport in a reservoir with a geothermal doublet with the aim to understand the influence of various structural parameters. I found that high permeabilities, permeability contrasts and anisotropies, caused by bedding and fractures, have a large potential to reduce the exploitable reservoir volume and thus the reservoir's quality. Accordingly, faults with highly conductive damage zones are likely to provide only small utilisable volumes and are thus, in many cases, less suitable as geothermal reservoir. My sensitivity study also shows the role of the hydraulic gradient and how its importance depends on permeability and reservoir configuration.

My dissertation helps to better estimate reservoir quality. I showed that structurally complex reservoirs are not only difficult to explore, but also potentially less yielding than homogenous reservoirs. In addition, increasing heterogeneity hinders the identification of outcrops as suitable analogues prior drilling. My sensitivity study constitutes a step forward in better understanding and classifying the parameters that control reservoir quality.

My findings show that only a combination of outcrop and well data, together with geophysical exploration and tracer tests, and detailed knowledge of the impact of different parameters can allow a reliable estimation of the reservoir's lifetime. 


\section{Kurzfassung}

Um vorhandene geothermische Ressourcen profitabel nutzen zu können, sind ausreichende Reservoirpermeabilitäten unerlässlich. Die Abschätzung von Permeabilitäten, und folglich möglichen Fließraten, in tiefengeothermischen Reservoiren ist aber durch eine geringe Informationsdichte im Untergrund generell schwierig. Störungsgebundene Reservoire versprechen ein erhöhtes Potenzial, da sie oft eine erhöhte Bruchdichte und damit eine erhöhte strukturelle Permeabilität aufweisen. Problematisch ist allerdings, dass die Permeabilitäten von Störungen auf kleinstem Raum stark variieren können.

Meine kumulative Dissertation, als Teil des Projektes AuGE (Aufschlussanalogstudien und ihre Anwendbarkeit in der Geothermischen Exploration), hatte zum Ziel, Aufschlussanalogstudien besser in das geothermische Explorationskonzept zu integrieren. Dazu haben wir die Vorhersagbarkeit von Gesteins- und Bruchsystemparametern um Störungszonen im Oberrheingraben (URG), einem potenziellen Gebiet für die hydrogeothermische Stromerzeugung in Deutschland, untersucht. Zusätzlich habe ich den Einfluss und die Wechselwirkung relevanter geologischer Parameter auf die Reservoirqualität in einer numerischen Sensitivitätsstudie untersucht.

Die Geländearbeiten haben wir an gestörten und ungestörten Aufschlüssen im Muschelkalk und Buntsandstein durchgeführt. Die Ergebnisse unserer Aufschlussstudien stützen das Potenzial von Störungszonen, die Permeabilität um mehrere Größenordnungen zu erhöhen. Weiterhin fanden wir einen Zusammenhang zwischen der Permeabilitätsstruktur von Störungszonen und lithologischen Parametern. Es wurde jedoch auch deutlich, dass störungsgebundene Permeabilitäten innerhalb vergleichbarer Lithologien stark schwanken. Eine Quantifizierung dieser Beobachtung war aber nicht möglich.

Um die Übertragbarkeit der an der Oberfläche gewonnenen Daten in den Untergrund zu überprüfen, haben wir diese mit Messungen aus einer im Arbeitsgebiet befindlichen Tiefbohrung verglichen. Die Ergebnisse zeigen, dass im Aufschluss bestimmte petrologische Eigenschaften mit ausreichender Genauigkeit auf das Reservoir übertragen werden konnten, die im Aufschluss beobachteten petrophysikalischen Eigenschaften wie Porosität und Permeabilität jedoch nicht. Auch die Bruchsystemparameter, welche hauptverantwortlich für die Fließraten sind, unterscheiden sich signifikant. Eine simple Extrapolation der Aufschlussdaten hätte somit zu einer Fehleinschätzung der Reservoirqualität geführt.

Die anschließende numerische Sensitivitätsstudie habe ich am Beispiel einer geothermischen Dublette durchgeführt. Die Ergebnisse zeigen ab welchen Werten Permeabilitätskontraste und -anisotropien, hervorgerufen durch Schichtung und Brüche, das nutzbare Reservoirvolumen negativ beeinflussen. Meine Studie beschreibt auch den zunehmenden Einfluss des hydraulischen Gradienten auf die Reservoirqualität bei steigenden Permeabilitäten. Hochpermeable Störungszonen sind meinen Modellierungen zu Folge aufgrund verringerter Reservoirvolumen als geothermisches Reservoir oftmals wenig geeignet.

Meine Dissertation hilft, die Qualität von geothermischen Reservoiren besser einzuschätzen und verdeutlicht, dass heterogene Reservoire nicht nur schwieriger zu explorieren, sondern potentiell auch weniger ergiebig sind als homogene Reservoire. Zunehmende Heterogenität erschwert es auch, geeignete Aufschlüsse vor dem Abteufen einer Bohrung als geeignetes Analog zu identifizieren. Meine Sensitivätsstudie ist ein Schritt, um Reservoirgüte bestimmende Parameter in ihrer Bedeutung besser einzuordnen.

Die gewonnenen Erkenntnisse zeigen, dass nur die Kombination von Aufschlussdaten mit vorhandenen und zukünftigen Observationsbohrungen, geophysikalischen Daten und Tracerversuchen sowie dem Wissen über den genauen Einfluss der verschiedenen Parameter eine sinnvolle Abschätzung der Eignung und Nutzungsdauer eines Reservoirs für die geothermische Nutzung ermöglicht. 
List of symbols and abbreviations

\begin{tabular}{|c|c|c|}
\hline Symbol & Unit & Description \\
\hline$A$ & $\mathrm{~mm}^{2}$ & cross-sectional area \\
\hline $\boldsymbol{b}$ & $\mathrm{mm}$ & fracture aperture \\
\hline$C_{p}$ & $\mathrm{~J} \mathrm{~kg}^{-1} \mathrm{~K}^{-1}$ & heat capacity \\
\hline$D$ & $\mathrm{~mm}$ & specimen diameter \\
\hline$\nabla D$ & & unit vector \\
\hline$d_{50}$ & $\mathrm{~m}$ & mean grain size \\
\hline $\boldsymbol{E}$ & $\mathrm{GPa}$ & Young's Modulus \\
\hline$\varepsilon$ & - & Strain \\
\hline$E_{d}$ & $\mathrm{GPa}$ & dynamic Young's Modulus \\
\hline$E_{e, e f f}$ & $\mathrm{GPa}$ & effective Young's modulus \\
\hline$E_{i}$ & $\mathrm{GPa}$ & Young's Modulus of intact rock \\
\hline$E_{s}$ & $\mathrm{GPa}$ & static Young's Modulus \\
\hline $\boldsymbol{F}$ & $\mathrm{kg} \mathrm{m} \mathrm{s}^{-2}$ & Force \\
\hline$f$ & $m^{-1}$ & fracture density \\
\hline$\Phi, d$ & $\mathrm{~mm}$ & grain size \\
\hline$g$ & $\mathrm{~m} \mathrm{~s}^{-2}$ & acceleration due to gravity \\
\hline $\boldsymbol{H}$ & $\mathrm{m}$ & reservoir height \\
\hline$\varphi$ & $\%$, fraction & fracture porosity \\
\hline $\boldsymbol{k}$ & $W m^{-1} K^{-1}$ & thermal conductivity \\
\hline $\boldsymbol{\kappa}$ & $m^{2}$ & Permeability \\
\hline$K_{f}$ & $m^{2}$ & fracture permeability \\
\hline $\boldsymbol{k}_{f}$ & $\mathrm{~m} \mathrm{~s}^{-1}$ & hydraulic conductivity of fractures \\
\hline$K_{m}$ & $m^{2}$ & matrix permeability \\
\hline $\boldsymbol{k}_{n}$ & MPa m-1 & fracture normal stiffness \\
\hline$L$ & $\mathrm{~m}, \mathrm{~mm}$ & profile length, specimen length \\
\hline$\mu$ & $\mathrm{kg} \mathrm{m}^{-1} \mathrm{~s}^{-1}$ & dynamic viscosity \\
\hline$\nabla p$ & $\mathrm{~mm} \mathrm{~m}^{-1}$ & pressure gradient \\
\hline$Q$ & $\mathrm{~m}^{3} \mathrm{~s}^{-1}, \mathrm{Wm}^{-3}$ & production rate, heat source or sink \\
\hline$q$ & $\mathrm{~m} \mathrm{~s}^{-1}$ & fluid velocity \\
\hline $\boldsymbol{\theta}$ & $\%$, phi, fraction & Porosity \\
\hline $\boldsymbol{R}$ & - & rebound hardness \\
\hline$R_{1}, P_{1}$ & - & synthetic shear fractures \\
\hline$\rho_{b}$ & $\mathrm{~kg} \mathrm{~m}^{-3}$ & bulk density \\
\hline$\rho_{f}$ & $\mathrm{~kg} \mathrm{~m}^{-3}$ & fluid density \\
\hline$\rho_{\log }$ & $\mathrm{kg} \mathrm{m}^{-3}$ & log based bulk density \\
\hline$\rho_{m}$ & $\mathrm{~kg} \mathrm{~m}^{-3}$ & matrix density \\
\hline$\Delta_{s}$ & $\mathrm{~m}$ & pressure reduction \\
\hline $\bar{S}$ & $\mathrm{~m}$ & average inverse discontinuity spacing \\
\hline$S$ & - & grain size sorting \\
\hline$\sigma$ & $\mathrm{MPa}$ & Stress \\
\hline$\sigma_{n}$ & $\mathrm{MPa}$ & normal stress \\
\hline$T$ & $\mathrm{~m}^{2} \mathrm{~s}^{-1},{ }^{\circ} \mathrm{C}$ & transmissivity or temperature \\
\hline$T_{0}$ & $\mathrm{MPa}$ & indirect tensile strength \\
\hline$\Delta t_{f}$ & $\mu \sec \mathrm{m}^{-1}$ & sonic travel time in a fluid \\
\hline$\Delta t_{\log }$ & $\mu \sec \mathrm{m}^{-1}$ & sonic travel time through the reservoir \\
\hline$\Delta t_{\text {matrix }}$ & $\mu$ sec $\mathrm{m}^{-1}$ & sonic travel time through the matrix \\
\hline UCS & $\mathrm{MPa}$ & uniaxial compressive strength \\
\hline$v_{p}$ & $\mathrm{~m} \mathrm{~s}^{-1}$ & compressional-wave velocity \\
\hline$v_{s}$ & $\mathrm{~m} \mathrm{~s}^{-1}$ & shear-wave velocity \\
\hline
\end{tabular}




\begin{tabular}{|c|c|}
\hline Abbreviation & Description \\
\hline AuGE & $\begin{array}{l}\text { Aufschlussanalogstudien und ihre Anwendbarkeit in der } \\
\text { Geothermischen Exploration }\end{array}$ \\
\hline BFH & Northern Black Forest High \\
\hline BG & Bresse Graben \\
\hline BL & Badenweiler-Lenzkirch Fault \\
\hline BT & Burgundy Trough \\
\hline CFC & central fault core \\
\hline CL & outcrop Cleebourg \\
\hline DFC & distal fault core \\
\hline DFN & discrete fracture network \\
\hline DSI & Dipole Sonic Imager log \\
\hline DZ & damage zone \\
\hline EG & Eger Graben \\
\hline FC & fault core \\
\hline FMI & Formation Micro Imager log \\
\hline FSH & Fenno-Scandia High \\
\hline FZ & fault zone \\
\hline GR & gamma ray log \\
\hline GT1 & geothermal well Brühl \\
\hline HB & outcrop Hanbuch \\
\hline HG & Hessian grabens, hydraulic gradient \\
\hline HIT & hundred-degree isothermal \\
\hline $\mathrm{Ho}-\mathrm{H}$ & Hochwald-Horst \\
\hline HR & host rock \\
\hline IL & outcrop Illingen \\
\hline IQR & interquartile range \\
\hline IT & outcrop Ittlingen \\
\hline KF & outcrop Kammerforster \\
\hline KN & outcrop Knittlingen \\
\hline KT & Kraichgau Trough \\
\hline LB & Baden-Baden-Lalaye-Lubine- Fault \\
\hline LDS & Litho Density Sonde log \\
\hline LG & Limagne Graben \\
\hline LRG & Lower Rhine Graben \\
\hline LS & outcrop Leistadt \\
\hline $\mathrm{mm}$ & Middle Muschelkalk \\
\hline MNH & Mid North Sea High \\
\hline mo & Upper Muschelkalk \\
\hline mu & Lower Muschelkalk \\
\hline MZ & mixed zone \\
\hline $\mathrm{n}$ & sample quantity \\
\hline NL & outcrop Nussloch \\
\hline $\mathrm{OH}$ & Odenwald-Spessart High \\
\hline OT & Offenburg Trough \\
\hline PPC & Powered Positioning Caliper \\
\hline QFL & quartz, feldspar, lithoclast \\
\hline REV & representative elementary volume \\
\hline RFH & Ringkobing-Fyn High \\
\hline RS & outcrop Riesenstein \\
\hline SGH & Main Southern German High \\
\hline SHB & South Hunsrück-Taunus border Fault \\
\hline SL & low-angle cross-bedded sandstones \\
\hline SNB & Saar-Nahe Basin \\
\hline SP & slip surface \\
\hline SPI & secondary porosity index \\
\hline ST & Schramberg Trough \\
\hline ST & trough cross-bedded sandstones \\
\hline URG & Upper Rhine Graben \\
\hline URH & Main Upper Rhine High \\
\hline VG & Vistrenque Graben \\
\hline ZB & Zaberner Basin \\
\hline
\end{tabular}




\section{List of figures}

Figure 1.1: The German electricity generation from 1990 to 2014 by energy sources .................................. 1

Figure 1.2: a) Map showing the temperature gradient in Germany .............................................................. 2

Figure 1.3: Basic concept and specific questions examined in this thesis ..................................................... 5

Figure 2.1: Localities and lithologies of the studied outcrops ................................................................... 7

Figure 2.2: Pre-rift setting of the URG area with Variscan fault traces.............................................................. 8

Figure 2.3: Schematic overview of the two-stress phases of the URG formation .............................................. 9

Figure 2.4: a) Geological map of the Upper Rhine Graben. ................................................................... 10

Figure 2.5: Buntsandstein Paleography and the location of the study area ............................................. 12

Figure 2.6: Lithostratigraphic correlation of the Buntsandstein between ................................................... 13

Figure 3.1: Photograph of a L-Type Schmidt Hammer, with detailed setup ................................................. 14

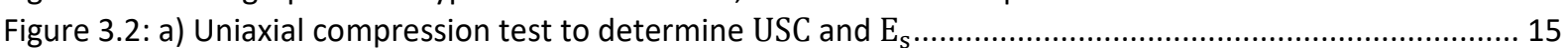

Figure 3.3: Image analysis in ImageJ. a) Scaled scan of a thin section under plane polarised light..................... 17

Figure 3.4: Coupling of different physical properties (after Oberdorfer, 2014). ............................................... 18

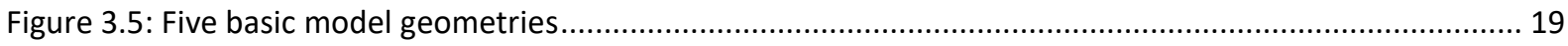

Figure 3.6: a) Model setup. b) Directions of the hydraulic gradient as used in the models ...............................20

Figure 3.7: Varying mesh quality, depending on the size of the modelled structures.................................... 21

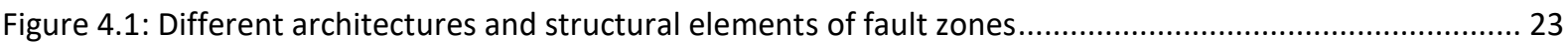

Figure 4.2: a) The European Cenozoic Rift System with N-S- to NNE-SSW-oriented graben systems ...................25

Figure 4.3: Schematic 3D-view of the studied outcrop with marked cross-sections ......................................... 27

Figure 4.4: a) Photograph of the main fault zone with highlighted fault core.................................................... 28

Figure 4.5: a) Orientations of slip surfaces (black dots), main fault zone (red rectangle) ................................ 29

Figure 4.6: a) Transition between the damage zone and the core zone ................................................... 30

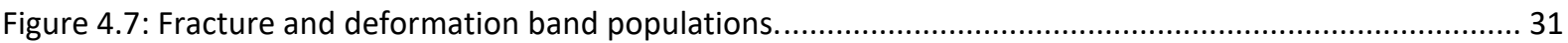

Figure 4.8: Histograms show the fracture density distribution perpendicular to the fault plane. ........................32

Figure 4.9: Diagrams showing the variations of fracture aperture $[\mathrm{mm}]$ and fracture length $[\mathrm{m}] \ldots \ldots \ldots \ldots \ldots \ldots . . . . . . . . . . .33$

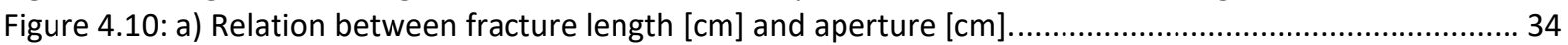

Figure 4.11: Histograms show the variations of fracture connectivity (a) and fracture mineralization (b).......... 35

Figure 4.12: Closely spaced rebound-hardness measurements against the distance from fault core ................ 36

Figure 4.13: Calculated effective and intact Young's Moduli [GPa] perpendicular to the fault zone .................. 37

Figure 5.1: Simplified geological maps (modified from Walter, 2007) of the Upper Rhine Graben ................... 45

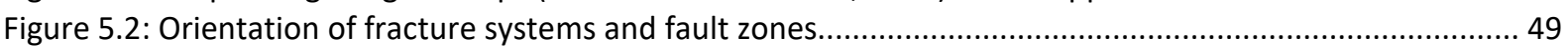

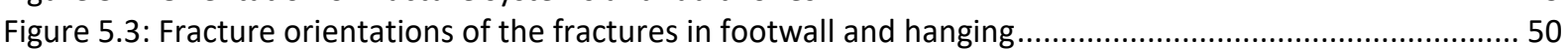

Figure 5.4: Fracture system orientation in the main fault zone in Illingen ......................................................5 51

Figure 5.5: Field pictures of the analysed fault zone in the Nussloch-quarry ..............................................5 52

Figure 5.6: Sketch and field picture of the analysed fault zone in the Nussloch-quarry .................................5 53

Figure 5.7: Fracture density distribution normal to the main fault zone in the Nussloch-quarry ...................... 54

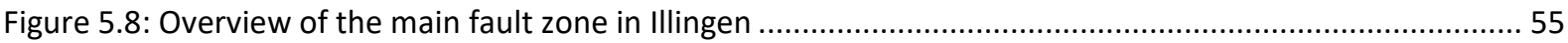

Figure 5.9: Overview pictures and sketch of the described fault zone (FZ 1) cropping out in the Knittlingen ..... 56

Figure 5.10: Fracture density distribution normal to the described fault zone ................................................5 57

Figure 5.11: Fracture connectivity of the fracture systems in the quarries Nussloch .......................................58

Figure 5.12: Fracture connectivity of the fractures within the main fault damage zones................................59

Figure 5.13: Percentage of stratabound vs. non-stratabound fractures .....................................................60

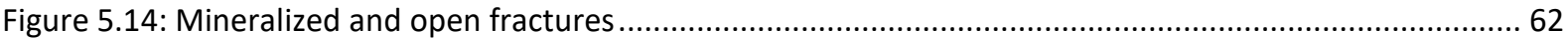

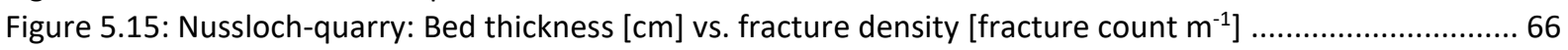

Figure 5.16: Based on surface measurements calculated hydraulic conductivity ..........................................6. 67

Figure 6.1: a) Location of the URG b) Solid geological map of the study area ............................................. 71

Figure 6.2: Geological maps of the outcrops studied on the western graben shoulder...................................... 73

Figure 6.3: Modal composition of sandstone samples from the different locations in a QFL diagram ............... 76

Figure 6.4: Box-whisker plots of the petrophysical and petrographical characteristics .....................................77

Figure 6.5: Box-whisker plots of a) shear-wave velocities and b) dynamic Young's Moduli.............................. 77 
Figure 6.6: Fracture orientation data shown in equal area-scaled rose diagrams with $10^{\circ}$ bin size ................... 78

Figure 6.7: Fracture orientation and intensity in Cleebourg, shown for three individual layers ........................ 79

Figure 6.8: Half-circular diagrams showing the relation between fracture strike and apertures........................ 80

Figure 6.9: Box-whisker plot of the calculated matrix permeabilities ........................................................... 80

Figure 6.10: Box-whisker plot of the calculated matrix permeabilities .......................................................... 81

Figure 6.11: Vertical bore logs of lithological and mineralogical properties ................................................... 82

Figure 6.12: Vertical bore logs of rock properties and corresponding histograms......................................... 83

Figure 6.13: Vertical variation of Young's Modulus with histogram ....................................................... 83

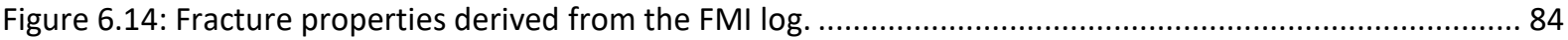

Figure 6.15: Plots showing the vertical variation of a) fracture aperture ..................................................... 85

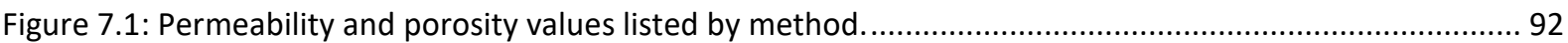

Figure 7.2: Temperature development and breakthrough times of homogeneous reservoir volume................93

Figure 7.3: Effect of variable hydraulic gradient (HG) directions on the reservoir shape in homogeneous.........94

Figure 7.4: Temperature development and breakthrough times of layered reservoir volumes ........................ 95

Figure 7.5: Effect of increasing permeability contrast on the reservoir shape in layered reservoir models ........ 95

Figure 7.6: Temperature development and breakthrough times of fractured reservoir volumes ......................96

Figure 7.7: Effect of increasing N-S-directed permeability anisotropy on the reservoir shape in fractured ........97

Figure 7.8: Temperature development and breakthrough times for layered and fractured reservoir ................98

Figure 7.9: Effect of increasing N-S-oriented permeability anisotropy and contrast on the reservoir................ 99

Figure 7.10: Temperature development, breakthrough times, and reservoir shape ................................... 100

Figure 7.11: Temperature development and breakthrough times of reservoirs utilising conductive ............... 102

Figure 7.12: Effect of increased permeability anisotropy in the fault damage zone on the reservoir .............. 103

Figure 7.13: Normalized number of thermal breakthrough times depending on the hydraulic gradient .......... 105

Figure 8.1: Heat flow map (a) and geothermal energy producing projects (b) worldwide .......................... 107

Figure 8.2: Overview of the planned geothermal site location - Brühl ...................................................... 114 


\section{Table of contents}

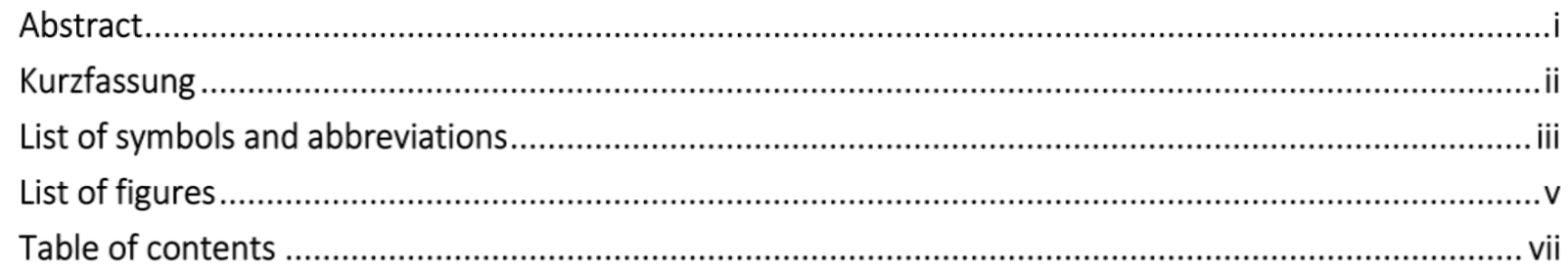

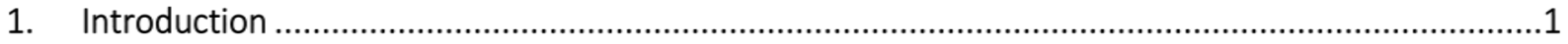

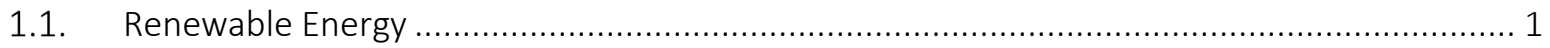

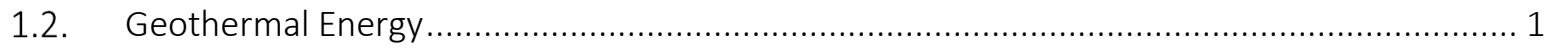

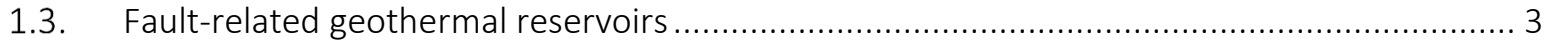

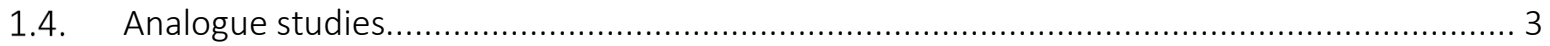

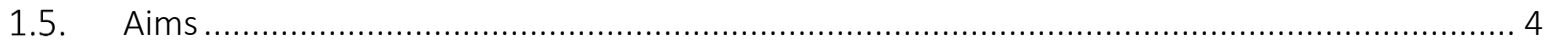

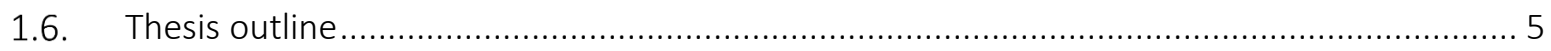

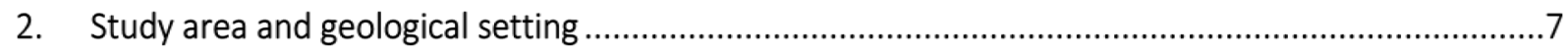

2.1. Study area

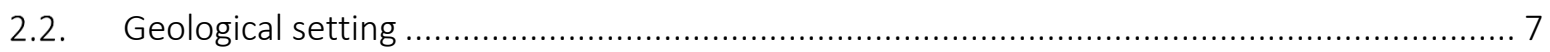

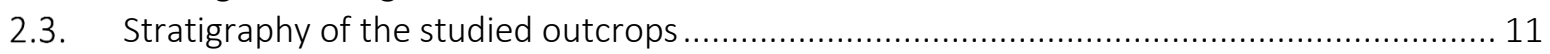

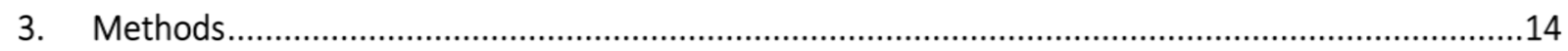

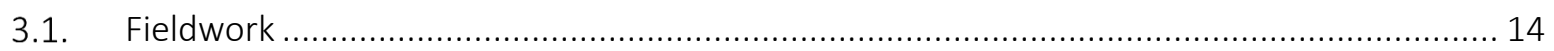

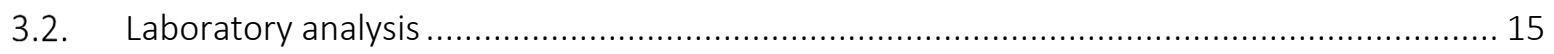

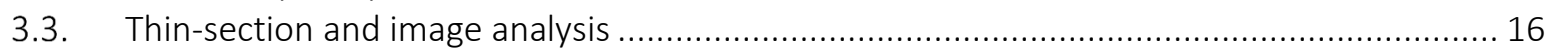

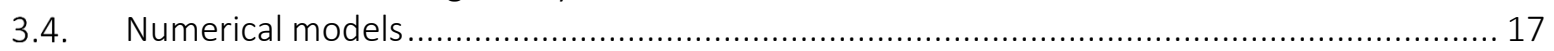

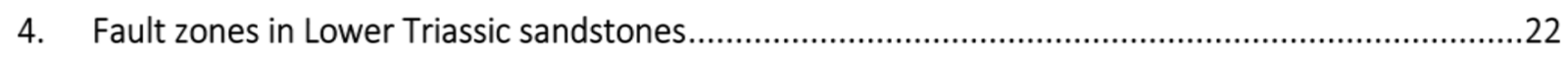

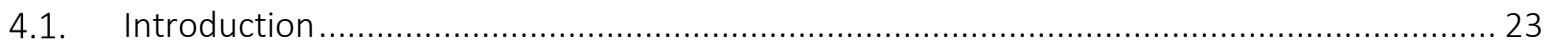

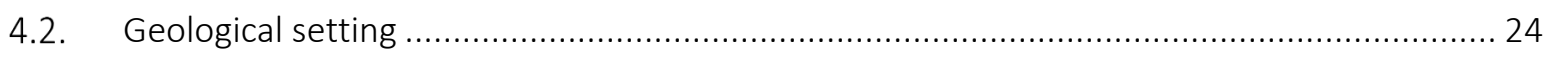

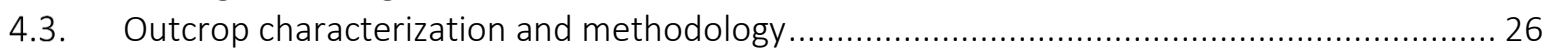

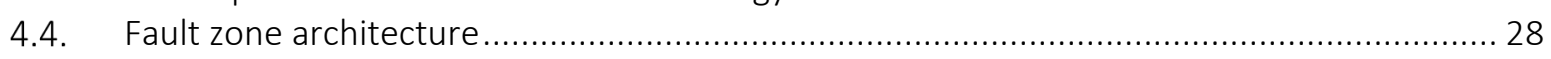

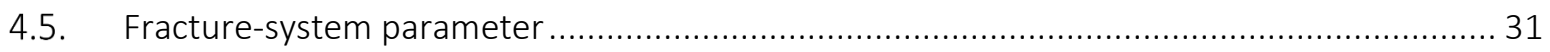

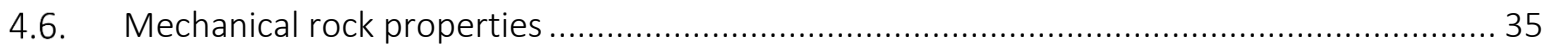

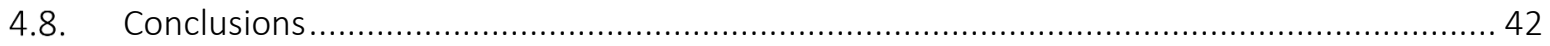

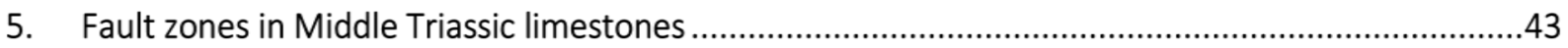

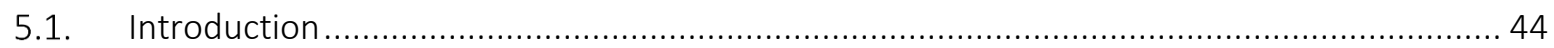

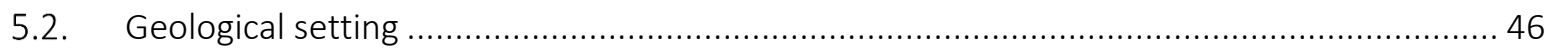

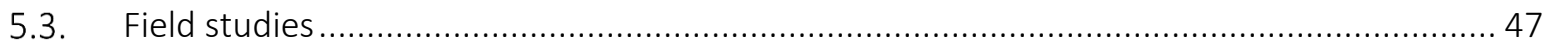

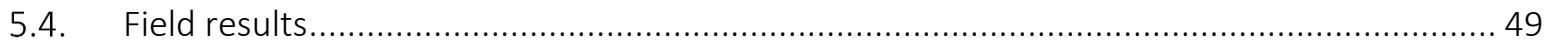

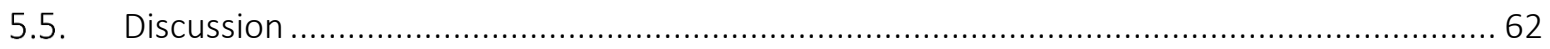

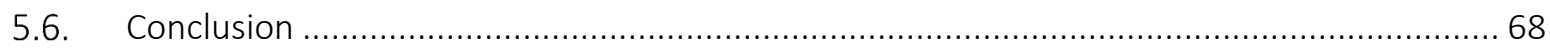

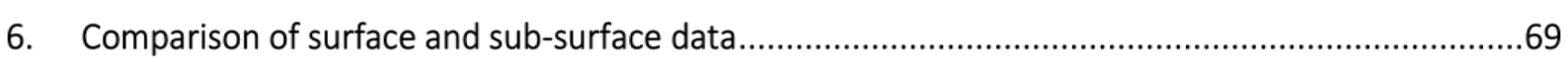

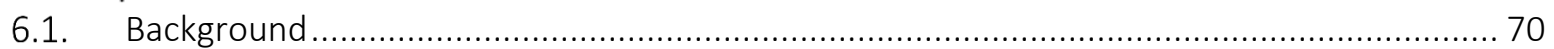

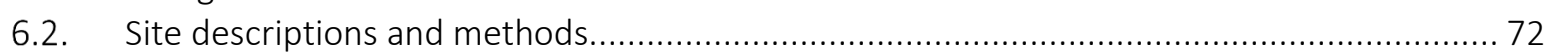

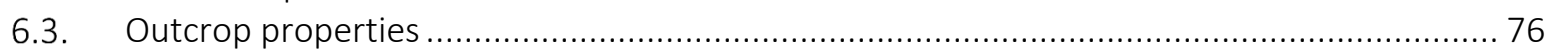

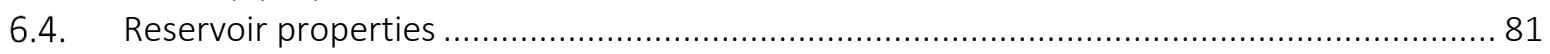

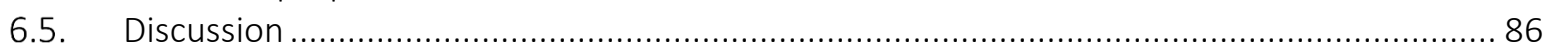

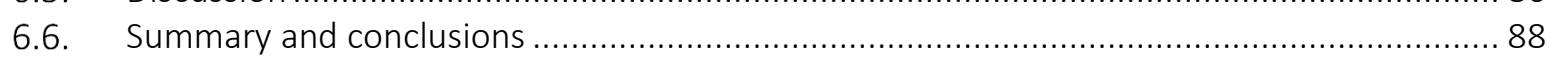


7. Numerical sensitivity study of parameters that control the quality of geothermal reservoirs..........90

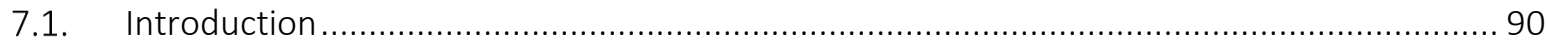

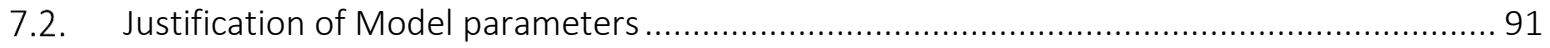

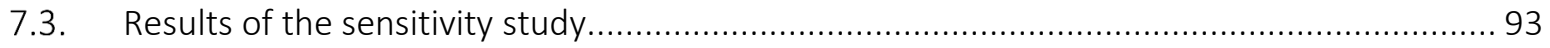

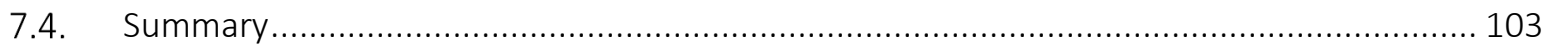

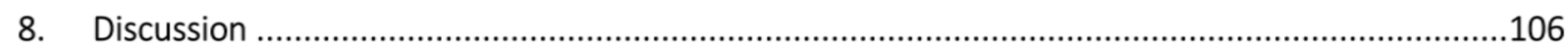

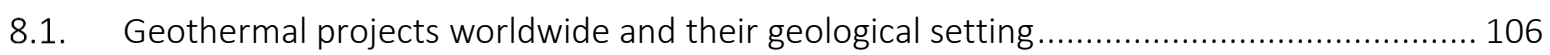

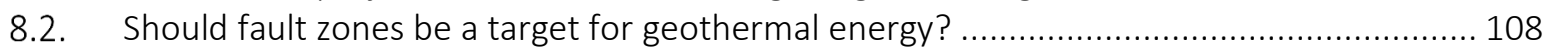

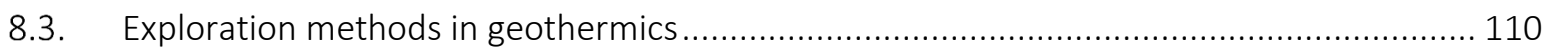

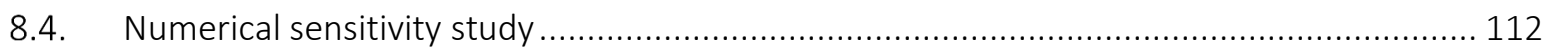

8.5. Possible improvements of numerical models of geothermal reservoirs............................. 115

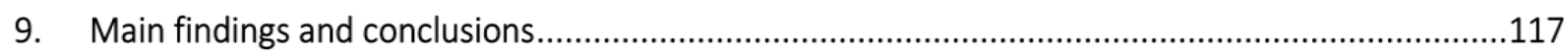

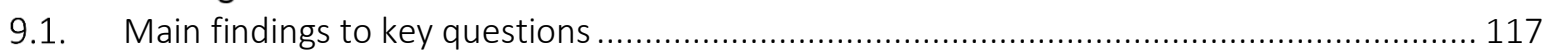

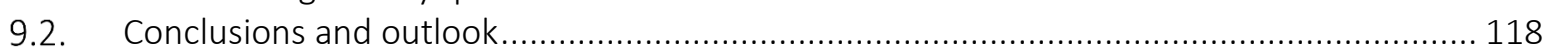

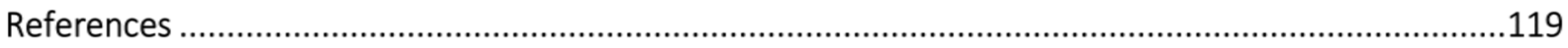

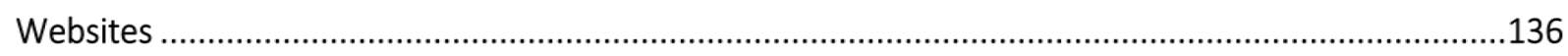

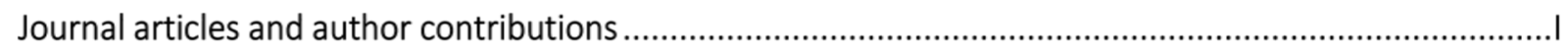

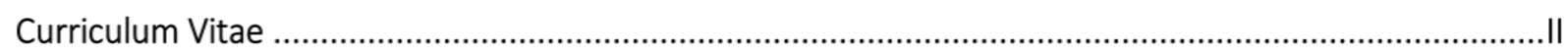

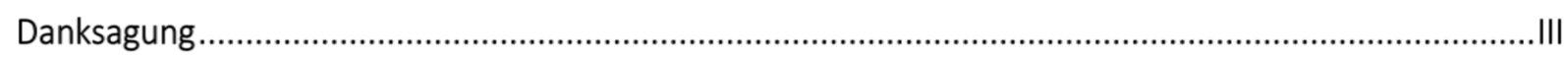

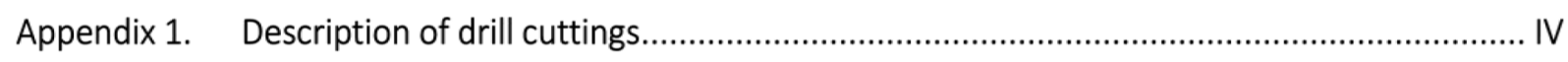

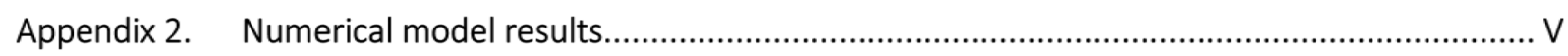




\section{Introduction}

\subsection{Renewable Energy}

The need to mitigate global climate change, to conserve finite fossil fuels, to secure the long-term energy supply, and to achieve nuclear phase-out in Germany by 2022, requires increasing exploitation of renewable energy resources (URL1: EEG 2014). The amount of renewable electricity generation in Germany has constantly risen and more than quadrupled from $7 \%$ in 2000 to $31 \%$ in 2015, when the "Renewable Energy Law" came into force. In 2011, the share of renewable energies on the gross electricity generation exceeded that of nuclear power, although fossil fuels are still the dominant energy source (Fig. 1.1). To achieve the target of the "Renewable Energy Law", i.e. to increase the share of renewable energies in the German energy mix to $40-45 \%$ in 2025 and to $80 \%$ until 2050, further expansion is mandatory (Fig. 1.1; URL2: U.S. Energy Information Administration, EIA).
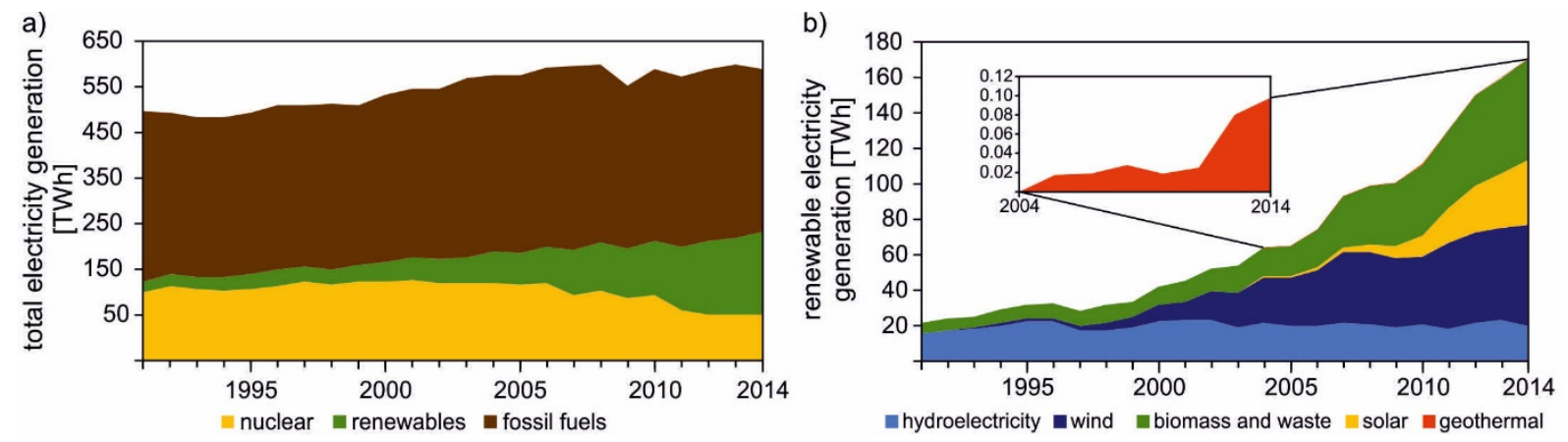

Figure 1.1: The German electricity generation from 1990 to 2014 by energy sources. a) The gross electricity production and b) detailed view on renewable energy sources (values from URL2: U.S. Energy Information Administration, EIA).

The largest share of the produced renewable electricity in 2014 is distributed between wind-, bio(biomass, waste), and solar-energy. While bio- and wind-power have increasingly grown in the last years, geothermal power generation still exists in a kind of niche (Fig. 1.1b). However, geothermal electricity generation has a high potential in Germany (Paschen et al., 2003) and, like water power, it has the advantage of continuous availability, which enables it to contribute to the base load supply. Since the generation of water power is restricted by the available storage space, further development of geothermal electricity generation is desirable.

Besides electricity generation, geothermal energy can be used for heating and cooling, which is already carried out in 333.000 operating systems in Germany (URL3: Bundesverband Geothermie). The proportion of thermal power on the total renewable heat supply, at $7 \%$, is clearly higher compared to its portion of the electricity sector (BDEW, 2016, Fig. 1b).

\subsection{Geothermal Energy}

The energy used by geothermal systems originates from radioactive decay processes of $\mathrm{U}, \mathrm{Th}$, and $\mathrm{K}$ isotopes in the Earth's crust (about 70\%), and from compressional heating (about 30\%). The mean geothermal gradient worldwide lies at about $25-30^{\circ} \mathrm{C} \mathrm{km}^{-1}$, but varies considerably (Stober and Bucher, 2012). Thus, geothermal energy is especially used in volcanically-active regions, such as Iceland, Italy, Indonesia, Philippines, and the United States (URL4: Thinkgeoenergy). In regions like Iceland, the geothermal gradient reaches values up to $200^{\circ} \mathrm{C} \mathrm{km}^{-1}$ (Flóvenz and Saemundsson, 1993). By contrast, in Germany the mean geothermal gradient is about $35^{\circ} \mathrm{C} \mathrm{km}^{-1}$, with highest mean values being reported for the Upper Rhine Graben at $45-50^{\circ} \mathrm{C} \mathrm{km}^{-1}$ (Fig. 1.2a; Sauer et al., 1982). Thus, deep geothermal reservoirs in Germany, that allow the production of electricity economically, can be found commonly at depths deeper than $3 \mathrm{~km}$, if a minimum temperature of $100^{\circ} \mathrm{C}$ for such purposes is assumed. 
Geothermal systems can be subdivided in "shallow" and "deep". Shallow geothermal systems are cost efficient, and have very limited exploration risk; but they are, in most cases, only capable of heating smaller facilities. In contrast, deep geothermal systems, commonly defined as systems below $400 \mathrm{~m}$ (Stober and Bucher, 2012), can be used to generate electrical power additionally to thermal energy. The utilization of deep geothermal systems has a higher risk due to the uncertainties in meeting the conditions needed in the target reservoir, the presently low degree of efficiency in generating electrical power, and the high drilling costs.
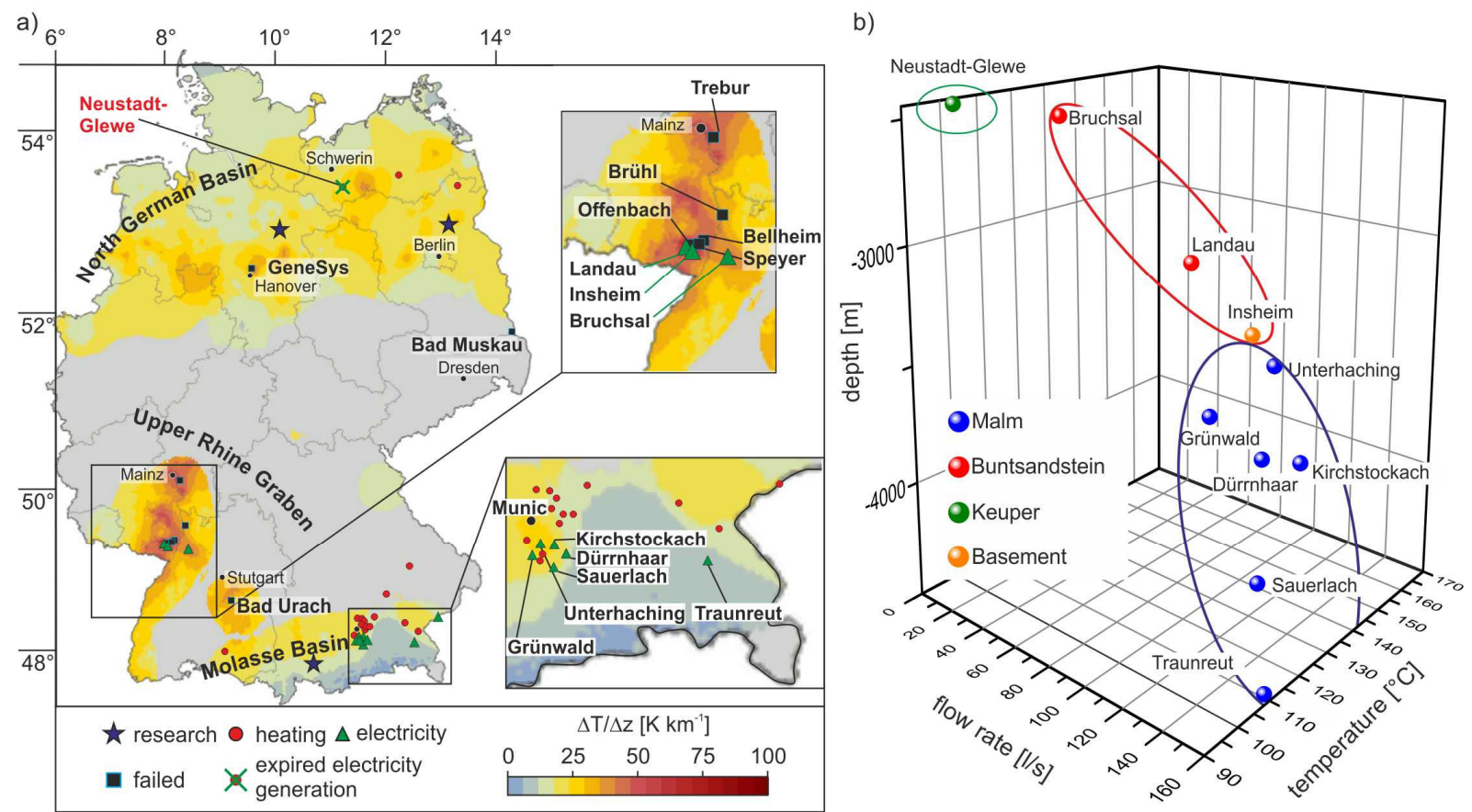

Figure 1.2: a) Map showing the temperature gradient in Germany (URL5: LIAG) and all deep geothermal projects. b) Presentation of the 10 power plants in Germany, colour coded by the reservoir formation, that produces or did produced electricity, including the technical parameters flow rate, temperature, and depth. Power plants encircled in blue, red, and green are located in the Molasse Basin, the Upper Rhine Graben, and the North German Basin, respectively.

With the current state of the art, geothermal electricity can be produced with binary methods at temperatures of at least $100^{\circ} \mathrm{C}$. These methods, Organic Ranking Cycles (ORC) or Kalina systems, use organic or ammonia solutions as carrier fluid with low evaporating temperature to drive turbines at lower temperatures (e.g., DiPippo, 2005; Schulz et al., 2009; Schulz, 2011). The required flow rate for power generation is 14 to $28 \mathrm{I} \mathrm{s}^{-1}$ (e.g., Paschen et al., 2003; Schulz et al., 2009). To achieve such flow rates, a minimum permeability of $10^{-13} \mathrm{~m}^{2}$ is needed (Jung et al., 2002; Stober et al., 2011). Insufficient permeabilities can be enhanced using stimulation methods, but these are linked to the problem of inducing seismic events (e.g., Häring et al., 2008; Baisch et al., 2009; Cladouhos et al., 2010). The strongest seismic event (magnitude of 2.7) was observed in Landau and lead to a growing public resistance to such projects (Plenefisch et al., 2015).

In general, two types of deep geothermal reservoirs are utilized. First, hydrogeothermal reservoirs, which are characterised by naturally high transmissivities and fluids that act as a heat carrier (aquifer). The second type is the petrothermal reservoir. In this case the reservoir is dry and is utilized by the injection of external fluids (e.g., DiPippo, 2005; Huenges, 2010; Stober and Bucher, 2012).

In Germany there are three regions with a known hydrogeothermal potential: The Upper Rhine Graben, the Molasse Basin, and the North German Basin (Fig. 1.2a; Stober et al., 2011; URL6: GeotIS). The Molasse Basin benefits from highly permeable karst aquifers (Malm), whereas the high geothermal 
gradient in the Upper Rhine Graben, and to a minor extent in the North German Basin, has the advantage of shallower-located geothermal reservoirs (Fig. 1.2; Jung et al., 2002; Paschen et al., 2003). Due to the rigorous demands on temperature and flow rate of the reservoir formation (e.g., Huenges et al., 1999; Paschen et al., 2003; Schulz et al., 2009), there are only nine successful deep geothermal projects that currently produce electrical power in Germany (URL6: GeotIS). Three others are under construction in the Molasse Basin (Kirchweidach, Oberhaching, Holzkirchen, URL6: GeotIS). Most of the successful power plants are located near Munich in the Molasse Basin that utilize karst aquifers in the Malm. In the Upper Rhine Graben, only 3 power plants were established. By contrast, the five failed projects in this region demonstrate the risk in establishing such systems (Fig. 1.2a). The reasons the geothermal projects failed were insufficient permeability or absence of thermal water, as, for instance, in Trebur (URL7: Trebur), Offenbach (URL6: GeotIS), Speyer (URL8: iTG), Bad Urach (URL8: iTG), Mauerstetten (URL8: ITG), and Geretsried (URL8: iTG), or too high fluid salinity, as in the Genesys project (URL8: iTG), or technical problems, as in Bellheim (URL6: GeotIS). Despite promising reservoir conditions, the geothermal project Brühl failed due to the insolvency of the planners (GeoEnergy $\mathrm{GmbH}$ ), increasingly public and political resistance, and because no new investors could be found (URL8: iTG). Additionally, the power plant Neustadt-Glewe in the North German Basin stopped electrical power generation after 5 years in 2007, when the production temperature became too low. However, this project still produces thermal energy (URL6: GeotIS).

\subsection{Fault-related geothermal reservoirs}

Faults often comprise two major architectural elements: the core zone and the damage zone. The latter often possesses an increased fracture density (e.g., Caine et al., 1996; Faulkner et al., 2010; Bense et al., 2013), which in turn may provide enhanced permeability. Faults are expected to have a high geothermal potential for three reasons. Firstly, brittle fault zones may constitute volumes with an increased chance of a naturally high permeability. Secondly, because of fluid circulation from greater depth, they may form small-scaled positive temperature anomalies. Lastly, along steep-dipping faults the exploitation depth can be readjusted within a certain range. That enables the producer to react on temperature deviations; a benefit compared to hydrogeothermal systems (Paschen et al., 2003; Jung, 2007).

However, the characteristics of a fault core and damage zones can largely vary, even on small scale (e.g., Knipe, 1993; Caine et al., 1996; Wibberley et al., 2008). This leads to large uncertainties in predicting and understanding fluid-flow behaviour at one specific location on one particular fault (Paschen et al., 2003; Jung, 2007).

\subsection{Analogue studies}

To date, geothermal exploration strategy comprises the evaluation of available data from seismic surveys, previous boreholes, and geological maps. Since none of these methods provides local information about the achievable fluid flow in the subsurface, there is a high risk of making the wrong decisions with regard to the selection of drilling targets.

Analogue studies have been utilised to improve the understanding of subsurface reservoir structure in the oil industry since 1960 (Budding and Inglin, 1981; Keogh et al., 2007). Since then it has become common practice to supplement sparse subsurface datasets with data derived from the surface (Howell et al., 2014). The most common analogue is the outcrop. Outcrops are used with the aim to obtain a more accurate impression of the sedimentological and stratigraphic features of the sub-surface, and thus to the petrophysical properties and subsequent information about the possible hydrocarbon flow 
(Howell et al., 2014). Further aspects have focused on the dimensions and distributions of faults and fractures to analyse the quality of oil traps (England and Townsend, 1998; Manzocchi et al., 2008).

However, the need to prospect site-specific high permeability is significantly higher for geothermal reservoirs than for the oil industry and thus the requirements on analogue studies are different. One fundamental problem of analogue studies is that they represent point information and the challenge is to interpret heterogeneous inter-well reservoir properties, or to extrapolate surface data, and correlation concepts to the subsurface. Wells provide high-resolution vertical datasets, but allow only sparse lateral sampling. Seismic profiles cover a large lateral area, but lack a high resolution to image structural features, such as fractures that control the fluid flow (Bense et al., 2013; Howell et al., 2014). Outcrop studies, in contrast, facilitate the possibility to map fault architecture, attributes, such as aperture and orientation of fractures and rock matrix permeabilities in detail. However, the vertical dimension is often restricted and it is impossible to measure the hydrogeological impact of the studied fault directly (Bense et al., 2013). Most problematic, however, is the distance between the outcrops and the envisaged reservoir.

\subsection{Aims}

This thesis is a part of the multidisciplinary research project "Outcrop Analogue Studies in Geothermal Exploration" (AuGE), funded by the German Federal Ministry for Economic Affairs and Energy (reference number: 0325302D), aimed to develop improved exploration strategies to enhance the success of deep geothermal energy projects. This project finished in 2015.

The first aim of my thesis is to analyse the applicability of outcrop analogue studies to determine the quality of fault-related geothermal reservoirs, prior to drilling activity.

The second aim is to rank the geological parameters that control geothermal reservoir quality in terms of their importance and to estimate the accuracy with which they must be determined. I then show how these parameters affect the temporal behaviour of a geothermal energy reservoir.

This thesis attempts to fulfil these aims using three different methods (Fig. 1.3): 


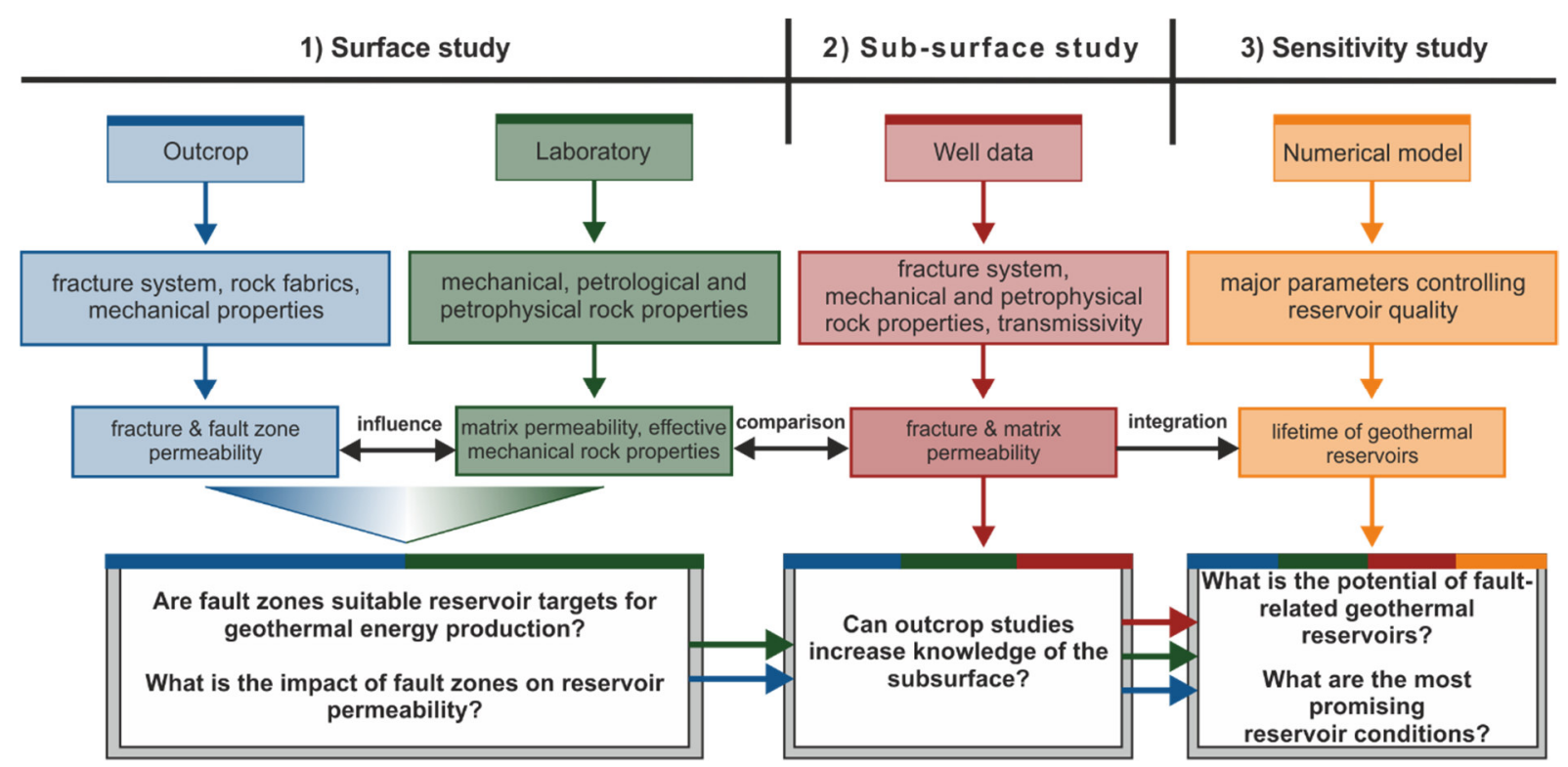

Figure 1.3: Basic concept and specific questions examined in this thesis.

The first part includes detailed field studies to investigate the suitability of fault zones as potential geothermal reservoirs in sand- and limestones. The aim is to obtain an impression of the main structural characteristics of fault zones and associated fracture systems, and variations in rock properties, for instance, estimates of the permeability anisotropy of different fault zones.

The second part compares outcrop analysis, i.e. fracture-system parameter, petrophysical and petrographical rock properties, with geophysical well-log measurements and drill cuttings. The aim is to analyse the transferability of outcrop measurements to the sub-surface and to identify to which extent surface-related studies can be used to increase the predictability of sub-surface characteristics.

In the third part, a numerical 4D-sensitivity study is presented that analyses the effect of different rock properties and natural flow field conditions on the thermal development of a geothermal reservoir. The objective is to demonstrate how the observed range of rock- and fracture-system parameters affects the fluid circulation within hydrogeothermal doublets over time. The aim is to assess the most important parameters and their extent to ensure geothermal energy production.

\subsection{Thesis outline}

This thesis is composed of the following chapters:

1. Introduction

2. Study area and geological setting

3. Methods

4. Publication (I): Bauer, J.F., Meier, S., Philipp, S.L., 2015: Architecture, fracture system, mechanical properties, and permeability structure of a fault zone in Lower Triassic sandstone, Upper Rhine Graben. Tectonophysics 647-648, 132-145.

5. Publication (II): Meier, S., Bauer, J.F., Philipp, S.L., 2015: Fault zone characteristics, fracture systems and permeability implications of Middle Triassic Muschelkalk in Southwest Germany. Journal of Structural Geology 70, 170-189.

Publications (I) and (II) address the first part of my thesis and present outcrop studies that investigate the structure of fault zones hosted in successions of (I) clastic- and (II) carbonate rocks. 
In publication (I) we present the structural and mechanical properties of a fault zone. The analysed fault is highly heterogeneous, i.e. fault zone structure and associated fracture-system parameter change over the different fault zone parts as well as between different layers. We show that this fault would allow fluid flow across the fault core, and that the possibility of a hydraulically active fracture system is enhanced within the fault. We concluded that faults in porous sandstones are potential targets for geothermal reservoirs.

Publication (II) deals with structural differences and past fluid flow between variably-oriented normal, reverse, and oblique-slip faults with displacements of 1 to $40 \mathrm{~m}$. Normal faults especially seem to enhance the fracture-induced permeability in directions parallel to the fault and regional structures of the URG in N-S and NW-SE, and NE-SW-direction.

6. Publication (III): Bauer, J.F., Krumbholz, M. Meier, S., Tanner, D.C., 2017: Predictability of properties of a fractured geothermal reservoir: the opportunities and limitations of an outcrop analogue study. Geothermal Energy 5 (1), 24. http://dx.doi.org/10.1186/s40517-017-0081-0.

The focus of the manuscript is to evaluate the applicability of outcrop studies to improve predictions on fault-related reservoirs in the tectonically-complex Upper Rhine Graben. It represents the second part of my thesis. Our results show that, in this case, the comparability of data from surface investigations and well data is not given. In addition, observed surface trends for e.g. rock porosity or cementation could not be extrapolated to depth.

\section{Numerical sensitivity study of parameters that control the quality of geothermal reservoirs}

In this chapter, I present a sensitivity study based on numerical models, which analyse the effect of different parameters and variations of parameters on the thermal development of a geothermal reservoir. Our results show that small variations in the hydraulic gradient configuration, permeability of different layers, fracture induced permeability anisotropy, and fault zones have significant effects on the utilized volume of the reservoir. Most importantly our models show that fault-related reservoirs are, in many configurations, very short lived.

\section{Discussion}

9. Conclusion and perspective 


\section{Study area and geological setting}

\subsection{Study area}

The study area is located in the Upper Rhine Graben (URG; Fig. 2.1). Selected Buntsandstein outcrops on the western graben shoulder are in the highlands of the Haardt (outer eastern edge of the Palatinate Forest) and the Wasgau (outer southern edge of the Palatinate Forest). Outcrops at the eastern graben shoulder are in the Kraichgau-Basin and in the highlands of the Odenwald. The studied lithostratigraphy, deposited within the Germanic Basin, comprises Lower to Middle Buntsandstein (Lower Triassic) and limestones of the complete Muschelkalk group (Middle Triassic). Well data, used in this study, is from the geothermal site (Brühl), in vicinity of the eastern graben shoulder. The locations and lithologies of the outcrops and the well are shown in Figure 2.1.

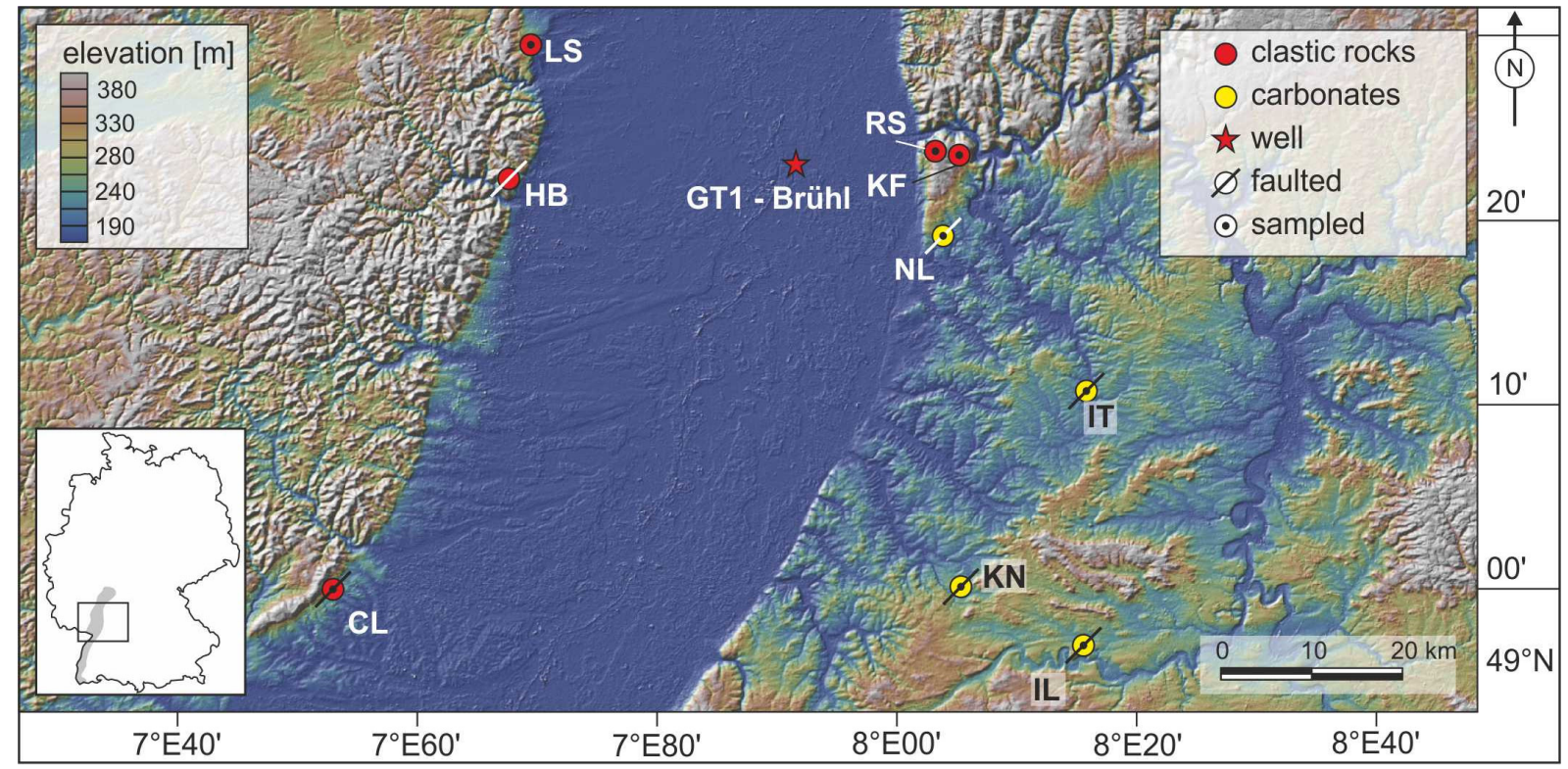

Figure 2.1: Localities and lithologies of the studied outcrops (LS - Leistadt, HB - Hanbuch, $\mathrm{Cl}$ - Cleebourg, RS - Riesenstein, KF - Kammerforster, NL - Nussloch, IT - Ittlingen, KN - Knittlingen, IL - Illingen) and borehole GT1-Brühl (Map basis: NASAASTER-USGS Elevation Model). The extension of the study area and the extension of the URG is marked on the schematic map of Germany.

\subsection{Geological setting}

\subsubsection{Prerift-setting}

The most important pre-rift structures of the Upper Rhine Graben were established during the Variscan Orogeny in the Palaeozoic (Devonian until Carboniferous), and consist of NE- to ENE-striking crustal discontinuities. These faults subdivide the different units of the Variscan Internides and form the boundaries of Permo-Carboniferous troughs and highs (Fig. 2.2). A further significant structural trend was formed during widespread basin formation and volcanic activity in the Carboniferous to early Permian; and consists of an NNE-SSW-trending system of sinistral-shear faults that are associated with the intrusive bodies of the Vosges, Black Forest, and Odenwald (e.g., Ziegler, 1990; Schumacher, 2002; Schwarz and Henk, 2005; Ziegler et al., 2006). 
After the Variscan Orogeny ended, the formation of the Germanic Basin at the Permian-Triassic

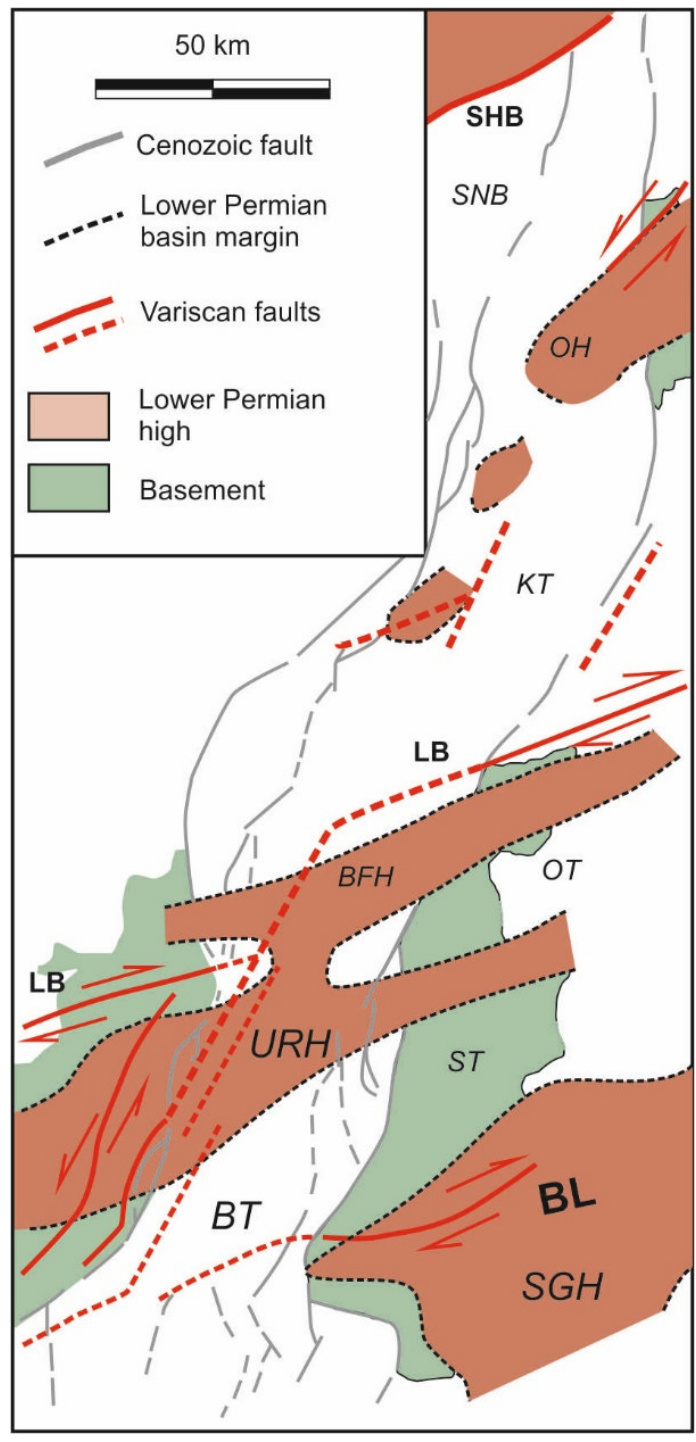

Figure 2.2: Pre-rift setting of the URG area with Variscan fault traces (SHB: South Hunsrück-Taunus border Fault; LB: Baden-Baden-Lalaye-Lubine Fault; BL: Badenweiler-Lenzkirch Fault) and Permo-Carboniferous troughs and highs (SNB: Saar-Nahe Basin; $\mathrm{OH}$ : Odenwald-Spessart High; KT: Kraichgau Trough; BFH: Northern Black Forest High; OT: Offenburg Trough; URH: Main Upper Rhine High; ST: Schramberg Trough; BT: Burgundy Trough; SGH: Main Southern German High). The later URG main fault traces are indicated in grey (after Schumacher, 2002). boundary started with the onset of the breakup of the Pangea supercontinent and the related widening of the Tethys Ocean (Ziegler, 1990; Scheck-Wenderoth et al., 2008). The intracratonic Germanic Basin, also called the Central European Basin, extends from the North Sea in the north to Switzerland in the south and from Poland in the east to England in the west. It persisted until the end of the Jurassic (Ziegler, 1990). The Germanic Basin was surrounded by several Variscan massifs, which provided the source of the clastic sediments (Ziegler, 1990; Feist-Burkhardt et al., 2008). The interaction between sea-level rise, sediment supply, and subsidence caused the formation of different facies types of the Triassic stratigraphy (Bachmann et al., 1999; Feist-Burkhardt et al., 2008; compare Section 2.3 and Fig. 2.5).

The Mesozoic sediments rest unconformably on the Permo-Carboniferous series (Schumacher, 2002; Szurlies, 2007; Feist-Burkhardt et al., 2008). In the URG area only Triassic to late Jurassic sediments (Kimmeridgian) were deposited. It is unsure whether Cretaceous sediments were eroded or not deposited at all in the URG (e.g., Ziegler, 1990; Schumacher, 2002; Reicherter et al., 2008). This hiatus is attributed to Late Cretaceous until late Palaeogene inversion tectonics with NNE-SSW-directed compression, caused by rifting in the south Atlantic and the Pyrenean Orogeny (Kley and Voigt, 2008). Far-field stresses of the continental collision e.g., led to southward tilting of Mesozoic rocks within the URG area and to the uplift of the Harz Mountains, the Rhenish Slate Mountains, and the Ore Mountains (e.g., Illies, 1975; Littke et al., 2005; Reicherter et al., 2008). During the late Eocene, the compressional stress field and the reactivation of Palaeozoic fault systems led to the formation of the URG (Schumacher, 2002; Dèzes et al., 2004; Schwarz and Henk, 2005).

\subsubsection{Synrift-setting}

The URG evolved in two major phases, characterized by complex interaction of extensional and strikeslip movements, due to major stress field changes (e.g., Illies, 1972; Schumacher, 2002; Ziegler et al., 2006). During the first phase, until the late Eocene, the NNE-SSW-directed compression, led to the reactivation of the Variscan and Permo-Carboniferous ENE-WSW- and NNE-SSW-striking fault systems into a transtensional strike-slip system. Under these conditions the individual Palaeozoic troughs coalesced and formed the initial structure of the URG (e.g., Schumacher, 2002; Schwarz and Henk, 2005). During the late Eocene to late Oligocene, the compressional period was followed by NW-SE- to WNWESE-extension that initiated the rifting of the URG (Fig. 2.3a; Larroque and Laurent, 1988; Schumacher, 
2002; Schwarz and Henk, 2005). The main rifting phase ended in Early Oligocene, but continued to a minor extent in the northern URG (e.g., Illies and Greiner, 1979; Ziegler, 1992; Schwarz and Henk, 2005; Ziegler and Dèzes, 2006).

a)

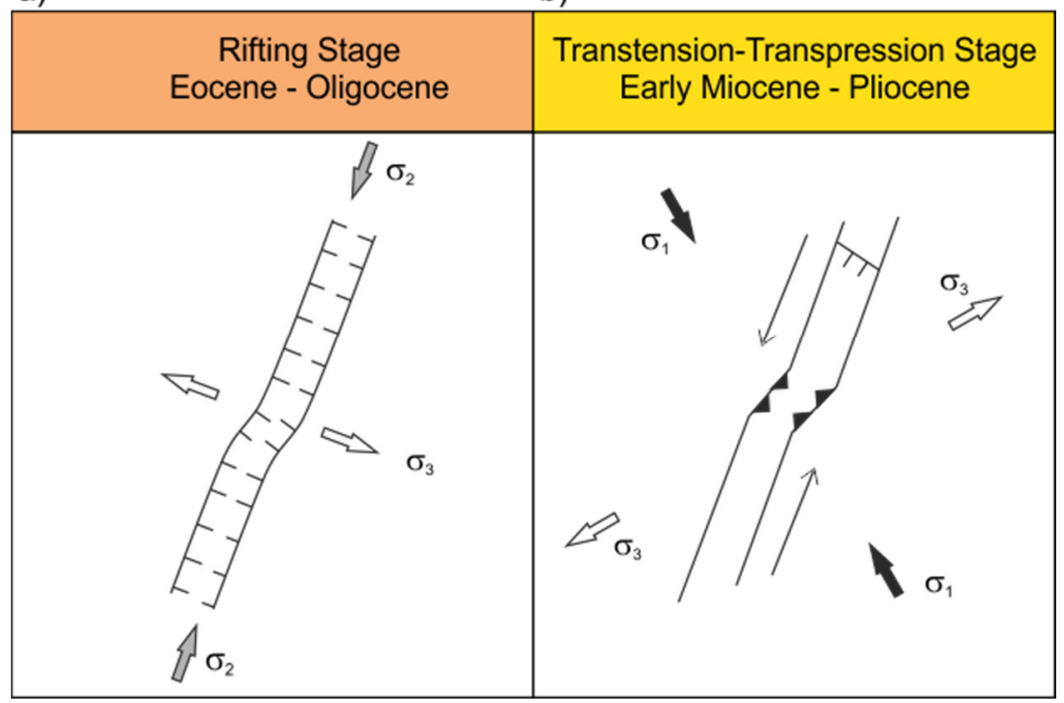

Figure 2.3: Schematic overview of the two-stress phases of the URG formation. a) The rifting phase is characterised by NW-SE- to WNW-ESE-directed extension. b) The transtension and transpression stage is characterised by NE-SW-directed extension (kinematics and stress-field orientation after Schwarz and Henk, 2005).

The second phase began in the Early Miocene and is characterized by the reorientation of the stress field from NW-SE to NESW extension (Fig. 2.3b). Under these conditions the major graben-forming faults were effected by sinistral and dextral oblique displacements, local inversion, and normal displacements (Illies and Greiner, 1979; Schumacher, 2002).

The recent stress field of the URG is relatively uniform distributed in the URG with NW-SE- to NNW-SSE-oriented maximum horizontal stress (Heidbach et al., 2008; Meixner et al., 2016). In the southern part of the URG the maximum horizontal stress component is, with a direction of $145^{\circ}$ to $160^{\circ}$, more variable than in the northern part with $130^{\circ}$ to $135^{\circ}$ (Delouis et al., 1993; Plenefisch and Bonjer, 1997; Heidbach et al., 2008). Recent stress- and faulting regimes vary from north to south in the URG: In the southern segment a strike-slip regime $\left(\sigma_{2}=\sigma_{V}\right)$ and in the northern part a combination of strike-slip and extension dominates $\left(\sigma_{1} \sim \sigma_{V} ; \sigma_{2}=\sigma_{V}\right.$; Larroque et al., 1987; Becker and Paladini, 1990; Plenefisch and Bonjer, 1997).

\subsubsection{Graben structure and Moho topography}

The Upper Rhine Graben has a north-south extension of about $300 \mathrm{~km}$ and is limited to the north by the Rhenish Massif near Frankfurt and to the south by the Jura Mountains near Basel. The NNE-SSWtrending and $40 \mathrm{~km}$ wide graben intersects thereby the tectonostratigraphic units of the Variscan Internides (Fig. 2.4a; Schumacher, 2002; Schwarz and Henk, 2005). 
a)

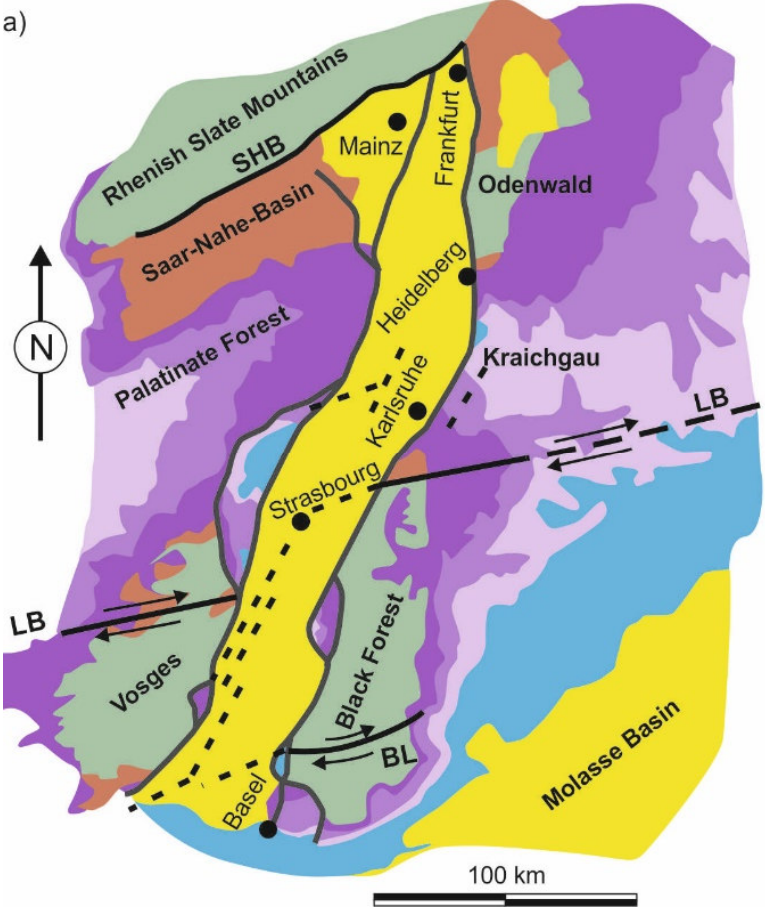

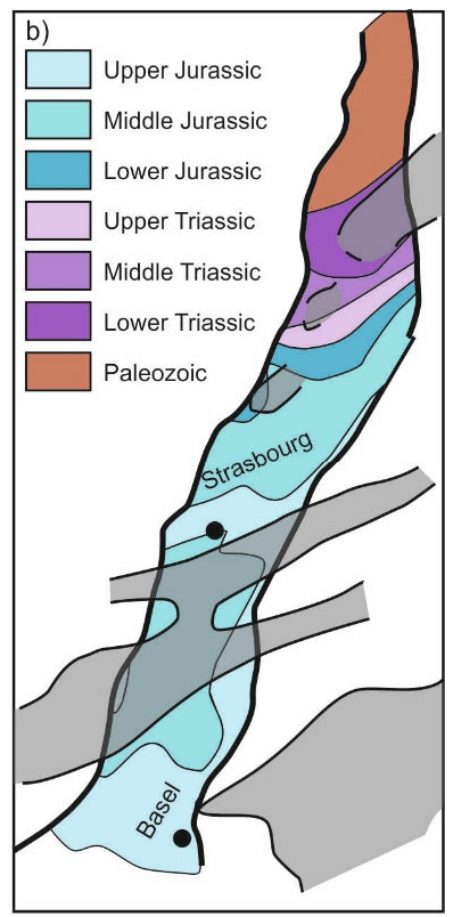

Figure 2.4: a) Geological map of the Upper Rhine Graben. Grey lines indicate main Cenozoic fault traces of the URG, black lines are Variscan fault traces (after Schumacher, 2002; Eisbacher and Fielitz, 2010). b) Subcrop of Mesozoic sediments of the URG, with indicated Permo-Carboniferous highs (grey; after Schumacher, 2002).

The uppermost Palaeozoic to Mesozoic pre-rift sediments increase in age from the south (Late Jurassic) to the north (Permian), and form a southward-dipping monoclinal structure in the northern URG (e.g., Pflug, 1982; Schumacher, 2002). Whereas in the southern part of the URG the pre-rift sediments form a synclinal-anticlinal structure, with Middle Jurassic sediments in the areas of Strasbourg and Basel, with Middle Jurassic sediments between these cities (Fig. 2.4b; e.g., Pflug, 1982; Schumacher, 2002).

The URG, as displayed in the seismic profiles DEKORP9N and DEKORP9S (Brun et al., 1991; Wenzel et al., 1991; Brun et al., 1992) and in isopach maps of the syn-tectonic graben sediments (Doebl and Olbrecht, 1974; Doebl and Teichmüller, 1979), has a half-graben structure. Syn-sedimentary thicknesses change along the N-S-extent of the graben, with the thickest depositions in the southern part located close to the western boundary, and in the northern part at the eastern boundary fault (Doebl, 1967; Brun et al., 1992). Accordingly, the greatest displacement (up to $5000 \mathrm{~m}$ ) of the boundary faults can be found in the NE and the SW (Brun et al., 1992). The structure of the boundary faults also changes its character along the extent of the graben. In the southern part a listric character of the western boundary fault has been interpreted (Brun et al., 1991; Brun et al., 1992), while in the northern part more planar boundary faults are predicted (Durst, 1991; Meier and Eisbacher, 1991; Wenzel et al., 1991).

The horizontal and lateral extension of the URG is still under debate. The amount of the horizontal extension is calculated to lie in the range between 2.5 and $8.5 \mathrm{~km}$ (Doebl and Teichmüller, 1979; Groshong, 1996; Schwarz and Henk, 2005), and the lateral extent of the NNE-striking boundary faults is likely between 1.5 and $4 \mathrm{~km}$ (Schwarz and Henk, 2005). In response to the graben extension and strike-slip movements, the graben shoulders were uplifted by about $1500 \mathrm{~m}$. However, the graben shoulders are mostly eroded and have lost their topographical elevation (Schwarz and Henk, 2005). 
Along the extent of the URG the Moho has been raised from $30 \mathrm{~km}$ outside the URG area to $27-28 \mathrm{~km}$ at the northeastern graben area, and $24-25 \mathrm{~km}$ at the southern part of the URG (Brun et al., 1991; Wenzel et al., 1991; Brun et al., 1992). Therefore, the geothermal gradient and the thermal heat flow are elevated in the URG. The temperature gradients range from $<30^{\circ} \mathrm{C} \mathrm{km}^{-1}$ up to $100^{\circ} \mathrm{C} \mathrm{km}^{-1}$ (Sauer et al., 1982; Schellschmidt and Clauser, 1996; Stober and Bucher, 2014; compare Fig. 1.2a). In comparison, the uplifted graben shoulders have values of $20-33 \mathrm{C} \mathrm{km}^{-1}$ (Doebl and Teichmüller, 1979; Teichmüller and Teichmüller, 1979).

\subsection{Stratigraphy of the studied outcrops}

The Triassic stratigraphy of the Germanic Basin is a result of the interaction between periodic marine ingressions, sediment supply, and subsidence. The Triassic succession is composed of the fluvial and playa deposits of the Buntsandstein, evaporites and marine deposits that form the Muschelkalk, and the Keuper that comprises mainly evaporates and fluvial deposits (Bachmann et al., 1999; FeistBurkhardt et al., 2008).

The Buntsandstein Group of the Germanic Basin is subdivided into three sub-groups: The Lower-, Middle-, and Upper Buntsandstein. It is composed of cyclic alternations of sand-, silt-, and claystone that were deposited under mostly fluvial conditions. The lithostratigraphic classification of the Buntsandstein is based on the correlation of cyclic grain-size variation and unconformities (e.g., Dachroth, 1985; Szurlies, 2007; Feist-Burkhardt et al., 2008; Hagdorn and Nitsch, 2009). However, at the southern margin of the Germanic Basin uncertainty regarding the lithostratigraphic classification of the Buntsandstein exists. This is caused by a combination of the lack of Buntsandstein unconformities, an overall decreased sediment thickness, an incomplete stratigraphic record, and the closer proximity to the sediments source area, i.e. resulting in larger grain-size (Fig. 2.5; e.g., Paul, 1982; Ziegler, 1990; Lepper et al., 2006). 


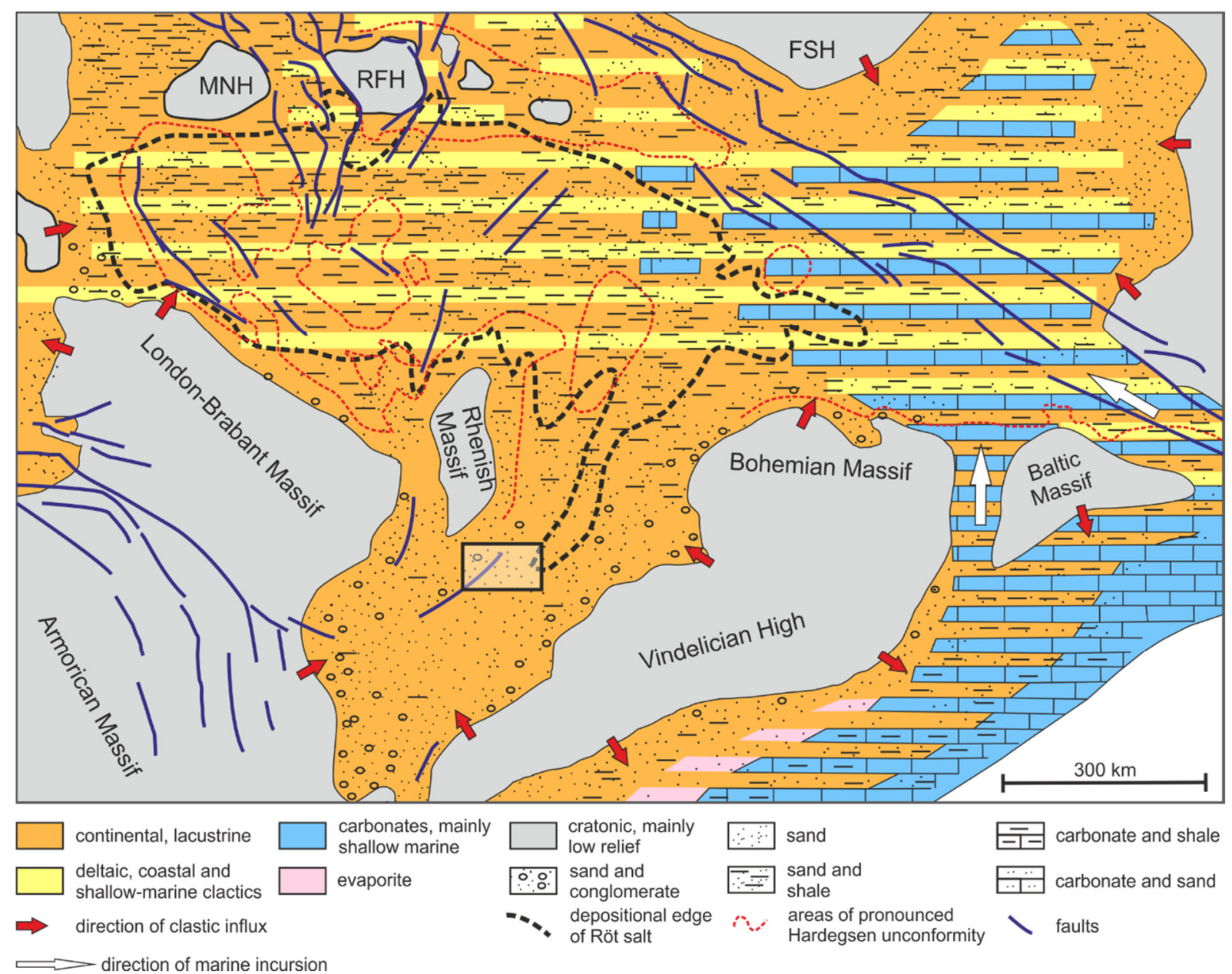

Figure 2.5: Buntsandstein Paleography and the location of the study area (black box). MNH: Mid North Sea High, RFH: Ringkøbing-Fyn High, FSH: Fenno-Scandia High; modified after Ziegler, 1990).

As a consequence of this uncertainty, the Buntsandstein formations have been classified in various ways that has led to many different local names (e.g., Dachroth, 1985; Szurlies, 2007; Feist-Burkhardt et al., 2008; Hagdorn and Nitsch, 2009). The correlation between the most common classifications is outlined in Fig. 2.6 for NE France (Bourquin et al., 2006), the Palatinate Forest (Backhaus, 1974; Richter-Bernburg, 1974), the Odenwald (Eisbacher and Fielitz, 2010), and the Kraichgau (Junghans, 2003).

The lithostratigraphic record of the Buntsandstein in the Odenwald comprises three major sedimentary cycles: Two progradational fluvial cycles (Eck'scher Zyklus, Hauptkonglomerat Zyklus), with NEdirected flow of pebbly and coarse-grained sands. These cycles were followed by a third SE-directed cycle within a retrograde fluvial system (Röt Zyklus; Dachroth, 1985; Eisbacher and Fielitz, 2010). All sandstone outcrops as well as the reservoir formation are located in the second cycle within the "Bausandstein" in the Odenwald and the "Rehbergschichten" in the Palatinate forest. However, the classification of the outcrop Cleebourg is uncertain. In Ménillet et al. (1989) the outcrop is characterized as "Lower Grés vosgiens", in Eisbacher and Fielitz (2010) the outcrop is allocated to the "Trifelsschichten", and in Andreae et al. (1892) it is simply assigned to the "Grés vosgiens" Formation (Fig. 2.6). 
a)

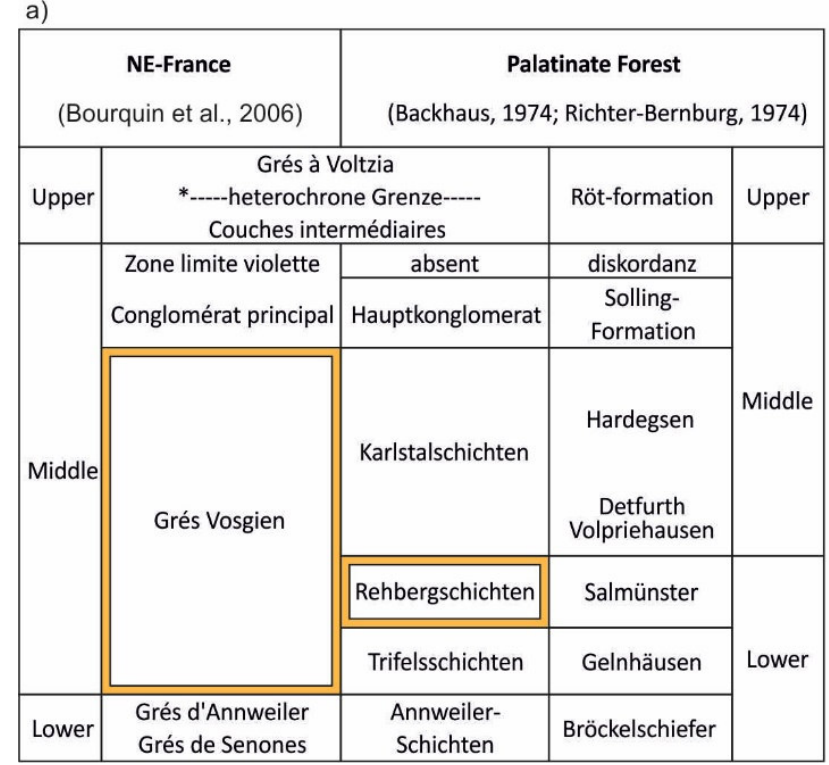

b)

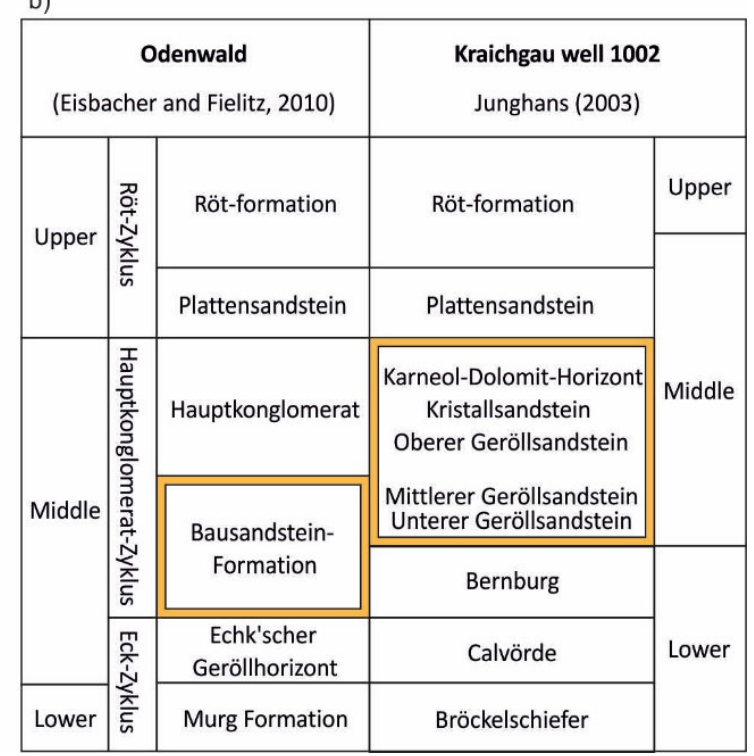

Figure 2.6: Lithostratigraphic correlation of the Buntsandstein between a) the western and $\mathbf{b}$ ) the eastern graben shoulder. The formations studied in the outcrops are indicated by yellow boxes from left to right: "Grés Vosgien" (Cleebourg), "Rehbergschichten" (Leistadt), "Bausandstein Formation" (Riesenstein and Kammerforster), "Karneol-Dolomit-Horizont" to "Unterer Geröllhorizont" (well Brühl GT1).

The Muschelkalk is subdivided into three sub-groups: The Lower-, Middle-, and Upper Muschelkalk that occur basin wide without significant changes in facies (Schweitzer and Kraatz, 1982; Engesser and Leiber, 1991; Hagdorn and Simon, 2005). In contrast to the Buntsandstein, index fossils and concise marker beds allow for a basin-wide correlation of the stratigraphy and a detailed classification of the Muschelkalk group (Hagdorn and Simon, 2005). The succession consists of alternating carbonates, evaporates, and to a minor extent of siliciclastic sediments, which were deposited under shallow marine conditions on a gently NW-inclined ramp (Schweitzer and Kraatz, 1982; Engesser and Leiber, 1991). The Lower Muschelkalk is composed of undulated-bedded limestones and marlstones (Wellenkalk), with subordinate oolites, and lithoclastic limestones (Eisbacher and Fielitz, 2010). The Middle Muschelkalk is characterized by micritic dolomites, gypsum-halite evaporites, and mudstones. Dissolution of the evaporites led to major thickness variations and to the formation of residual clays (Engesser and Leiber, 1991). The Upper Muschelkalk comprises a succession of fossil-rich carbonates, marls, and clays interbedded with micritic limestones characterized by a low fossil content (Schweitzer and Kraatz, 1982; Engesser and Leiber, 1991). Muschelkalk outcrops that were analysed in this work cover the complete Muschelkalk group. 


\section{Methods}

Methods applied in this thesis comprise structural geological fieldwork, laboratory-, thin section-, and image analysis, as well as numerical methods, and are briefly introduced in the following sections.

The sub-surface datasets were provided by John Reinecker (GeoThermal Engineering $\mathrm{GmbH}$ ) and comprise geophysical borehole measurements, descriptions of drill cuttings, pumping- and injection tests. The descriptions of cuttings are given in Appendix 1 - Fig. A1.

\subsection{Fieldwork}

Field measurements were carried out to determine (I) fracture-system- and (II) rock-mechanical parameters.

(I) Fracture systems were recorded using scanline and rectangular window-sampling methods. When applying the scanline method, only attributes of fractures that intersected the tape are recorded (e.g., Priest and Hudson, 1981; Priest, 1993; Adler et al., 2013). The fracture parameters that were measured include: orientation, density, connectivity, aperture, trace length, termination, and filling. The scanlines were carried out in at least two different directions to minimize measuring error, i.e. to avoid underrepresentation of unfavourably-oriented fractures. The advantages of the scanline method are its simple and quick application, and the possibility to measure spatial variations of the fracture system across fault zones to analyse, e.g. the extent and expression of the damage- and core-zone (e.g., Terzaghi, 1965; Priest, 1993; Adler et al., 2013). However, scanlines sub-perpendicular to the fault zone cannot capture the variations of fractures that are of the same orientation. Thus, a rectangular window-sampling method was also applied to measure the 2-D fracture system variability across and along fault zones and to reduce the sampling bias (Priest, 1993; Watkins et al., 2015).

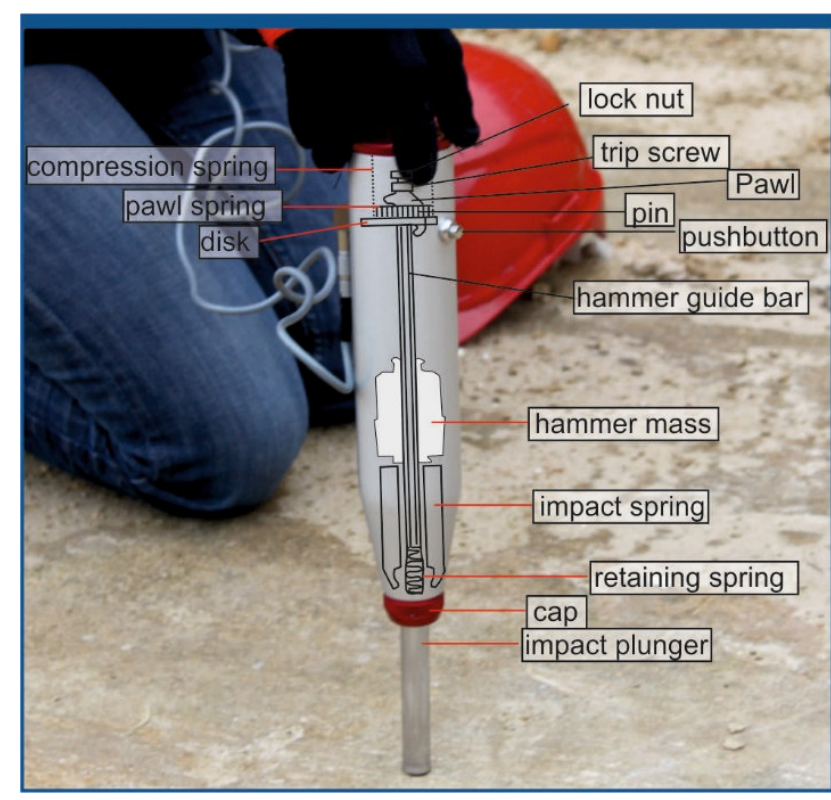

Figure 3.1: Photograph of a L-Type Schmidt Hammer, with detailed setup of the device (setup from DigiSchmidt operating instructions URL9: proceq).
(II) During fieldwork, an L-Type Schmidt Hammer was used to determine the rebound hardness, an indirect method to evaluate the hardness and strength of rocks (e.g., Cargill and Shakoor, 1990; Torabi et al., 2010; Fig. 3.1). The mode of operation of the Schmidt Hammer is as follows: when the Schmidt Hammer is pressed against a surface, it's piston, which is loaded to $0.735 \mathrm{Nm}$ is automatically released. Impact with a surface absorbs part of the piston's energy. The remaining energy, which represents the "rebound hardness", is measured by the rebound distance of the piston (e.g., Deere and Miller, 1966; Aydin and Basu, 2005; Viles et al., 2010). The advantages of the Schmidt Hammer include portability, non-destructivity, and time and cost efficiency. However, regressions between the rebound hardness and mechanical rock properties, such as uniaxial compressive strength $(U C S)$ and Young's Modulus $(E)$ measured in the laboratory often vary significantly, even within the same lithology (see Yagiz, 2009 for summary). Further limitations are its extreme sensitivity to, e.g. surface roughness, discontinuities, and moisture content (e.g., Barton and Choubey, 1977; Viles et al., 2010). Nonetheless, many measurements were 
performed in this work to supplement the limited number of laboratory measurements and to obtain rock hardness variations at different areas of the fault zone and in different layers.

\subsection{Laboratory analysis}

In the laboratory, static measurements of the rock strength, static and dynamic elastic parameters were determined, parallel and perpendicular to bedding. These measurements were carried out on 15 oriented rock samples taken from outcrops.

Specimen Preparation: For the rock-mechanical tests right circular specimens were prepared. The usual specimen diameter to measure uniaxial compressive strength (USC) is $50 \mathrm{~mm}$, whereas samples for static Young's Modulus $\left(E_{S}\right)$ and indirect tensile strength $\left(T_{0}\right)$ should be $40 \mathrm{~mm}$ in diameter. Specimen height to diameter ratios are 2:1 for the measurement of UCS and $E_{S}$. Additionally, the upper limit of UCS was measured on specimens with a ratio of 1:1 (Fairhurst and Hudson, 1999; Mutschler, 2004). Because it was not possible to collect samples of the necessary dimensions in the Cleebourg and Riesenstein outcrops with a hammer, cylinders, $30 \mathrm{~mm}$ in diameter, were directly cored with a water-cooled drill. Nevertheless, the specifications which require a sample diameter of at least $30 \mathrm{~mm}$ and at least 10 - 20 times the maximum grainsize were maintained (Fairhurst and Hudson, 1999; Mutschler, 2004).

Uniaxial compressive tests to determine USC and $E_{S}$ were performed according to DIN-EN-1926 (2007) and ISRM 2007 (Ulusay and Hudson, 2007), using a Universal Class 1 Testing Machine from the company Walter \& Bai at the University of Göttingen. The tests were performed on dry specimens with two different height to diameter ratios: 1:1 for USC and $E_{S}, 2: 1$ for maximum USC. During uniaxial compression tests (Fig. 3.2a) a specimen is compressed axially $\left(\sigma_{1}>0, \sigma_{2}=\sigma_{3}=0\right)$ at a constant rate of $1000 \mathrm{~N} \mathrm{~s}^{-1}$. The peak stress or USC is reached when the rock loses its ability to support the applied stress (Fig. 3.2b). Each test for $E_{S}$ includes preloading until the sample approximately reaches $70 \%$ of the expected USC, to close microfractures and flaws; the specimens is then loaded until rock failure. The relationship between stress $(\sigma)$ and strain $(\varepsilon)$ is directly proportional and is defined by Hook's Law (Eq. 3.1). The recorded slope of the straight-line portion of the stress-strain curve gives $E_{S}$ (Fig. 3.2b),

$$
E_{s}=\frac{\delta \sigma}{\delta \varepsilon} \quad[\mathrm{Pa}],
$$

where $\delta \sigma$ and $\delta \varepsilon$ are the differences between stress and strain between 40 and $60 \%$ of maximum USC (Fig. 3.2b).
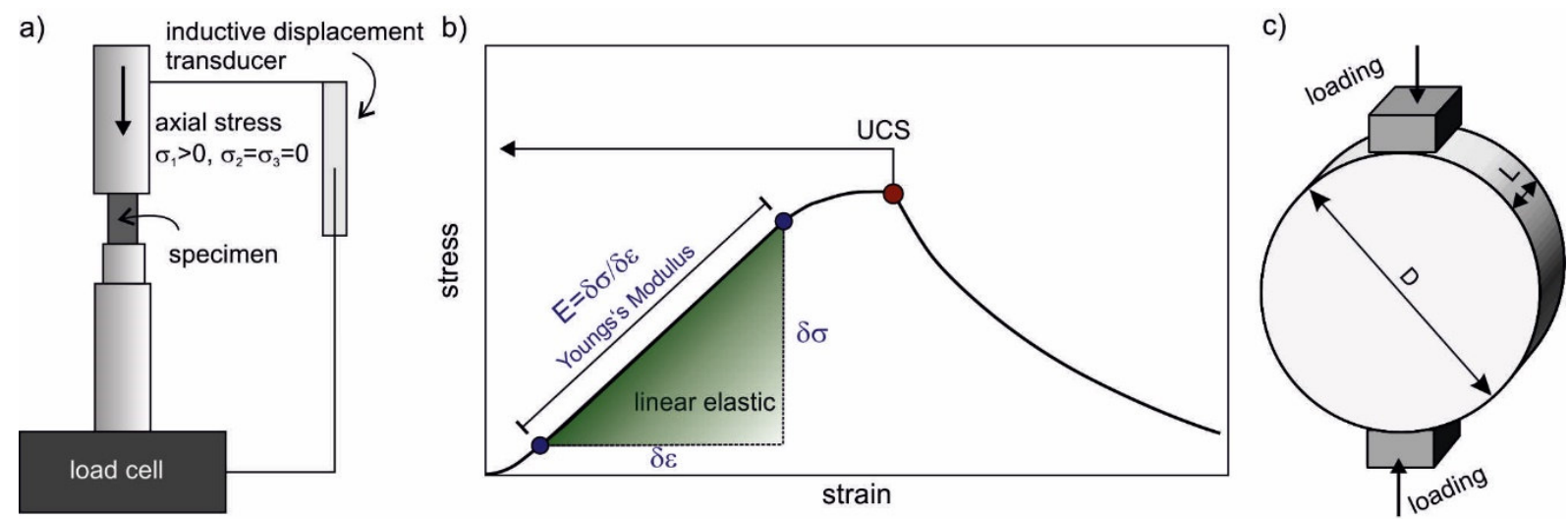

Figure 3.2: a) Uniaxial compression test to determine $U S C$ and $E_{S}$. b) Corresponding stress-strain curve of a compressive test to determine UCS and E). c) Measuring procedure of the Brazilian test to determine $T_{0}$ after Thuro et al., 2001). 
Brazilian test: To determine $T_{0}$, Brazilian tests according to DIN-22024 (1989) and ISRM 1981 (Brown, 1981) were performed. Specimens were loaded perpendicular to the disc-shaped specimen axis with a constant rate of $30 \mathrm{Ns}^{-1}$ (Fig. 3.2c). The loading causes tensile deformation parallel to the load direction. Based on the Brazilian test, $T_{0}$ is calculated from the sample dimensions $(L, D)$ and the peak force $(F)$ :

$$
T_{0}=\frac{2000 F}{\pi L D}
$$

Ultrasonic measurements: Transient times of ultrasonic pulses with a frequency of $0.25 \mathrm{MHz}$ were measured parallel and perpendicular to bedding using a ScopeMeter from the firm Fluke at the University of Göttingen. The corresponding shear-wave velocities can be calculated from the specimen's diameters. Corresponding compressional velocities $\left(v_{p}\right)$ are estimated based on the typical $v_{p} / v_{s}$ ratio of 1.7 for sandstones (Pickett, 1963). The dynamic elastic constant (Young's Modulus $-E_{d}$ ), was calculated with the following equation:

$$
E_{d}=2 \cdot\left(1+v_{p}\right) \rho v_{s}^{2} \quad[\mathrm{~Pa}] .
$$

In these equations $\rho$ is the density that was determined based on the known specimen volume and masses (Eq. 3.4):

$$
\rho=\frac{\text { weigth }}{\text { Volume }}=\frac{k g}{\pi r^{2} h} \quad\left[\mathrm{~kg} \mathrm{~m}^{-3}\right]
$$

Eq. 3.4

\subsection{Thin-section and image analysis}

Thin-section analysis: Thin sections were impregnated with blue resin for optical microscopy with a transmitted light microscope (Zeiss Axioplan 2). For the petrographic quantification of the rocks the thin sections were analysed by classical point-counting, using the half-automated point counter Petrolog lite. The grid size for point counting was set to 1.5 times of the maximum grainsize. The number of points measured in each thin section is 300 . Components distinguished were quartz, feldspar, lithic components, clay minerals, and cement. The modal composition was used for classification, after McBride (1963). According to Soyk (2015) opaque grain coatings or patches in the pore space are classified as clay minerals associated with Fe-oxides.

Image analysis: A scan of each thin section (300 DPI) was taken under plane-polarized light to determine textural characteristics such as grainsize, sorting, and porosity with the software ImageJ (Rasband, 2011). 
a)

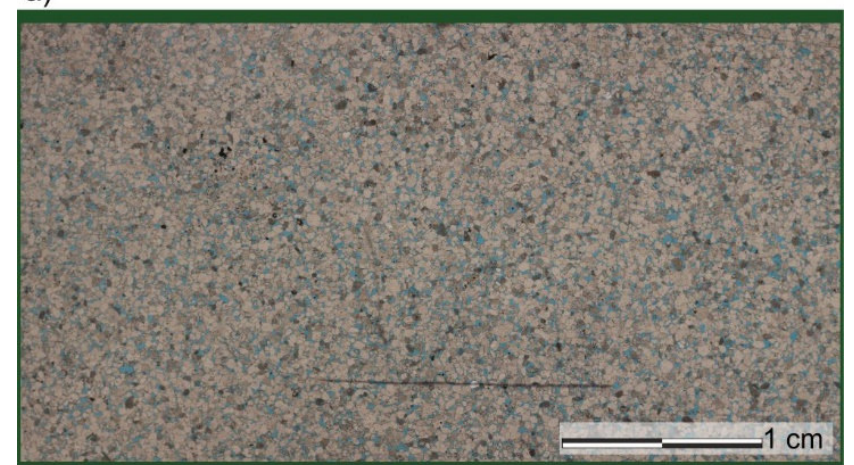

b)

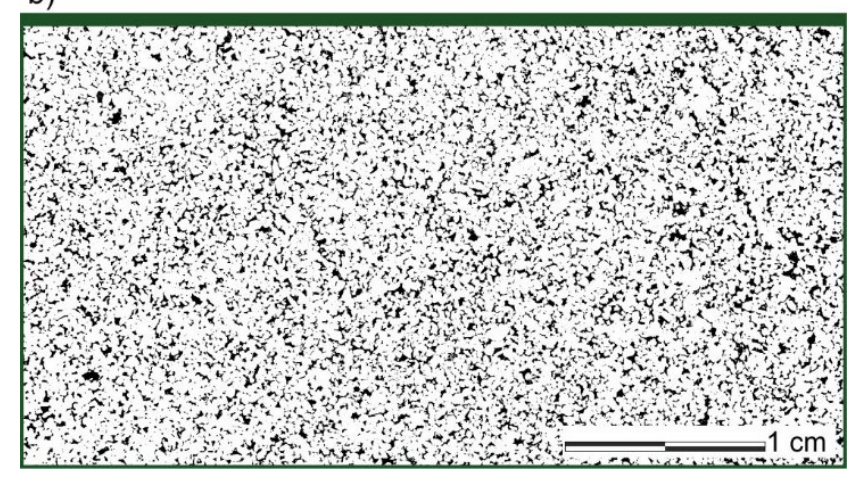

Figure 3.3: Image analysis in ImageJ. a) Scaled scan of a thin section under plane polarised light. b) The generated binary file, with white pixels representing the grains and black pixels representing the pores.

$$
S=\frac{\phi_{84}+\phi_{16}}{4}+\frac{\phi_{95}-\phi_{5}}{6.6}
$$

To distinguish between the grains and the pore space filled with blue resin, a binary image was calculated, in which white and black pixels represent the grains and pore space, respectively (Fig. 3.3). The binary file was compared with the original image to identify mismatches in the classification of pore space. Identified mismatches were eliminated either by manual adjustment or by re-training the software identification for the whole image. These processes were repeated until the binary image had sufficient quality. Porosity was than calculated as area fraction in ImageJ.

For each thin section, the grainsize was also measured. For this purpose, the grainsize of about 100 grains was measured along a scanline using a 1D measuring tool. The grainsize was classified after Wentworth (1922) and the sorting $(S)$ was calculated and defined after Folk and Ward (1957) and Eq. 3.5,

where $\phi_{84}, \phi_{16}, \phi_{95}$, and $\phi_{5}$ represent the grain size in phi values at $84,16,95$, and 5 percentiles.

\subsection{Numerical models}

\subsubsection{Numerical software}

The numerical models were constructed with the software package Comsol Multiphysics 5.0, that uses the Finite Element Method (FEM). In this method, the modelled volume is subdivided into several smaller elements. For each of these smaller and thus simpler elements, the required initial functions and physics are solved separately. The implementation of these initial functions into partial differential equations and the definition of boundaries as well as initial conditions produce a numerical solvable equation system. Thus the interaction between each element and its surroundings can be specified, resulting in a valid solution for the whole model (e.g., Pinder and Gray, 1977; Zielke et al., 1991; Kolditz, 1997).

The software conducts multiphysical simulations, i.e. different physics, physical properties, and equations that are stored within different software modules and can be coupled. The interfaces used in this thesis are in the subsurface-flow module, which provides basic equations that define the heat transport in porous media (Eq. 3.6) and fluid flow, as described by Darcy's law (Eqs. 3.9 and 3.10). 
Heat transport in porous media is calculated with the partial differential equation (PDE),

$$
\left(\rho C_{p}\right)_{e q} \frac{\partial T}{\partial t}+\rho C_{p} q \cdot \nabla T=\nabla \cdot\left(k_{e q} \nabla T\right)+Q,
$$

which describes that the temperature $(T)$ change at one point caused by conductive and advective processes (left hand side) or due to a heat source or $\operatorname{sink}(Q$, right hand side). The effective volumetric heat capacity $\left(\left(\rho C_{p}\right)_{e q}\right.$ : Eq. 3.7) and the effective thermal conductivity ( $k_{e q}$ : Eq 3.8) used in this equation, represents the equalised value between the rock matrix and the fluid ( 1 - porosity $[\theta])$ :

$$
\begin{array}{ll}
\left(\rho C_{p}\right)_{e q}=\theta_{s}\left(\rho c_{p}\right)_{s}+\left(1-\theta_{s}\right)\left(\rho c_{p}\right)_{f} & {\left[\mathrm{~kg}^{-1} \mathrm{~K}^{-1}\right]} \\
k_{e q}=\theta_{s} k_{s}+\left(1-\theta_{S}\right) k_{f} & {\left[\mathrm{~W} \mathrm{~m}^{-1} \mathrm{~K}^{-1}\right] .}
\end{array}
$$

The velocity field $q$ of the advective term in Eq. 3.8 is implemented by adding the flow field described by Darcy's law (Eqs. 3.9 and 3.10), which states that the fluid flow direction is controlled by the pressure gradient $(\nabla p)$,

$$
\begin{array}{ll}
Q=\frac{\partial}{\partial t}\left(\rho \theta_{s}\right)+\nabla \cdot(\rho q) & {\left[\mathrm{kg} \mathrm{m}^{-3}\right]} \\
q=-\frac{\kappa}{\mu}(\nabla p+\rho g \nabla D) & {\left[\mathrm{m} \mathrm{s}^{-1}\right],}
\end{array}
$$

where $c_{p}$ is the heat capacity, $k$ is the thermal conductivity, $\theta$ is the porosity, $Q$ is the mass source, $\rho$ is the density, $\kappa$ is the permeability, $q$ is the fluid velocity field, $\mu$ is the fluid viscosity, $\nabla p$ is the pressure gradient vector, $g$ is the acceleration due to gravity, and $\nabla D$ is the unit vector over which the gravity acts. The subscripts $s$ and $f$ denote the characteristics for solids and fluids, respectively.

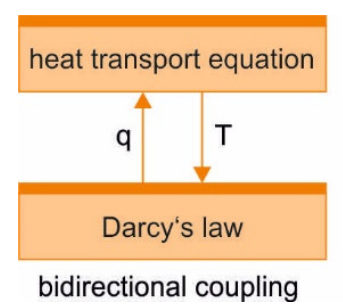

Figure 3.4: Coupling of different physical properties (after Oberdorfer, 2014).
The parameters $\rho_{f}$ and $\mu$ in Darcy's law are temperature dependent. That means there is a bidirectional coupling between these PDE's (Fig. 3.4). However, in my study bidirectional coupling was deactivated. Thus, only the pressure-driven fluid-flow is simulated, i.e. the conductive or density-driven heat-transport and fluid-flow is neglected. The justification for this limitation is given in detail in Section 3.4.3 (Model calibration and simplifications).

\subsubsection{Model design}

The thermal development of a geothermal reservoir was modelled by coupling heat transfer and groundwater flow in a time-dependent study. To investigate the effects of different rock permeabilities, types of heterogeneities and anisotropies (layering, fracturing), depending on the natural fluid flow regime within the sub-surface, five basic model scenarios were designed (Fig. 3.5). 


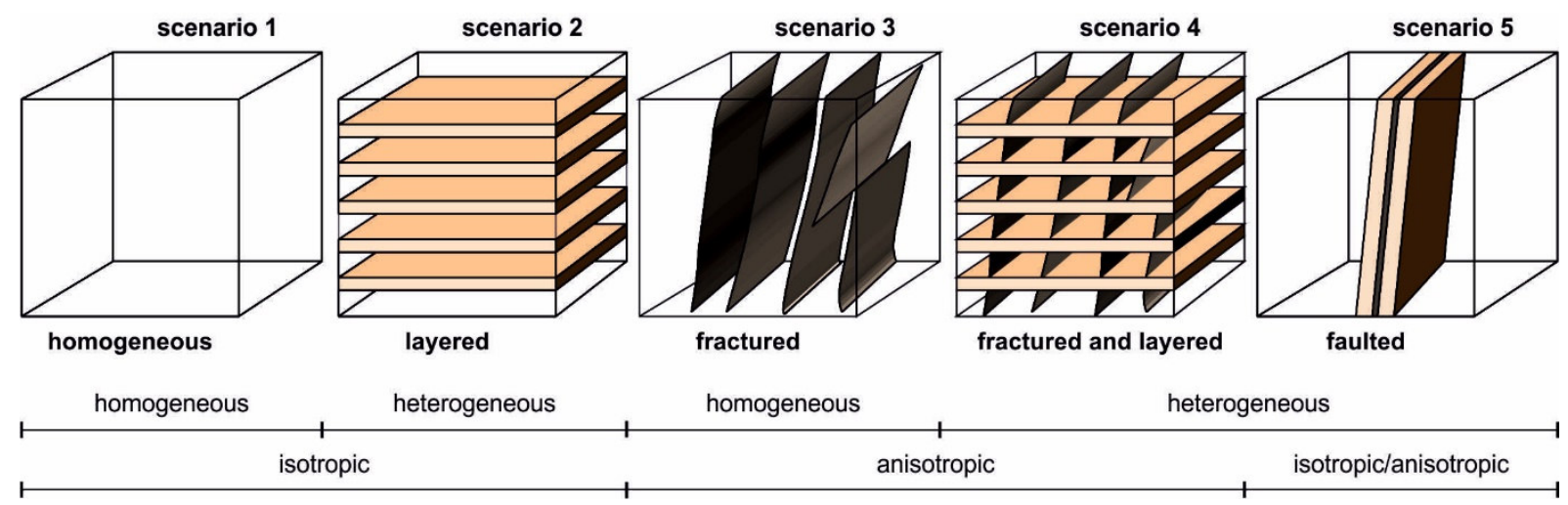

Figure 3.5: Five basic model geometries. For explanation of the different model configurations, see the model scenario description.

The modelled volume is defined as a box with a side length of $4000 \mathrm{~m}$ and a height of $2400 \mathrm{~m}$. The modelled volume lies between 1600 and $4000 \mathrm{~m}$ depth. A geothermal doublet was simulated by including two cylindrical wells, spaced $1500 \mathrm{~m}$ apart, and arranged in N-S direction, $3200 \mathrm{~m}$ below the land surface (Fig. 3.6a). Since typical borehole diameters of ca. 65/8" (ca. $17 \mathrm{~cm}$ ) cannot be realised due to meshing restrictions, the well is modelled with a diameter of $1 \mathrm{~m}$. To account for the larger diameter, the well length was reduced to simulate the surface area of the geothermal well Brühl GT1.

Scenario 1 simulates a fully-homogeneous rock volume. In this scenario, the input parameters, permeability and porosity, were systematically modified to assess their interplay and impact on the thermal development of the reservoir. The parameters were varied within ranges that, according to Bär (2012) and Jodocy and Stober (2011), are typical for the Buntsandstein in the Upper Rhine Graben.

In scenario 2 sedimentary layers were included to test for the effect of different permeabilities.

In scenario 3 the effect of fracture-induced anisotropy was analysed. To realize fracture flow, a continuum approach was applied. The continuum approach uses replacement media, that provide properties identical to the mean hydraulic properties of a given fracture system (e.g., Berkowitz et al., 1988; Lege et al., 1996; Kolditz, 1997). Thus, fracture flow was implemented by defining anisotropic equivalent porous media for the different domains (c.f., Section 3.4.3).

In scenario 4 the combination of fractured and layered reservoirs was tested. The effect of a successively increased amount of non-stratabound fractures was investigated.

Scenario 5 models fault-related reservoirs. A fault that strikes $\mathrm{N}$-S with a normal displacement of $60 \mathrm{~m}$ was implemented. The fault has a $7 \mathrm{~m}$ thick core and two $40 \mathrm{~m}$ wide damage zones. The hydrogeological properties of the fault-zone domains were successively changed to simulate hydrological end-members, as defined by Caine et al. (1996). They are: barrier, conduit, and the combined conduitbarrier system.

\subsubsection{Model calibration and simplification}

Temperature model: The initial temperature $\left(T_{0}\right)$ of the modelled volume was assigned with a temperature gradient of $0.047^{\circ} \mathrm{C} \mathrm{m}^{-1}$ resulting in $150^{\circ} \mathrm{C}$ at a depth of $3200 \mathrm{~m}$, as measured for the Brühl reservoir (Reinecker et al., 2015; URL6: GeotIS). The top and bottom boundaries were thermally isolated (Eq. 3.11),

$$
n(\kappa \nabla T)=0,
$$

with $n$ being a vector normal to the boundaries, states that there is no temperature difference across the boundaries, i.e. there is no heat flux across the boundaries. 


\subsection{Numerical models}

The side boundaries, however, are modelled as open boundaries (Eqs. 3.12 and 3.13):

$T=T_{0}$ if $n \cdot q<0$

$-\nabla T \cdot n=0$, if $n \cdot q \geq 0$

Eq. 3.13

This means that heat can flow out or into the modelled volume at the exterior temperature of $T_{0}$. Thus, the modelled temperature field is not limited by, but extends across these model boundaries.

The injection temperature of the injection well was set to $40^{\circ} \mathrm{C}$ and the reservoir cools down in accordance with the fluid-flow model.

Fluid-flow model: The pressure gradient $(\nabla p)$ that controls fluid flow (Eq. 3.10), was defined by several uniform hydraulic gradients, set as fixed boundary conditions at the model sides. The top and bottom boundaries are no flow boundaries that define a vertically-confined aquifer. Variable flow directions were assigned by the rotation of the hydraulic gradient from $0-315^{\circ}$ in $45^{\circ}$ steps (Fig. 3.6b). The height of the hydraulic gradient was calculated from the surface elevation and groundwater depth maps within the study area and by assuming hydrostatic conditions within the sub-surface (GMTED, 2010; Fan et al., 2013; Gleeson et al., 2016). Corresponding to the groundwater gradient of the study area, the height of the hydraulic gradient was varied from $0,1,5$, to $20 \mathrm{~mm} \mathrm{~m}^{-1}$ (Fig. 3.6c, d). Hydraulic circulation between the implemented geothermal doublet was induced by predefined production- and injection rates of $75 \mathrm{I} \mathrm{s}^{-1}$. In consequence, the pumping and injection pressures could become economically inefficient or unrealistic, depending on the predefined rock permeability.
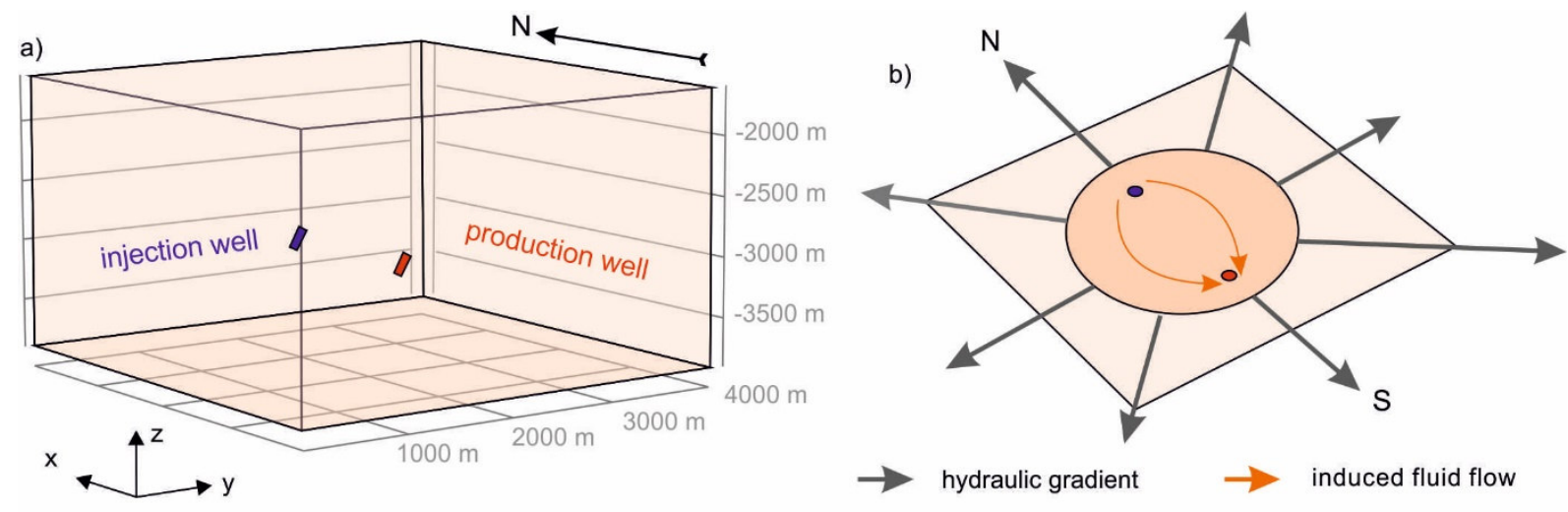

c)

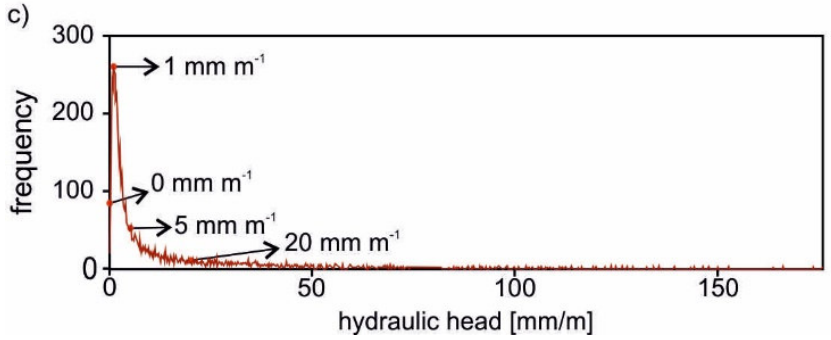

d)

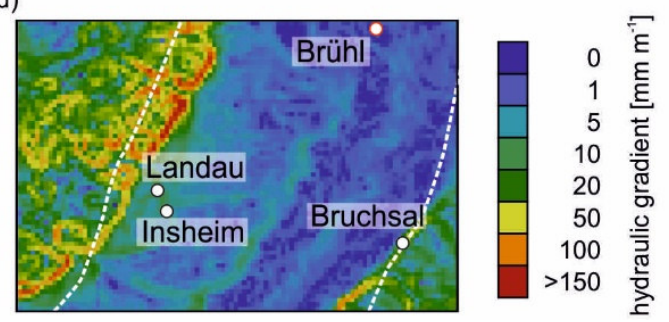

Figure 3.6: a) Model setup. b) Directions of the hydraulic gradient as used in the models were simulated by the rotation of the boundary conditions. c) Frequency of the hydraulic gradients as determined for the study area by using d) the groundwater gradient map in vicinity of the geothermal well Brühl GT1 (database from GMTED, 2010; Fan et al., 2013; white dashed lines show the boundary faults of the URG).

To gain the best compromise between computing times and realistic results, it was necessary to deactivate the bidirectional coupling between fluid-flow model and the temperature model. This meant that water density and viscosity were set to a constant, which excludes density-driven fluid-flow (Eq. 3.6, left hand side, left term). However, conductive heat transport and density-driven fluid-flow are relatively small in comparison to the pressure-driven fluid-flow and advective heat transport (Bergman et al., 2011). Furthermore, the resistance to flow does not change with temperature; this leads to 
constant and identical injection- and production pressures. I also tested for the effect of bidirectional coupling and found that its implementation does not change the general trend of the modelled temperature development, except that in homogeneous models the reservoir cools down slower (Appendix 2.1 - Fig. A2). Further simplifications were necessary to reduce the complexity of the fracture models (scenario 3). Certainly, discrete fracture models would provide optimal comparability to natural fracture systems. However, discretizing fracture domains require an extremely fine mesh to allow modelling of individual fractures with apertures on the $\mathrm{mm}$-scale and thus produce excessive computational effort. Especially for large-scale consideration, rocks with high fracture density and connectivity can be assumed to form a homogeneous continuum (REV) and continuum models provide sufficient approximations (e.g., Berkowitz et al., 1988; Lege et al., 1996; Kolditz, 1997).

Mesh: The numerical mesh consists of 220,658 tetrahedral elements with side lengths ranging from 1 to $712 \mathrm{~m}$ (Fig. 3.7a). The domain surrounding the well needs to have a finer mesh, otherwise it would not be possible to build geometry components of $1 \mathrm{~m}$. This, however, would exceed the computational budget of the whole model. Thus, the injection and production well was surrounded by cylinders with a smaller mesh-size (Fig. 3.7b). Equally, the other domains were meshed at different sizes to gain best compromise between computational effort and precision.

a)

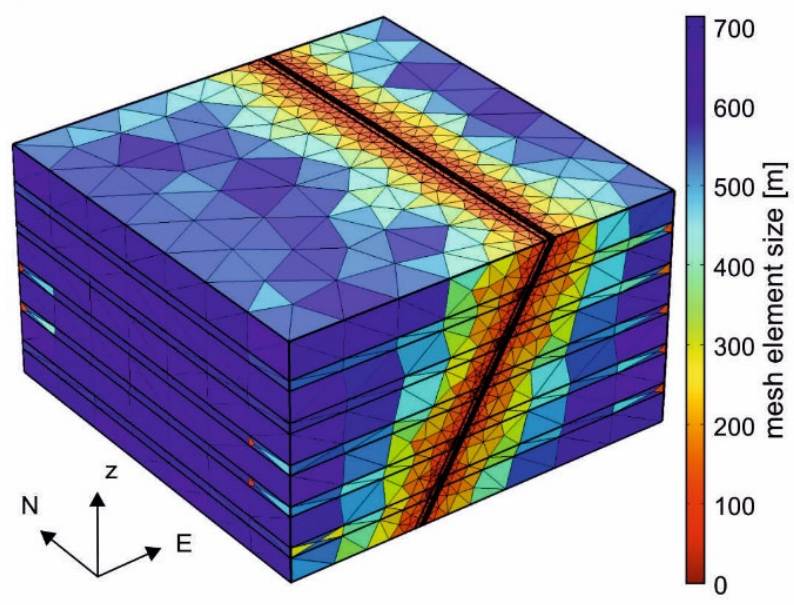

b)

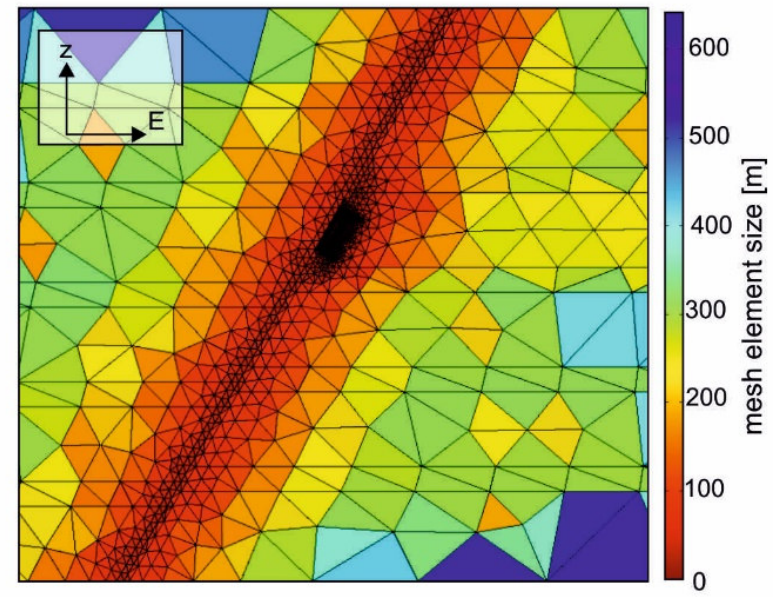

Figure 3.7: Varying mesh quality, depending on the size of the modelled structures. a) whole model. The fault and damage zone are modelled with a fine mesh, while the rest of the domain is assigned a coarse mesh. b) shows an E-Z cross-section through the injection well. 


\title{
4. Fault zones in Lower Triassic sandstones
}

\section{Architecture, fracture system, mechanical properties, and permeability structure of a fault zone in Lower Triassic sandstone, Upper Rhine Graben}

\author{
Tectonophysics 647-648 (2015). doi: 10.1016/j.tecto.2015.02.014 ${ }^{1}$
}

\begin{tabular}{ll}
\hline Keywords: & $\begin{array}{l}\text { fault zone; fracture-system parameter; mechanical rock properties; permeability; } \\
\text { Buntsandstein; Upper Rhine Graben }\end{array}$ \\
Highlights: & Fault zone in porous Bunter sandstone includes core-, transition- and damage zone. \\
& Segregated core zone may provide fluid flow through linked host rock lenses. \\
& Stiff and strong transition zone shows characteristics from core- and damage- zone. \\
& Fracture aperture, connectivity, thus permeability increases towards the fault core. \\
& Fracture affected mechanical rock properties decrease towards the fault core.
\end{tabular}

\begin{abstract}
Close to the western Upper Rhine Graben Main Fault, Alsace, a NNE-SSW-striking fault zone, crosscutting porous, thick bedded Triassic Middle Bunter sandstone was investigated in detail, including its architecture, discontinuity system, mechanical rock properties and implications on its permeability structure and fault zone type. Field observations indicate a three-part fault zone structure including core-, transition- and damage zone. The at least $14 \mathrm{~m}$ thick fault core is composed of various slip surfaces and deformation bands, which encompass fractured host rock lenses. When connected, host rock lenses may transport fluids through the core zone. Adjacent transition zones are highly fractured in $\mathrm{R}_{1}$-orientation, show folded beds and contain $\mathrm{P}_{1}$-oriented deformation bands. $\mathrm{R}_{1}$ and $\mathrm{P}_{1}$ - fractures are synthetic shear fractures and project with an acute angle $\left(10-20^{\circ}\right)$ towards the fault plane. Only in the damage zone, fault-parallel striking fractures occur. Here, increasing fracture apertures and connectivity may increase the permeability towards the fault core. Mechanical rock properties from 12 rock samples (Young's Modulus, uniaxial compressive strength, tensile strength) measured in all the parts of the fault zone, show highest values within the transition zone. In-situ measurements of the rebound-hardness with a Schmidt Hammer and analytical approaches, however, indicate that effective Young's moduli are two to sixteen times lower than the Young's moduli of intact rock. Values clearly decrease towards the fault core, even in the transition zone and are in average lower than effective Young's moduli in the damage zone. Although many fault zones in sandstone are sealing structures these field study show, that fault zones in porous sandstone may allow fluid flow.
\end{abstract}

\footnotetext{
${ }^{1}$ This Chapter is largely identical to the article entitled „Bauer, J.F., Meier, S., Philipp, S.L. (2015): Architecture, fracture system, mechanical properties, and permeability structure of a fault zone in Lower Triassic sandstone, Upper Rhine Graben. Tectonophysics 647-648, 132-145."
} 


\subsection{Introduction}

Fault zones are of particular importance to estimate reservoir permeability because they, depending on their architecture, enhance or impede permeability of the rock (Caine et al., 1996; Caine and Forster, 1999; Agosta et al., 2007; Gudmundsson et al., 2010). In that connection, outcrop analogue studies are useful to analyse the fault zone architecture and thereby increase the predictability of fluid flow behaviour through and across fault zones in the corresponding deep reservoir (Chesnaux et al., 2009; Reyer et al., 2012).

Based on outcrop studies of consolidated brittle rocks, Caine et al. (1996) developed a conceptual fault zone model comprising core zone and surrounding damage zones with different properties and thicknesses. The fault core accommodates most of the strain and displacement of the fault zone and is formed by gouge and cataclasite, which cause a low permeability. The damage zone consists of minor faults and an increased fracture density (as fracture count per meter) compared to the host rock and therefore exhibits an enhanced permeability. Fracture induced permeability depends mainly on fracture aperture and connectivity. The fracture connectivity itself depends on fracture lengths, orientations and densities (De Marsily, 1986; Hestir and Long, 1990; De Dreuzy et al., 2001). In the fault zone model after Caine et al. (1996), the ratio between damage zone and total fault zone thickness contributes to the overall fluid flow behaviour of the entire fault zone.

Although this conceptual model is widely accepted, it does not apply to all rock types, in particular not to porous sandstone (Heynekamp et al., 1999; Rawling et al., 2001; Rawling and Goodwin, 2006; Caine and Minor, 2009). Therefore, two additional fault zone models have been proposed for different rock types (Fig. 4.1).
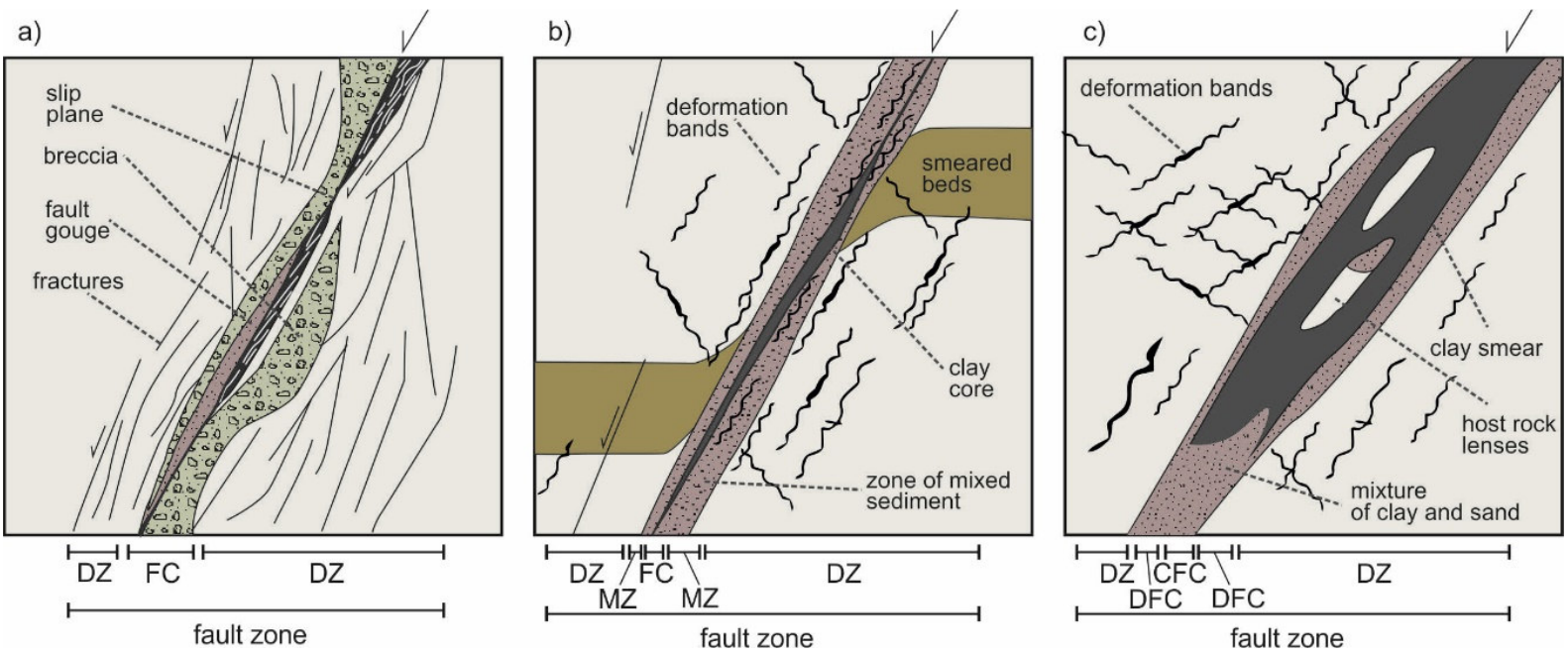

Figure 4.1: Different architectures and structural elements of fault zones in a) crystalline rocks with fault core (FC) composed of breccia and fault gouge and damage zone (DZ) with increased fracture density (Caine et al., 1996), b) in porous sandstones with fault core (FC) composed of clay and a damage zone (DZ) with deformation bands. As a third fault zone part mixed zones (MZ) with deformed and mixed sediments where established (Heynekamp et al., 1999; Rawling and Goodwin, 2006) and in c) in unlithified to poorly lithified sediments with structured fault core into a central part (CFC) with clay membranes and host rock lenses and the distal part (DFC) composed of a mixture of sand and clay or clay lenses in a matrix of sand. The damage zone includes clusters of or single deformation bands. (Fig. 4.1a, b modified after Loveless et al., 2011; Fig. 4.1c modified after Clausen et al., 2003).

They also separate a central core zone and surrounding damage zones with different mechanical, hydrological, and structural characteristics. For porous rocks Heynekamp et al. (1999) found that there are mixed zones between the core and damage zone (Fig. 4.1b). 
In this model, the damage zone includes deformation bands or zones of deformation bands. The main impact of deformation bands, referred as zones with grain deformation, is the porosity reduction and therefore they also commonly involve a permeability reduction (Antonellini and Aydin, 1994; Rawling et al., 2001). The adjacent mixed zones are composed of deformed sediments, or zones with destroyed bedding. Within the mixed zone host rock lenses (elongated rock bodies originating from the damage zones) are common. In the centre a clayey core occurs and is often reported as a low permeability zone (Heynekamp et al., 1999; Caine and Minor, 2009). In contrast, the fault zone model developed by Clausen et al. (2003) for unconsolidated to poorly consolidated sediments, divides the core zone into a central and a distal part instead of mixed zones (Fig. 4.1c). The central part is composed of host rock lenses, enveloped by clay membranes, and is surrounded by the distal fault core: a mixture of sand and clay. The damage zone also includes mostly deformation bands. In the latter two fault zone models in porous sandstone permeability decreases because of fault-related processes such as cataclasis or the formation of deformation bands rather than fractures. Thus, fault zones in clastic reservoirs may have a high sealing capacity (Antonellini and Aydin, 1994). In cases, however, where highly permeable beds juxtapose across the fault zone strike, the formation of host rock lenses in the core zone may allow fluid flow across the reservoir (Lindanger et al., 2007). Fault zone architecture does not only vary due to different lithology, but also along fault zone strike, down dip and time (e.g., Faulkner et al., 2010).

Beside the different effects of fractures and deformation bands on rock permeability they have contrary effects on effective rock mechanical properties. While fractures reduce the effective mechanical rock properties, such as uniaxial compressive strength (Kemeny and Cook, 1986), Young's Modulus (Priest, 1993) or the brittle strain of a fault zone (Schultz, 2003) and increase permeability of the rock mass, mainly compaction deformation bands reduce the permeability and mechanical rock properties increase within the band (Fossen et al., 2007). These differences in the mechanical evolution in turn modify the mode of failure within the fault zone and therefore the permeability structure (Aydin and Johnson, 1978; Fossen et al., 2007). Thus, good constraints on the effective material properties are needed to investigate and to model the permeability structure of the faulted lithology (Renshaw, 1996; Loveless et al., 2011).

In this paper, we present a detailed study of one outcrop exposing a fault zone at the western graben shoulder of the Upper Rhine Graben near Cleebourg (France). The study has two main objectives: First, we present the architecture of the fault zone. We examine, whether the described fault zone models (cf., Fig. 4.1) can be used and are focused on a highly-deformed transition zone between the core and the damage zone. In particular, we discuss the permeability structure of the fault zone, including its fracture system within the different parts of the fault zone. Second, we present results of mechanical laboratory measurements of 12 intact outcrop rock samples. We examine the effects of fractures on the effective mechanical properties using the measured fracture data and mechanical rock properties in an analytical approach (Priest, 1993). To compliment these calculations, we also estimate effective mechanical properties with in-situ Schmidt Hammer measurements.

\subsection{Geological setting}

The European Cenozoic Rift System is a system of NNE-SSW- to N-S-trending grabens (Fig. 4.2a). Most prominent part of the system is the Upper Rhine Graben that extends about $300 \mathrm{~km}$ from the Rhenish Massif (Frankfurt) in the north to the Jura Mountains (near Basel) in the south (Fig. 4.2b). Thereby the Upper Rhine Graben crosses the tectonostratigraphic units of the Variscan internides (e.g., Illies, 1977; Ziegler, 1992; Schumacher, 2002). 
b) $7^{\circ}$ $8^{\circ}$ $9^{\circ}$

c)

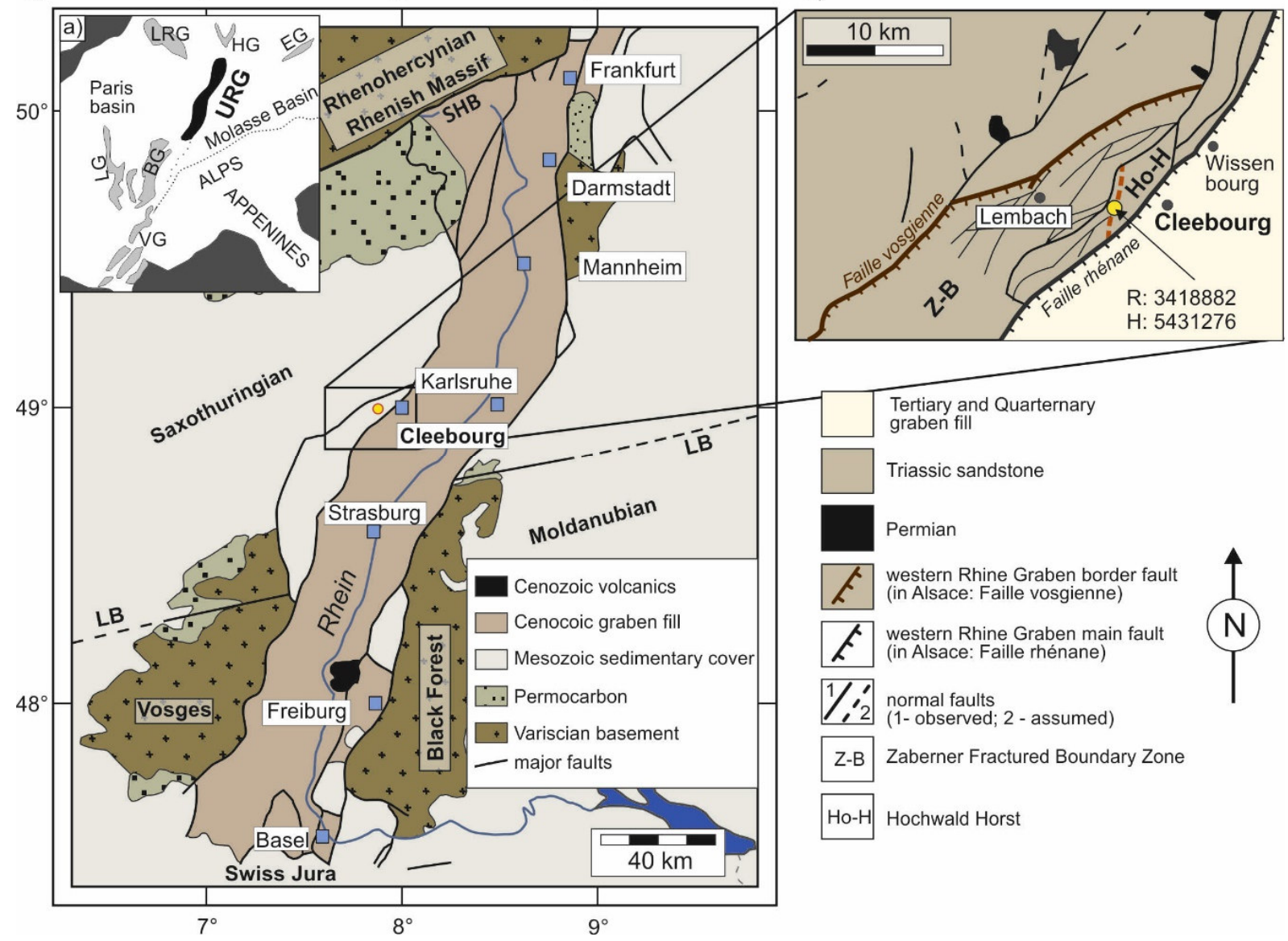

Figure 4.2: a) The European Cenozoic Rift System with N-S- to NNE-SSW-oriented graben systems (light grey; LRG: Lower Rhine Graben; HG: Hessian grabens; EG: Eger Graben; BG: Bresse Graben; LG: Limagne Graben; VG: Vistrenque Graben); in black the study area; URG: Upper Rhine Graben simplified after Ziegler and Dèzes, 2007). b) Simplified tectonic map of the Upper Rhine Graben. Black lines represent the main fault systems with Variscan terrain boundaries (LB: Baden-Baden-LalayeLubine Fault; HSR, South Hunsrück-Taunus border Fault (modified after Ziegler and Dèzes, 2007). c) Zoom into the tectonic details of the studied outcrop area (white dot) at the Zaberner Fractured Boundary Zone with the western Rhine Graben Border Fault (in Alsace: Faille vosgienne) in the west and the Rhine Graben Main Fault (in Alsace: Faille rhénane) in the east (modified after Stapf, 1988, 1996). The GPS-coordinates give the location of the outcrop and the red dashed line indicates the studied fault zone.

Traditionally, the graben has been geomorphological divided into a southern, central and a northern part, because the section between Strasbourg and Karlsruhe has more NE-SW-orientation (Schumacher, 2002). Its initiation started during the middle Eocene to early Miocene as an extensional rift valley in consequence of orogenic activity in the Alps and Pyrenees (e.g., Illies and Greiner, 1978; Ziegler, 1992; Ziegler and Dèzes, 2006). First climax of subsidence took place from Eocene to Early Oligocene and was interrupted during Miocene to Lower Pliocene and started again in Pliocene until recent time (Illies, 1977). The development of the Upper Rhine Graben was partly controlled by mantle diapirism, different stress fields and structures inherited from Variscan orogeny (e.g., Bergerat, 1987; Schumacher, 2002; Ziegler and Cloetingh, 2004; Edel et al., 2007). The evolution of the Upper Rhine Graben included four different stress regimes from its initiation until today. In the late Eocene rifting episode, the Upper Rhine Graben was affected by an N-S-oriented compressional regime, alternated by an E-W-oriented extension in Oligocene and renewed compression with NE-SW-orientation during Early Eocene. The most significant change in the stress field took place in Miocene at which the maximum stress field shifts to a horizontal position with a new NW-SE- to NNW-SSE-orientation (Bergerat, 
1987; Schumacher, 2002). Under these conditions the Upper Rhine Graben is characterized by a continental transform zone with an N-S-trending sinistral motion (Illies and Greiner, 1978; Schumacher, 2002).

The Upper Rhine Graben is limited by prominent eastern and western boundary fault systems (Fig. 4.2b), which separate the sediment-filled graben and the uplifted graben shoulders. Along large parts of its boundary the Upper Rhine Graben has two sets of dominant fault zones (Brun et al., 1991; Schumacher, 2002).

The studied outcrop at Cleebourg is located between those nearly NE-SW-striking distinct fault zones at the Zaberner Fractured Boundary Zone, namely the western Rhine Graben Border Fault (in Alsace: Faille vosgienne) in the west and the western Rhine Graben Main Fault (in Alsace: Faille rhénane) in the east (Eisbacher and Fielitz, 2010). The $10 \mathrm{~km}$ wide Zaberner Fractured Boundary Zone exposes roughly $1 \mathrm{~km}$ thick Triassic sediments. The NE-SW-striking faulted blocks are separated and offset by $\mathrm{N}$ - to NNE-striking faults of younger ages (Fig. 4.2c) (Eisbacher and Fielitz, 2010). The studied NNESSW-striking fault zone is located in the Hochwald-Horst, a flexure with dip of around $30^{\circ}$ in direction to the near western Upper Rhine Graben Main Fault (in Alsace: Faille rhénane; Eisbacher and Fielitz, 2010). The outcrop is located close to the western graben margin. In this area the Upper Rhine Graben Main Fault has a normal offset of $1.2 \mathrm{~km}$ (Eisbacher and Fielitz, 2010).

\subsection{Outcrop characterization and methodology}

The outcrop is located in Alsace (north-east France; cf., Section 4.2), exposing porous, thick bedded Trifels sandstones belonging to the Triassic Middle Bunter (Ménillet et al., 1989; Eisbacher and Fielitz, 2010). The exposure allows a 3D-view, including quarry floors, on the northwestern fault block and core zone of one fault zone (Fig. 4.3). Fault zone type and displacement are difficult to obtain and discussed in detail below.

Fault zone characteristics and fracture-system parameter were examined by using cross-section and window survey measurements. The maximum length of the cross-sections is limited by outcrop size. The following fracture-system parameter were recorded: fracture density, orientation (strike direction and dip angle), aperture, length, mineralization, and connectivity. The length is measured linearly between fracture ends. If either one or both fracture tips extend beyond the outcrop we measured the fracture's minimum length. The aperture is measured perpendicular to fracture walls at its maximum value. As an indication for fracture connectivity and thus for a potential hydraulically active fracture network we measured fracture terminations in three different categories: fracture tips free, one tip connected, and both tips connected. Paleo-fluid transport is derived by fracture mineralization in five different categories: open, coloured or discoloured, incrustation, clay filled and mineralized.

Within the fault core zone deformation bands, slip surfaces (layers composed of fault gouge with some displacement), host rock lenses and lithological content were reported. To avoid cross-section orientation bias recording fractures with parallel strike to one surface, cross-sections were placed parallel and perpendicular to the strike of the fault zone (cf., Terzaghi, 1965; Caine and Tomusiak, 2003). Cross-section measurements perpendicular to the fault plane started at the fault core margin. To get three-dimensional data of the fracture sets and to analyse the variations in horizontal connectivity, window survey measurements on four locations on the quarry floors with different distances to the main fault zone were used. 


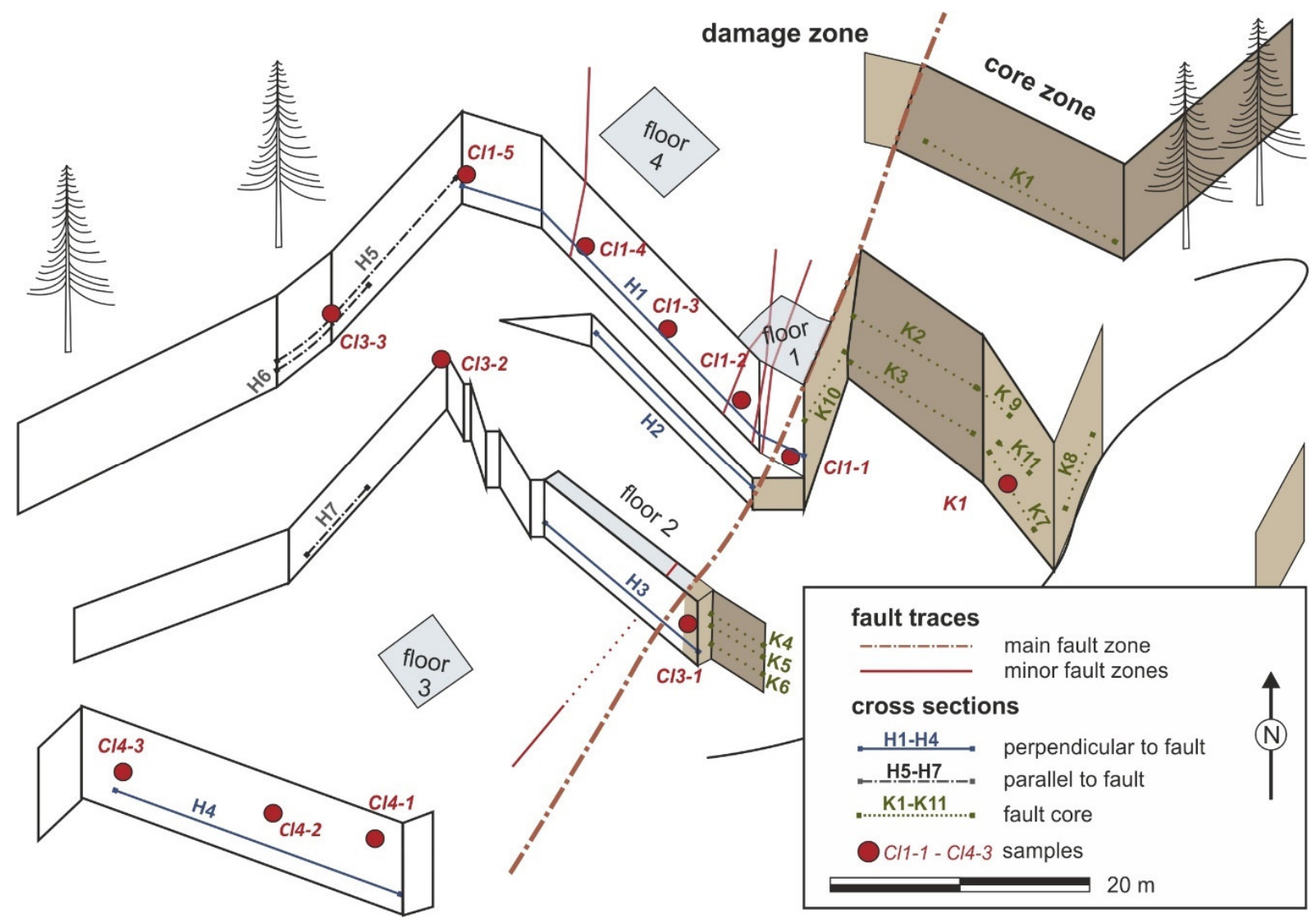

Figure 4.3: Schematic 3D-view of the studied outcrop with marked cross-sections, as well as the four recorded quarry floors (rectangles) on different outcrop levels and distances to the main fault zone and sample points $\mathrm{Cl} 1-1$ to $\mathrm{Cl} 4-3$ and $\mathrm{K} 1$ for mechanical laboratory measurements (red dots).

To characterize the mechanical effects of fractures on rock mass properties, laboratory experiments, analytical approaches, and in-situ experiments were performed. In the different parts of the fault zone cylindrical rock samples were drilled out (Fig. 4.3) with a coring-machine to enforce compression tests (Mutschler, 2004) and Brazilian tests (Brown, 1981; diametral compressive strength test) to investigate the uniaxial compressive strength UCS [MPa], static Young's Modulus $E_{S}[\mathrm{GPa}]$ and indirect tensile strength $T_{0}[\mathrm{MPa}]$ of unfractured rock mass. Where possible, the specimens were taken parallel and perpendicular to bedding or parallel and across fault zone strike, respectively. Differing from Fairhurst and Hudson (1999) specimen diameters for $E_{S}$ and $T_{0}$ measurements was $35 \mathrm{~mm}$ and for UCS $45 \mathrm{~mm}$. The specimen ends are flat to $\pm 0.05 \mathrm{~mm}$. In advance of compression tests, we determined the specimen's volumes and masses to calculate their bulk densities $\rho_{\mathrm{b}}\left[\mathrm{kg} \mathrm{m}^{-3}\right]$.

Since fractures reduce the stiffness of in-situ intact rock masses we use an inverse correlation of the number of discontinuities to calculate effective Young's moduli $E_{e}$ to get the distribution of mechanical rock properties along fault zone parts after Priest (1993; Eq. 4.1),

$$
E_{e}=\frac{\sigma_{n} L}{\Delta L}=\left(\frac{1}{E_{s}}+\frac{1}{\bar{S} k_{n}}\right)^{-1}
$$

When a fractured rock cube with a length $L[\mathrm{~m}]$ gets compressed normal to fracture plane with a normal stress $\sigma_{n}[\mathrm{MPa}]$ the change in length $\Delta L[\mathrm{~m}]$ (or strain) depends on the Young's Modulus $E_{i}[\mathrm{GPa}]$ of the intact rock mass, on the fracture normal stiffness $k_{n}\left[\mathrm{MPa} \mathrm{m}^{-1}\right.$ ] (normal stress per unit closure of the fracture) and $\bar{s}[\mathrm{~m}]$ the average, inverse discontinuity density. The first part of Eq. 4.1 corresponds to Hooke's Law, but includes the strain through fracture closure (Gudmundsson, 2011). 
In the following calculation of $E_{e}$ perpendicular and parallel to the fault plane, with the second part of Eq. 4.1, parameters $E_{s}$ and $\bar{s}$ were used as obtained in the field at different positions at the crosssections. For $k_{n}$, which is very difficult to obtain in the field (Zangerl et al., 2008), published data and empirical relations to UCS were used (e.g., Chang et al., 2006; Reyer and Philipp, 2014).

An L-Type Schmidt Hammer (impact energy: $0.735 \mathrm{Nm}$, USC range: $18-70 \mathrm{MPa}$ ) was used to estimate the effective uniaxial compressive strength and Young's Modulus along the cross-sections as well as at the rock sample positions before drilling (Deere and Miller, 1966; Aydin and Basu, 2005; Yagiz, 2009; Torabi et al., 2010; Viles et al., 2010). In a Schmidt Hammer, a hammer released by a spring, indirectly impacts against the rock surface through a plunger. Part of the energy released by the spring is consumed by plastic deformation on the rock surface. The remaining elastic energy determines the rebound distance of the hammer. The travelled distance corresponds to the rebound-hardness $R[-]$, expressed as a dimensionless scale on the device. Thereby, higher rebound-distances indicate a higher stiffness of the tested rock mass. Each measured rebound-hardness $(R)$ is a mean value determined from 10 impacts, applied at different points spaced at minimum $20 \mathrm{~mm}$ apart from each other. For mean value calculations, the minimal and maximal $R$-value remains unaccounted to eliminate outliers. That instrument allows a detailed map of mechanical property variations, but no detailed absolute values, within the different fault zone parts (Viles et al., 2010). Correlations between $R$ with $E$ and USC are commonly used; see Yagiz (2009) for a summary. Included constants in those relationships, however, mainly depend on lithological characteristics, making it difficult to find one relationship for all rock types. Therefore, we use the $R$-value only for rough estimations on the effective mechanical property variations.

\subsection{Fault zone architecture}

In the damage zone of the NNE-SSW-striking fault zone four normal faults (FZ1 - 4) with displacements of 2 to $6 \mathrm{~cm}$ and one oblique slip fault are formed (FZ5; Fig. 4.4a, c, d). The displacement and the fault zone type of the main fault zone are unknown because only the northwestern fault block and no slickensides are exposed and therefore part of the discussion. The bedding dips $15-65^{\circ}$ towards the southeast, gets steeper, and is sometimes folded towards the fault core (Fig. 4.4b).

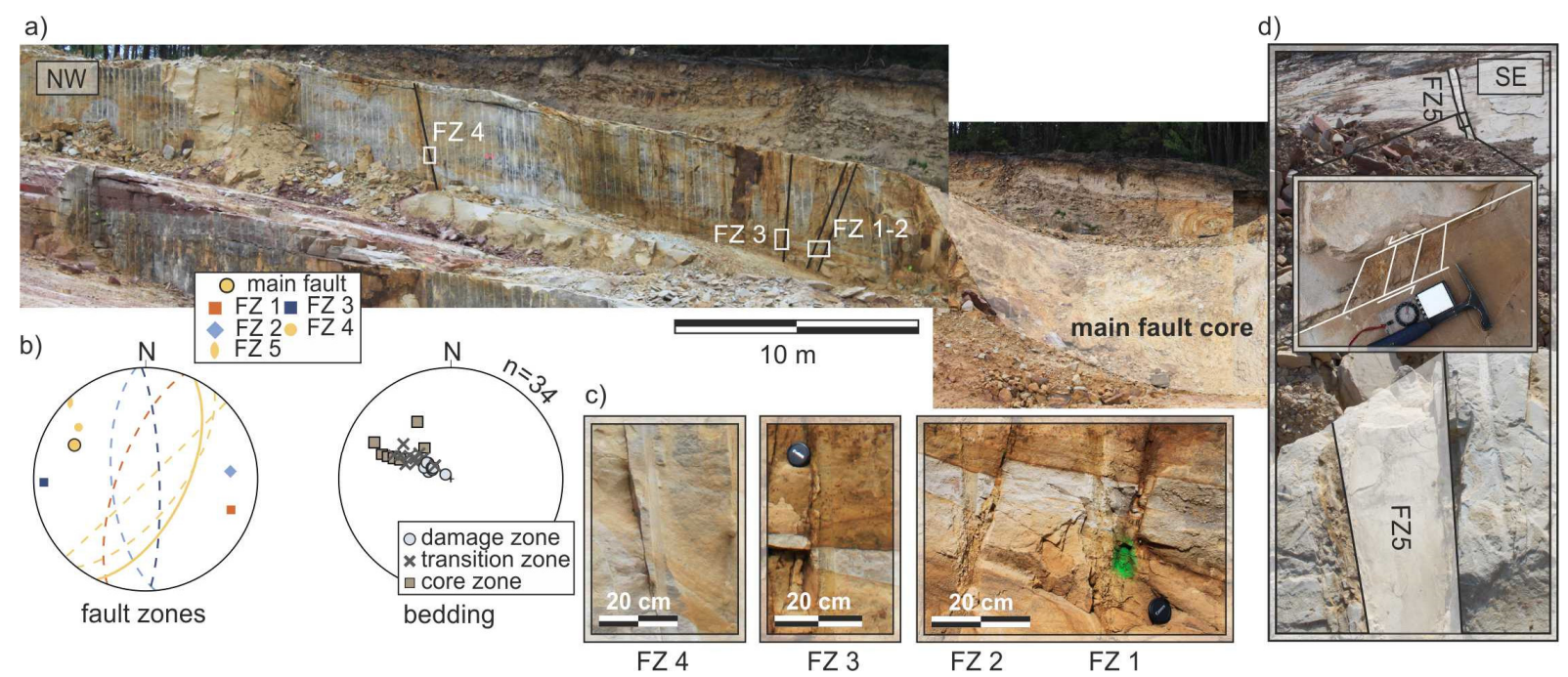

Figure 4.4: a) Photograph of the main fault zone with highlighted fault core and minor fault zone locations (FZ1-4, crosssection H1). b) Fault zone orientations of the minor faults (dashed lines) and the main fault zone strike (bold line) as well as the dip of bedding (equal area, lower hemisphere). c) Detailed photographs of the minor normal fault zones (FZ1-4) in the damage zone. d) Top view on oblique-slip fault FZ5 at quarry floor 2 (cf., Fig. 4.3). 
The main fault zone and all minor faults strike sub-parallel to the main fault trends (N-S to NNE-SSW and NE-SW) of the Zaberner Fractured Boundary zone. Two minor faults $(F Z 1,2)$ are antithetic and three $(F Z 3-5)$ synthetic with respect to the observed main fault zone strike within this outcrop (Figs. 4.2 and $4.4 \mathrm{~b})$.

\subsubsection{Core zone}

The partly exposed fault core shows an internally segregated zone with a minimum thickness of $14 \mathrm{~m}$. Most common features are slip surfaces (sometimes transport water) and deformation bands, which encompass host rock lenses. Also common are Fe-Mn-concretions and sand pebbles or patchy clay (Fig. 4.5). Most of these slip surfaces strike parallel to the main fault zone, others in N-S-direction, are unpolished and not silicificated but oftentimes iron-stained (Fig. 4.5a). They can be detected easily, due to separation of lithological distinct components on each side. They merge with each other but are most discontinuous. Lower strained host rock lenses are fractured and range from consolidated or unconsolidated material composed of clay, silt or sand.

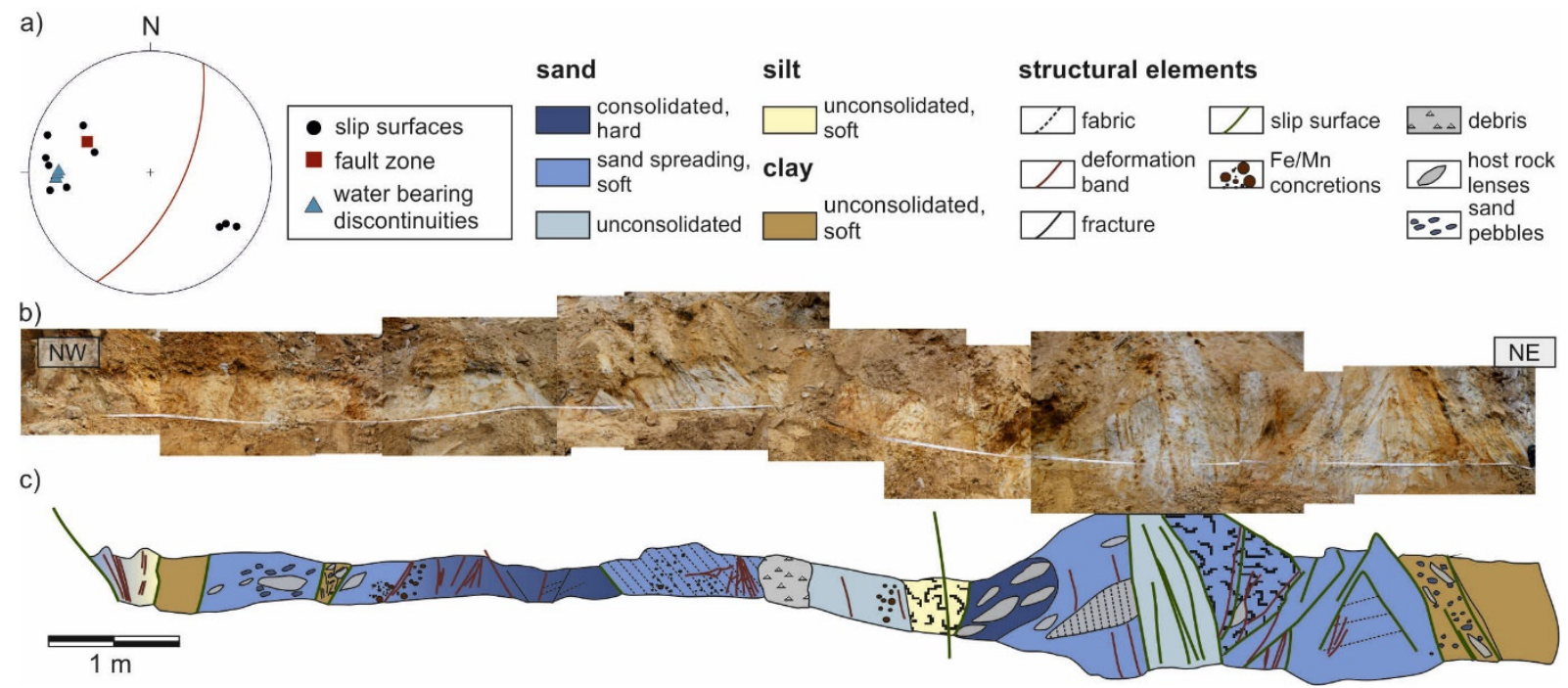

Figure 4.5: a) Orientations of slip surfaces (black dots), main fault zone (red rectangle) and discontinuities which transport water (blue triangle) within the core zone (lower hemisphere, equal area) b) Photograph of the central fault core at crosssection K3. c) Sketch of the architecture of the central core zone. 


\subsubsection{Transition zone}

According to Heynekamp et al. (1999), there is a transition zone between the fault core and the damage zone with different deformation characteristics. This zone can be characterized either as distal fault core (Fig. 4.6a, b) (Clausen et al., 2003) or as mixed zone (Fig. 4.6c, d) (Heynekamp et al., 1999). In both cases, this fault zone part combines characteristics from the central fault core and the damage zone. The transition zone includes mostly fractures and to minor degree deformation bands, which separate small host rock lenses, bedding is more continuous, and the rock is more compact than in the fault core. In some cases, there are small clay lenses in a sandy matrix as well as beds that can be traced from the damage zone into the transition zone. At cross-section K4 to K6 occurs a clear slip surface between the damage zone and the aforementioned transition zone, relating this part to a unit of the fault core (distal fault core), but at cross-sections K1 to K3 a clear slip surface separates the central fault core from this transition zone, making it comparable to the mixed zones after Heynekamp et al. (1999).
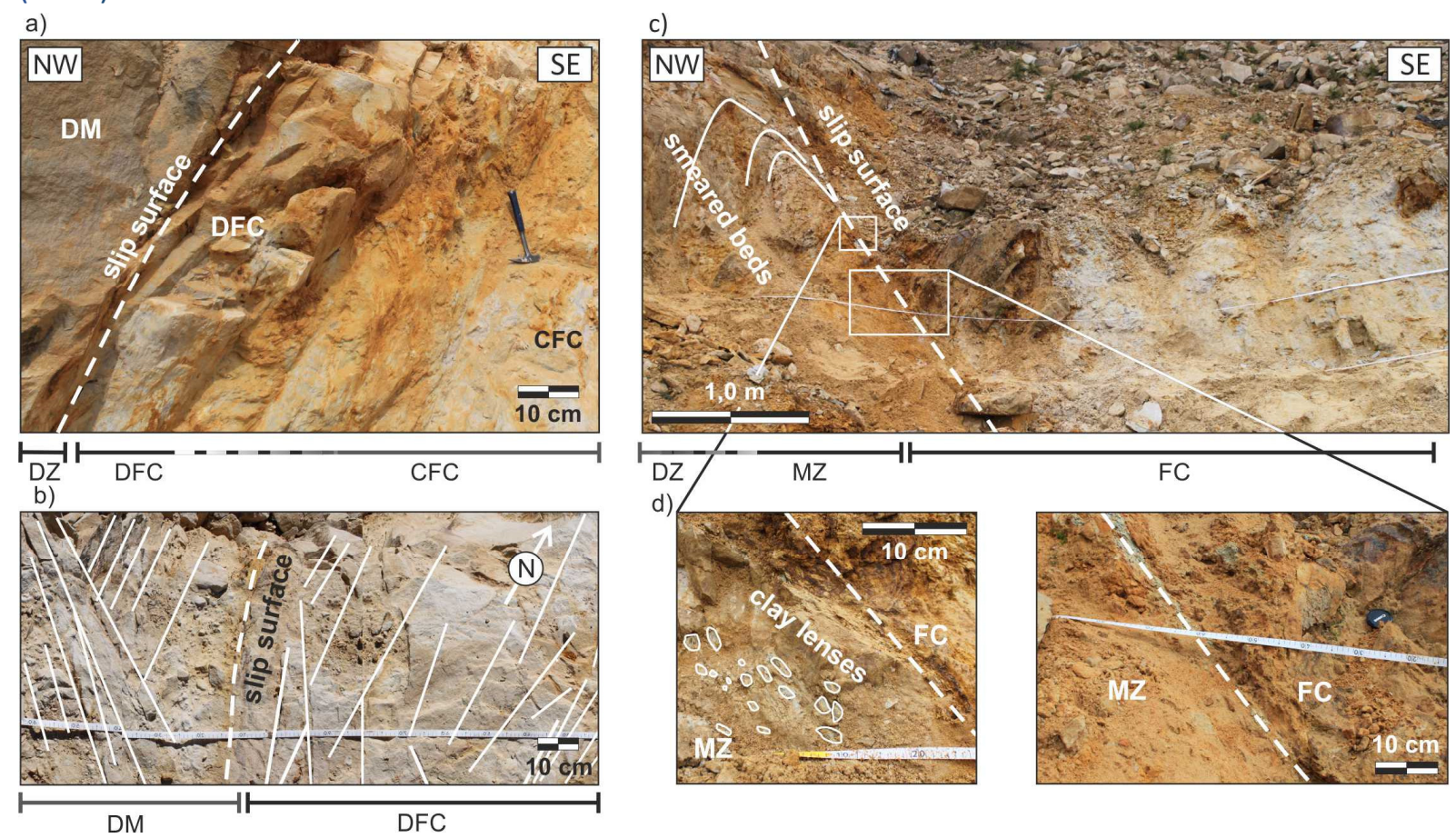

Figure 4.6: a) Transition between the damage zone and the core zone at cross-sections K4 - K6. A clear slip surface between the damage zone (DZ) and the transition zone causes a distal fault core (DFC) with fault parallel host rock lenses and high fracture density. b) Top view on quarry floor 3 with the transition from the damage zone to distal fault core apparent through the reduced fracture density and their change in strike. c) Transition between the damage zone and the core zone at crosssection K2. A clear slip surface between the transition zone and the core zone, characterizes this part as mixed zone (MZ). The mixed zone contains smeared beds, clay lenses, deformation bands as well as a high fracture density. d) Detailed photographs of the transition zone at cross-section K2.

\subsubsection{Damage zone}

The damage zone is less affected by deformation than the core and transition zone. Most common structural elements in the damage zone are fractures. Deformation bands, common features in porous rocks or sands (Bruhn et al., 1994) are absent or invisible in this porous sandstone. Further, the damage zone also includes five minor fault zones. The lateral extension of the damage zone is vague and part of the discussion. 


\subsection{Fracture-system parameter}

\subsubsection{Orientation of structural features}

The most common discontinuities in the damage zone are fractures. Fracture orientations are plotted in symmetrical rose diagrams as well as normal to fracture planes in stereographic projection to get statistical fracture orientation data from the different parts of the fault zone (Fig. 4.7). In general, four main different orientations occur, namely: NNE-SSW, NE-SW, E-W and N-S.

The main fracture set of the damage zone has a fault parallel (NNE-SSW) orientation with equal quantity of synthetic and antithetic fractures. Antithetic fractures show a wider scatter and become less frequent with larger distance to the core zone, whereas synthetic fractures are uniformly distributed in the northwestern faulted block (Fig. 4.8b).

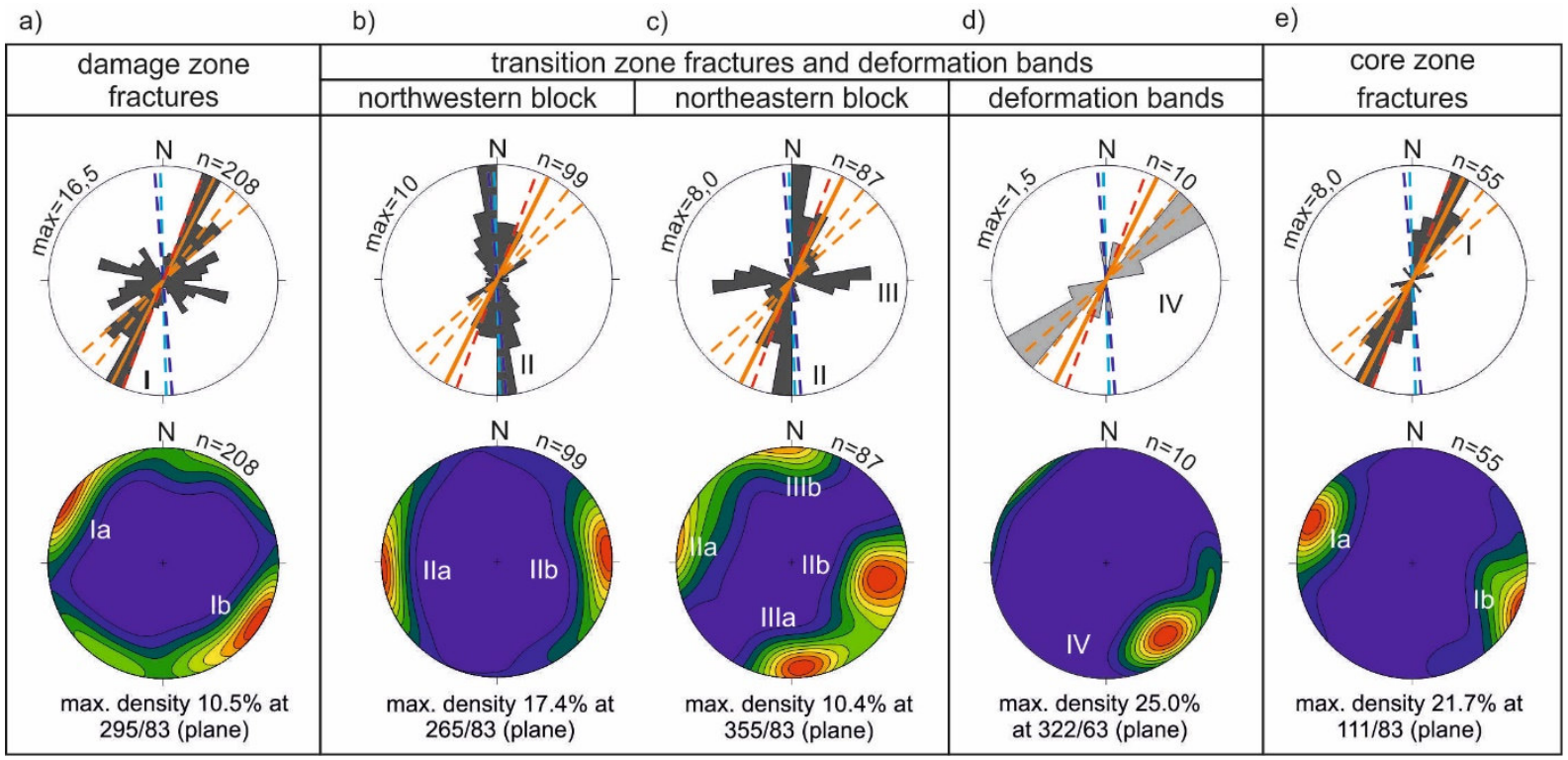

Figure 4.7: Fracture and deformation band populations (marked with roman numerals: I-IV) in the different fault zone parts shown in symmetrical rose-diagrams and as contour plots of poles to fracture planes (equal area, lower hemisphere). The main fault strike is marked by a bold line and minor faults by dashed lines. a) NNE-SSW-striking fractures in the damage zone (population I). b) N-S-striking fractures in the transition zone of the northwestern faulted block (population II). c) N-S- and EW-striking fractures within the transition zone of the northeastern faulted block (population II and III). d) NE-SW-striking deformation bands in the transition zones (population IV). e) NNE-SSW-striking fractures in host rock lenses in the core zone (population I). Fractures in host rock lenses (e) and damage zone fractures (a) have a fault parallel strike, whereby fractures in the transition zones (b, c) strike N-S and deformation bands (d) parallel to regional structures in NE-SW-direction.

In contrast to the fracture orientation in the damage zone reflecting the fault orientation, the main fracture set in the transition zones strikes N-S and forming a $20-30^{\circ}$ angle to the main fault zone. Additionally, there are E-W-striking fractures in the northeastern transition zone (Fig. 4.7a, b, c). Beside fractures, deformation bands are common in the transition zones and core zone. Most of the deformation bands in the transition zones strike parallel to the regional structures in NE-SW and consequently form a $26^{\circ}$ angle to the main fault plane (Fig. 4.7d). Fractures in host rock lenses of the central core zone strike, similar to the uppermost slip surfaces, mostly parallel and synthetic to the main fault zone in NNE-SSW-direction (Fig. 4.7e). 


\subsubsection{Fracture density}

To obtain the fracture density distribution across and along the fault we measured the density perpendicular and parallel to the main fault at cross-sections and on quarry floors.

The data of window surveys show an increasing fracture density towards the fault core. The density of parallel striking fractures is much higher compared with perpendicular striking fractures, but the relative enhancement of perpendicular striking fractures towards the fault core is 1.5 times higher.

Data from horizontal cross-sections show a relation similar to measurements from window surveys, where fracture densities increase towards the major fault plane and at contacts to minor faults as well (Fig. 4.8a). The highest fracture density occurs in the northwestern transition zone, including mostly $\mathrm{N}$-S-striking fractures (Fig. 4.8a, c). Fault parallel fractures are nearly absent in this transition zone and increase only in the damage zone (Fig. 4.8b, c).

Within the transition zone at the northeastern faulted block E-W- and fault-parallel fractures are more frequent than in the northwestern transition zone (Fig. 4.8b, c), but this zone is still dominated by N-S-striking fractures.
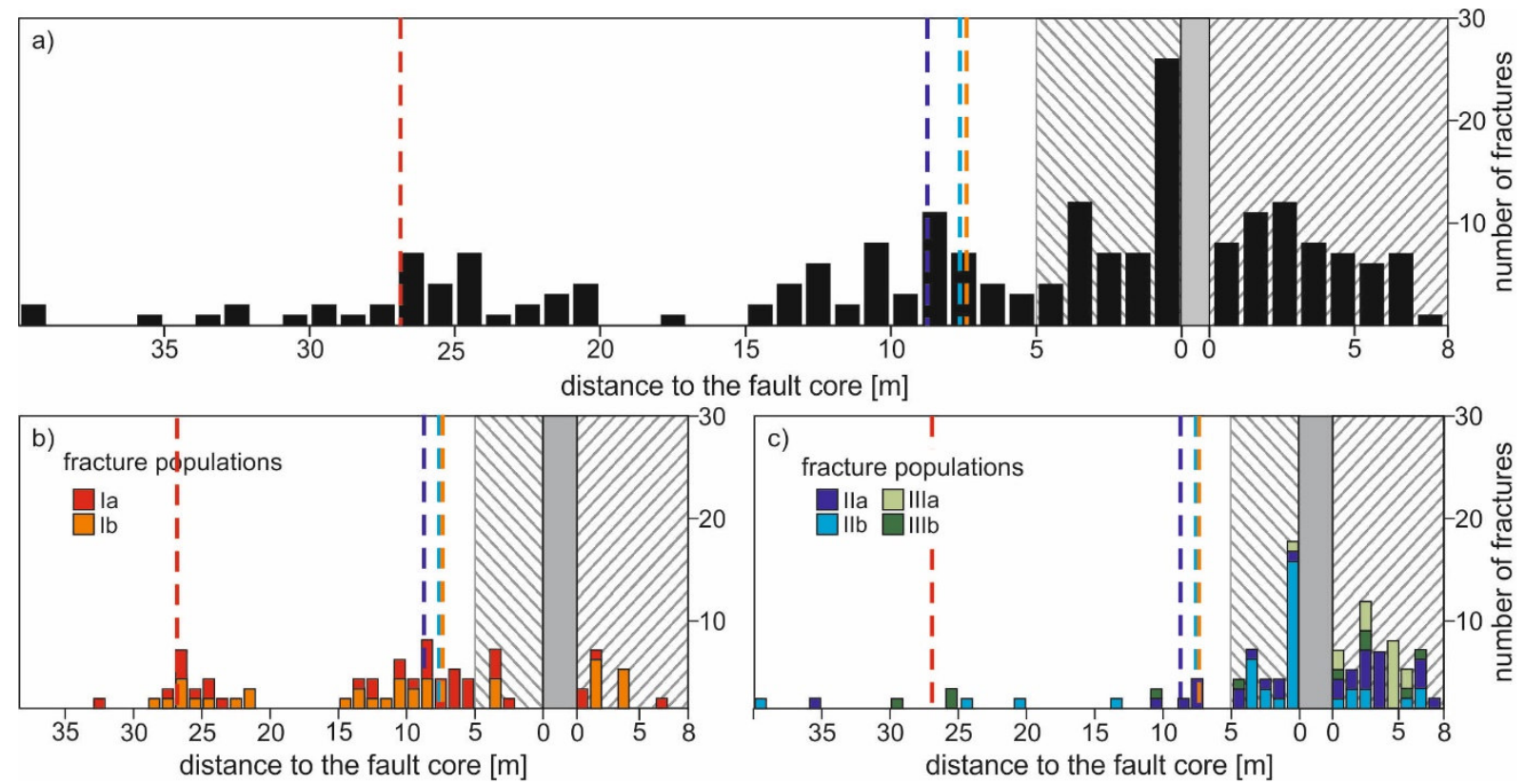

Figure 4.8: Histograms show the fracture density distribution perpendicular to the fault plane at cross-section $\mathrm{H} 1$. Lines indicate the minor fault zone location, grey bars the fault core position and the dashed area the transition zone between the fault core and the damage zone. a) Fracture density distribution for all fractures. b) Fracture density distribution of fracture population I (strike-direction: NNE-SSW). Fracture population la is synthetic (dip ESE), lb is antithetic to the fault (dip WNW). c) Fracture density distribution of fracture population II and III (strike direction: N-S and E-W). Fracture population Ila dip east, IIb dip west, IIla dip $\mathrm{N}$ and IIIb in S-direction.

\subsubsection{Fracture length and aperture}

Fracture length and aperture data were plotted against the distance from fault core and strike direction. Because fracture lengths and apertures are specific for different fracture populations, they are separated according to orientation data (Fig. 4.9). In general, longer fractures have higher fracture apertures. The ratio of aperture (b) and length (I) is defined as the fracture aspect ratio (b/l). It follows that the shorter the fracture in relation to its aperture the higher is its aspect ratio.

The widest apertures occur in the transition zone of the northwestern faulted block and decline with increasing distance from the core zone and increase again around the minor faults. However, in the 
damage zone ESE-dipping fractures (synthetic to the main fault zone) show the highest and WNWdipping (antithetic fractures) the lowest values of apertures (Fig. 4.9a, b).

The fracture length distributions show contrary relations. The lowest values occur in the distal zone and show an abrupt increase in the damage zone, where the longest fractures are mostly antithetic to the main fault zone (Fig. 4.9c, d).
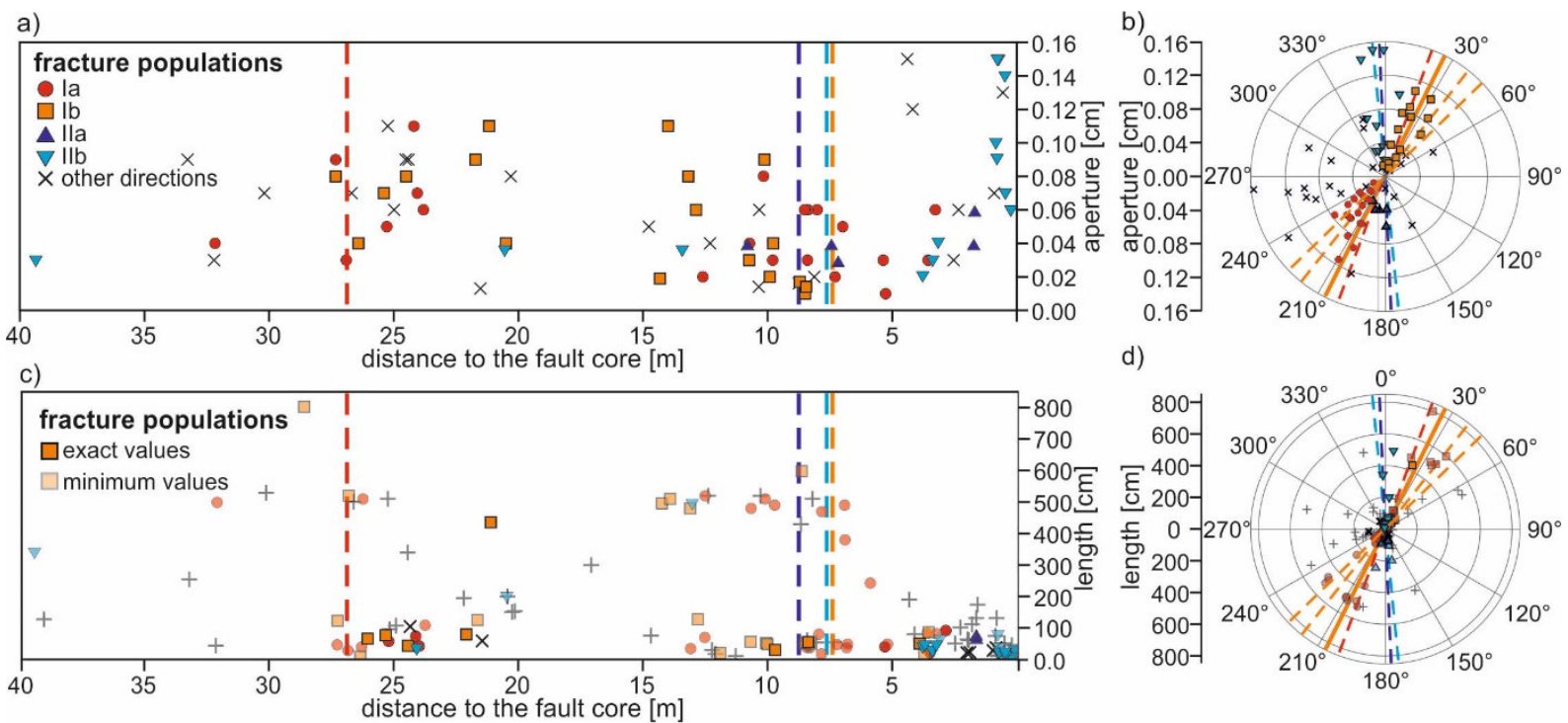

Figure 4.9: Diagrams showing the variations of fracture aperture $[\mathrm{mm}]$ and fracture length $[\mathrm{m}]$. a) Apertures against distance from fault core separated after their dip direction (la: dip ESE, Ib: dip WNW, Ila: dip E and IIb: dip S). Lines indicate the minor fault zone positions. b) Apertures in a circular diagram versus strike direction. c) Fracture length against distance from fault core with marked minimum length values. Lines indicate the minor fault zone positions. d) length in a circular diagram versus strike direction.

In contrast to the cross-sections, fracture apertures measured on the quarry floors get wider with increasing distance from the fault core. Comparable is, that NNE-SSW striking fractures (fracture population I) are longer compared with other orientations. However, fracture lengths do not change clearly with increasing distance from fault core, neither perpendicular nor parallel to the main fault zone. 


\section{Legend:}

profil $\mathrm{H} 1$ - exact values

+ profil H3 - exact values

$\square$ profil $\mathrm{H} 4$ - exact values

$\checkmark$ profil $\mathrm{H} 7$ - exact values

profil $\mathrm{H} 1$ - minimum length

profil $\mathrm{H} 3$ - minimum length

$\square$ profil $\mathrm{H} 4$ - minimum length

$\checkmark$ profil H7 - minimum length

b)

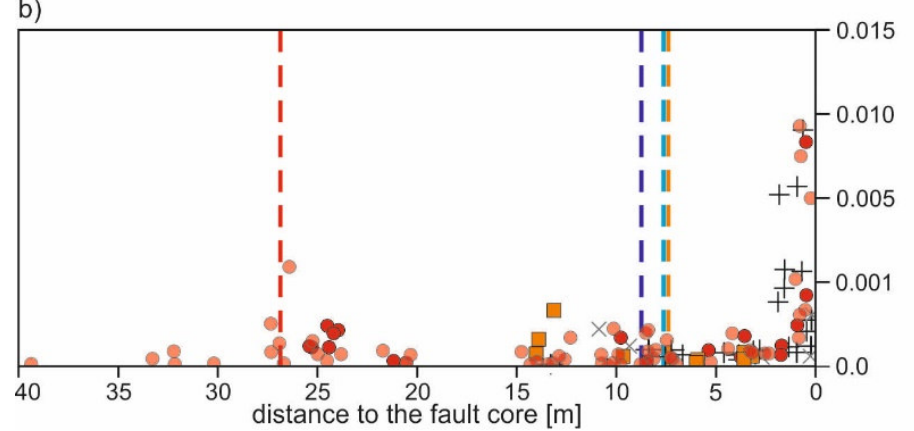

a)

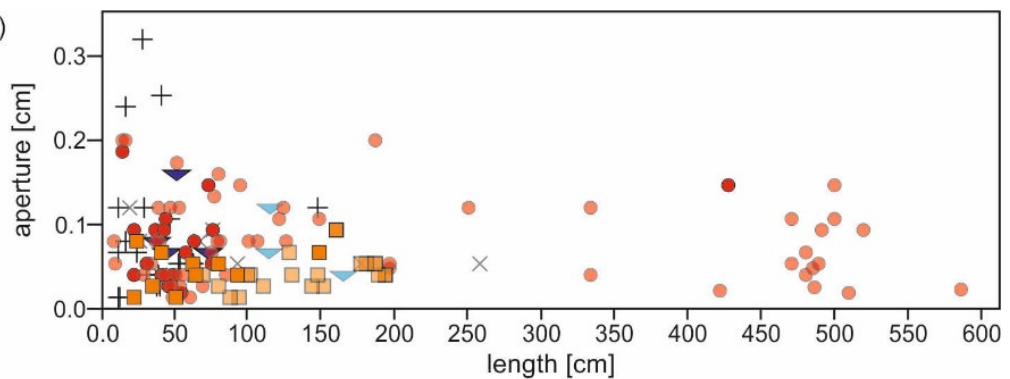

c)

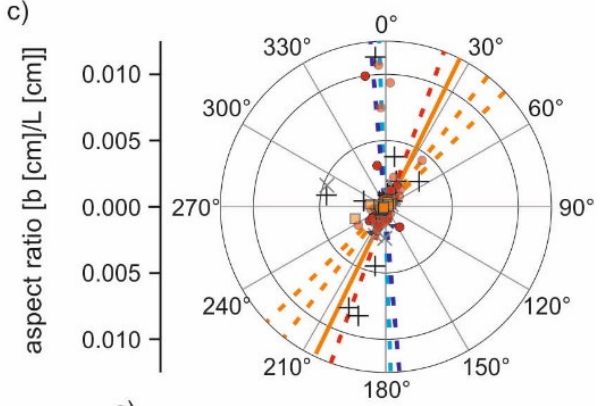

c)

Figure 4.10: a) Relation between fracture length $[\mathrm{cm}]$ and aperture $[\mathrm{cm}] . \mathbf{b}$ ) The aspect ratio (aperture $[\mathrm{cm}] /$ length $[\mathrm{cm}]$ ) with increasing distance from fault core at cross-section $\mathrm{H} 1$. A high aspect ratio indicates a short fracture in relation to its aperture. c) aspect ratios of fractures in a circular diagram versus strike direction according to the profiles measured.

The relation between fracture length and fracture aperture shows that they are negatively correlated within the outcrop (Fig. 4.10). In most cases fractures with high apertures have short lengths.

\subsubsection{Fracture connectivity and mineralization}

The fracture connectivity in the outcrop is low with $51 \%$ unconnected and just $14 \%$ fractures connected at both tips. In general, the connectivity increases with proximity to the core zone. In detail, $86 \%$ of all fractures connected at both tips and $49 \%$ of fractures connected at one tip are located in the transition zones and get less frequent with increasing distance from the fault core (Fig. 4.11a, b). The highest fracture connectivity is given for N-S-striking fractures and the lowest for fractures striking sub-parallel to the main fault plane.

Most fractures are open (71\%) and only $7 \%$ are mineralized. $95 \%$ of all mineralized fractures are located in the transition zones (Fig. 4.11c, d). 

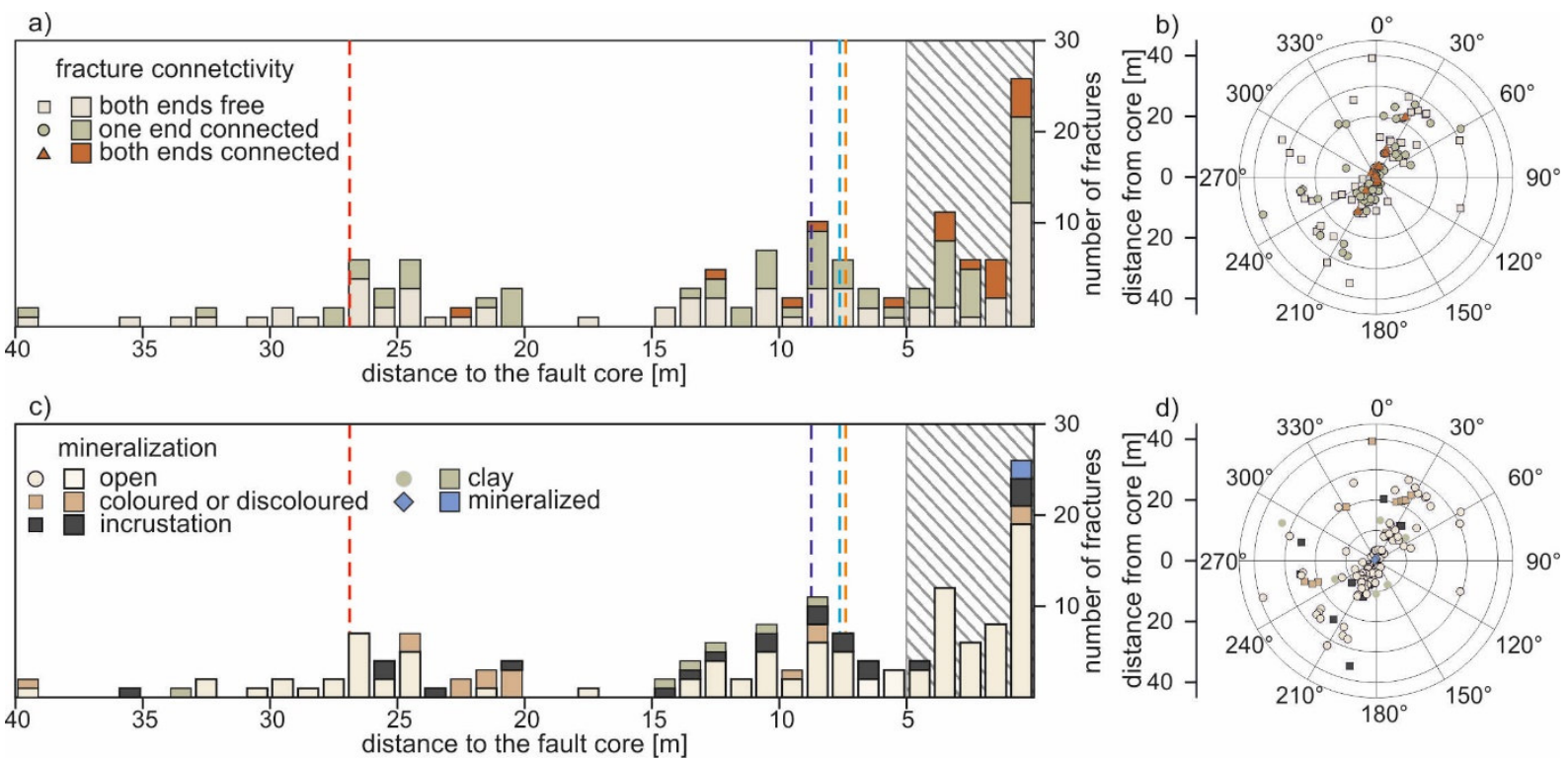

Figure 4.11: Histograms show the variations of fracture connectivity (a) and fracture mineralization (b) across the fault zone at cross-section H1. Lines indicate the minor fault zone positions, the hatched area the transition zone. Circular diagrams showing the fracture connectivity (c) and mineralization (d) versus strike direction and distance from core zone of all fractures measured in the outcrop.

\subsection{Mechanical rock properties}

\subsubsection{Laboratory measurements}

The measured mechanical rock properties are listed in Table 1. For the 12-measured rock samples the uniaxial compressive strength (UCS) values range between $33.4 \mathrm{MPa}$ and $60.8 \mathrm{MPa}$ within the damage zone, 53.4 MPa and 66.6 MPa within the transition zone and the one sample taken in the core zone has a UCS of $15.0 \mathrm{MPa}$ parallel to bedding. Values measured perpendicular to bedding range between $36.7 \mathrm{MPa}$ and $60.1 \mathrm{MPa}$ inside the damage zone and between 48.6 MPa and 73.9 MPa inside the transition zone.

Young's moduli $\left(E_{S}\right)$ parallel to bedding range between $7.6 \mathrm{GPa}$ and $17.0 \mathrm{GPa}$ within the damage zone, 8.2 GPa and 15.6 GPa within the transition zone and the value taken in the core zone is 4.2 GPa. The values perpendicular to bedding are $9.2 \mathrm{GPa}$ and $18.4 \mathrm{GPa}$ within the damage zone, $9.5 \mathrm{GPa}$ and 18.6 GPa inside the transition zone.

Indirect tensile strength $\left(T_{0}\right)$ measurements amount about 1.7 $\mathrm{MPa}$ to $3.5 \mathrm{MPa}$ inside the damage zone and within the transition zone about $2.3 \mathrm{MPa}$ and $2.8 \mathrm{MPa}$, the core zone sample gives $0.6 \mathrm{MPa}$ parallel to bedding. The values perpendicular to bedding range between $1.2 \mathrm{MPa}$ and $2.0 \mathrm{MPa}$ within the damage zone and between 1.7 MPa and 2.7 MPa within the transition zone. The core sample amounts to $0.6 \mathrm{MPa}$. Measured $U C S$ and $E_{S}$ values with compression parallel to bedding are mostly 1 to 1.9 times lower than values perpendicular to bedding. $T_{0}$ is however 1 to 1.7 times lower with compression perpendicular to bedding planes than values parallel to bedding (Table 4.1). 
Table 4.1: Summarized mean values of the mechanical rock properties: $\boldsymbol{U C S}, \boldsymbol{E}_{\boldsymbol{S}}$ and $\boldsymbol{T}_{\mathbf{0}}$ parallel and perpendicular to bedding. Grey marked samples are located in the transition zone, $\mathrm{K} 1$ in the core zone. All other samples are located in the damage zone.

\begin{tabular}{|c|c|c|c|c|c|c|}
\hline \multirow{2}{*}{ sample } & \multicolumn{3}{|c|}{ parallel to bedding } & \multicolumn{3}{|c|}{ perpendicular to bedding } \\
\hline & UCS [MPa] & $E_{s}[\mathrm{GPa}]$ & $T_{0}[\mathrm{MPa}]$ & UCS [MPa] & $E_{s}[\mathrm{GPa}]$ & $T_{0}[\mathrm{MPa}]$ \\
\hline $\mathrm{Cl} 1-1$ & $53.4 \pm 0.4$ & $8.2 \pm 2.2$ & $2.3 \pm 0.6$ & $48.6 \pm 6.2$ & $9.5 \pm 1.1$ & $1.7 \pm 0.4$ \\
\hline $\mathrm{Cl} 1-2$ & $33.4 \pm 1.5$ & $8.6 \pm 1.0$ & $1.9 \pm 0.1$ & $40.5 \pm 2.8$ & $11.4 \pm 1.1$ & $1.7 \pm 0.3$ \\
\hline $\mathrm{Cl} 1-3$ & $33.4 \pm 6.1$ & $10.5 \pm 2.0$ & $1.7 \pm 0.4$ & $36.7 \pm 7.6$ & $9.3 \pm 1.2$ & $1.7 \pm 0.3$ \\
\hline $\mathrm{Cl} 1-4$ & $46.7 \pm 6.7$ & $11.9 \pm 4.3$ & $2.6 \pm 0.7$ & & & $2.0 \pm 0.1$ \\
\hline $\mathrm{Cl} 1-5$ & $36.7 \pm 6.2$ & $7.6 \pm 1.0$ & $2.2 \pm 0.3$ & $44.5 \pm 1.1$ & $14.5 \pm 3.3$ & $1.2 \pm 0.3$ \\
\hline $\mathrm{Cl} 3-1$ & $61.1 \pm 1.0$ & $13.6 \pm 1.4$ & $2.5 \pm 0.3$ & $58.7 \pm 0.8$ & $14.7 \pm 1.1$ & $2.5 \pm 0.4$ \\
\hline $\mathrm{Cl} 3-2$ & $40.5 \pm 6.8$ & $8.9 \pm 2.9$ & $3.0 \pm 0.4$ & $49.6 \pm 2.2$ & $9.2 \pm 0.3$ & $2.0 \pm 0.2$ \\
\hline $\mathrm{Cl} 3-3$ & $35.9 \pm 2.2$ & $11.4 \pm 0.6$ & $2.2 \pm 0.1$ & $39.8 \pm 11.0$ & $10.0 \pm 1.7$ & $1.3 \pm 0.3$ \\
\hline $\mathrm{Cl} 4-1$ & $66.6 \pm 6.8$ & $15.6 \pm 1.8$ & $2.8 \pm 1.1$ & $73.9 \pm 3.1$ & $18.6 \pm 2.9$ & $2.7 \pm 0.4$ \\
\hline $\mathrm{Cl} 4-2$ & $60.8 \pm 12.4$ & $17.0 \pm 0.3$ & $3.5 \pm 0.3$ & $56.6 \pm 15$ & $18.4 \pm 3.4$ & $3.3 \pm 0.9$ \\
\hline $\mathrm{Cl} 4-3$ & $46.6 \pm 5.6$ & $13.2 \pm 0.7$ & $3.4 \pm 0.4$ & $60.1 \pm 2.6$ & $11.0 \pm 1.1$ & $1.7 \pm 0.2$ \\
\hline K1 & $15.0 \pm 1.6$ & $4.2 \pm 0.8$ & $0.6 \pm 0.2$ & & & $0.6 \pm 0.1$ \\
\hline
\end{tabular}

That means the highest $U C S$ values, perpendicular and parallel to bedding, occur within the transition zone and the lowest within the core zone. The distribution of the highest $E_{S}$ is differing from the UCS values. At cross-section $\mathrm{H} 3$ the highest $E_{S}$ values occur in the transition zone, at cross-section $\mathrm{H} 1$ albeit in the damage zone and at cross-section $\mathrm{H} 4$ the values are nearly similar for the transition and damage zone. $T_{0}$ reaches the highest values inside the damage zone, followed by the transition and core zone. The lowest values always occur in the core zone. Generally, the mechanical properties are the highest at cross-section $\mathrm{H} 4$, followed from cross-section H3. The lowest values occur at cross-section $\mathrm{H} 1$. Also the bulk rock density $\rho$ increases from cross-section $\mathrm{H} 4$ to $\mathrm{H} 3$ to $\mathrm{H} 1$ with 2146 to 2183 to $2188 \mathrm{~kg} \mathrm{~m}^{-3}$.

\subsubsection{Schmidt Hammer rebound-hardness}

Values from cross-section surveys $\mathrm{H} 1, \mathrm{H} 2$ and $\mathrm{H} 3$ were taken under wet conditions and are therefore much lower than sample values at the corresponding position (measured in the laboratory) and crosssections $\mathrm{H} 4$ and $\mathrm{K} 7$ which are taken under dry conditions. Previous studies have shown that moisture reduces rock hardness about 10 to 30\% (Barton and Choubey, 1977; Viles et al., 2010). This implies that these data cannot be compared directly. At any rate, the in-situ rebound-hardness tests exhibit higher $R$-values with increasing distance from the fault core (Fig. 4.12).

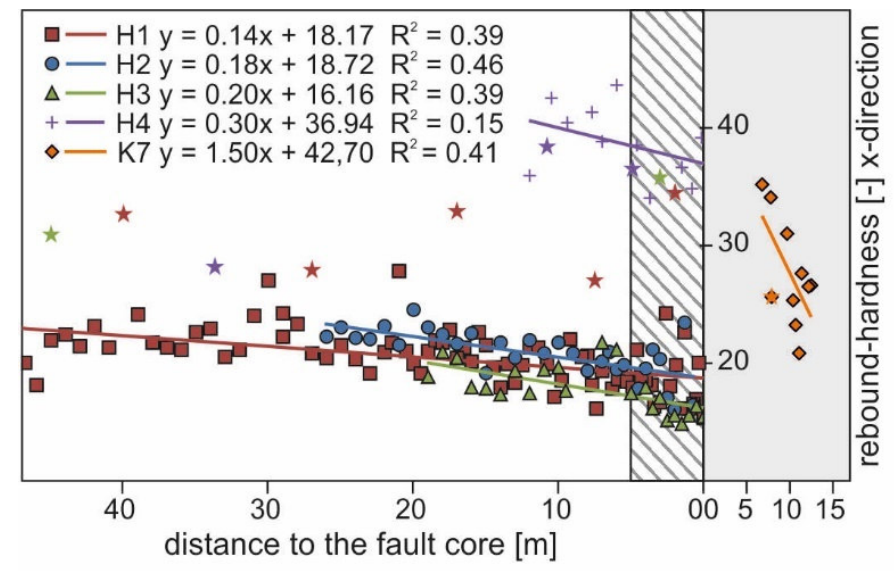

Figure 4.12: Closely spaced rebound-hardness measurements against the distance from fault core at different cross-sections. Rebound-hardness from the rock samples are marked with stars. The hatched area shows the transition zone between the fault core and the damage zone and the grey area show the core zone.

Measurements within the fault core were not possible in large parts, meaning that the rebound-hardness must be lower than 15 , which is the lowest measured value inside the outcrop. The only measurements at cross-section $\mathrm{K} 7_{\mathrm{dry}}$ range between 26 and $32[-]$ in $\mathrm{x}$-direction. The sample value in that 
cross-section averages 26 [-]. The highest $\boldsymbol{R}$-values occur at cross-section $\mathrm{H} 4_{\mathrm{dry}}(34-44)$, followed by cross-section $\mathrm{H}_{1}$ wet $(15-28), \mathrm{H} 2_{\text {wet }}(16-25)$ and $\mathrm{H} 3_{\text {wet }}(15-22)$.

\subsubsection{Effective Young's moduli}

Using the determined fracture densities along the damage zone, $E_{S}[\mathrm{GPa}]$ and UCS $[\mathrm{MPa}]$ of the rock samples (Table 1), the effective Young's moduli $E_{e}[\mathrm{GPa}]$ were calculated with equation 1 (cf., Section 4.3; Fig. 4.13).

The increased fracture densities near the fault core clearly decrease $E_{e} . E_{e}$-values range between 1 and $7 \mathrm{GPa}$ compared with the laboratory values $\left(E_{s}\right)$ between 8 to $17 \mathrm{GPa}$. In particular, $E_{e}$ is two to sixteen times lower than $E_{s}$. The decrease of $E_{e}$ is highest near the fault core as well as around the minor fault zones.
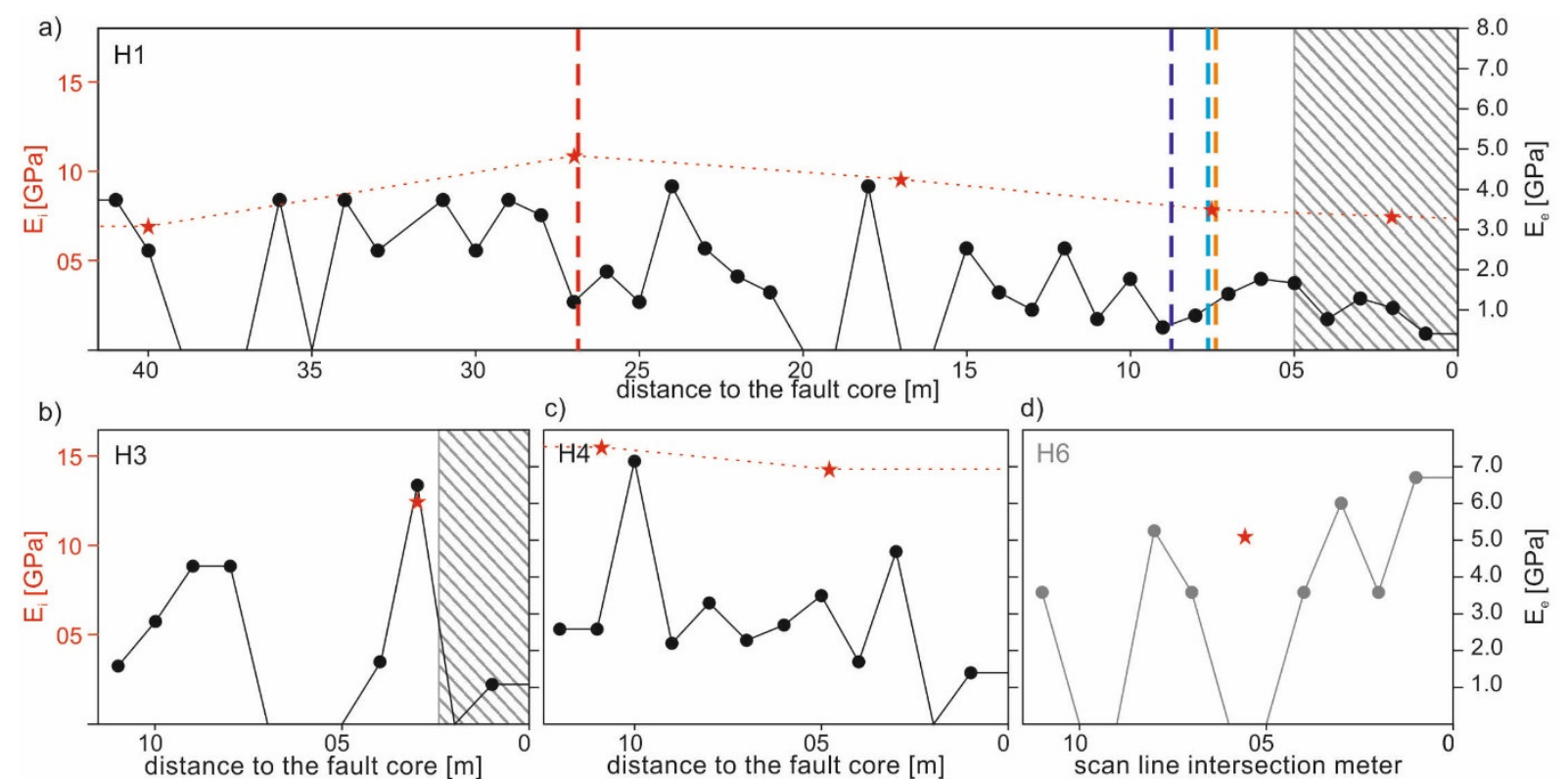

Figure 4.13: Calculated effective and intact Young's Moduli [GPa] perpendicular to the fault zone at cross-section a) $\mathrm{H} 1$, b) $\mathrm{H3}$ c) $\mathrm{H} 4$ and d) parallel to the fault zone at cross-section $\mathrm{H6}$ (cf., Fig. 4.3). The hatched areas show the transition zone between the fault core and the damage zone and dashed lines in a) the position of the minor fault zones.

\subsection{Discussion}

\subsubsection{Fault zone architecture}

The studied fault zone, crosscutting porous, thick bedded sandstones, can be divided into three different parts: damage zone, transition zone and core zone. The at least $14 \mathrm{~m}$ thick central fault core contains high strain zones (slip surfaces), separated by low strain zones with different grain sizes, porosities, and consolidation states (host rock lenses). Similar heterogeneous fault core characteristics have been described by Faulkner et al. (2003; Carboneras strike slip fault - mica shists - south-eastern Spain) and Foxford et al. (1998; salt related normal Bartlett fault zone - sandstone - SE Utah), where individual high strain zones encompass less strained host rock lenses. Such distributed fault cores were explained with the aid of varying mechanical rock properties and the transition of stress to strain or rather strain hardening and strain softening processes (Faulkner et al., 2003; Faulkner et al., 2010).

Strain softening, or reduced load bearing capacity in the stress-strain curve after failure, leads to strain concentration on fractures, which develop into fault zones. Strain softening is induced through e.g. intense fracturing, incorporated weak rocks into the slip surface forming clay smear, breccia or gouge. Particularly, clays are mechanically weak (Byerlee, 1978) and clayey fault cores with low shear 
resistance would localize deformation and form weak narrow fault cores like the five minor fault zones within the damage zone. Thus, strain softening would prevent the building of the observed $14 \mathrm{~m}$ thick fault core structure. In contrast, strain hardening is an increased load bearing capacity after failure, where the rock gets stronger with increasing strain. Strain hardening causes, for example by the formation of deformation bands, porosity reduction or generic increasing grain contact area and increased shear resistance. In cases where a slip surface strain hardens, a self-locking effect, new slip planes in weaker rocks may generate. Strain hardening processes may be an explanation regarding the large thickness of the observed fault core, consisting of various slip surfaces (Childs et al., 1996; Foxford et al., 1998). The development and incorporation of host rock lenses further increase the fault core thickness and may result in the observed $14 \mathrm{~m}$ thick fault core.

The fault core is surrounded by a $1-5 \mathrm{~m}$ thick transition zone. We observed that this architectural fault zone part combines characteristics from the core and the damage zone. This comes apparent through the change in fracture orientations, degree of deformation and occurrence of deformation bands within the transition zone. There is a sharp contact either distal or proximal to the central fault core and thus, the transition zone is not just a part of the core or the damage zone.

Our observations, concerning the structural characteristics of the transition zone, show some similarities with those described by Heynekamp et al. (1999) and Clausen et al. (2003). The former authors characterize this zone as a "mixed zone", which is also observed in poorly lithified sediments by Rawling et al. (2001) and Rawling and Goodwin (2006; Sand Hill Fault - Rio Grande Rift), Caine and Minor (2009; San Ysidro Fault - Albuquerque Basin), and Minor and Hudson (2006; various faults - northern Albuquerque Basin). Mixed zones range from intact, friable sediments to mixtures of clay, sand and gravel with relicts of sedimentary bedding. Bedding is mostly rotated in direction towards the fault zone strike. Further, they observed a sharp contact between the mixed zone and the core zone. This description is consistent with our observation in the upper part of the outcrop. The transition in the middle part of the outcrop coincides to a larger extent with the model by Clausen et al. (2003). Based on extensional faults in unconsolidated silt to fine-grained sand (Northwestern Bornholm, Denmark), they distinguished between a distal and a central fault core. The distal fault core has similar characteristics as the mixed zones, but is in sharp contact towards the damage zone and is thus comparable to our observation in the middle part of the outcrop. Divergent to the descriptions above, we observed the highest fracture densities within the entire fault zone in the transition zone and lower incidence of deformation bands.

The transition zone is encompassed by the damage zone and is composed of mostly open fractures and minor faults. Fractures within the damage zone are mostly sub-parallel to the fault zone strike. Estimation of the lateral extent of the damage zone is not possible. Due to the minimum fault core thickness of $14 \mathrm{~m}$, however, the damage zone thickness is presumably larger than the outcrop dilation (>40 m). 


\subsubsection{Fracture-system parameter}

For all exposed fault zone parts, we observed differing fracture-system parameter. As already mentioned, the most obvious distinction between the damage zone and the transition zone comes apparent by changing fracture orientations. Within the damage zone mostly fault parallel fractures occur (NNE-SSW) as well as an orthogonal-oriented fracture set, which is shifted toward an N-S-orientation within the transition zone and then rotated back within the core zone (Fig. 4.8). We conclude that these fractures are shear fractures in an $\mathrm{R}_{1}$-orientation after Petit (1987). This observation has an important effect on the interpretation of the fault zone type (see below).

Fracture density, aperture and connectivity control the hydraulic connectivity of the fracture network (De Marsily, 1986; Hestir and Long, 1990; De Dreuzy et al., 2001). Previous studies of fault zones show an increased fracture density towards the fault core (Caine et al., 1996; Reyer et al., 2012). Similarly, we observe that the relative enhancement of fractures oriented perpendicular to the fault strike is higher than for parallel striking fractures. This may play an important role regarding the fracture connectivity, because the probability of interconnected fractures increases with (i) density and (ii) fracture orientations. Therefore, the fracture connectivity increases with proximity from the fault core and is highest for $\mathrm{R}_{1}$-fractures ( $\mathrm{N}$-S-orientation) within the transition zone.

We observed slightly increased fracture apertures with decreasing distance from the fault core, whereby the fracture length clearly decreases. N-S-striking fractures within the transition zone have the widest apertures and shortest length. Fracture aperture partly depends on the local stress field (cf., Philipp et al., 2007): Fractures perpendicular to $\sigma_{1}$ get closed and parallel striking fractures tend to open. Due to the recent stress field (active since Miocene; $\sigma_{1}$ NW-SE; Schumacher, 2002) NNE-SSWstriking damage zone fractures are rather closed than N-S-striking transition zone shear fractures. It is also known that even small shearing leads to twisted fracture walls (self-propping effect) and lead to a sustained increase of the fracture aperture even under unfavourable stress fields (Häring, 2007).

We propose two main reasons to explain that most of the transition zone fractures remain short. First, the phenomenon is explainable by mechanical layering and related changes in rock stiffness (Young's Modulus). A propagating fracture is arrested, when it reaches a mechanically weak contact such as an open bedding contact or a fracture (Economides and Nolte, 2000; Gudmundsson, 2011). Mechanical layering does not necessarily coincide with sedimentary bedding, but rather coincides with changes in grain size, porosity or mineralization in one bed and thus induced changes in mechanical rock properties. In particular, due to changes of Young's Modulus within and around the transition zone (see below), the stress field may change locally and form an inhomogeneous or unfavorable stress field for a propagating fracture. Second, the short fractures are mostly interconnected and their high density implies that these beds are saturated with fractures resulting in stress shadows. Therefore, these fractures get linked to each other and remain consequently short (cf., Van der Pluijm and Marshak, 2004).

Consistent with the described fracture network the only mineralized fractures occur within the transition zone. Also common are Fe-Mn-oxide incrustations or staining within the entire fault zone, mostly in NE-SW-orientation. These features indicate a hydraulically active fracture network in the past. Our observations correspond to the description by Eisbacher and Fielitz (2010). They found mineralizations mostly in NNW- to WNW-striking or locally in N-S-striking faults or fractured zones. Near the western Rhine Graben Main Fault, they further describe NE-striking Fe-Mn-ore (sometimes Pb-Zn) mineralization. Most fractures within the outcrop, however, remain open and enable a potentially enriched recent fluid transport. 


\subsubsection{Fault zone type and displacement}

The type, displacement and thickness of the described fault zone are unknown. Various indications, however, allow us to characterize it as an ESE-dipping, sinistral oblique-slip fault (see below).

The orientation of structural components (fractures, deformation bands, minor faults, slip surfaces), are used to define the fault slip direction. The slip direction is defined as the bisecting plane between $R_{1}$ - and $P_{1}$-fractures. Riedel shear fractures ( $R_{1}$-fractures) are synthetic towards the fault zone, project into and form mostly $10-20^{\circ}$ angles towards the fault plane. $P_{1}$-fractures are likewise synthetic (Petit, 1987; Katz et al., 2004). With respect to the main fault zone orientation, transition zone fractures occur predominantly in the $\mathrm{R}_{1}$-shear orientation with left lateral motions. $\mathrm{P}_{1}$-orientation is in particular marked at the minor fault FZ5 (NE-SW-orientation), which also shows a sinistral motion. Also, deformation bands within the core zone are in $\mathrm{P}_{1}$-orientation. This indicates a sinistral movement caused by a NNW-SSE-oriented $\sigma_{1}$ during fault zone formation. That may relate the fault zone formation to Miocene with a NW-SE- to NNW-SSE-oriented stress field (including a sinistral slip regime; Bergerat, 1987; Schumacher, 2002; cf., Section 4.2). This assumption also fits with the general description of the Zaberner Fractured Boundary Zone with mostly N- to NNE-striking faults that cut and offset the graben parallel (NE-SW) faults (Fig. 4.2; Eisbacher and Fielitz, 2010). Because the south-eastern terrain clearly cut downwards in direction to the graben centre and the closeness to the graben centre an ESE-dipping normal component is likely. All these assumptions define the exposed fault block as the footwall.

Scaling relationships of the displacement have often been performed based on the damage zone thickness (Faulkner et al., 2011), core zone thickness (Scholz, 1987; Bastesen et al., 2013) or the trace length of the fault zone (Dawers and Anders, 1995). They exhibit mostly a wide scatter (even in log-log plots), because of different host rocks, tectonic regimes or different methods defining damage or core zone thickness (Faulkner et al., 2010; Bense et al., 2013). Most of these scaling relationships show increasing displacement with increasing damage zone or core zone thicknesses. In our study, however, such relations are not applicable, since the thickness of the different fault zone parts and the trace length are unknown. In general, the at least $14 \mathrm{~m}$ thick core zone and the proximity to the Rhine Graben border lead to the assumption of a high displacement fault.

\subsubsection{Permeability structure}

The fault zone model after Caine et al. (1996) gives four end members for the overall permeability structure of brittle fault zones. The fault core is outlined as a barrier to fluid flow and the damage zone enhances the permeability due to a high fracture density. Depending on the thickness of the different zones, distributed conduits, localized conduit, localized barriers and combined conduit-barrier systems were identified (Caine et al., 1996). Small-scale normal fault zones in sandstones, described by Reyer et al. (2012), tend to be localized barriers. They further observed that higher displacement faults more likely are combined conduit-barrier systems. In those cases, the damage zone contains deformation bands. Rawling et al. (2001) classified large displacement faults in poorly lithified sediments (Sand Hill Fault) with deformation band dominated damage zones, as barriers to fluid flow.

Both fault zone models, however, are not applicable on the presented fault zone, because the transition zone is not taken into account, the presented fault core is not just a sealing structure and the damage zone does not contain deformation bands.

An exact determination of the fluid flow category after Caine et al. (1996) is not possible because of the unknown fault zone thickness, but it best corresponds into the combined conduit-barrier classification. The fracture dominated damage zone increases the permeability. The structure of the fracture 
system indicates an increased permeability towards the fault core in NE-SW direction and orthogonal to it, because of increasing apertures and densities of such striking fractures.

Mixed zones are referred to have a reduced permeability compared with the host rock (Rawling et al., 2001; Rawling and Goodwin, 2006). But within the studied transition zone, besides deformation bands, also the highest fracture density, aperture and connectivity occur. Thus, the fracture induced permeability may even be higher in comparison with the damage zone and shifted towards N-S and $\mathrm{E}-\mathrm{W}$.

The central core zone, which contains permeability reducing structures like narrow slip surfaces composed of fault gouge as well as deformation bands, also includes areas with more consolidated, porous and fractured rock. This means that the core zone itself represents a combined conduit-barrier system. Fluid flow across the fault zone could be possible when the fractured lenses within the core zone are interconnected or rather allow fluids to pass through the low-permeability high strain zones. Such processes are, for example, observed by hydraulic pumping tests within a deformation band dominated fault zone in sandstone, where a mostly uninterrupted fluid communication occurs between both fault walls (Medeiros et al., 2010). Furthermore, we observed some areas which transport water around slip surfaces within the core zone, which also imply a fault core parallel fluid transport. Otherwise some water storage within the porous sands between the in permeable fault gouges may be possible.

Under high fluid pressure, the slip tendency reaches twice the tensile strength of the rock $\left(2 T_{0}\right.$, Gudmundsson et al., 2010). The low tensile strength of the core zone (cf., Section 4.5) may facilitate, even under low shear stresses, slip events within the fault core (Gudmundsson et al., 2010).

\subsubsection{Mechanical properties of the fault rock}

Knowing the mechanical rock properties is a key issue to understand and predict fault zone formation, architectural components, and therefore fluid flow conditions. We determined that UCS-values are higher in the transition zone than in the damage zone. In comparison to the damage zone also $E_{S}$ values are sometimes higher within the transition zone and $T_{0}$ does not clearly change. Obviously, mechanical rock properties within the core zone are by far the lowest. All measured values are particularly comparable with the lower end from normal values of sandstones $\left(E_{S}: 0.4-84.3 \mathrm{GPa}, U C S\right.$ : 6- $170 \mathrm{MPa}, T_{0}$ : 0.4-25 MPa; Gudmundsson, 2011).

Normally, it is easier for fractures to propagate along bedding planes, than to pass through it and accordingly mechanical rock properties measured perpendicular to bedding are higher than parallel values (Hoek and Brown, 1997). Within this sandstone there is just a slight anisotropy between the mechanical rock properties of bedding parallel and bedding perpendicular measurements (Table 4.1). That means beddings planes within this sandstone have little impact on mechanical rock properties. Further it is possible that microfractures reduce the mechanical rock properties perpendicular to bedding in comparison to values parallel to bedding planes.

However, laboratory data are higher than in-situ values due to smaller amounts of fractures (Priest, 1993). These variations were measured by using a Schmidt Hammer and calculated by analytical approaches after Priest (1993). Both methods do not reflect increased UCS or $E_{S}$ within the transition zone. First, the $R$-values taken from rock samples do not show clearly increased values within the transition zone. Second, the closely spaced taken in-situ $R$-values (which are effective values) rather indicates gradually increasing mechanical rock parameters, with decreasing fracture densities (Fig. 4.13). Also, our calculations regarding $E_{e}$ show that the Young's Modulus in particular is reduced around the minor faults and within the transition zone, where the highest fracture density occurs (Figs. 4.9 


\subsection{Conclusions}

and 4.14). From that we derive that the mechanical parameters of intact rock are highest in the transition zone, but effective values are in average lower than in the damage zone. These variations in effective Young's moduli lead to stress concentrations within the outer part of the damage zone or in the host rock, where $E_{e}$ is higher because of lower fracture densities. However, although the core zone rather tends to form a stress shadow, most strain remains within this zone, for example because of already existing weak fault planes (Gudmundsson et al., 2010; Gudmundsson, 2011).

\subsection{Conclusions}

1. Detailed field studies of a fault zone crosscutting Lower Triassic sandstones in Alsace (north-east France) show that previous conceptual fault zone models are not applicable to the observed fault zone in porous sandstone because of a thick fault core and a fracture dominated transition zone and damage zone.

2. Fault zones in porous rocks are often deformation band dominated, but here these are less common within the transition and core zone so that the sealing effect of these structures is less developed within the described fault zone. Also the fault core, consisting of highly strained slip surfaces and lower strained fractured host rock lenses, may allow fluid flow across the fault induced by linked fractured host rock lenses.

3. Within the damage zone the aperture and density of fault parallel striking fractures as well as fault perpendicular striking fractures increase towards the fault core. This may lead to an increased fracture connectivity and enhance the possibility of a hydraulically active fracture network.

4. Compared with the damage zone larger fracture apertures and connectivity on fracture tips occur within the transition zone. This may enhance the fracture induced permeability in N-S-direction to a greater extent compared with other directions and fault zone parts.

5. Mechanical laboratory measurements of intact rock specimens display the highest uniaxial compressive strength and Young's Modulus within the transition zone. But fracture affected effective Young's moduli (determined with a Schmidt Hammer and analytical approaches) are smaller in the transition zone and increase with increasing distance from the fault core.

6. Fault zones in the Lower Triassic Bunter, and possibly other porous sandstones, not always are sealing structures. Even a thick fault core is not inevitably a barrier for fluid flow. Low tensile strength within the core enhances the risk for slip events during ongoing reservoir production. The damage zone, with mostly open fractures, may be potentially drilling targets for geothermal projects in the Upper Rhine Graben system. But because the connectivity decreases clearly with increasing distance from the fault core hydraulic stimulations may be needed.

\section{Acknowledgments}

The authors appreciate the support of the German Federal Ministry for Economic Affairs and Energy (BMWi), previously of the German Federal Ministry for the Environment, Nature Conservation and Nuclear Safety (BMU) as part of the Research and Development Project AuGE (Outcrop Analogue Studies in Geothermal Exploration) within the framework of the 5th Energy Research Program (FKZ 0325302). Thanks to the company RAUSCHER for the permission to perform the field studies in the outcrop. Comments from Agust Gudmundsson and an anonymous reviewer helped improving the manuscript. We also acknowledge the editor Laurent Jolivet and the Tectonophysics team for publishing our work. 


\title{
5. Fault zones in Middle Triassic limestones
}

\section{Fault zone characteristics, fracture systems, and permeability implications of Middle Triassic Muschelkalk in Southwest Germany}

\author{
Journal of Structural Geology 70 (2015). doi: 10.1016/j.jsg.2014.12.005²
}

\begin{tabular}{ll}
\hline Keywords: & fault zone, fracture system, permeability implication, Middle Triassic Muschelkalk, south- \\
& west Germany \\
Highlights: & Fault zone structure and lithology affect permeability in Muschelkalk rocks. \\
& The fault zones are clearly related to the formation of main regional structures. \\
& Fracture system connectivity and permeability is improved close to fault cores. \\
& Various mechanical properties affect permeability evolution (fracture propagation). \\
& All analysed fault zones were hydraulically active during evolution.
\end{tabular}

\section{Abstract}

Fault zone structure and lithology affect permeability of Triassic Muschelkalk limestone-marl-alternations in Southwest Germany, a region characterized by a complex tectonic history. Field studies of eight fault zones provide insights into fracture-system parameter (orientation, density, aperture, connectivity, vertical extension) within fault zone units (fault core, damage zone). Results show decreasing fracture lengths with distances to the fault cores in well-developed damage zones. Fracture connectivity at fracture tips is enhanced in proximity to the slip surfaces, particularly caused by shorter fractures. Different mechanical properties of limestone and marl layers obviously affect fracture propagation and thus fracture system connectivity and permeability. Fracture apertures are largest parallel and subparallel to fault zones and prominent regional structures (e.g., Upper Rhine Graben) leading to enhanced fracture-induced permeabilities. Mineralized fractures and mineralizations in fault cores indicate past fluid flow. Permeability is increased by the development of hydraulically active pathways across several beds (non-stratabound fractures) to a higher degree than by the formation of fractures interconnected at fracture tips. We conclude that there is an increase of interconnected fractures and fracture densities in proximity to the fault cores. This is particularly clear in more homogenous rocks. The results help to better understand permeability in Muschelkalk rocks.

\footnotetext{
${ }^{2}$ This Chapter is largely identical to the article entitled „Meier, S., Bauer, J F., Philipp, S.L., 2015. Fault zone characteristics, fracture systems and permeability implications of Middle Triassic Muschelkalk in Southwest Germany. Journal of Structural Geology 70, 170-189".
} 


\subsection{Introduction}

Since fault zones show a different permeability structure compared with their host rocks, they may control crustal fluid flow (Chester and Logan, 1986; Caine et al., 1996; Sibson, 1996; Caine and Forster, 1999; Agosta and Kirschner, 2003; Micarelli et al., 2006b; Caine et al., 2010; Faulkner et al., 2010; Gudmundsson et al., 2010; Agosta et al., 2012; Philipp, 2012; Reyer et al., 2012). They can either act as conduits or barriers, depending on their infrastructure and the local stress field (e.g., Caine et al., 1996; Agosta et al., 2010; Gudmundsson et al., 2010). In general, fault zones consist of distinct units with different properties. Namely, the fault core in the fault-zone centre, comprising fault gouge, brecciated material and mineral precipitations, and the surrounding damage zone, characterized by an increased fracture density and minor faults (Chester and Logan, 1986; Caine et al., 1996; Berg and Skar, 2005), where pre-existing structures such as bedding are commonly preserved (e.g., Billi et al., 2003). The increased fracture densities in the damage zones may lead to an enhanced permeability (Caine et al., 1996; Faulkner et al., 2010; Gudmundsson et al., 2010). In contrast, fault gouge with reduced grain sizes as well as mineral precipitation within the fault core decrease permeability in many cases. During slip in active fault zones, however, fractures or pores may get interconnected and provide an enhanced permeability within this unit (e.g., Sibson, 1994; Caine et al., 1996).

The damage-zone/fault-core model based on of fault zones in brittle rock, however, is not applicable to all fault zones due to their formation in different rock types with various mechanical properties (e.g., porous sedimentary rocks). Some authors therefore describe additional units in high porosity or unconsolidated sediments, such as mixed zones embedded between fault core and damage zone (Heynekamp et al., 1999), or a distal fault core at the margins of the fault core (Clausen et al., 2003). Furthermore, additional structures in porous rocks may form which show contrary effects on permeability compared to fractures: deformation bands (sandstones, carbonates) or stylolithes (carbonate rocks), with enhanced sealing capacities (Aydin, 1978; Antonellini and Aydin, 1994; Tondi et al., 2006). These structures are the result of either grain movement, grain rotation or grain fracturing in narrow bands of localized strain (deformation bands), and pressure solution (stylolithes) (Aydin, 1978; Antonellini and Aydin, 1994; Tondi et al., 2006), and may lead to a decreased permeability (Antonellini and Aydin, 1994; Fossen et al., 2007).

In fractured reservoirs fractures may have great effects on fluid flow, since they can either increase reservoir permeability or increase permeability anisotropy (Nelson, 1985; Gudmundsson, 2011; Philipp et al., 2013). Because matrix permeability in geothermal reservoir rocks is negligible in most cases and high flow rates are needed for successful geothermal projects, the characterization of fault zones and associated fracture systems is of particular importance (Paschen et al., 2003; Philipp et al., 2010; Stober et al., 2011; Reyer et al., 2012). In the present study, we use outcrop analogues to analyse the effect of fault zones on fracture-system parameter and permeability in fault-related and fractured geothermal reservoirs.

Outcrop analogues expose rocks similar to those found at geothermally relevant depths (in terms of stratigraphy, lithology, facies) and therefore provide an opportunity to study fracture-induced permeability of potential geothermal reservoir rocks (Philipp et al., 2010). We focus on the Middle Triassic Muschelkalk which forms one potential geothermal reservoir in a region with comparatively high geothermal gradient in Germany: the Upper Rhine Graben (URG; Paschen et al., 2003; Stober and Jodocy, 2009; Stober et al., 2011). We investigate whether the simplified fault core-/damage zone model is applicable to define the permeability structure of fault zones crosscutting more or less brittle carbonates. In particular, we focus on the fracture systems associated with the fault zones. Deformation 
bands or stylolithes were not visible macroscopically in the field and therefore are not taken into account.

We present results of eight fault zones crosscutting Muschelkalk rocks of the Kraichgau Syncline located on the eastern graben shoulder of the URG (Fig. 5.1) aiming at characterizing fault zones and associated fracture systems. First, we show preferred orientations of fault zones and associated main fracture sets in the Kraichgau Syncline. Here we aim at integrating fault zone developments in the context of the regional stress field evolution. Second, we characterize three selected fault zones in detail. We examine selected fracture-system parameters (orientation, density, aperture, connectivity, vertical extension) within defined fault-zone units and their distributions across the fault zones. Special attention is given to record mineral precipitations within the fault zone units and in particular within fractures to highlight preferred orientations of past fluid flow. With the studies, we gain insights into the development of fracture-associated permeability of Muschelkalk rocks.

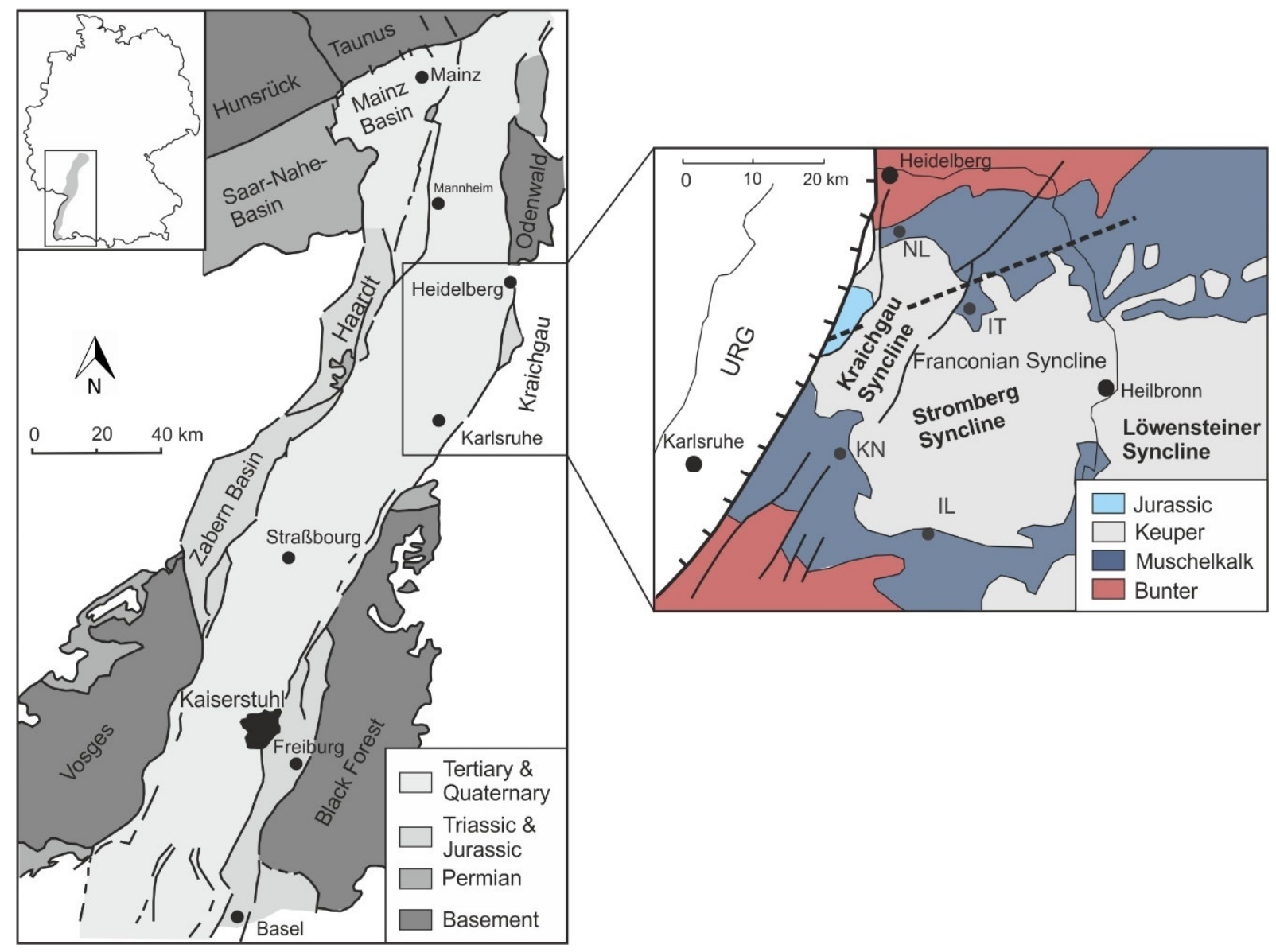

Figure 5.1: Simplified geological maps (modified from Walter, 2007) of the Upper Rhine Graben (URG; left) and the Kraichgau study area (right). The locations of the quarries are marked by dark-grey dots (IL - Illingen; IT - Ittlingen; KN - Knittlingen; NL - Nussloch). The axis of the Kraichgau Syncline is marked by a dashed line. 


\subsection{Geological setting}

The URG forms the central part of the Cenozoic European Rift System, which extends from the North Sea to the Mediterranean Sea (IIlies, 1972; Ziegler, 1992; Schumacher, 2002; Ziegler and Dèzes, 2005). This extensional structure, margined by master normal faults, was formed since Eocene in a weakened region, due to a thinned crust and a thermal anomaly, and exhibits a displacement of approximately 4 km (Illies, 1972; Illies and Greiner, 1978; Ziegler and Dèzes, 2005). The graben interior is filled with Tertiary and Quaternary sediments. The Variscan basement as well as Permian and Mesozoic formations crop out at the eastern and western graben shoulders (Illies, 1972; Walter, 2007), which were uplifted during subsidence within the graben (Schweitzer and Kraatz, 1982; Trunkó, 1984; Ziegler, 1992).

The URG shows an asymmetric setting with larger displacement at the eastern graben margin (Illies, 1972; Eisbacher and Fielitz, 2010). Due to a complex fault block structure within the graben and variations in displacement, lithological changes are common and an irregular graben floor is developed (IIlies, 1972; Trunkó, 1984).

The URG evolution is marked by repeated stress field changes, for example in Oligocene and Miocene (Illies, 1972; Trunkó, 1984; Schumacher, 2002). In the Pliocene, the URG was reactivated again, resulting in strike-slip movements from changes in the regional stress field (Illies and Greiner, 1978; Schumacher, 2002). The shear components led to reactivations of primary normal faults as obliquereverse faults in particular at the eastern graben margin (Illies, 1972; Ziegler, 1992). The recent stress field provides a strike-slip stress regime parallel to the graben axis as well (e.g., Ziegler, 1992, and references therein; Schumacher, 2002; Heidbach et al., 2008).

Our study area, the Kraichgau Syncline (Fig. 5.1), is located on the eastern graben shoulder of the URG and part of the Franconian-Syncline (Walter, 2007). This syncline belongs to a system of ENEWSW trending intramontane basins, which developed during the Stephanium and Early Permian due to reactivations of Variscan structures (Schumacher, 2002; Ziegler and Dèzes, 2005). In context of the URG tectonics the Kraichgau Syncline was mildly uplifted compared with the adjacent highs of Odenwald and Black Forest on the eastern graben shoulder (Schweitzer and Kraatz, 1982; Engesser and Leiber, 1991). Various fault zones crosscut the Kraichgau Syncline with preferred orientations of SSWNNE, SW-NE and NW-SE (Trunkó, 1984).

The Middle Triassic Muschelkalk, divided into Lower, Middle and Upper Muschelkalk, has a total thickness of $200 \mathrm{~m}$ to $230 \mathrm{~m}$. The succession is composed of alternating carbonates and evaporates (Schweitzer and Kraatz, 1982; Engesser and Leiber, 1991). These alternations are the results of sealevel-changes during their deposition in the epicontinental sea (Engesser and Leiber, 1991).

The Lower Muschelkalk shows a total thickness of approximately $75 \mathrm{~m}$ to $78 \mathrm{~m}$ and comprises carbonates, i.e. limestones, marly limestones, marls and dolomites, which were deposited under shallow marine conditions (Schweitzer and Kraatz, 1982; Engesser and Leiber, 1991). The thickness of Middle Muschelkalk rocks is varying but shows a maximum of $100 \mathrm{~m}$ (Engesser and Leiber, 1991; Eisbacher and Fielitz, 2010). These alternating carbonates and evaporites (dolomite, gypsum, anhydrite, rock salt) were formed under a shallow marine environment in a marine basin that repeatedly became isolated and experienced significant evaporation. Leaching of these evaporates has led to the aforementioned thickness variations, and only residual clay is commonly present (Engesser and Leiber, 1991). The $85 \mathrm{~m}$ to $100 \mathrm{~m}$ thick formation of the Upper Muschelkalk can be further subdivided into three main subunits, named as Trochiten-Kalk (mo1), Nodosus-Schichten (mo2) and Semipartitus-Schichten (mo3). They are characterized by micritic limestones, which are low on fossils, alternating with fossil- 
rich carbonates, marls and clay (Schweitzer and Kraatz, 1982; Engesser and Leiber, 1991). Deposition has been ascribed to a shallow marine environment characterized by changing water conditions (micritic limestones versus tempestites; Schweitzer and Kraatz, 1982; Engesser and Leiber, 1991).

\subsection{Field studies}

To obtain information on fault-zone infrastructures, well exposed fault zones with distinct fault zone units are needed. The selected quarries, where the Muschelkalk rocks are crosscut by various fault zones, are located in the northern and southern part of the Kraichgau Syncline (Fig. 5.1). The Nusslochquarry is situated near the URG master-fault, whereas the Illingen-quarry shows the maximum distance of approximately $30 \mathrm{~km}$ to the graben margin. Due to the tectonic history of the study area, including changes in the regional stress field resulting in reactivations (cf., Section 5.2 and 5.5.1), the fault zones are of different types and show various displacements (cf., Table 5.1; Section 5.5.1). The damage zones of some main fault zones include minor faults, as is expected by progressive fault growth (e.g., Childs et al., 2009).

To characterize the fault zone infrastructures, we determined the thicknesses and lithological features of the fault cores as well as the damage zone characteristics (damage zone widths and properties of the fracture systems within the damage zones; see below). According to previous studies we define the boundary between fault core and damage zone as the boundary between faulted rock (e.g., fault gouge or breccia, lenses, dragged bedding) and pronounced original bedding where the fracture density is higher than the background density (cf., Braathen et al., 2009; Bastesen and Braathen, 2010; Bastesen et al., 2013; Schueller et al., 2013).

Cinematically and mechanically, fractures can be distinguished in extension fractures and shear fractures, depending on their relative movement to the fracture plane (Fossen, 2010; Gudmundsson, 2011). Extension fractures show a relative movement normal to the fracture plane (opening/extension mode, for example joints and veins) and shear fractures in direction parallel to it (shear modes: e.g., Twiss and Moores, 2007; Gudmundsson, 2011). Since there is not always the possibility to obtain clear evidence for fracture kinematics in the field, we use the general term fracture for a surface across which the rock has lost cohesion.

Table 5.1: Analysed fault zones. The fault zone types refer to the reflections in the discussion (Section 5.5.1).

\begin{tabular}{|c|c|c|c|}
\hline quarry & number of fault zones & fault zone type & displacement \\
\hline Nussloch (NL) & 1 & $\begin{array}{l}\text { normal fault zone with } \\
\text { associated minor fault }\end{array}$ & $\begin{array}{l}\sim 40 \mathrm{~m}, \\
\text { minor fault unknown }\end{array}$ \\
\hline Knittlingen (KN) & 1 & reactivated reverse fault zone & unknown \\
\hline Knittlingen (KN) & 2 & $\begin{array}{l}\text { normal fault zone, } \\
\text { reactivated as reverse fault }\end{array}$ & $\sim 4 \mathrm{~m}$ \\
\hline Illingen (IL) & 1 & $\begin{array}{l}\text { oblique-slip fault zone } \\
\text { with minor fault }\end{array}$ & $\begin{array}{l}\text { horizontal unknown, } \\
\text { vertical } \sim 0.15 \mathrm{~m} \text {, } \\
\text { minor fault unknown }\end{array}$ \\
\hline Illingen (IL) & 1 & normal fault zone & $0.30 \mathrm{~m}$ \\
\hline Illingen (IL) & 1 & reverse fault zone & $0.57 \mathrm{~m}$ \\
\hline Ittlingen (IT) & 1 & normal fault zone & $\sim 3 \mathrm{~m}$ \\
\hline
\end{tabular}

To determine the damage zone width, the fracture density distribution (number of fractures per unit length) normal to the slip surface was detected, if possible, in several limestone beds of these limestone-marl-alternations, using the scanline-method (e.g., Priest and Hudson, 1981; Berg and Skar, 2005; Micarelli et al., 2006b). The selected limestone beds are well exposed and traceable over several 
meters. In rare cases of covered beds, we used beds with comparable thicknesses for continued scanlines. Each scanline starts at the boundary of the fault core and damage zone (the fault core thickness was measured at this zero point) and runs towards the damage-zone-/host-rock transition of the hanging wall and footwall, except for the scanline across the Illingen oblique-slip fault (cf., Sections 5.4.1 and 5.4.2 - IL). Additional scanlines within the undisturbed host rock give information on background fractures. We define the outer boundary of the damage zone as the point where the fracture density clearly decreases towards background fracturing (e.g., Childs et al., 2009; Schueller et al., 2013). Besides the fracture orientations (strike direction and dip angle), the properties of each fracture within the defined fault zone units were examined as follows.

One important fracture parameter in terms of reservoir permeability is the fracture aperture. Few open fractures with larger apertures may enhance the permeability, because the flow rate depends on the cube of the fracture aperture (cubic law; De Marsily, 1986; Odling et al., 1999) and fluid flow may be channelled along the widest parts of a fracture (Odling and Roden, 1997; Philipp et al., 2013, and references therein). We show the maximum values of fracture apertures, that is the maximum fracture dimension measured perpendicular to the fracture walls (Philipp et al., 2013). However, we have to consider that measurements under surface conditions are not directly applicable for permeability calculations for example due to uplift induced expansion and erosion as well as weathering effects such as karstification. It is intended that our measurements provide indications for fracture aperture distributions within fault zones, but no absolute values.

Additionally, it is necessary to distinguish between open fractures and fractures sealed with mineral precipitations. Open fractures include no filling material between the fracture walls (Nelson, 1985). We name fractures showing mineral precipitations, for example deposits of calcite or silica, mineralized fractures. They are indicators for past fluid flow, whereas they could act as barriers for recent fluid flow in potential geothermal reservoirs (Nelson, 1985; De Marsily, 1986; Philipp, 2012). Thus, the fracture orientations and distance to the fault core of mineralized fractures were noted during the field studies. Due to sealing of these fractures the fracture thickness was measured instead of fracture aperture.

Furthermore, the fracture system connectivity is of great importance in our investigation, because only interconnected fractures could form a hydraulically active fracture network (Stauffer and Aharony, 1994; Odling et al., 1999; Ortega and Marrett, 2000; Micarelli et al., 2006b; Philipp et al., 2013). We distinguish between connected and unconnected fractures, that is, between fractures whose tips terminate against other fractures, and unconnected fractures with no visible connection. These observations indicate the degree of physical connection of the fracture system.

Additionally, we take the fracture vertical extension into account. First, the fracture length was investigated as the distance of a straight line connecting the two fracture tips in vertical direction (also referred to as fracture height). Second, we considered how far the fractures propagate through the mechanically layered rocks, distinguishing 'stratabound' and 'non-stratabound' fractures (Odling et al., 1999). Stratabound fractures are restricted to only one limestone bed. Non-stratabound fractures, however, expand across several beds and therefore may create a hydraulically relevant flow path between multiple layers. 


\subsection{Field results}

In this section, first a short overview of the orientations of all analysed fault zones and of the fracture systems within the quarries is presented. Second, detailed results of fault-zone infrastructures and associated fracture system properties of selected, well exposed fault zones are shown to analyse their complex structures and discuss their most likely specific tectonic development.

\subsubsection{Fault zone and fracture system orientations}

We show the orientation of the fracture system (all fracture data of fault zones and host rock) as well as the fault zone orientations within the quarries Nussloch (NL), Illingen (IL), Knittlingen (KN) and Ittlingen (IT) (Fig. 5.2; the colour code refers to the fault zone classifications in the discussion; Section 5.5.1). Despite the Knittlingen-quarry exposes additional fault zones, we only present results of three fault zones due to the best accessibility in the outcrop.
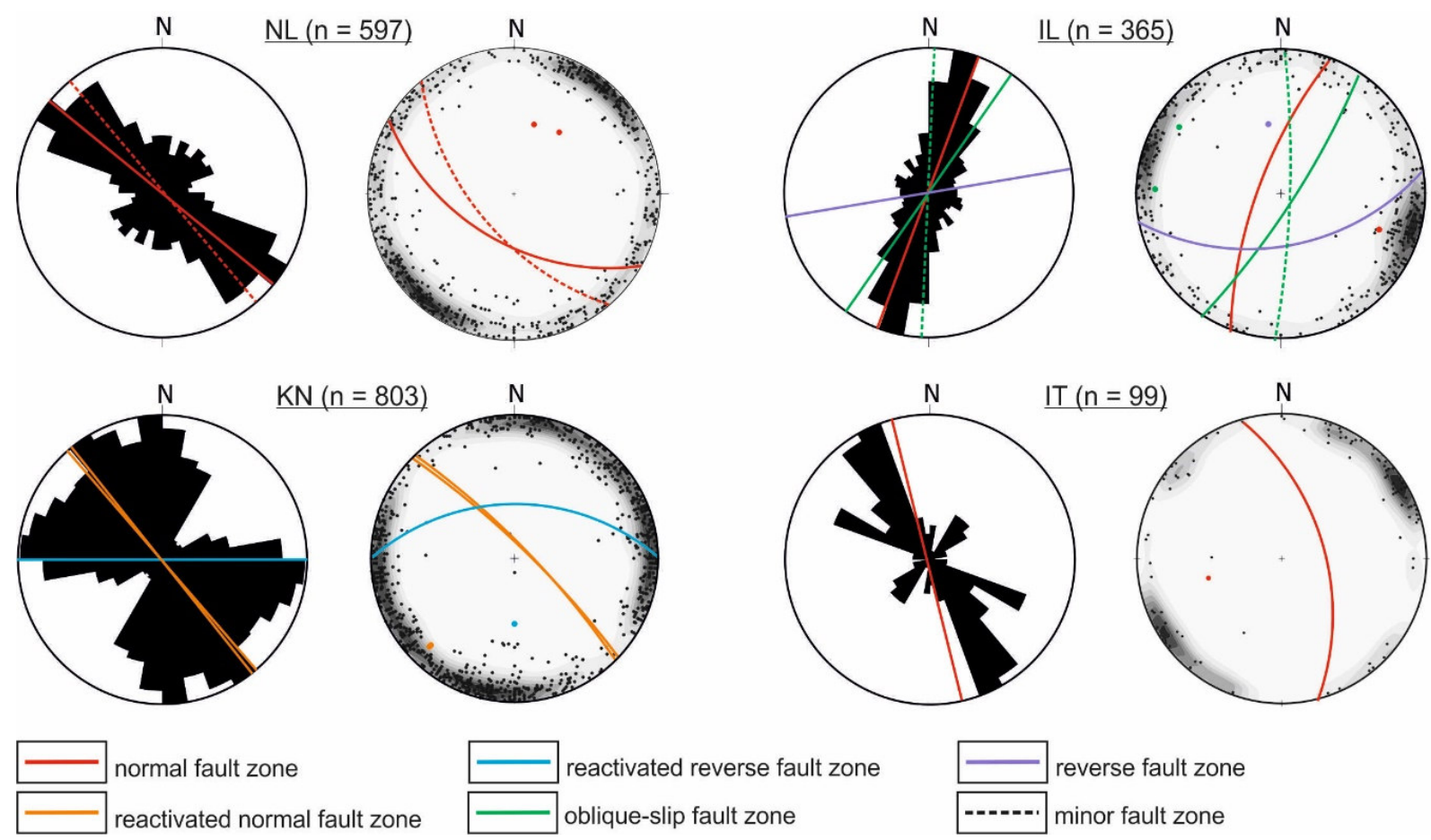

Figure 5.2: Orientation of fracture systems and fault zones ( $n=$ number of fractures) in the quarries Nussloch (NL), Illingen (IL), Knittlingen (KN) and Ittlingen (IT). Left: Symmetrical Rose Diagram ( $10^{\circ}$-classes), the fault zones are plotted as lines. Right: Schmidt Diagram, equal area projection, lower hemisphere. The fractures are marked by poles (black), the fault zones by great circles and poles. Colour code indicating fault zone type see key. These definitions refer to the reflections in the discussion (Section 5.5.1).

The analysed fault zones are formed parallel to regional structures of the URG and the Kraichgau Syncline in NNE-SSW- to N-S-direction, NW-SE-direction and E-W-direction. The individual fracture systems are clearly affected by the fault zones: main fracture sets are formed parallel or sub-parallel to the fault zone strikes, except for the Knittlingen-quarry, where a wider scatter in fracture orientations occurs.

Since footwall and hanging wall show an asymmetric deformation behaviour resulting in different fracture patterns within these fault blocks (e.g., Berg and Skar, 2005; Reyer et al., 2012), detailed fracture data are separated in fractures in footwalls versus fractures in hanging walls of the fault zones (Fig. 5.3; the colour code refers to the fault zone classifications in the discussion; Section 5.5.1). The main fracture set is developed parallel to the fault zone strike in almost all hanging walls. In the footwalls, however, the fracture sets are formed either sub-parallel to or exhibit an angle of approximately 
$30^{\circ}$ to the fault zone strike. These fractures may be shear fractures (Riedel shears) associated with the fault zone. Some of these fractures, however, may be not directly fault-related, but rather background fractures associated with the main regional stress field. Differing fracture orientations within the defined fault zone units are developed particularly in the Knittlingen-quarry.

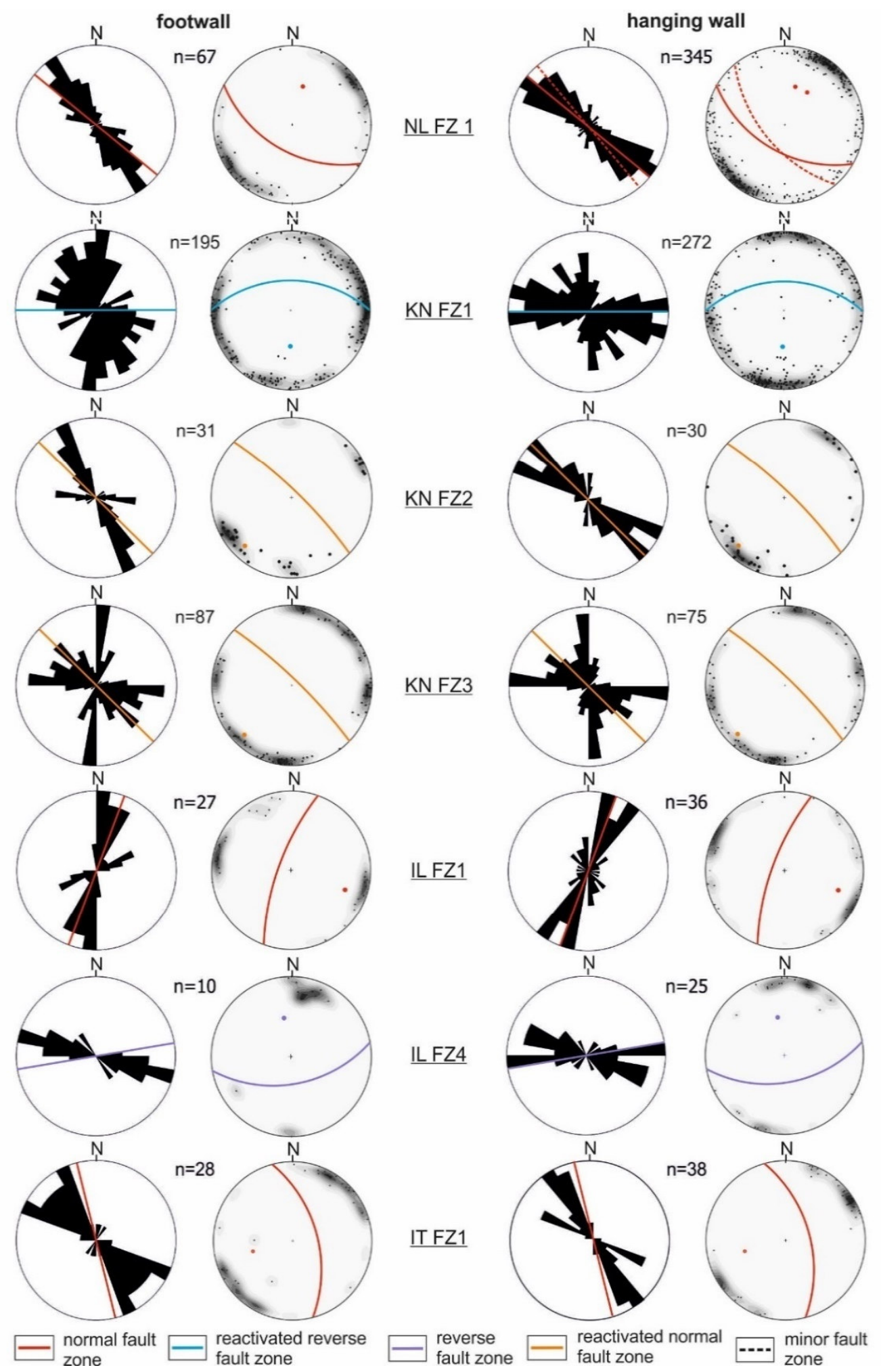

Figure 5.3: Fracture orientations of the fractures in footwall and hanging wall of the fault zones (FZ) analysed in Nussloch (NL), Knittlingen (KN), Illingen (IL) and Ittlingen (IT). Left: Symmetrical Rose Diagram ( $10^{\circ}$-classes), the fault zones are plotted as lines. Right: Schmidt Diagram, equal area projection, lower hemisphere. The fractures are marked by poles (black), the fault zones by great circles and poles. Colour code indicating fault zone type see key. These definitions refer to the reflections in the discussion (Sections 5.1.1. to 5.1.3.). 
Figure 5.4 shows the fracture system orientation within the fault zone in Illingen. Due to the steep dip of this fault zone, we distinguish between eastern fault block, western fault block and fault core only. The fracture systems in the eastern and western fault blocks contain main fracture sets parallel to main and minor (western fault block) slip surfaces. Fractures with differing orientation in the eastern fault block are interpreted as background fractures associated with main regional structures. The main fracture set in the fault core is different with strike NNE-SSW.
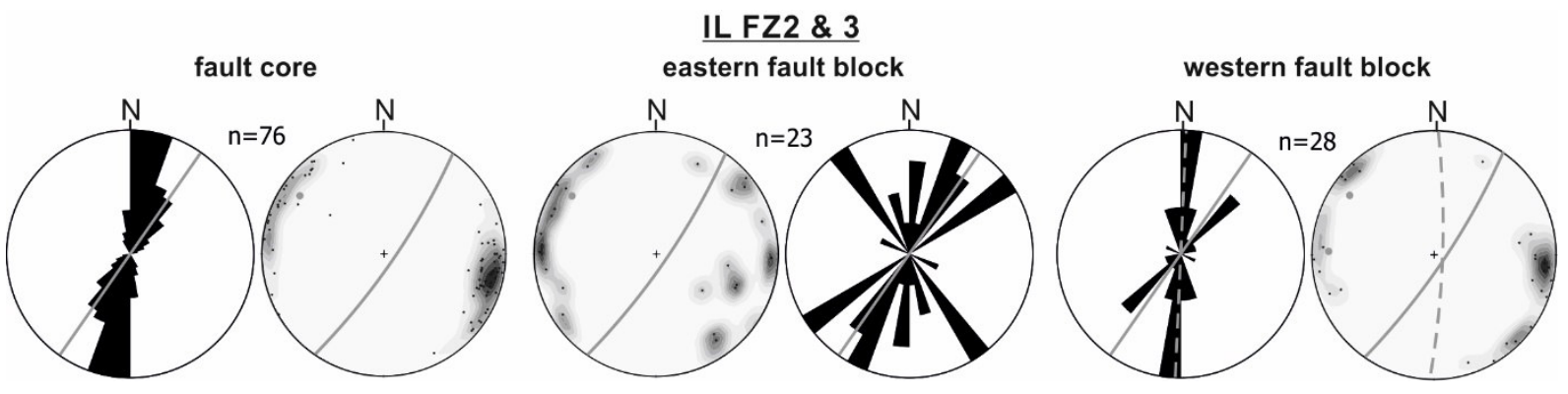

Figure 5.4: Fracture system orientation in the main fault zone in Illingen (IL) separated in eastern fault block, fault core and western fault block: Fault zone (FZ) 2 as main fault and FZ 3 as minor fault within the western fault block (marked by dashed lines). Left: Symmetrical Rose Diagram ( $10^{\circ}$-classes), the fault zones are plotted as grey lines. Right: Schmidt Diagram, equal area projection, lower hemisphere. The fractures are marked by poles (black), the fault zones by great circles and poles in each case (grey).

\subsubsection{Detailed fault zone analysis}

Nussloch: The steep-dipping fault zone cropping out in the Nussloch quarry (northern Kraichgau; cf., Fig. 5.1) is hosted in parts of the entire succession of the Muschelkalk. The first slip surface (SP 1; NE) juxtaposes Middle Muschelkalk rocks, mainly residual clay and dolomite, and limestone-marl-alternations of the Lower Muschelkalk in the lower outcrop-level as well as Middle Muschelkalk rocks in the upper level. Another adjacent slip surface (SP 2; SW) juxtaposes these Middle Muschelkalk rocks and the Upper Muschelkalk (Fig. 5.5). A synthetic minor fault zone located in the hanging wall (Upper Muschelkalk) intersects with this main slip surface SP 2. The triangularly shaped area embedded between the slip surfaces of main and minor fault is highly fractured at their intersection (named as fractured zone; Fig. 5.5b). 

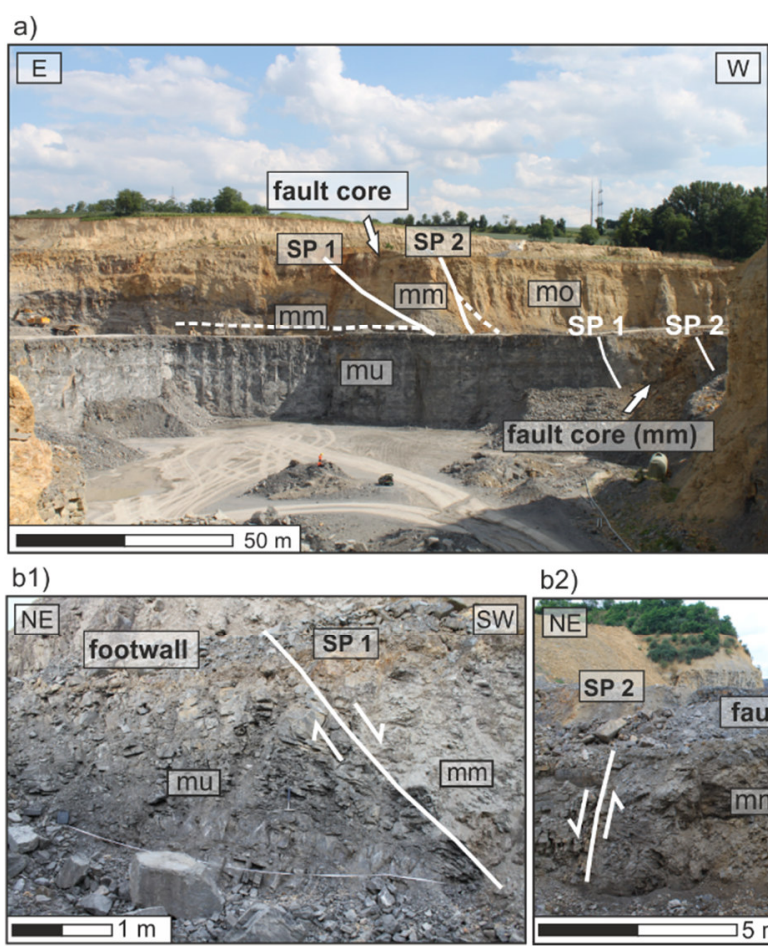

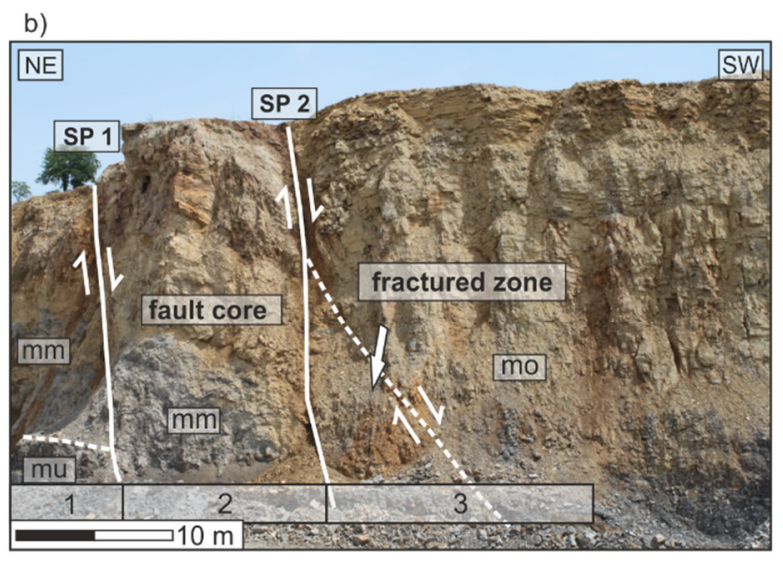

b3)
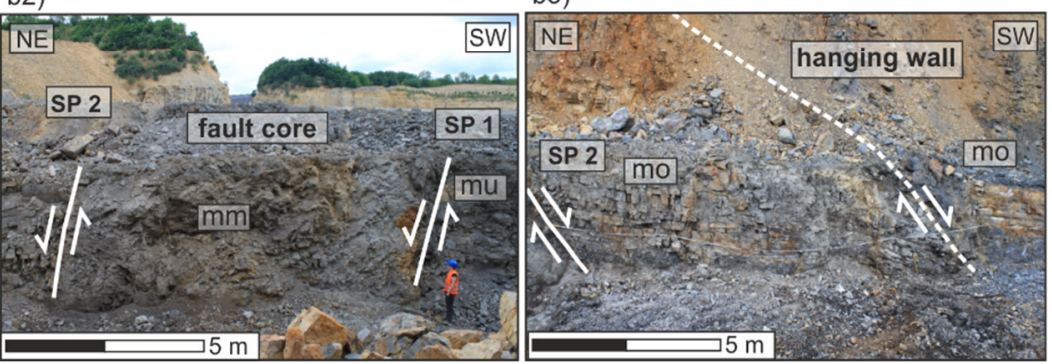

Figure 5.5: Field pictures of the analysed fault zone in the Nussloch-quarry (SP = slip surface, also referred to as slip plane). a) Outcrop overview. View S. b) Fault zone overview, fault zone parts 1 to 3 are shown in detail in the lower section. View SE (b1 and b3) or to NW, respectively (b2). The trace of the minor fault is marked by a dashed line.

The up to $13 \mathrm{~m}$ wide fault core is embedded between the main slip surfaces and consists of inclined Middle Muschelkalk rocks and underlying Lower Muschelkalk rocks (Figs. 5.5 and 5.6). In general, this fault core comprises deformed rock, fault breccia and isolated host rock lenses, particularly at the fault core/hanging-wall-transition. In the Middle Muschelkalk part, grey coloured residual clay is dragged downwards in an s-shape. Minor slip surfaces within the fault core displace the rocks at several locations. At the fault core-hanging-wall-boundary the fault core is characterized by red-coloured, up to $1.5 \mathrm{~m}$ wide mineralizations (Fig. 5.6). 

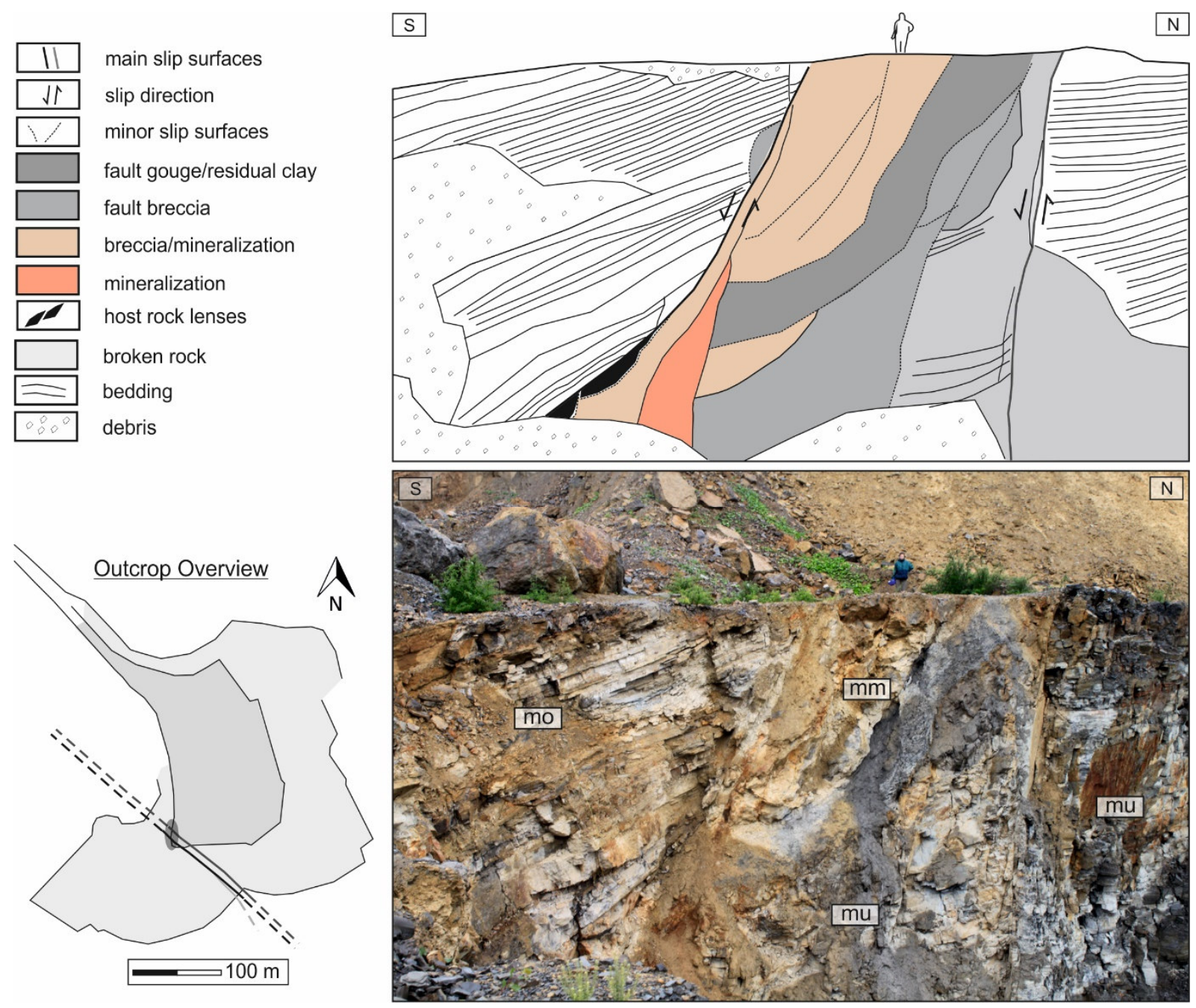

Figure 5.6: Sketch and field picture of the analysed fault zone in the Nussloch-quarry (view W). See person for scale. Outcrop overview: Picture location is displayed by the grey ellipse, the fault zone trace by grey, and black lines (dashed lines - assumed fault zone trace).

The fracture density distribution normal to the fault zone was examined in several scanlines. The highest fracture density occurs at contact to the slip surface (Fig. 5.7). However, there is no decrease to background fracturing with rising distance to the fault core. We assume that the outer damage zone boundary is not reached in the analysed fault zone section and that our measurements were exclusively performed within the damage zone. Two scanlines cut the minor fault zone within the hanging wall damage zone and therefore their minor damage zone as well (Fig. 5.7b). 

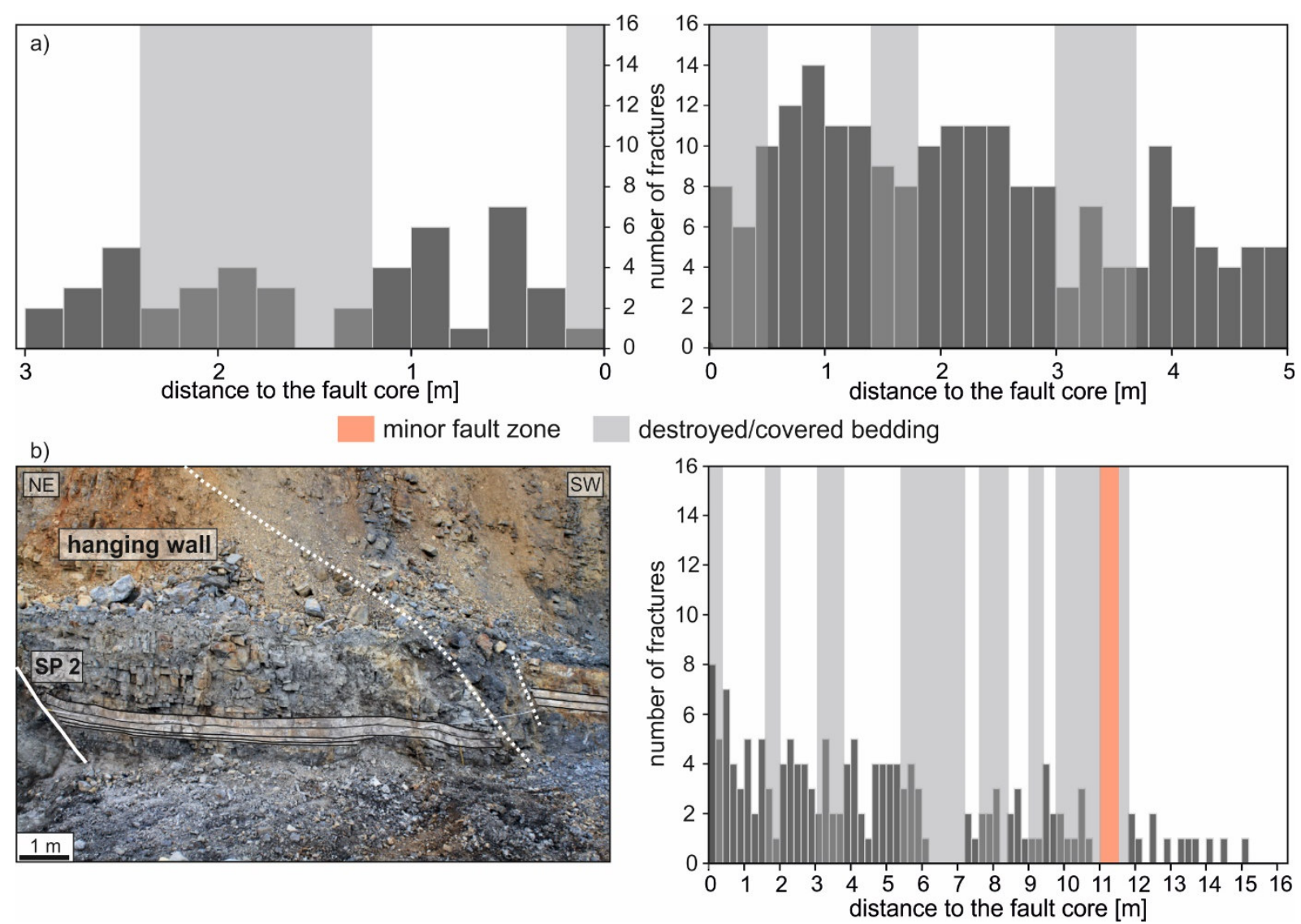

Figure 5.7: Fracture density distribution normal to the main fault zone in the Nussloch-quarry. a) Data from all scanlines in the footwall up to $3 \mathrm{~m}$ (left) and hanging wall up to $5 \mathrm{~m}$ (right) distance to the fault core. b) Overview-picture of the hanging wall including one minor fault zone (left, view SE; scanline locations are traced) and fracture density distribution in the longest profiles 1 and 2 (up to $16 \mathrm{~m}$ ). These profiles cut the minor fault zone in the SW (marked by the red bar) and therefore their damage zone. In the grey labelled zones, the rock mass is destroyed or covered, not every fracture was detected individually.

Illingen: The steep fault zone in Illingen shows slight changes in strike-direction (see above; Fig. 5.8). The quarry provides the possibility to study both the fault core in the south (Figs. $8 \mathrm{a}$ and $8 \mathrm{~b}$ ) and one slip surface in the north (Fig. 5.8c). Various structures are hosted on the undulating slip surface exposed in the North such as slickenlines and slip fibers. Additionally, we observed limestone beds rotated and truncated against each other (Fig. 5.8c).

The fault core in the south, embedded within the two main slip surfaces, comprises fault breccias at contact to the main slip surfaces, limestone beds folded to an anticline in the upper center, flexures at contact to the western slip surface, and limestone lenses (Fig. 5.8a). Minor slip surfaces juxtapose the rocks at the bottom of the wall with a normal displacement of approximately $15 \mathrm{~cm}$ (Fig. 5.8b). The dip-direction and dip-angle of the bedding changes within the fault core, with a steeper angle towards the western main slip surface (Fig. 5.8b). Similar flexures are formed in the eastern fault block at contact to the slip surface, whereas the bedding in the western fault block is more or less horizontal. The western fault block is crosscut by one minor fault zone. 

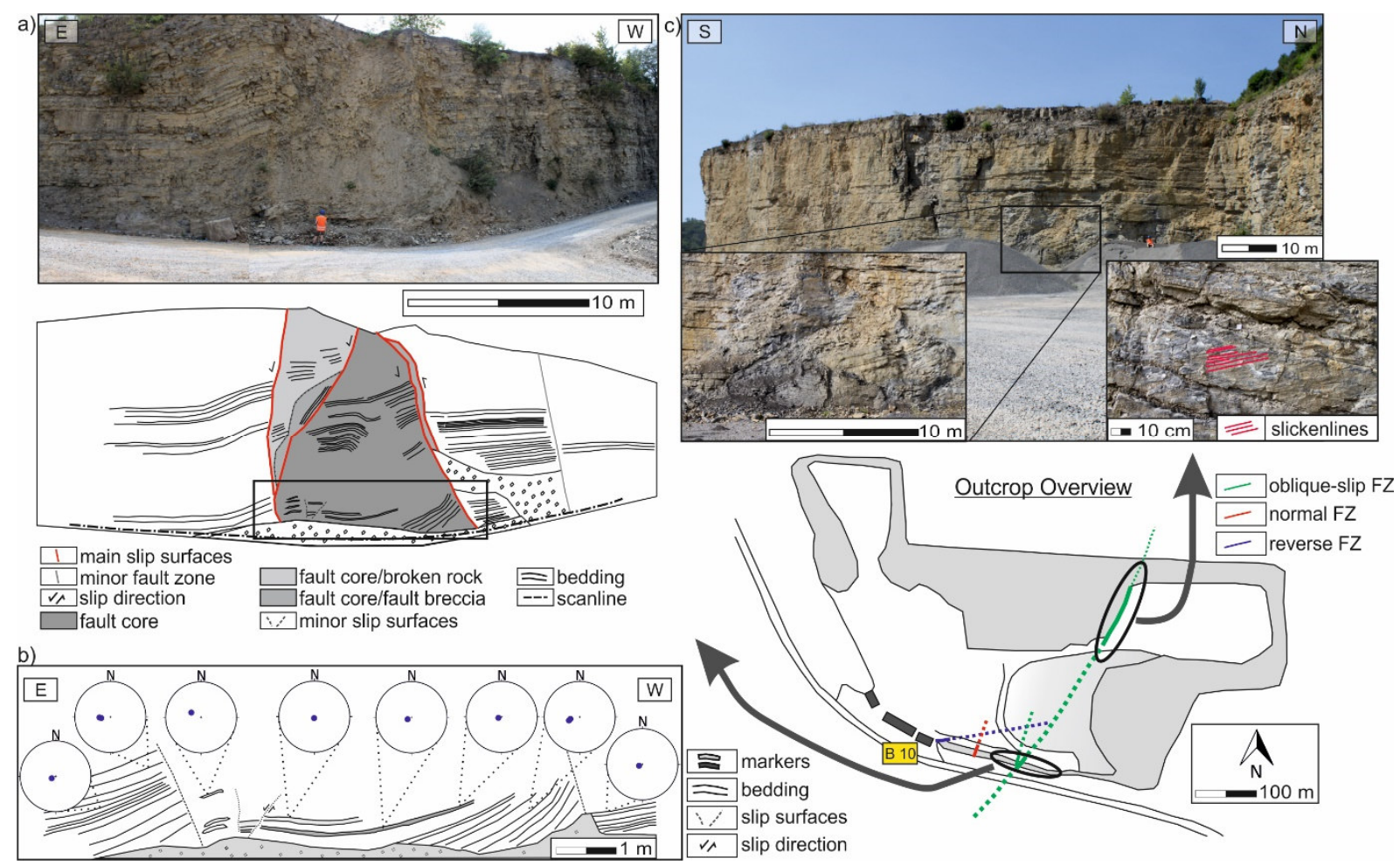

slip direction

Figure 5.8: Overview of the main fault zone in Illingen: Trace of main and minor fault zones are displayed by lines in the outcrop overview (colour code indicating fault zone type see key; these definitions are based on the reflections in the discussion in Section 5.5.1; dashed lines - assumed fault zone trace). a) Fault core at the southern quarry border (view S). b) Detailed sketch of the lower fault core part with lower hemisphere projection of the poles (bedding). c) Field pictures of the exposed fault plane in the northern outcrop part (view W).

Knittlingen: The low-angle fault zone in Knittlingen with unknown displacement because of lacking visible marker horizons shows various deformation structures in hanging wall and footwall in particular (Fig. 5.9). The most conspicuous structure in the footwall is a synthetic minor fault. Between main and minor slip surface thin and softer layers are folded, but the thick and competent bed underneath is broken and shows a counter clockwise rotation. Another noticeable structure in the footwall is one water-bearing antithetic discontinuity, which intersects with the aforementioned minor slip surface. The hanging wall, where a flexure is formed, is less deformed than the footwall.

The fault core comprises various structures like lenses and both upwards and downwards dragged, tilted, and folded bedding. Other fault core parts are completely mineralized or comprise brecciated rock. 

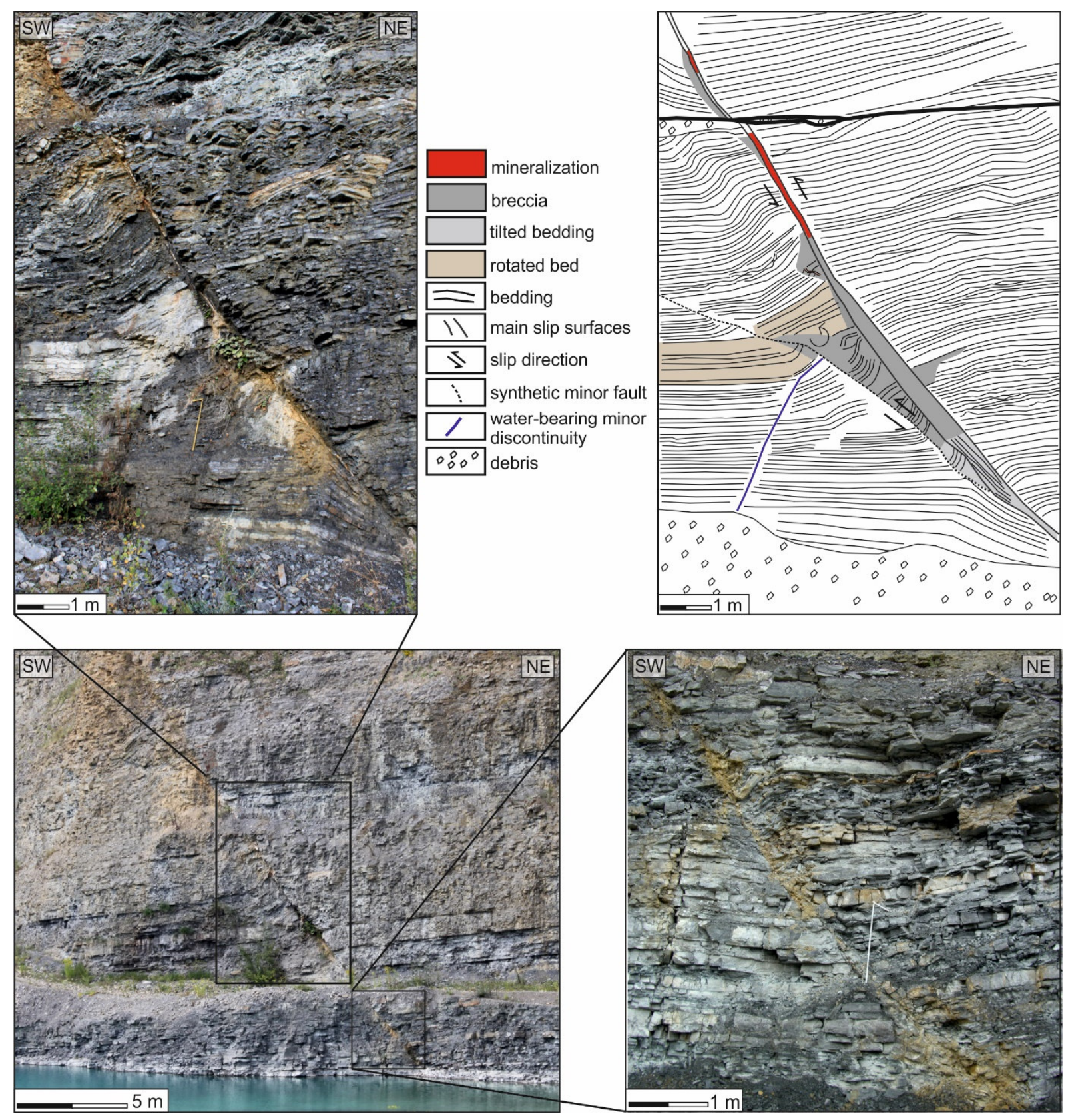

Figure 5.9: Overview pictures and sketch of the described fault zone (FZ 1) cropping out in the Knittlingen-quarry (view NW). The sketch shows the soft and thin folded layers as well as the broken and rotated competent bed.

One outcrop-level beneath, where decimetre-thick limestone beds crop out, a differing deformation behaviour is observable in the footwall. The competent beds are compressed, but not folded. In contrast, flexures occur in the hanging wall. The fault core in this fault zone part is brecciated and comprises discoloured zones. Some limestone beds are dragged upwards in the fault core, similar to the upper section of this fault zone.

We determined the fracture density distribution normal to the fault zone (Fig. 5.10). Our results show no clear decrease to background fracturing with rising distance to the fault core. In addition to the high fracture density at contact to the slip surface an increased fracture density was detected at a distance of 2 to $3 \mathrm{~m}$ in the hanging wall. 

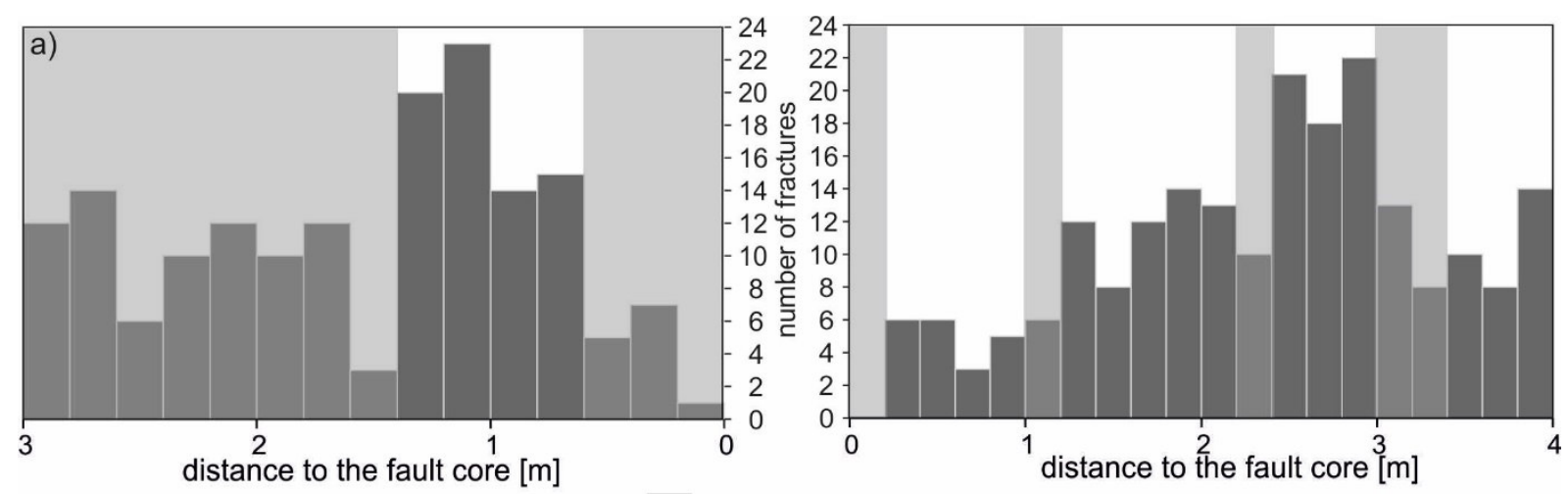

b)

destroyed/covered bedding
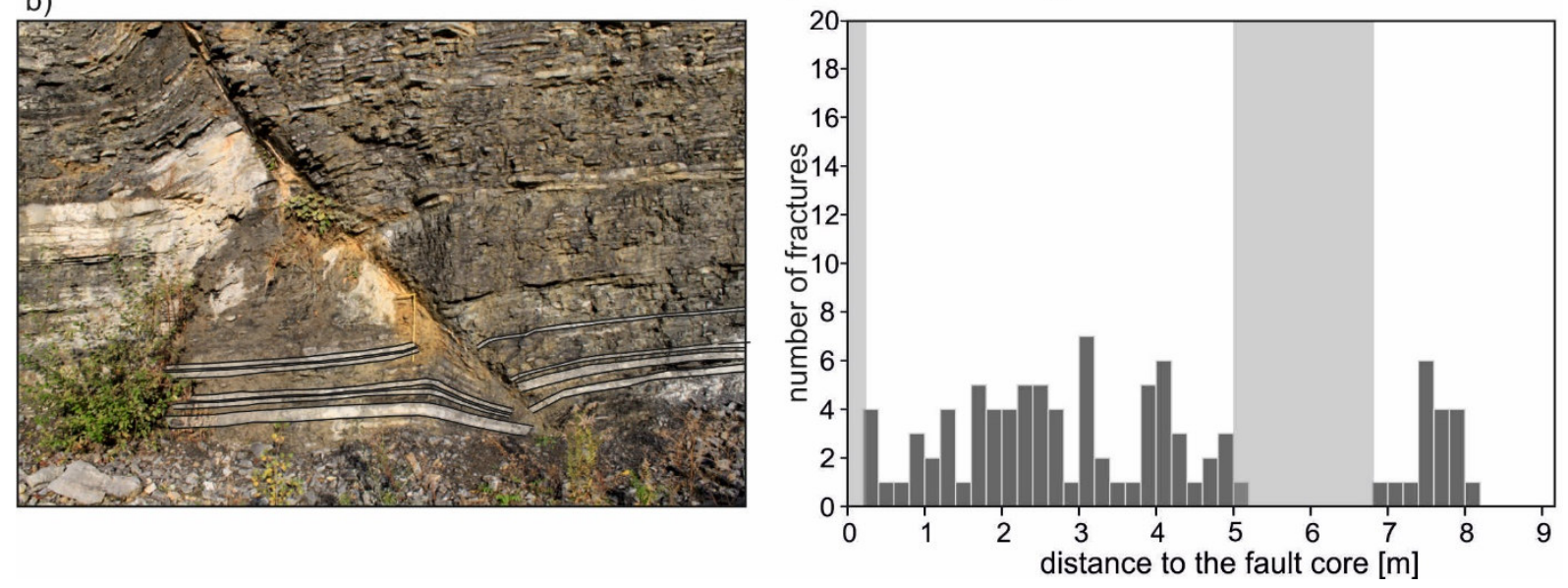

Figure 5.10: Fracture density distribution normal to the described fault zone (FZ 1) in the Knittlingen-quarry. a) Data from all scanlines in the footwall up to $3 \mathrm{~m}$ (left) and hanging wall up to $4 \mathrm{~m}$ (right) distance to the fault core. b) Overview-picture of this fault zone (left, view NW; scanline locations are traced; scale: see folding rule expanded to $1 \mathrm{~m}$ ) and fracture density distribution in the longest profile (right, up to $8.5 \mathrm{~m}$ ). In the grey labelled zones, the rock mass is covered or destroyed, not every fracture was detected individually.

\subsubsection{Fracture connectivity}

As mentioned in Section 5.3, the fracture connectivity is one important parameter in terms of reservoir permeability (Stauffer and Aharony, 1994; Odling et al., 1999; Micarelli et al., 2006b). We plot the fracture length versus fracture orientation (scale: $0^{\circ}-180^{\circ}$; Fig. 5.11), and fault core distance $[\mathrm{m}]$ (Fig. 5.12) respectively, where we distinguish between connected (connected at either one or both tips) and unconnected fractures. Some fractures are marked by a star, because only the minimum length could be detected when one fracture tip was visible.

We plot the fracture length $[\mathrm{m}]$ of all fractures within the fracture systems vs. fracture orientation (Fig. 5.11a). In general, shorter fractures (up to a fracture length of $1 \mathrm{~m}$ ) are more common within the quarries. Due to this huge number of comparatively shorter fractures, we show the data of fractures up to a fracture length of $1 \mathrm{~m}$ (Fig. 5.11b), in addition, to get a higher resolution on their fracture connectivity. The percentage of fractures with great length is generally higher for fractures parallel or subparallel to major slip surfaces and to regional structures (i.e. URG, axis of the Kraichgau Syncline).

Most of the fractures are unconnected, whereby especially shorter fractures formed parallel to the fault zones provide a better connectivity within the fracture system. The highest percentage of interconnected fractures, and fractures connected at both fracture tips in particular, occurs within the Nussloch fracture system. 
a)

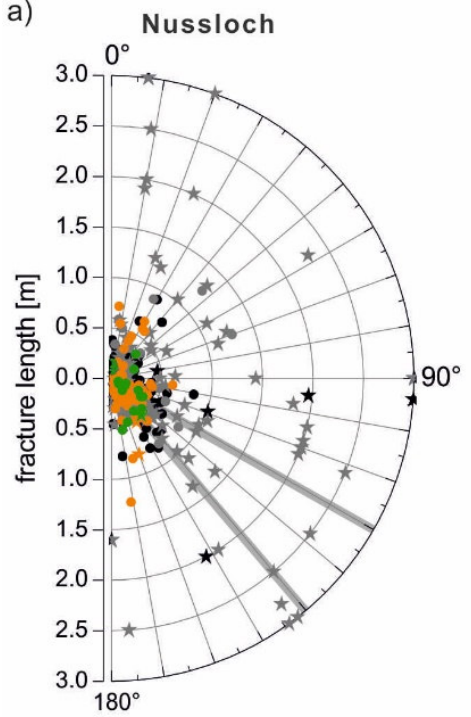

fracture type

connected at both tips connected at one tip unconnected

b)

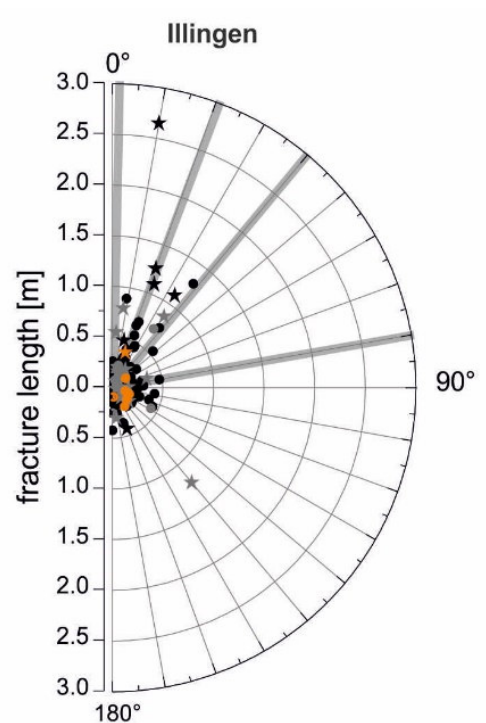

fracture type

connected at both tips connected at one tip unconnected no declaration

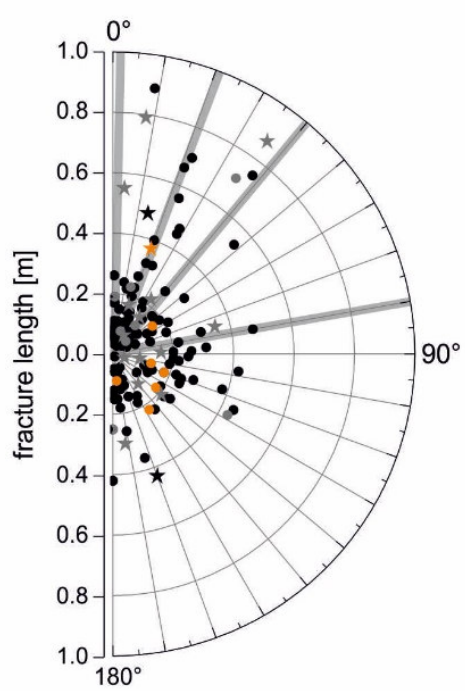

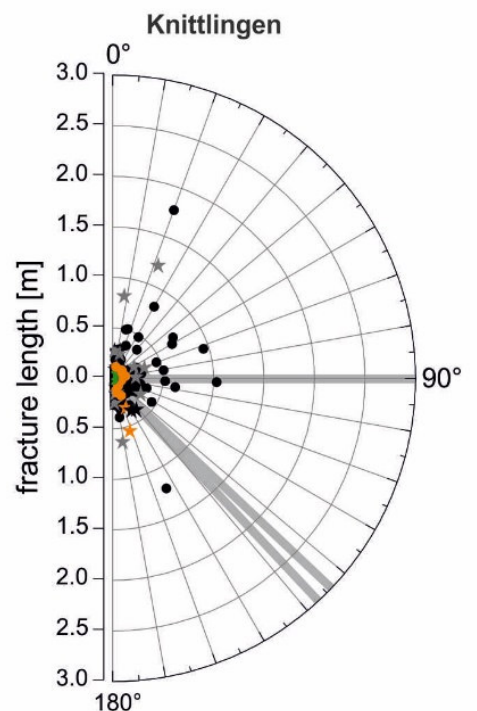

fracture type

connected at both tips 1 connected at one tip

unconnected no declaration

[\%]

11

83
5

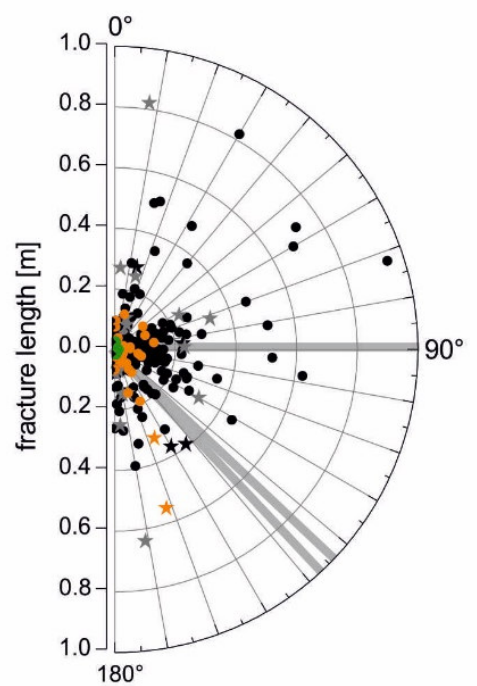

connected at both tips
connected at one tip no declaration
- unconnected

Figure 5.11: Fracture connectivity of the fracture systems in the quarries Nussloch, Illingen and Knittlingen (colour code see key; classified fracture types: percentage is shown for the entire dataset). Fracture length [m] vs. strike $\left(\right.$ scale: $\left.0^{\circ}-180^{\circ}\right)$. a) All fracture data. b) Fracture data for shorter fractures up to $1 \mathrm{~m}$ length. The fault zone orientations are marked by a grey line. Fractures, from which only the minimum length was determined because only one tip was visible, are labelled with a star.

To show the connectivity of the fracture system within the fault zones, we plot the fracture length [m] and connectivity vs. fault core distance [m]. Individual long fractures are formed up to $6 \mathrm{~m}$ distance to the fault core of the fault zone in Nussloch, whereby the fracture length decreases with distance to this unit. Very few fractures (up to $0.5 \mathrm{~m}$ in length) are connected at both tips in the hanging wall of this fault zone, mainly up to a maximum distance of $3 \mathrm{~m}$ to the fault core (Fig. 5.12a). In the footwall fewer fractures with lengths up to $0.3 \mathrm{~m}$ are connected at one fracture tip.

The fracture system within the fault zone in Illingen contains mostly unconnected fractures, apart from individual fractures in the eastern fault block (Fig. 5.12b). Within the separated fault zone units of the fault zone in Knittlingen some fractures show connectivity at one fracture tip (Fig. 5.12c). These 
fractures, however, do not exceed a fracture length of $0.2 \mathrm{~m}$, with one exception in the footwall $(0.6 \mathrm{~m})$.

In general, the data show a decreasing fracture length with increasing distance to the fault cores but a better connectivity of fractures with lengths up to $0.5 \mathrm{~m}$ (Fig. 5.12). That implies an improvement of fracture system vertical connectivity based on these comparatively shorter fractures in the fault zone units, as mentioned above.
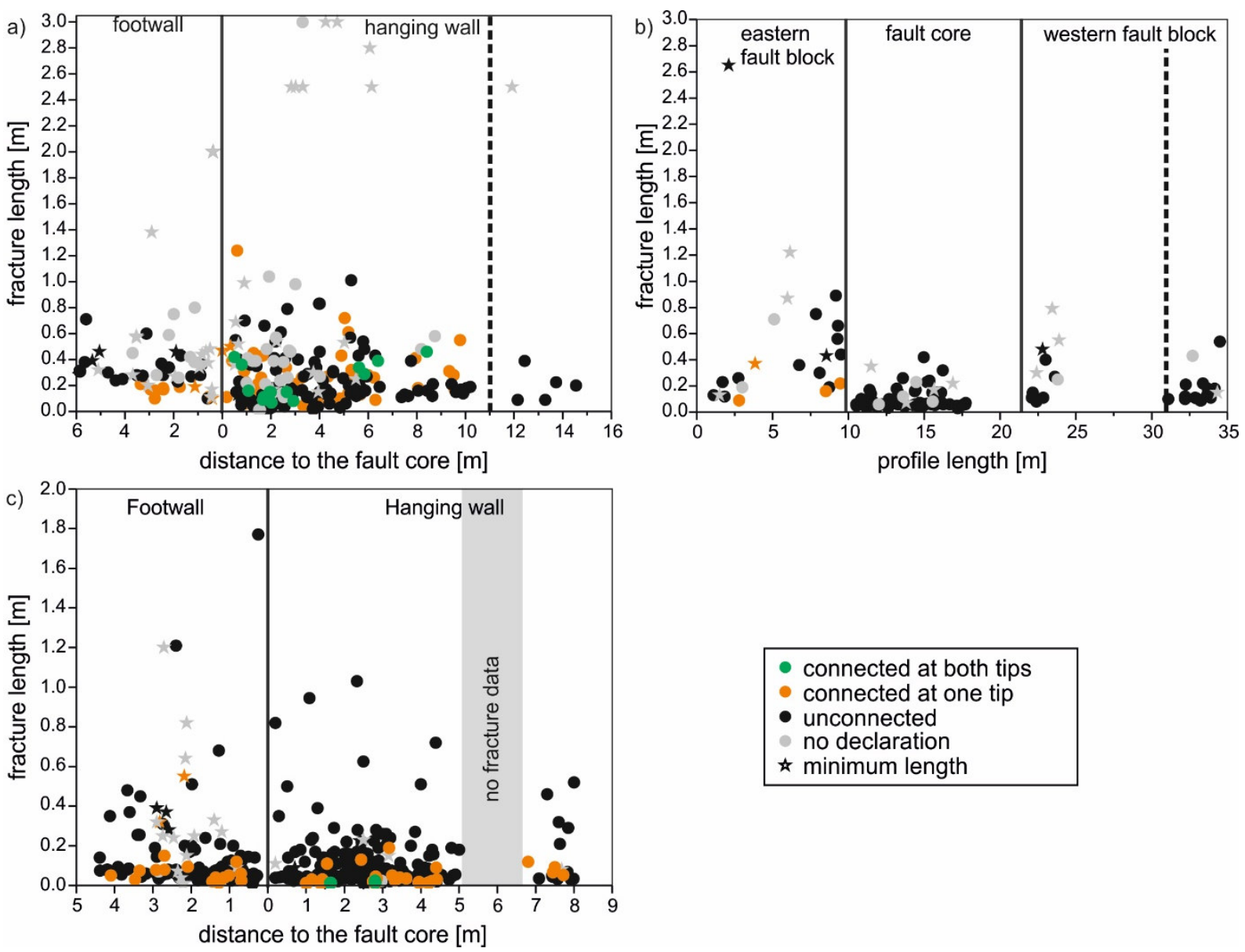

- connected at both tips

- connected at one tip

- unconnected

no declaration

$\star$ minimum length

Figure 5.12: Fracture connectivity of the fractures within the main fault damage zones (colour code see key): a) Nussloch. b) Illingen. c) Knittlingen. In the grey labelled zone, the rock formation is covered or destroyed, not every fracture was detected individually. The positions of fault core and minor fault zones are marked by dark-grey or by black dashed lines, respectively. Fractures, from which only the minimum length was determined because only one tip was visible, are labelled with a star.

\subsubsection{Fracture vertical extension}

Fractures extending over multiple limestone beds (i.e. non-stratabound fractures) may increase the reservoir permeability across the mechanically layered Muschelkalk rocks in vertical direction. Stratabound fractures, however, are restricted to one bed (cf., Section 5.3.; Odling et al., 1999). Therefore, we plot the percentage of stratabound to non-stratabound fractures determined in the quarries separately for the unit's fault zone and host rock and the same data in relation to the fault core distance of the detailed fault zones (cf., Section 5.4.2; Figs. 5.13b, 5.13d, and 5.13f). Due to isolated limestone beds within the fault core of the fault zone in Illingen and a resulting rare dataset compared with the other outcrops, the fracture system within this fault zone is separated to eastern fault block, fault core and western fault block (Fig. 5.13d). In Figure 5.13 the fault zone types refer to the definitions in the discussion (Section 5.5.1.).

The percentage of non-stratabound fractures in the Nussloch-quarry is higher for all separated units, with a slightly increased value in the analysed fault zone and a lowest value in the host rock of Upper 


\subsection{Field results}

Muschelkalk (HR mo, Fig. 5.13a). Within the fault zone, non-stratabound fractures clearly increase with proximity to the core zone (Fig. 5.13b). At the minor fault crosscutting the hanging wall of the main fault zone, the amount of non-stratabound fractures is enhanced in the minor fault hanging wall.
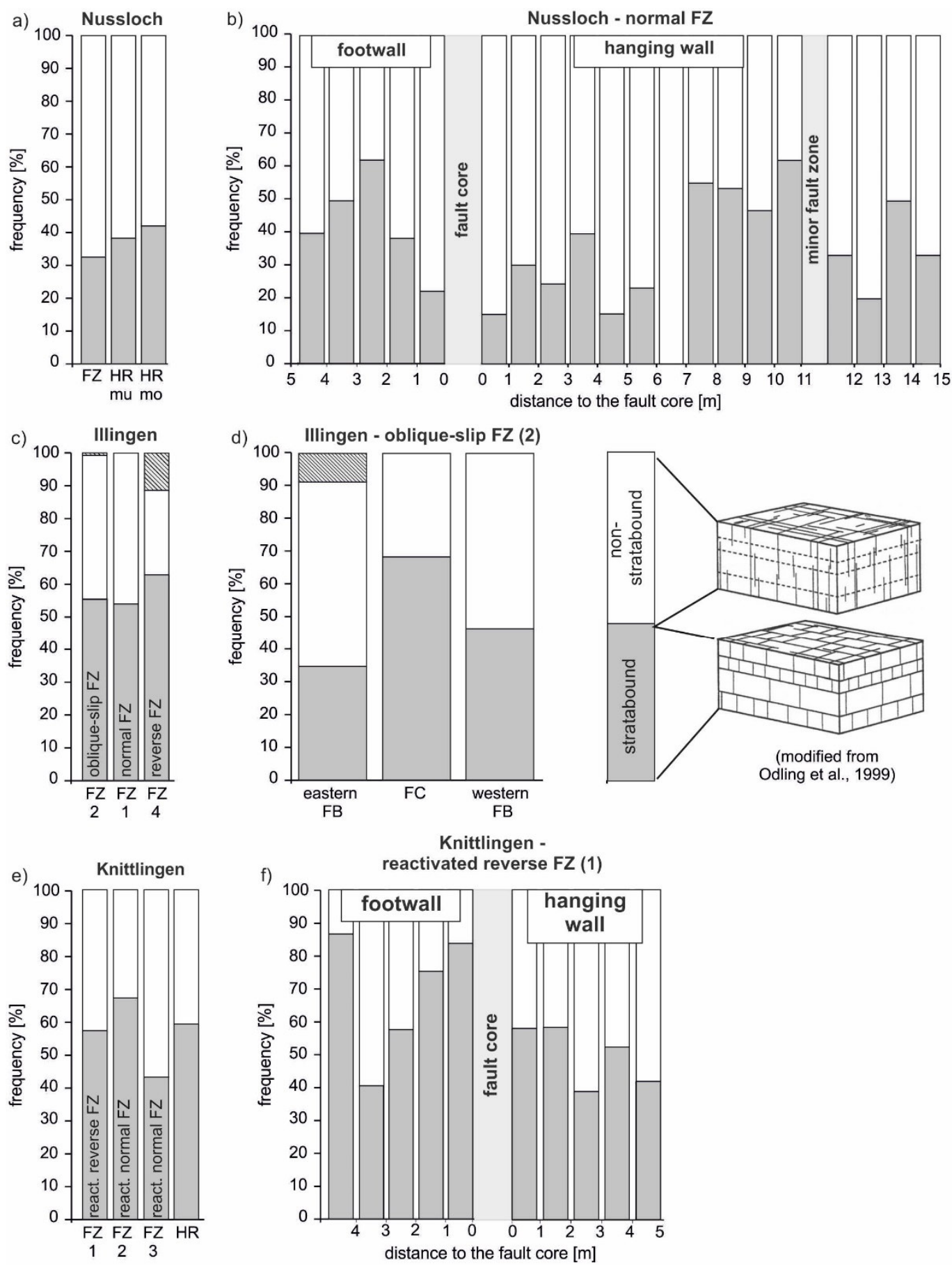

Figure 5.13: Percentage of stratabound vs. non-stratabound fractures. a) Fracture data of the Nussloch-quarry separated to the main fault zone (FZ), host rock of the Lower Muschelkalk (HR mu) and of the Upper Muschelkalk (HR mo). b) Fracture data determined normal to the main fault zone in the Nussloch-quarry (cf., Section 5.4.2). c) Fracture data of the Illingenquarry separated to FZ 2 (main fault zone), FZ 1, and FZ 4. d) Fracture data determined normal to the main fault zone (FZ 2) in the Illingen-quarry (cf., Section 5.4.2) separated to eastern fault block (FB), fault core (FC) and western fault block. The percentage of fractures with no declaration in Illingen is marked by a shaded signature. e) Fracture data of the Knittlingenquarry separated in FZ 1, FZ 2, FZ 3 and host rock (HR). f) Fracture data determined normal to FZ 1 in the Knittlingen-quarry (cf., Section 5.4.2). The definition of stratabound and non-stratabound fractures is illustrated with a sketch (modified from Odling et al., 1999). The fault zone types refer to the reflections in the discussion (Section 5.5.1). 
In contrast, the general percentages of stratabound fractures in Illingen and Knittlingen are higher (Figs. 5.13c and 5.13e), except for fractures within one fault zone in Knittlingen (FZ 3; Fig. 5.13e). The fault zone in Illingen contains a higher percentage of non-stratabound fractures within the eastern and western fault blocks, but a smaller value within the core zone of this main fault.

Within one fault zone in Knittlingen, described in detail in Section 5.4.2 - KN (FZ 1), the percentage of stratabound fractures at contact to the fault core is high (Fig. 5.13f), particularly in the footwall. Non-stratabound fractures, however, increase in direction to the aforementioned antithetic discontinuity crosscutting the footwall (cf., Section 5.4.2-KN).

\subsubsection{Mineralized and open fractures}

We show the fracture aperture data to describe the fracture aperture distribution within the fault zones. Preferred fracture orientations and fracture locations for past fluid flow are highlighted by recording mineral-precipitations within the fracture system (cf., Section 5.3). We plot the fracture aperture or thickness [mm] versus fracture orientation (Fig. 5.14, left) as well as the percentages of mineralized fractures (Fig. 5.14, centre). Finally, we plot the fracture aperture or thickness [mm] in relation to the fault core distance (Fig. 5.14, right). In all plots, we distinguish between mineralized and open fractures. Mineralized fractures with unknown thicknesses (e.g., due to only one visible fracture plane) are plotted with a fracture thickness of $0.1 \mathrm{~mm}$ in order to represent the fracture location in relation to the fault core distance.

The fracture systems in the quarries Nussloch, Illingen and Knittlingen contain mainly open fractures. The highest amounts of mineralized fractures were observed in the host rock of the Upper Muschelkalk and within the damage zone of the main fault zone in Nussloch. In Knittlingen and Illingen a minor amount of mineralized fractures was detected, where the few mineralized fractures are developed mainly within the fault zones.

In general, our data show a preferred orientation of fractures sealed with minerals parallel and subparallel to the analysed fault zones and to regional structures like the URG, Variscan and Hercynian structures (Fig. 5.14), that is in NNE-SSW-, NE-SW- and NW-SE- direction. Fractures with comparatively larger apertures or thicknesses up to $4 \mathrm{~mm}$ (Illingen) are accumulated in these main directions as well. Several of these thicker fractures show mineral-precipitations, particularly in the Nussloch quarry (Fig. 5.14a).

In all described fault zones, the fracture apertures or thicknesses decrease with increasing distance to the slip surfaces. By contrast, no clear relation between mineralization and fault core distance becomes apparent. In Nussloch and Knittlingen (Figs. 5.14a and 5.14c) many fractures located close to the fault core show mineralizations, but also at distance up to a few meters. In the Illingen oblique-slip fault zones (Fig. 5.14b), however, only few fractures, located in the fault core, are mineralized. 

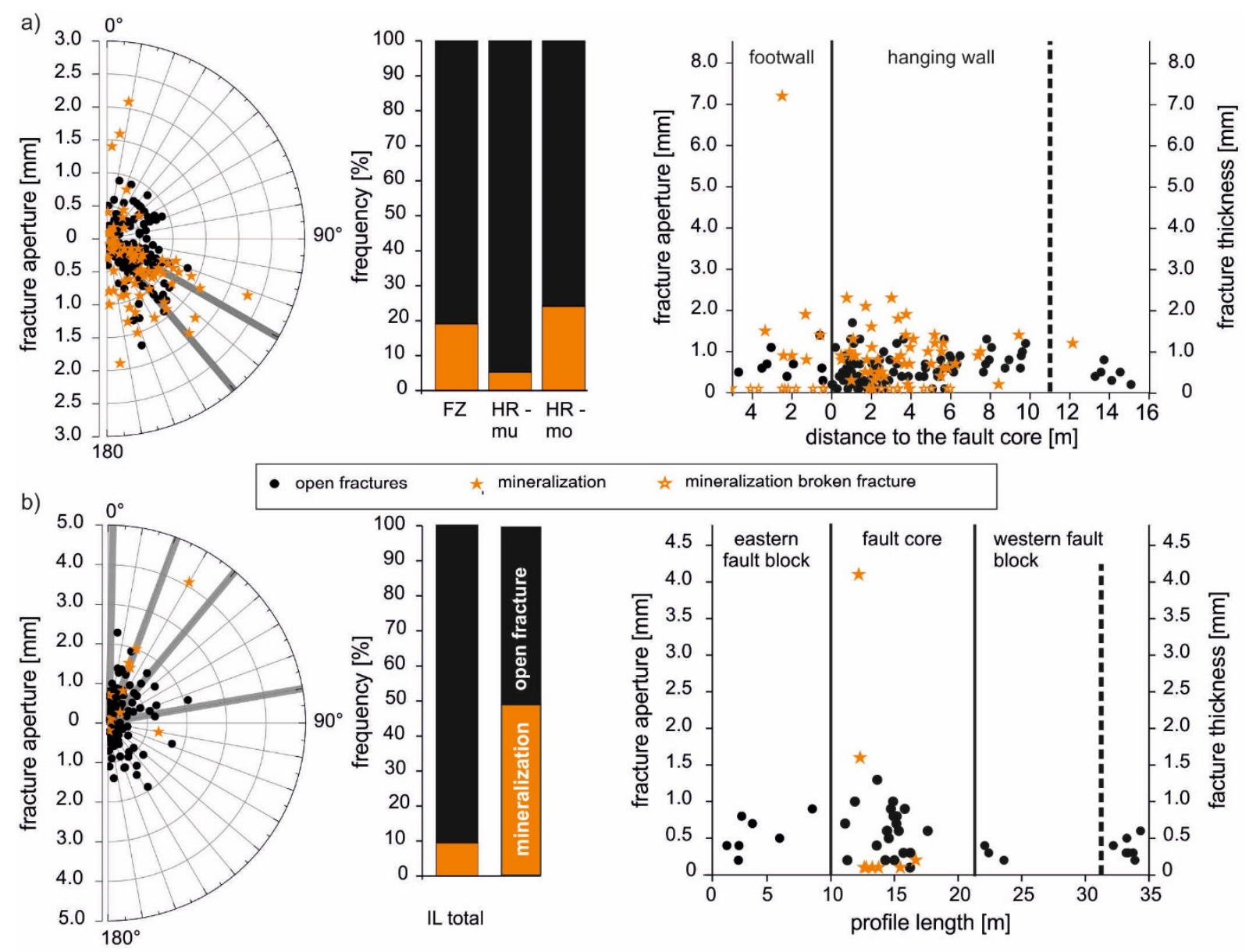

fractures mineralization

$\downarrow$ mineralization broken fracture
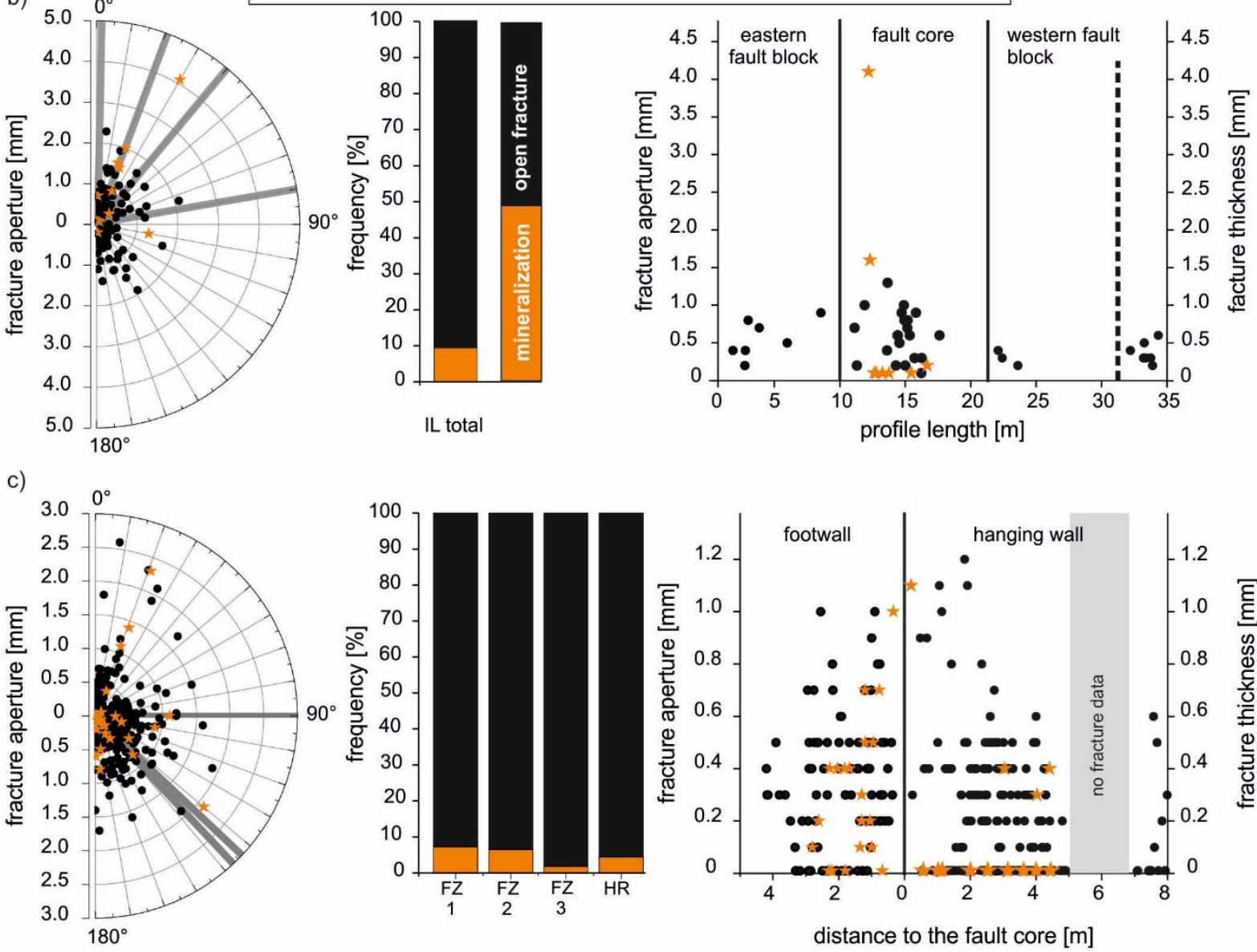

Figure 5.14: Mineralized and open fractures: a) Nussloch. b) Illingen. c) Knittlingen. Left: Fracture aperture and thickness $[\mathrm{mm}]$ vs. strike. The fault zone orientations are marked by a grey line. Centre: Percentage of mineralized fractures separated in fault zones and host rock (except for Illingen (b) due to the minor database). Right: Fracture aperture and thickness [mm] in relation to the fault core distance [m], the positions of fault core and minor fault zones are marked by dark-grey or by black dashed lines, respectively. The positions of mineralized fractures with unknown aperture are marked by open stars.

\subsection{Discussion}

\subsubsection{Kinematics and tectonic evolution of the fault zones}

The described fault zones show different geometric features and dissect this area in different blocks. In this section, we aim at explaining the evolution of the analysed fault zones, regarding to the different stress field phases and interpreting fault zone kinematics. 
Schumacher (2002) discusses the evolution of the URG within a changing regional stress field environment in detail and names four main evolution phases:

1. Late Eocene: N-S- to NNE-SSW-oriented compression ( $\sigma_{1}$-direction: NNE) resulting in left lateral strike-slip. Primary ENE-WSW- and NNE-SSW- oriented faults were reactivated as normal faults or strike-slip faults, respectively.

2. Early Oligocene: WNW-ESE- to E-W-oriented extension ( $\sigma_{3}$-direction: WNW) within the main rifting phase with regional normal faulting.

3. Late Oligocene: NE-SW-oriented compression ( $\sigma_{1}$-direction: $\mathrm{NE}$ ) resulting in right lateral strike-slip (also reactivation of URG-parallel faults as right lateral strike-slip faults).

4. Miocene (to recent): NW-SE-oriented compression ( $\sigma_{1}$-direction: NW) resulting in left-lateral strike-slip.

Beside extensional and shear induced elements, structures indicating a compressional regime in the study area also are described in previous studies. Illies and Greiner (1978) for example mention primary normal faults of the eastern graben rim, which had been overprinted by younger reverse faults and small scale up-thrusts are described formed north of Karlsruhe (Ziegler, 1992).

The fault zones analysed in the present study reflect the aforementioned stress field changes and are clearly related to the formations of main regional structures, in particular URG and Kraichgau Syncline. Like the URG, the Kraichgau Syncline consists of a block mosaic, separated by various fault zones, caused by extension, left lateral strike-slip or compression within the stress field of the URG formation (e.g., Kleinschnitz and Engesser, 2009, and references therein).

Nussloch: We define the Nussloch fault zone as a normal fault zone with a total displacement of at least $40 \mathrm{~m}$, distributed on step faults. This extension structure is located close to the graben master fault and most probably part of a fault system described in literature: Kleinschnitz and Engesser (2009) mentions a stepwise fault zone induced subsidence of the Kraichgau east of Nussloch. One of these fault zones crosscutting the Kraichgau east of Nussloch juxtaposes the Upper Muschelkalk and the Lower Muschelkalk formation. Both strike direction (NW-SE) and displacement coincide with the analysed Nussloch normal fault zone. The stress field of this normal fault zone formation is in good accordance with the stress field characterized by left-lateral strike-slip and NE-SW-extension in Miocene (cf., Schumacher, 2002).

Illingen: Based on the flexures in the fault core and the eastern fault block at contact to the main slip surfaces of the Illingen fault zone (southern quarry-part) we assume a step fault induced normal displacement from western towards eastern fault block. Due to the exposed slickenlines which show a strike-slip and a dip-slip component (northern quarry-part) and the minor slip surfaces within the fault core (southern quarry-part) we define the Illingen fault zone as an oblique-slip fault zone. The aforementioned structures and the high deformation grade of the slip surface exposed in the North indicate also a reactivation of the fault zone.

We assume that the tectonic elements within the Illingen quarry are affected by a strike-slip regime, but also by E-W-extension, probably caused by $\sigma_{1}$ oriented NNW-SSW, resulting in the formation of the main oblique-slip fault zone. Due to the orientation, parallel to the URG, this fault zone can be linked to the regional stress field of the URG. Beside the normal dip-slip component within the main oblique-slip fault zone another extension induced structure occurs in the formation of one NNE-SSWoriented normal fault zone. We define a third fault zone as an ENE-WSW-oriented reverse fault zone due to exposed markers which indicate a reverse displacement and therefore a compression induced 
structure. The associated stress fields of fault zones formation and reactivation are in-line with the regional stress field in late Eocene or Oligocene (cf., Schumacher, 2002).

Knittlingen: Both extension and compression structures are exposed in Knittlingen and indicate a complex local tectonic history. Compression induced structures, i.e. reverse faults and folds (particularly flexures) are the most prominent structures in this quarry.

The rock formation within the characterized fault zone (FZ 1) in Knittlingen shows a high deformation grade. We assume repeated slip events on the fault plane and a formation of this fault zone by fault linkage within these rocks characterized by alternating mechanical properties. Fault linkage could explain the variety in fault core characteristics along the fault plane (lenses, tilted bedding or fault breccia) (Bastesen et al., 2009; Childs et al., 2009; Bastesen and Braathen, 2010; Bastesen et al., 2013). Flexures in the hanging wall indicate a main upward movement of this fault block. Furthermore, flexure monoclines of softer limestone and marl beds as well as one broken and rotated competent bed hosted in the footwall are clearly caused by compression, where different mechanical properties of limestone and marl obviously have led to different deformation of the limestone beds.

However, it seems that this fault zone was subjected to an extensional regime to a minor degree since some fault zone parts locally show extension structures (downward tilted bedding at contact and within the fault core). We propose a partially reactivation of this fault zone due to changes in dip angle where some fault core parts (probably with lower dip angle) were reactivated first. However, compressional structures predominate and thus we characterize this fault zone as reactivated reverse fault zone. Within this quarry, additional structures of compressive deformation occur in form of flexure monoclines (strike direction NW-SE), which show beginning fracturing and fault development along the axial surface (fold propagation fault).

Two other exposed fault zones (strike direction: NW-SE) show both a normal displacement and compressional structures like flexures or compressed limestone beds indicating a reactivation (inversion) of these primary normal faults.

A changing local stress field is common in regions characterized by a complex fault block structure due to rotation of $\sigma_{1}$-direction at fault zones. The formation may be related to the regional stress field of the URG in Miocene (cf., Schumacher, 2002) with slight changes of the local stress field. It is, however, difficult to classify the local stress field at fault zone formation and reactivation. The fracture system, characterized by a wide scatter in fracture orientation, is affected by this complex local stress field as well.

\subsubsection{Past Fluid flow}

Mineralized fractures and mineralizations within fault zones crosscutting the study area are described in several previous studies. Illies (1972) mentions tertiary mineral veins (e.g., barite, fluorite and various ore minerals), which are developed at both graben shoulders as consequence of mineralization through open fissures, but absent within the graben fill due to a differing stress regime. In addition, Eisbacher and Fielitz (2010) refer to NW-oriented fault zone and fractures, which are sealed by mineralizations.

Our data show that fractures formed in this NW-SE-direction are mineralized within the fracture systems of the studied quarries as well, particularly in the Nussloch-quarry. Furthermore, mineralized fractures accumulate in directions parallel and sub-parallel to the graben master fault and may therefore be related to the graben formation. 
In the present study, the comparatively high amount of mineralized fractures within the Nusslochquarry is conspicuous. We conclude that these mineralizations may be connected to the formation of the well-known Pb-Zn-deposit of Wiesloch (e.g., Walter, 2007; Kleinschnitz and Engesser, 2009), which is located close to the Nussloch-quarry. This Pb-Zn-deposit was formed in context of the URG development, as hydrothermal metal-bearing fluids circulated through the fractures and faults (Kleinschnitz and Engesser, 2009).

\subsubsection{Past fluid flow with regard to fault zone permeability evolution}

The permeability structure within fault zones and thereby associated fluid flow is changing during fault zone evolution and depends on their individual infrastructure (e.g., Caine et al., 1996; Agosta and Kirschner, 2003; Billi et al., 2003). The fault core of active faults zones may act as a conduit for fluid flow, if fractures or pores get interconnected during slip, whereas this unit acts as a barrier in inactive fault zones due to reduced grain sizes (cf., Section 5.1; e.g., Sibson, 1994; Caine et al., 1996).

Billi et al. (2003) discuss fault zone permeability development during their evolution in carbonate rocks in detail, including the following two main stages. First, they define a conduit stage, which precedes the formation of the fault core. When fracturing starts, the fault zone permeability increases and the fault zone acts as a self-enhancing conduit. In the second stage, the fault zone permeability structure is changing, due to the beginning of particle rotation and particle fracturing. The fine-grained matrix increases within the particle population and reduces the fracture connectivity and permeability (Billi et al., 2003; Micarelli et al., 2006a). As a result, the fault core starts to seal and may become a barrier for fluid flow. Fluid flow is limited to the fault damage zone at this stage, particularly in proximity to the fault core, where the rock is still highly fractured (Billi et al., 2003).

This evolutionary model of fault zone permeability is applicable to our study. The fault cores of all analysed fault zones show mineralizations and therefore signs of fluid flow within this fault zone unit, independently of their type, particularly the up to $1.5 \mathrm{~m}$ wide mineralizations at the fault core-hangingwall-boundary in Nussloch. Both fractures within the fault core (Illingen oblique-slip fault zone) and the whole fault core unit of smaller scale fault cores (Knittlingen reactivated reverse fault zone) are sealed by minerals as well. Additionally, red coloured areas and zones of discolorations indicate fluid flow within the fault cores in Nussloch and Knittlingen.

During fault zone evolution, this fluid flow, but also a grain size reduction, led to sealing of the fault cores and barrier formation within this fluid circulation system. As proposed by Billi et al. (2003) we assume that fluid flow was then localized within the fault zone damage zones characterized by an enhanced fracture density. In the present study, several fractures are sealed with minerals within this unit, particularly with orientations parallel and sub-parallel to the fault zones.

\subsubsection{Fracture system characterization within the fractured reservoir}

In order to enable fluid flow in a fractured reservoir, the fracture system and the individual beds have to be hydraulically connected (e.g., Odling et al., 1999; Ortega and Marrett, 2000; Micarelli et al., 2006a; Micarelli et al., 2006b; Reyer et al., 2012). Previous studies show enhanced percentages of interconnected fractures within damage zones and an increase in fracture connectivity from the protolith-damage zone boundary towards the fault plane (Micarelli et al., 2006a; Agosta et al., 2010). Despite our data show that most of the fractures are not connected with other fractures at fracture tips we conclude improved fracture vertical connectivity in proximity to slip surfaces of the fault zones, particularly caused by comparatively shorter fractures up to a length of $0.5 \mathrm{~m}$. The Nussloch normal fault zone with a displacement of some tens of meters, which was formed under an extensional regime 
in context of the URG and Kraichgau tectonics, exhibits the best fracture connectivity within the damage zone fracture system of all analysed fault zones since fractures connected at both fracture tips are included in particular.

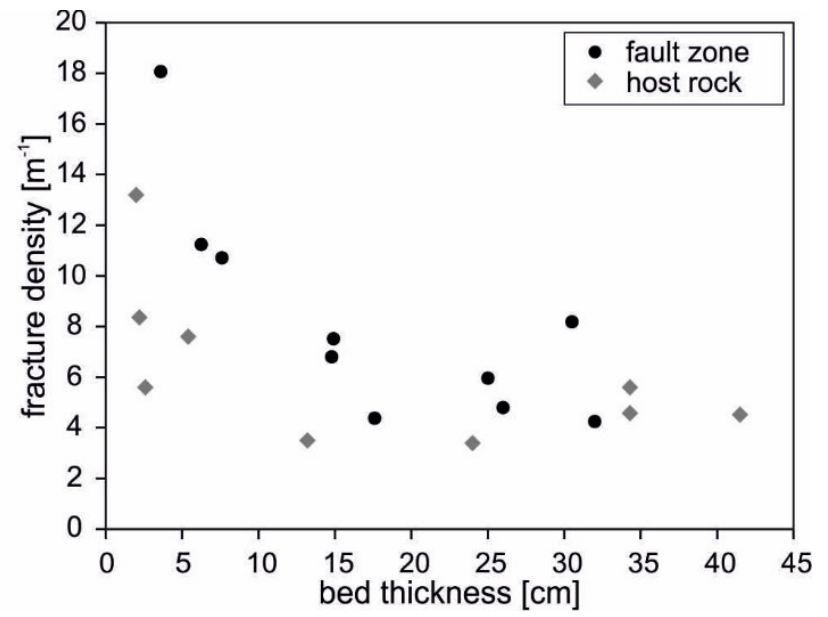

Figure 5.15: Nussloch-quarry: Bed thickness [cm] vs. fracture density [fracture count $\mathrm{m}^{-1}$ ], separately for fault zone and host rock.
It has long been recognized that the average fracture density in thinner beds is typically higher compared with thicker beds due to the formation of a stress shadow (Hobbs, 1967; Narr and Suppe, 1991; Gross et al., 1995; Van der Pluijm and Marshak, 2004). In general, our data show a similar behaviour, with highest fracture densities in comparatively thinner limestone beds. Figure 5.15 exemplary shows the bed thickness $[\mathrm{cm}]$ versus fracture density (number of fractures per meter) of all fracture data in Nussloch, separately for fault zone and host rock. In addition, we observe that limestone beds with similar thicknesses show higher fracture densities within the fault damage zone compared with the host rock. As proposed in previous studies (Caine et al., 1996; Berg and Skar, 2005; Micarelli et al., 2006a; Reyer et al., 2012), we observed a further enhanced fracture density in proximity to the slip surface. Thus, the probability of the formation of interconnected fractures in horizontal direction increases in this fault zone part.

Our data generally show the significance of mechanical layering for fracture propagation and fracture arrest at contacts, as shown in several previous studies (Narr and Suppe, 1991; Odling et al., 1999; Gross and Eyal, 2007; Larsen et al., 2010; Reyer et al., 2012; Boro et al., 2013; Philipp et al., 2013; Afşar et al., 2014). Reyer et al. (2012), for example, propose that the number of stratabound fractures is generally higher in mechanically layered sedimentary rocks, which are characterized by abrupt lithological changes (Narr and Suppe, 1991; Gross et al., 1995), such as the Lower Muschelkalk of the North German Basin, compared with more homogeneous units. The mechanical layering of these limestonemarl-alternations affects the fracture propagation and fracture arrest respectively due to stiffness variations and stress field changes (Gross and Eyal, 2007; Larsen et al., 2010; Reyer et al., 2012). For example, Larsen et al. (2010) and Philipp et al. (2013) describe the effects of fracture arrest at contacts such as stylolithes, zones of multilayers, welded layers, and cavities which induce a mechanical layering that does not coincide with clear lithological changes. In the limestone-marl-alternations of the Middle Triassic Muschelkalk, however, the mechanical contrasts match with lithological contacts: stiff limestone beds alternate with soft marl layers. Despite this effect of mechanical layering is obvious, nonstratabound fractures may be formed as result of linkage processes of pre-existing fractures induced by faulting (Agosta et al., 2010). Therefore, we focus on the distribution of non-stratabound fractures in relation to the fault core distance for further reservoir characterization in the present study and summarize fracture data of all scanlines, neglecting the limestone bed thicknesses.

Our data of the Knittlingen-quarry show that the comparatively thick marl layers (ca. $10 \mathrm{~cm}$ ) which induce a strong mechanical layering clearly act as stress barriers for fracture propagation. Many fractures become arrested at contacts to marl layers due to the changing stress field, regardless of the fracture locations (close to the slip surface or at distance). 


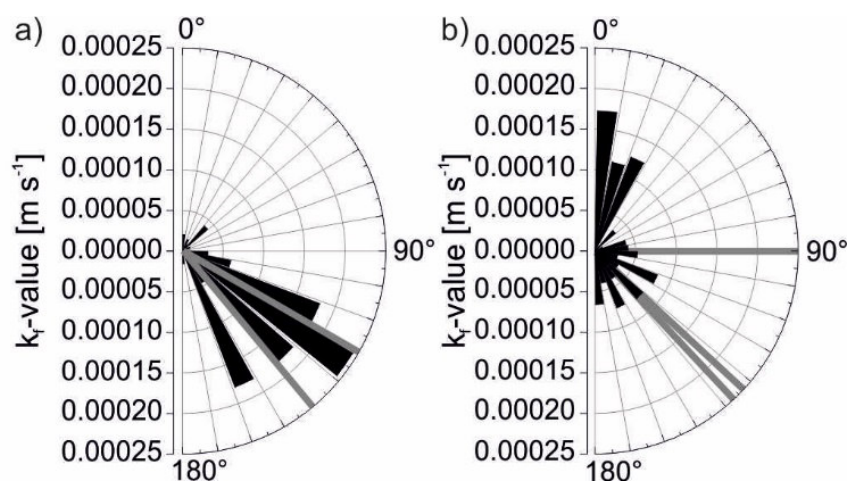

Figure 5.16: Based on surface measurements calculated hydraulic conductivity $\left(\boldsymbol{k}_{\boldsymbol{f}}\right.$-value) [ $\left.\mathrm{m} \mathrm{s}^{-1}\right]$ : a) Nussloch. b) Knittlingen. The fault zone orientations are marked by grey lines.
In both other quarries (marl thickness 0.5 to $2 \mathrm{~cm}$ ) a better connectivity between multiple limestone beds is caused by nonstratabound fractures, particularly at contact to the fault core in the Nusslochquarry, where the fractures propagate across the thinner marl layers in the more homogenous rock formation. Therefore, we assume that the effects of mechanical layering on fracture propagation in fault zones are significant.

Philipp et al. (2013) propose that diagenetic processes (cementation, pressure solution, mechanical compaction) in reservoirs lead to stiffness homogenizations of adjacent layers where a formerly mechanically layered succession may behave mechanically as a single layer. Thus, this effect is of particular importance for fracture propagation and permeability in a fractured reservoir and should be taken into account.

In general, our data show that the possibility of interconnected fracture formation increases with increasing fracture densities in proximity to the fault core, particularly in more homogenous rocks. The reservoir permeability is enhanced by the development of hydraulically active pathways across several beds (non-stratabound fractures) to a higher degree compared with the improvement caused by the formation of fractures interconnected at the fracture tips.

The best fracture induced reservoir permeability in the present study is proposed for the Nussloch normal fault. The enhanced permeability in this normal fault is caused by a high percentage of nonstratabound fractures, which may provide a hydraulically active pathway across several limestone beds (e.g., Odling et al., 1999) and supported by improved fracture vertical connectivity.

\subsubsection{Permeability implications on the analysed fracture systems}

Open fractures are of particular importance in terms of reservoir permeability. In the present study, many fractures remained open. These open fractures are potential pathways for recent fluid flow in fractured reservoirs associated with the characterized fault zones.

As an extension of the cubic law (cf., Section 5.3) we use calculations of the hydraulic conductivity $k_{f}\left[\mathrm{~m} \mathrm{~s}^{-1}\right]$ for sets including parallel and open fractures [ $\left.\mathrm{m} \mathrm{s}^{-1}\right]$ after Bear (1993; Eq. 5.1) to show fracture orientations of fractures which enhance the permeability of the fracture system:

$$
k_{f}=\frac{\rho_{f} \cdot g}{12 \mu \cdot L}\left(\sum_{i=1}^{m} b^{3}\right) \quad\left[\mathrm{m} \mathrm{s}^{-1}\right],
$$

where $\rho_{f}$ is the fluid density $\left[\mathrm{kg} \mathrm{m}^{-3}\right], g$ the acceleration due to gravity $\left[\mathrm{m} \mathrm{s}^{-2}\right], \mu$ the dynamic viscosity [Pa s], $L$ the profile length [m] and $b$ the fracture aperture $[\mathrm{m}]$.

Since fracture data of surface measurements in the outcrop analogues are used for our calculations, for fluid reservoirs we have to consider that fracture parameters change with increasing depth, resulting for example in reduced fracture apertures and densities (Lee and Farmer, 1993). Therefore, we aim at highlighting fracture orientations with enhanced permeabilities, but no absolute values.

We show permeability calculations based on the surface measurements exemplary for the quarries Nussloch and Knittlingen. We conclude that increased fracture frequencies in the damage zones and larger fracture apertures parallel and sub-parallel to fault zone strike and to regional structures like 
the URG and Variscan structures may lead to enhanced permeability compared with other orientations (Fig. 5.16).

We propose that surface data may be used for estimations of fault zone characteristics at depth. Several fault zone and fracture system characteristics or at least relationships should be applicable to reservoir conditions. Also at depth the fracture density would be enhanced at contact to the slip surfaces. Furthermore, we assume that the distribution of fractures with largest apertures at contact to the slip surface and parallel and sub-parallel to fault zone strikes remains the same. Thus, estimations on reservoir permeability are generally possible based on surface measurement in outcrop analogues. In order to obtain realistic permeability estimations, it is essential to vary fracture-system parameter such as aperture and density to adapt these parameters to reservoir conditions in further investigations. The received fracture data of the present study serve as a basis of future numerical models for example of fluid and heat transport in fault zones.

\subsection{Conclusion}

Based on outcrop analogue studies of eight fault zones crosscutting limestone-marl-alternations of the Middle Triassic Muschelkalk in the Kraichgau Syncline (Southwest Germany) we conclude:

1. Fault zone formation and reactivation in the Kraichgau Syncline is clearly affected by regional stress field changes of the Upper Rhine Graben development. Fault zones and associated main fracture sets have orientations similar to prominent regional structures, such as the NNE-SSW-oriented oblique-slip fault zone parallel to the URG or the NW-SE-oriented normal fault zone parallel to the step faults which induced the subsidence of the Kraichgau Syncline.

2. Fractures extending across multiple limestone beds of the exposed limestone-marl-alternations may create pathways for fluid flow across these beds in the reservoir, but different mechanical properties of limestone and marl obviously also affect fracture propagation. An enhanced fracture density and fracture connectivity of shorter fractures within the fracture system in the fault damage zones at contact to the fault core may improve reservoir permeability.

3. Increased fracture frequencies in fault damage zones and largest fracture apertures in direction of fault zone strike and of prominent regional structures may lead to enhanced permeability compared with other orientations. Fractures formed in these directions which are sealed by minerals as well as mineralizations within fault cores indicate hydraulic activity during fault zone evolution.

4. The fault damage zones in the Middle Triassic Muschelkalk may be potential drilling targets of geothermal wellbores in the adjacent Upper Rhine Graben although in many cases the hydraulic connectivity of the natural fracture network may need to be improved. Well-developed fault cores may be potential barriers for fluid flow in inactive fault zones.

\section{Acknowledgments}

The authors appreciate the support of the German Federal Ministry for Economic Affairs and Energy (BMWi), previously of the German Federal Ministry for the Environment, Nature Conservation and Nuclear Safety (BMU) as part of the Research and Development Project AuGE (Outcrop Analogue Studies in Geothermal Exploration) within the framework of the $5^{\text {th }}$ Energy Research Program (FKZ 0325302). We thank our AuGE-project partners Geothermal Engineering GmbH, GeoEnergy GmbH, University of Heidelberg, and University of Erlangen for their support. Thanks to the owners of the quarries for the permission to perform the field studies (Sämann Stein- und Kieswerke GmbH \& Co. KG and HeidelbergCement). Careful reviews by Alvar Braathen and Agust Gudmundsson helped improve the manuscript. 


\title{
6. Comparison of surface and sub-surface data
}

\section{Predictability of properties of a fractured geothermal reservoir: The oppor- tunities and limitations of an outcrop analogue study}

\author{
Geothermal Energy 5 (2017). doi: 10.1186/s40517-017-0081-0³
}

\begin{tabular}{ll}
\hline Keywords: & $\begin{array}{l}\text { Geothermal energy; Geothermal exploration; Outcrop analogue study; Rock proper- } \\
\text { ties; Fracture-system parameters; Upper Rhine Graben }\end{array}$ \\
Highlights: & We test the potential of outcrop studies in exploration for geothermal energy. \\
& Essential reservoir parameters are compared in outcrop and well data. \\
& Because important reservoir parameters strongly differ they are not predictable. \\
& Such studies have limited potential for geothermics in complex faulted areas.
\end{tabular}

\section{Abstract}

Minimizing exploration risk in deep geothermics is of great economic importance. Especially, knowledge about temperature and permeability of the reservoir is essential. We test the potential of an outcrop analogue study to minimize uncertainties in prediction of the rock properties of a fractured reservoir in the Upper Rhine Graben. Our results show that although mineralogical composition, clay content, grain size, and fabric type are basically comparable, porosity and quartz cementation are not. Young's Modulus, as observed in the outcrop closest to the reservoir is about twice as high ( $64 \mathrm{GPa}$ ) as observed in the reservoir ( $34 \mathrm{GPa}$ ). Most importantly, however, the parameters that describe the fracture system, which are essential to predict reservoir permeability, differ significantly. While the outcrops are dominated by perpendicular fracture sets (striking NE-SW and NW-SE), two different conjugate fracture sets (striking NW-SE and N-S) occur in the reservoir. Fracture apertures, as reported from the FMI, are one order of magnitude wider than in the outcrop. We conclude that our outcrop analogue study fails to predict important properties of the reservoir (such as permeability and porosity). This must be in part because of the tectonically complex setting of the reservoir. We propose that analogue studies are important, but they must be treated with care when attempting to predict the controlling parameters of a fractured reservoir.

\footnotetext{
${ }^{3}$ This Chapter is largely identical to the article entitled „Bauer, J.F., Krumbholz, M., Meier, S., Tanner, D.C., 2017. Predictability of properties of a fractured geothermal reservoir: The opportunities and limitations of an outcrop analogue study. Geothermal Energy 5 (1), 24."
} 


\subsection{Background}

The most essential requirements for a geothermal reservoir are sufficient temperature and permeability (e.g., Jung et al., 2002; Paschen et al., 2003; Schulz et al., 2009; Schulz, 2011). Whereas the geothermal gradient for a given region is commonly constrained to a sufficient degree, estimates of porosities, fracture systems, permeabilities, and therefore the achievable convective heat flow in a planned fractured reservoir are subject to large uncertainties (Domenico and Palciauskas, 1973; Agemar et al., 2012). Permeability provided by barren fractures, commonly referred to as structural permeability (e.g., Sibson, 1996; Jolie et al., 2015), and thus the convective heat flow, may be substantially increased in fault-related reservoirs by locally enhanced fracture intensities and therefore create prime targets for geothermal exploration (Paschen et al., 2003; Jung, 2007; Vidal et al., 2016). However, estimating the potential of a fractured hydrogeothermal reservoir is a major problem. This is because of the limited amount of data available to estimate the permeability in the subsurface and thus to predict achievable flow rates for geothermal power exploitation (at least $20 \mathrm{~kg} \mathrm{~s}^{-1} \mathrm{MW}^{-1}$, Franco and Villani, 2009). Permeability values are typically at best restricted to a small number of existing wells close to the envisaged reservoir and not necessarily representative of larger volumes. It is thus inherent that the quality of predictions made on reservoir properties largely depends not only on the distance between exploration wells in the reservoir, but also on the heterogeneity of the latter (e.g., Müller et al., 2010; Fitch et al., 2015). This holds particularly true for fluvial sedimentary rock sequences that are characterized by frequent changes of rock properties, both laterally and vertically (Morad et al., 2010). This is the case for the Lower Triassic (Buntsandstein) in the Upper Rhine Graben (URG), where lithostratigraphic correlations are further complicated by a complex system of fault block tectonics (Boigk and Schöneich, 1970; Sauer et al., 1982; Villemin et al., 1986).

Predictions of heterogeneities on a larger scale from point information such as borehole logs have therefore large uncertainties. Geophysical methods, such as 2D or 3D reflection seismics, in contrast, provide continuous spatial information, which can be used to image large structural geological heterogeneities, such as faults. Due to their resolution, however, they can only provide limited data on small-scale structures such as fractures.

One common approach to reduce the observational gap between well and seismic data is to include outcrop data into the exploration strategy (Chesnaux et al., 2009; Philipp et al., 2010; Howell et al., 2014; Reinecker et al., 2015). The advantages of this approach are that, if good outcrops exist, lateral as well as vertical heterogeneities of rock- and fracture-system properties can be observed in detail. These properties are challenging or even impossible to sample adequately using borehole logs and in general they are invisible to seismics.

An outcrop will always be different from its subsurface analogue, even if it exposes age-equivalent rocks, since it must have experienced a different burial/uplift history and thus different diagenetic conditions. In addition, outcrops are not always available in the desired size, quality, and/or quantity.

Consequently, the resolution of the different methods used to analyse a reservoir needs to be scaled accordingly. For instance, the scale of observation is important with respect to fracture orientation. While (sub)recent microcrack orientations are commonly consistent over large volumes (e.g., Vollbrecht et al., 1994; Krumbholz et al., 2014a) and therefore predictable, larger fractures have usually a more complex history and thus exhibit more variable systematics. A direct implication is that the strength of the rocks is also scale dependent (Krumbholz et al., 2014b).

However, outcrop studies only provide limited 2D/3D information and it is necessary for the observed rock properties to be corrected to be comparable with the conditions at reservoir depth. In addition, 
the deformation history of the target formation may be different from that of the outcrop. For instance, faults at depth may juxtapose rock units, but possibly not in the outcrop.

The structural permeability provided by fractures (joints and faults) may vary locally within several orders of magnitude. Numerous studies have shown that the fracture intensity in a fault zone often increases towards the fault core, and with increasing fault displacement (e.g., Hull, 1988; Faulkner et al., 2011; Reyer et al., 2012; Shipton et al., 2013). Thus, damage zones of large-scale fault zones are prime targets for geothermal exploration. When evaluating fault properties, it is, however, crucial to take into account that (1) faults and fault zones may act either as conduits, barriers, or as combined conduit-barrier systems for fluid flow (e.g., Chester and Logan, 1986; Caine et al., 1996; Evans et al., 1997; Farrell et al., 2014) and (2) that the characteristics of faults and brittle fault zones can vary considerably, even on small spatial scale (e.g., Caine et al., 1996; Schulz and Evans, 2000; Faulkner et al., 2010; Laubach et al., 2014). Consequently, reliable prediction of the structural inventory of faults and its hydrological impact on the planned geothermal reservoir is crucial. Given the amount of parameters needed to be investigated to predict the properties of fractured and fault-related reservoirs, careful selection of outcrop analogues is essential to ensure their comparability to the reservoir under exploration.

This study focusses on the rock properties and fracture-system parameters in outcrops and compares them with equivalent reservoir data. The study was carried out in the Lower Triassic of the Upper Rhine Graben (URG), a potential, but still underexplored target for geothermal exploitation. Outcrop data are compared with reservoir information from the geothermal well Brühl GT1 within the URG, close to the eastern graben shoulder. In total, four outcrops on the eastern and western graben shoulders were selected; they belong to the Lower to Middle Buntsandstein (Fig. 6.1).

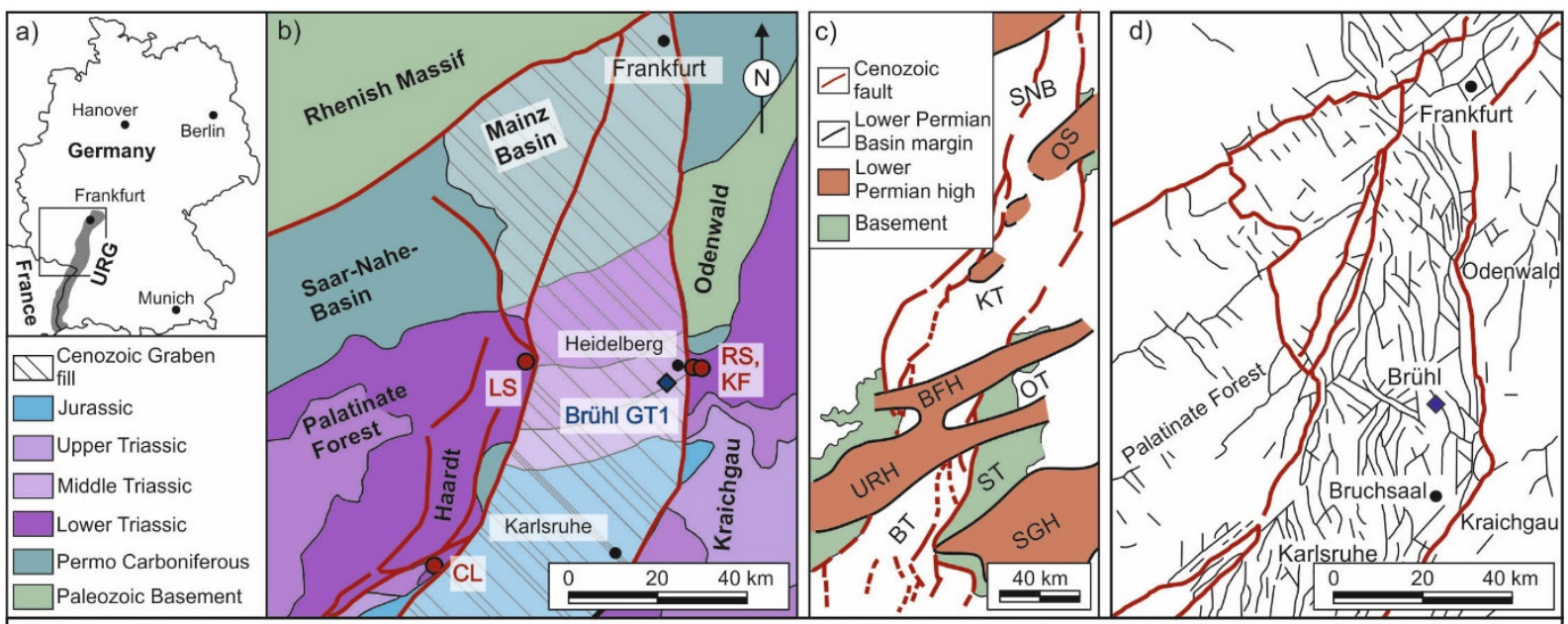

SNB: Saar-Nahe Basin, OH: Odenwald-Spessart High, KT: Kraichgau Trough, BFH: Northern Black Forest High, URH: Main Upper Rhine High, BT: Burgundy Trough, ST: Schramberg Trough, SGH: Main Southern German High

Figure 6.1: a) Location of the URG b) Solid geological map of the study area. The locations of the outcrops studied (LS: Leistadt; CL: Cleebourg; RS: Riesenstein; KF: Kammerforster) are indicated by red dots, the geothermal well Brühl GT1 is represented by a blue diamond (map modified after Eisbacher and Fielitz, 2010). c) Permo-Carboniferous troughs and highs in the URG. Black lines indicate Variscan fault traces (after Schumacher, 2002). d) Fault map showing major fault traces in the graben and on adjacent graben shoulders that indicates the complex deformation history (modified after Meixner et al., 2016). Red lines in b) to d) show main Cenozoic boundary faults of the URG.

We analyse the rock parameters that directly control the reservoir performance, they are porosity, and fracture-system parameters, such as mineralization, orientation, intensity, and aperture. Other rock parameters, such as tensile strength, Young's Modulus, and uniaxial compressive strength are of interest from an engineering point of view, e.g. in terms of borehole stability or in case reservoir stimulation becomes necessary. 


\subsection{Site descriptions and methods}

\subsubsection{Regional geology and geothermal setting}

The URG is part of the European Cenozoic Rift System and strikes NNE-SSW, its length is about $300 \mathrm{~km}$, and it is about 30-40 km wide (e.g., Illies, 1977; Ziegler, 1992; Schumacher, 2002; Fig. 6.1).

The structural pre-rift setting of the URG was established during the Variscan Orogeny; Permo-Carboniferous wrench tectonics formed NE- to ENE-trending fault zones (e.g., Ziegler, 1990; Schumacher, 2002; Schwarz and Henk, 2005). These fault zones form the boundaries of the Variscan Internides and Permo-Carboniferous troughs and highs (Fig. 6.1c). Early Carboniferous, NNE- to SSW-oriented, sinistral shear zones are associated with Lower Carboniferous to Permian intrusive bodies (Vosges, Black Forest, Odenwald; e.g., Ziegler, 1990; Schumacher, 2002; Schwarz and Henk, 2005).

The formation of the URG in the Cenozoic occurred in two main phases and was controlled by multiphase reactivation of Variscan and Permo-Carboniferous discontinuities (e.g., Illies, 1972; Schumacher, 2002; Ziegler et al., 2006). The first rifting phase occurred during the Late Eocene until Late Oligocene, and was characterized by NW-SE- to WNW-ESE-directed extension (e.g., Ziegler, 1992; Schwarz and Henk, 2005; Ziegler and Dèzes, 2006). The second main phase of graben formation began in Early Miocene and was marked by reorientation of the stress field to NE-SW extension. As a consequence, the major graben-forming faults are characterized by sinistral and dextral oblique displacements, local inversion, and normal displacements (Illies and Greiner, 1979; Schumacher, 2002). Uplift and erosion was limited to the central and southern parts of the URG, while subsidence and sedimentation shifted southwards during the Miocene (Bartz, 1974; Pflug, 1982). The recent maximum horizontal stress component in the URG is NW-SE to NNW-SSE-oriented (Heidbach et al., 2008). However, fault-plane solutions reveal a change in faulting regime from dominantly strike-slip faulting in the southern part to a combination of strike-slip- and extensional movement in the northern URG (Larroque et al., 1987; Plenefisch and Bonjer, 1997).

The Buntsandstein rocks that were studied here represent the marginal facies of the Germanic Basin and comprise mainly fluvial to playa deposits. The Odenwald-Spessart High separates different depositional areas of the studied outcrops (Fig. 6.1c). Within the Palatinate Forest, fluvial and aeolian facies alternate, whereas aeolian sediments are absent in the Odenwald (Hagdorn and Nitsch, 2009). Since the unconformities that define the basic lithostratigraphic units of the Buntsandstein in the northern Germanic Basin are not clearly documented in the study area, distinction between the different units is difficult (Dachroth, 1985; Bourquin et al., 2006; Szurlies, 2007; Feist-Burkhardt et al., 2008; Hagdorn and Nitsch, 2009). Further complications are introduced by the varying Buntsandstein thicknesses; they vary from about $60 \mathrm{~m}$ in the south of the graben to approximately $500 \mathrm{~m}$ around Karlsruhe, but further northward the thickness decreases again to about $300 \mathrm{~m}$ (Boigk and Schöneich, 1970; Stober and Bucher, 2014). Additionally, the Buntsandstein can be found at different depths, ranging from about $1000 \mathrm{~m}$ below the land surface, down to $4000 \mathrm{~m}$ near Karlsruhe. This is due to intense block tectonics and differences in the subsidence and exhumation history (Boigk and Schöneich, 1970; Sauer et al., 1982; Villemin et al., 1986). One consequence of the complex geology is that several lithostratigraphic classifications of the Buntsandstein units exist (e.g., Backhaus, 1974; Richter-Bernburg, 1974; Hagdorn and Nitsch, 2009). Within the URG, the regional geothermal gradient is elevated to $45-50^{\circ} \mathrm{C} \mathrm{km}^{-1}$, with local hot spots that have temperature gradients of up to $100^{\circ} \mathrm{C} \mathrm{km}^{-1}$ and make the URG a prime target for geothermal exploration in Germany (Schellschmidt and Clauser, 1996; Stober and Bucher, 2014). This positive temperature anomaly is commonly explained by a raised Moho 
due to the graben formation (Brun et al., 1992) or by advective fluid flow (Schellschmidt and Clauser, 1996; Pribnow and Schellschmidt, 2000).

\subsubsection{Study area}

The graben shoulders expose Triassic rocks of Lower to Upper Buntsandstein. The outcrops studied (Figs. 6.1 and 6.2) comprise one outcrop with a fault zone (Fig. 6.2a; Cleebourg) and one without an exposed fault zone (Fig. 6.2b; Leistadt) on the western graben shoulder. On the eastern graben shoulder, two additional outcrops without fault zone exposure were studied (Fig. 6.2c; Riesenstein and Kammerforster).

The location of the geothermal well Brühl GT1 is southwest of Heidelberg, approximately $12 \mathrm{~km}$ west of the eastern graben shoulder (Fig. 6.1a, d). The thickness of the reservoir is $162 \mathrm{~m}$ and lies between 3157 and 3319 m measured depth (MD), close to a system of three NNW-, W-, and NE-dipping transtensional faults that are part of a negative flower structure (Lotz, 2014a). The targeted reservoir zone is intersected by an $80^{\circ}$ westwards-dipping transtensional fault. The normal vertical displacement of this fault is approximately $70 \mathrm{~m}$ (Reinecker et al., 2015), although the strike-slip component is unknown.

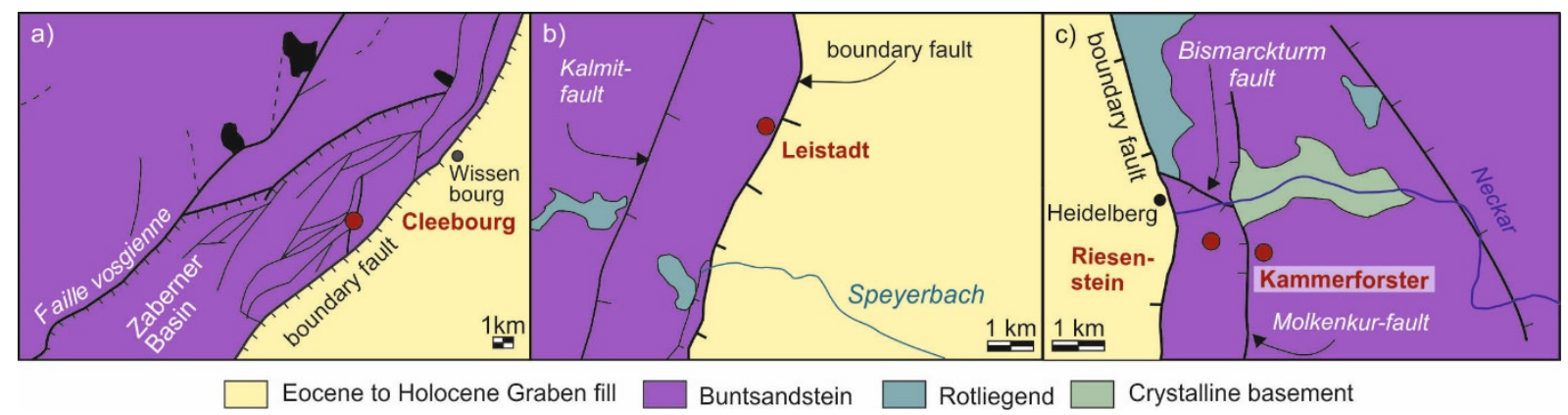

Figure 6.2: Geological maps of the outcrops studied on the western graben shoulder, a) Cleebourg and b) Leistadt, and on the eastern graben shoulder, c) Riesenstein and Kammerforster (maps modified after Eisbacher and Fielitz, 2010).

\subsubsection{Methods}

\section{Outcrop-based methods}

In this study, we used classic structural geological fieldwork, including mechanical rock-property measurements, and optical microscopy, which included image analysis of selected thin sections of rock samples.

Standard parameters of the fracture system were recorded using scanline and window-sampling methods (e.g., Terzaghi, 1965; Priest, 1993; Adler et al., 2013). The recorded fracture-system parameter include orientation, intensity (number of fractures per meter), connectivity, aperture, and whether the fractures are cemented or not.

Laboratory-based methods:

16 rock samples were taken: 12 from the outcrop at Cleebourg, 1 from Leistadt, 2 from Riesenstein, and 1 from Kammerforster. From each of the samples, at least six right-circular cylinders were taken for mechanical testing. The rocks were classified according to their fabric type after Miall (1978) and dried samples were used to determine the ultrasonic shear-wave velocity $\left(v_{s}\right)$, uniaxial compressive strength $(U C S)$, static Young's Modulus $(E)$, tensile strength $\left(T_{0}\right)$, and bulk density $\left(\rho_{b}\right)$. Transient times of shear-wave velocities were measured at a frequency of $0.25 \mathrm{MHz}$. The compression tests were carried out according to ISRM 1989 (Fairhurst and Hudson, 1989) and the indirect tensile strength was 
measured using a Brazilian test after ISRM 1981 (Brown, 1981). The bulk densities of the samples were calculated using their mass to volume ratios.

For comparison of petrophysical and petrographical properties, 24 thin sections of the samples from Cleebourg were saturated with blue resin. Using optical microscopy, we determined porosity, cementation, grain size, and mineralogical composition. For petrographical quantification of the rock, thin sections were analysed using classical point-counting (300 points) and classified after McBride (1963). Petrographic analyses of rock samples of the other outcrops (Leistadt, Riesenstein, and Kammerforster) were previously performed by Soyk (2015).

Porosity and grain size were assessed by digital image analysis with the software ImageJ (Rasband, 2011). An optical scan of each thin section with a resolution of $300 \mathrm{dpi}$ was taken under plane polarized light. To distinguish between the grains and the dyed resin-filled pore space, a binary image was calculated, with white pixels representing the grains and black pixels the pore space. The porosity was then calculated as an area fraction in ImageJ. The sizes of about 100 grains along a scanline were measured and classified after Wentworth (1922). While our 2D approach cannot compete with the accuracy of 3D analysis, e.g., Sahagian and Proussevitch (1998), Berg et al. (2016) concluded that, in the majority of cases, the accuracy of $2 \mathrm{D}$ porosity estimates can be considered sufficiently close to $3 \mathrm{D}$ results.

Analytical methods:

To estimate the matrix permeability $\left(K_{m}\right)$ in the reservoir from the properties determined in the outcrop study, the porosity-permeability relation (Kozeny-Carman, Eq. 6.1) was utilized,

$$
K_{m}=\left|\frac{\theta^{3}}{(1-\theta)^{2}}\right|\left(\frac{d_{50}^{2}}{180}\right) \quad\left[\mathrm{m}^{2}\right], \quad \text { Eq. } 6.1
$$

in which $\theta$ is the porosity and $d_{50}$ is the mean grain size (Freeze and Cherry, 1979).

To estimate the structural permeability in analytical models, it is an accepted approach to approximate naturally rough fractures by parallel plates with a constant aperture and to apply the cubic law (e.g., Snow, 1965, 1969; Witherspoon et al., 1980; Bear, 1993). Consequently, the permeability $\left(K_{f}\right)$ of sets of differently-oriented fractures was estimated using:

$K_{f}=\frac{1}{12 L}\left(\sum_{i=1}^{m} b^{3}\right) \quad\left[\mathrm{m}^{2}\right]$,

where $L$ is the profile length [m] and $b$ is the fracture aperture [m] (Bear, 1993).

Reservoir-based methods:

The reservoir formation was analysed based on drill cuttings, i.e. no core was taken, but pumping and injection tests and standard wireline logging were carried out.

The geophysical logging devices that were used are listed in Table 6.1. The logs are available for the uppermost $140 \mathrm{~m}$ of the reservoir section.

The density-correction log from the LDS tool records the absolute deviation from the measured bulk density. For deviations larger than $15\left[\mathrm{~kg} \mathrm{~m}^{-3}\right]$, the determined bulk density was found to be not reliable and corresponding well sections were rejected during the evaluation of the bulk density and, thus, also for calculations of bulk porosity and the dynamic elastic parameters. The logging quality was further evaluated by the well caliper from the FMI tool. In the places where the well caliper returned values that deviate more than $15 \%$ from the bit size $(>0.22 \mathrm{~m},<0.16 \mathrm{~m})$, log signals from the LDS were found to affect the bulk density measurements and therefore rejected in further interpretation. 
Table 6.1: Wireline-logging tools used in this study (GR: Gamma Ray, FMI: Formation Micro Imager, DSI: Dipole Sonic Imager, LDS: Litho Density Sonde. MD: Measured Depth).

\begin{tabular}{|c|c|c|c|}
\hline tool & log interval (MD) (m) & measurements of & evaluation of \\
\hline GR & $3305-3150$ & natural gamma rays & $\begin{array}{l}\text { sand/clay content, depth correlation of } \\
\text { the various logging tools }\end{array}$ \\
\hline FMI & $3295-3150$ & $\begin{array}{l}\text { electrical resistance, well cali- } \\
\text { per }\end{array}$ & $\begin{array}{l}\text { sedimentary facies, detection of } \\
\text { open/closed fractures, fracture orienta- } \\
\text { tion, fracture intensity, fracture apertures }\end{array}$ \\
\hline DSI & $3293-3150$ & $\begin{array}{l}\text { compressional- and shear-wave } \\
\text { velocities }\end{array}$ & $\begin{array}{l}\text { matrix porosity, elastic mechanical rock } \\
\text { properties, lithology }\end{array}$ \\
\hline LDS & $3294-3150$ & $\begin{array}{l}\text { emitted gamma rays, Compton } \\
\text { scattering and photoelectric ab- } \\
\text { sorption }\end{array}$ & bulk porosity, bulk density, lithology \\
\hline
\end{tabular}

Density- or bulk porosity $\Phi_{\mathrm{b}}$ was determined using a quartz equivalent rock density $\left(\rho_{\text {matrix }}\right)$ of $2650 \mathrm{~kg} \mathrm{~m}^{-3}$, a formation fluid density $\left(\rho_{\text {fluid }}\right)$ of $1170 \mathrm{~kg} \mathrm{~m}^{-3}$, and the measured bulk density $\log \left(\rho_{\text {log }}\right)$ after (Schlumberger, 1989):

$\Phi_{b}=\frac{\rho_{\text {matrix }}-\rho_{\text {log }}}{\rho_{\text {matrix }}-\rho_{\text {fluid }}}$

The sonic- or matrix porosity $\Phi_{m}$ was estimated with the Wyllie time-average method using p-wave velocities (Schlumberger, 1989). This method requires an estimate of fluid and matrix travel times $\left(\Delta t_{\text {fluid }}=607 \mu \mathrm{sec} \mathrm{m}^{-1}, \Delta t_{\text {matrix }}=182 \mu \mathrm{sec}^{-1}\right)$ and compares these with travel times measured in the reservoir $\left(\Delta t_{l o g}\right)$ :

$\Phi_{m}=\frac{\Delta t_{\text {log }}-\Delta t_{\text {matrix }}}{\Delta t_{\text {fluid }}-\Delta t_{\text {matrix }}}$

Since sonic log-derived porosities largely ignore secondary porosity, such as fractures, and the density log responds primarily to as the bulk porosity, the difference was used to calculate the fracture porosity, referred to the secondary porosity index (SPI) of the reservoir (Schlumberger, 1989).

To compare the bulk densities of the dried surface samples and the fluid saturated rocks in the well, the log measurements were corrected by replacing the water-filled pores with air.

Elastic properties of the reservoir rock include dynamic Young's Modulus $\left(E_{d}\right)$. It is derived from the measured densities and elastic wave velocities (compressional- $v_{p}$ and shear-wave velocity $v_{s}$ ):

$$
E_{d}=\rho v_{s}^{2} \cdot \frac{3 v_{p}^{2}-4 v_{s}^{2}}{v_{p}^{2}-v_{s}^{2}}
$$

The formation structural permeability was determined equivalent to outcrop calculations, using the cubic law (Eq. 6.2). Data on fracture apertures and densities are based on FMI images; data on fracture mineralization was analysed using a combination of FMI, LDS, and DSI, provided by J. Reinecker (GeoT). The results were compared with determined bulk permeabilities from pumping and injection tests. The reservoir transmissivity is specified as follows:

$$
T=\frac{2.3 \cdot Q}{4 \pi \cdot \Delta s} \quad\left[\mathrm{~m}^{2} \mathrm{~s}^{-1}\right]
$$

and the formation permeability $\left[\mathrm{m}^{2}\right]$ as:

$$
K=\frac{T}{H} \cdot \frac{\eta}{\rho_{f} g}
$$

where $Q$ is the production rate $\left[\mathrm{m}^{3} \mathrm{~s}^{-1}\right], \Delta s$ is the pressure reduction $[\mathrm{m}], H$ is the reservoir height $[\mathrm{m}]$, $\rho_{f}$ is the fluid density $\left[\mathrm{kg} \mathrm{m}^{-3}\right], g$ is the acceleration due to gravity $\left[\mathrm{m} \mathrm{s}^{-2}\right]$, and $\eta\left[\mathrm{kg} \mathrm{m}^{-1} \mathrm{~s}^{-1}\right]$ the dynamic fluid viscosity (Kruseman and Ridder, 1992). 


\subsection{Outcrop properties}

\subsubsection{Rock properties}

Whereas the Triassic sandstones in outcrops on the western graben shoulder are yellowish, brownish to red coloured, and, in some cases, they are totally bleached, the investigated sandstones from the eastern flank are red, and not, or only slightly, bleached. Typical fabric types of the studied rock samples comprise trough cross-bedding, partly with mudstone intraclasts (St) and low-angle $\left(<10^{\circ}\right)$ crossbedding (SI). Both fabric types are interbedded by thin silty claystone layers.

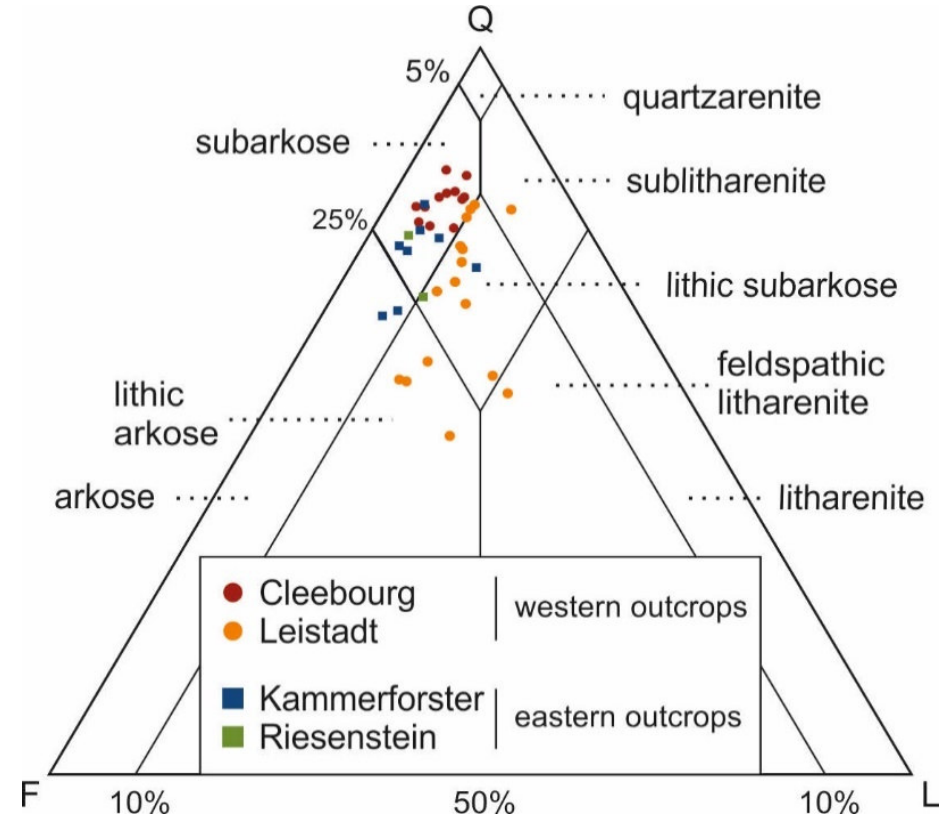

Figure 6.3: Modal composition of sandstone samples from the different locations in a QFL diagram, after McBride (1963). Sandstone compositions of Leistadt, Riesenstein, and Kammerforster are adopted from Soyk (2015).

Despite different lithostratigraphies, the mineralogical compositions for all studied outcrops cluster narrowly in the fields of subarkose and lithic subarkose; the Leistadt samples show an increased amount of lithic components (Fig. 6.3).

Rock porosity estimations based on image analysis show that the rock porosities at the eastern flank have only minor variations and lie between 3 and 8\%: the porosities estimated at the western flank vary between 2 and $22 \%$ (Fig. 6.4a). Quartz cementation at the western flank does not exceed $7 \%$ and covers only a small range, in contrast to the eastern flank, where the cementation lies between 2 and 23\% (Fig. 6.4b). The average clay content lies in a narrow range between 6 and $8 \%$ for the outcrops of Cleebourg, Leistadt, and Riesenstein. Only in the Kammerforster outcrop is the clay content of $12 \%$ significantly higher (Fig. 6.4c). The corresponding API values (from gamma-ray measurements) in the outcrops lie in the range of $77-95$ (Reinecker et al., 2015). The grain size is medium sand with a slight tendency to finer sand in the easterly outcrops, and sorting is moderate to well (Fig. 6.4d). The bulk densities are lower on the western graben shoulder, with mean values for the outcrops ranging from 2150 to $2240 \mathrm{~kg} \mathrm{~m}^{-3}$. On the eastern graben shoulder, the mean bulk density lies between 2330 and $2340 \mathrm{~kg} \mathrm{~m}^{-3}$ (Fig. 6.4e). Notably, the low-angle cross-bedded sandstones (SI) in Cleebourg have in general higher porosities, bulk densities, and quartz cementations compared with the trough cross-bedded sandstones (St). 

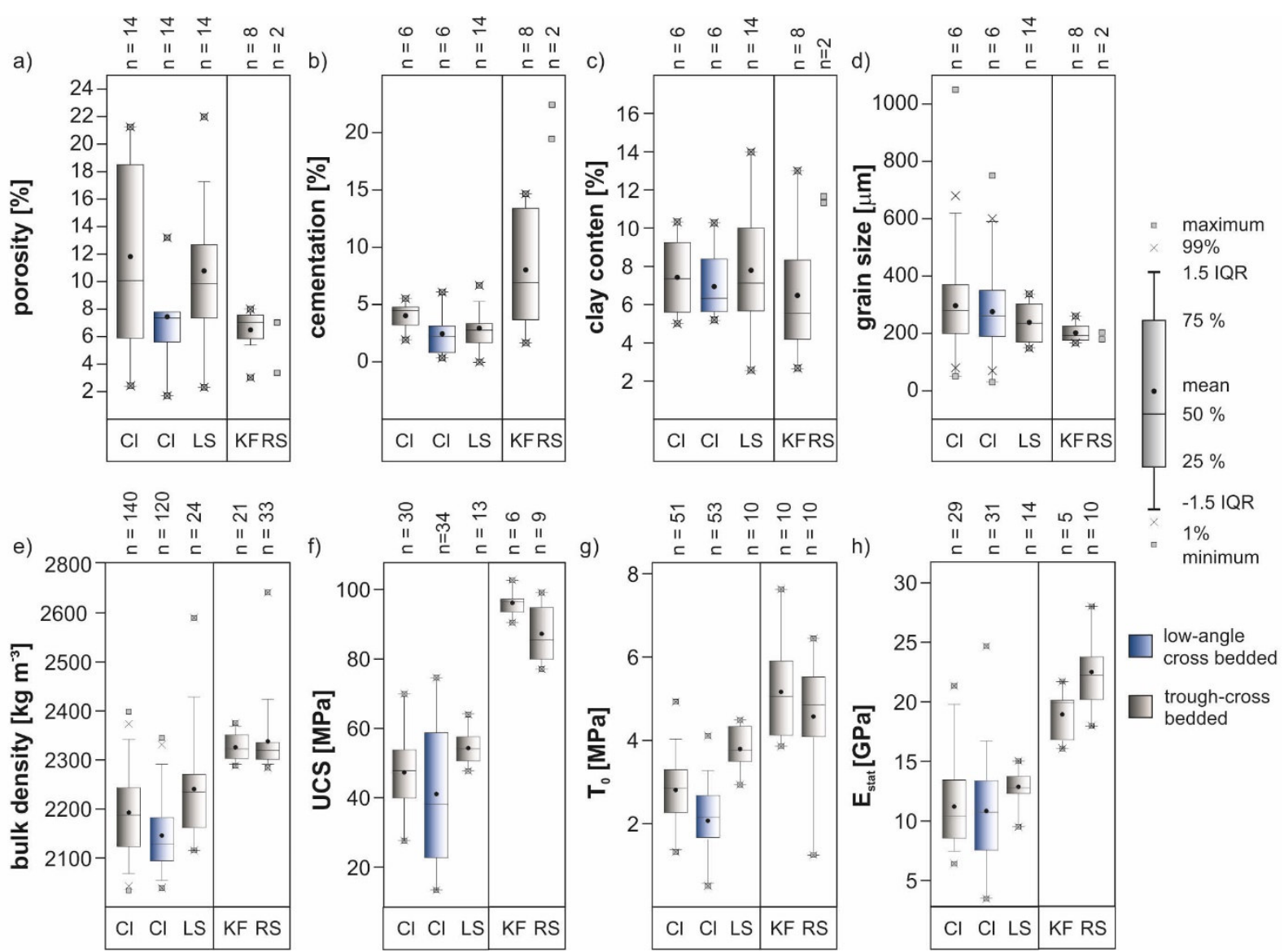

Figure 6.4: Box-whisker plots of the petrophysical and petrographical characteristics of the analysed sandstones. Data are presented according to their locations, from west to east. The individual boxes are coloured according to their fabric type. a) Porosity, b) cementation, c) clay content, d) grainsize, e) bulk density, f) uniaxial compressive strength (UCS), g) indirect tensile strength $\left(\boldsymbol{T}_{\mathbf{0}}\right)$, and $\mathbf{h}$ ) static Young's Modulus $\left(\boldsymbol{E}_{\text {stat }}\right)$. Equivalent information from Leistadt, Riesenstein, and Kammerforster are adopted from Soyk (2015).

The mechanical properties determined include uniaxial compressive strength (UCS), indirect tensile strength $\left(T_{0}\right)$, and static Young's Modulus $\left(E_{\text {stat }}\right)$. The properties exhibit comparable values on the

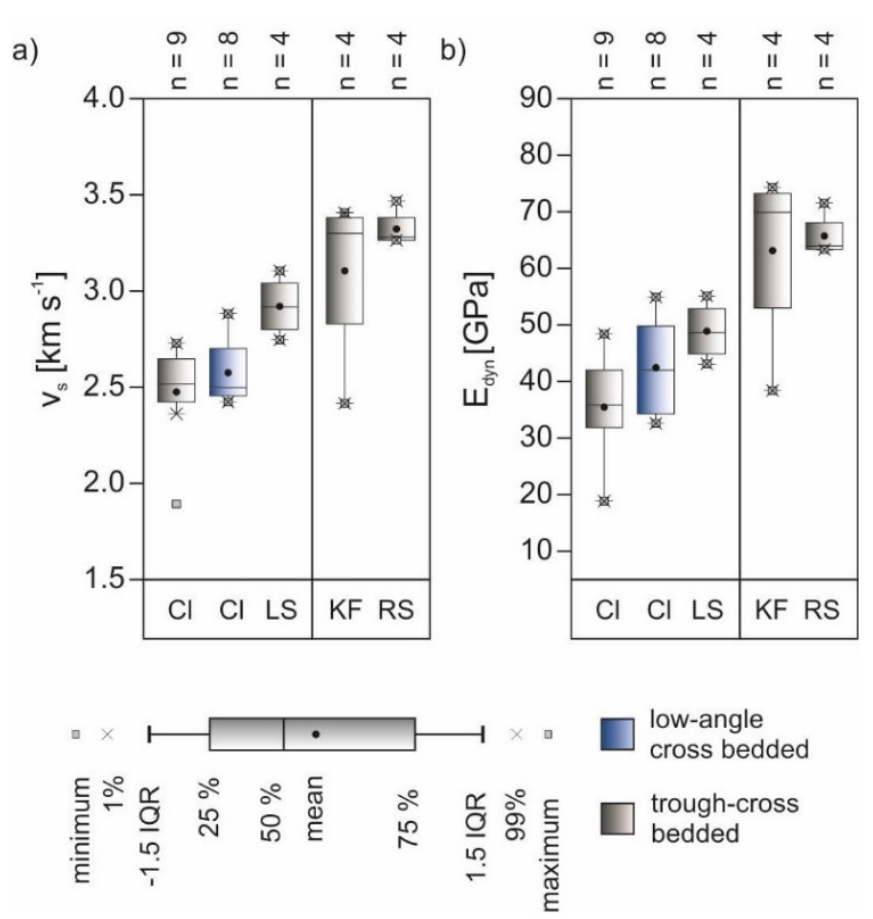
western graben shoulder (UCS: $41.0-54.3$ [MPa]; $T_{0}: 2.1-3.8[\mathrm{MPa}] ; E_{\text {stat }}: 10.8-12.8$ [GPa]), but on the eastern graben shoulder they are consistently about twice as large (UCS: 80-100 [MPa]; $T_{0}: 4-7$ [MPa]; $\left.E_{\text {stat }}: 15-25[\mathrm{MPa}]\right)$. The only exception is the indirect tensile strength $\left(T_{0}\right)$, where the difference between the eastern and western outcrops is smaller, but still considerable. In general, there is a clear tendency that the mechanical rock properties increase eastwards (Fig. 6.4f-h). Accordingly, sonic velocity $\left(v_{s}\right)$

Figure 6.5: Box-whisker plots of a) shear-wave velocities and b) dynamic Young's Moduli $\left(\boldsymbol{E}_{\boldsymbol{d y n}}\right)$, as calculated from sonic velocities. Outcrops ordered according to their location, from west to east, and colour coded according to fabric type. 
follows the same trend as static Young's Modulus and also increases towards the east (Figs. 6.4h, 6.5a). Assuming a typical $v_{p} / v_{s}$ ratio of about 1.7 for sandstones (Pickett, 1963), we calculated the dynamic Young's Modulus. The mean values range from $35 \mathrm{GPa}$ in Cleebourg to $64 \mathrm{GPa}$ in Kammerforster (Fig. 6.5b), and are thus two to four times higher than the corresponding static measurements.

\subsubsection{Fracture-system parameter}

NE- to SW-striking fractures are present at all the different locations (Fig. 6.6). In addition to this, a small group of fractures strike NW - SE in the Leistadt and Kammerforster outcrops (Fig. 6.6b, c). In Leistadt, the NE- to SW-striking fracture set is the main set, whereas in Kammerforster the NW- to SEoriented set appears to dominate.

Notably in the Cleebourg outcrop (Fig. 6.6a), within fault zone exposure, the orientation of the main fracture set seems to be layer specific, i.e. in layers 1 and 2 the fractures are sub-parallel to the fault, whereas in layer 3 the dominant fracture orientation is about $30-40^{\circ}$ rotated clockwise compared to layers 1 and 2 and the fault (Fig. 6.7).
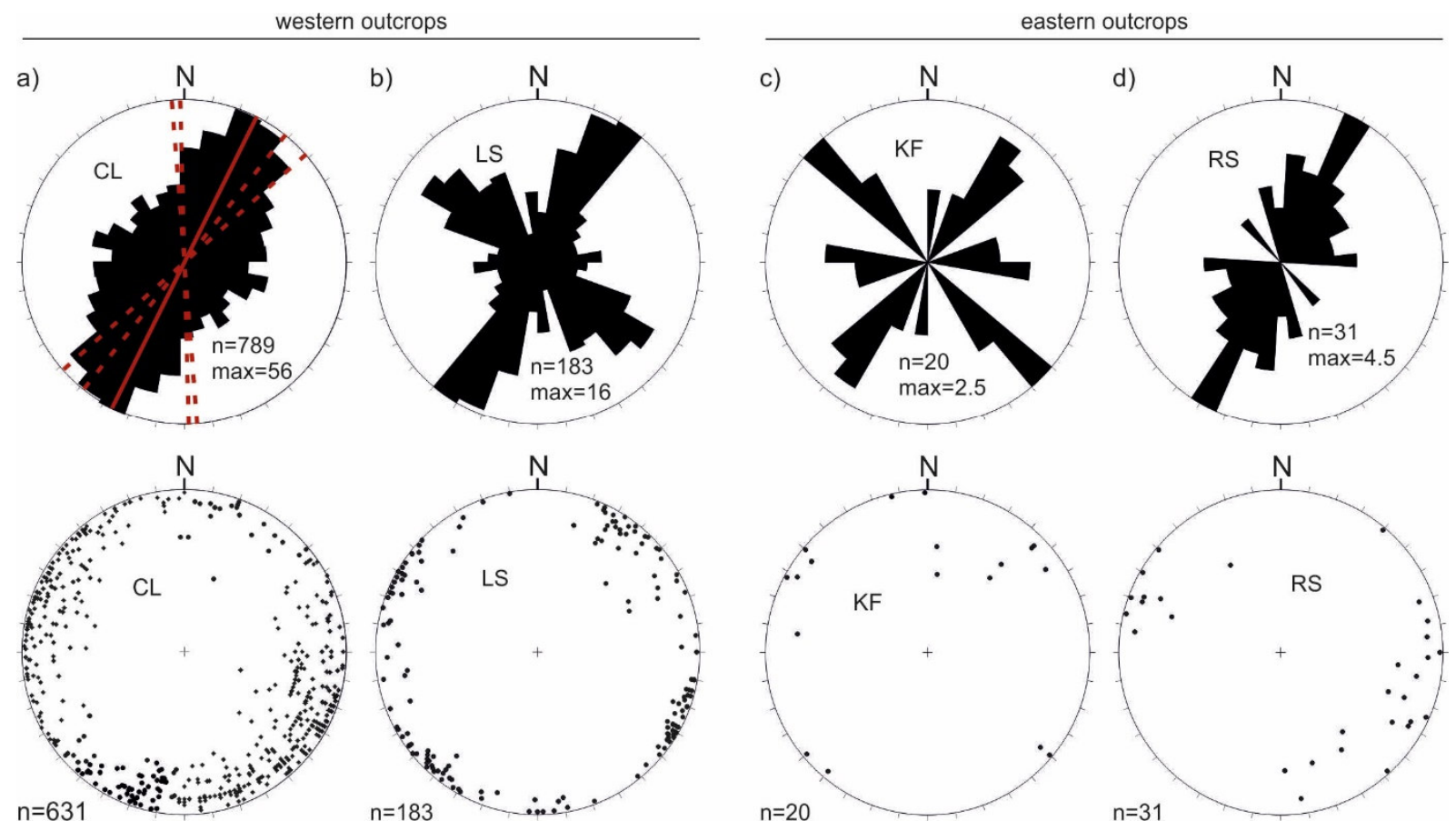

Figure 6.6: Fracture orientation data shown in equal area-scaled rose diagrams with $10^{\circ}$ bin size and in pole plots (equal area, lower hemisphere). a) Cleebourg (CL) fracture orientation data with the strike of the main fault (bold line) and minor faults (dashed lines) marked, b) Leistadt (LS), c) Kammerforster (KF), and d) Riesenstein (RS).

The mean fracture intensities in the outcrops without fault zone exposure on the eastern graben shoulder do not exceed $0.8 \mathrm{~m}^{-1}$, compared to up to $1.2 \mathrm{~m}^{-1}$ in Leistadt on the western graben shoulder. In the Cleebourg outcrop with fault zone exposure, the mean fracture intensity is $3.3 \mathrm{~m}^{-1}$ in the damage zone and, in two of three measured layers, shows increasing fracture intensity towards the fault plane (Fig. 6.7). In layer 1, the fracture intensity reaches a maximum of $27 \mathrm{~m}^{-1}$ in the vicinity of the fault plane, but in layer 3 the maximum is only $9 \mathrm{~m}^{-1}$. 
a)

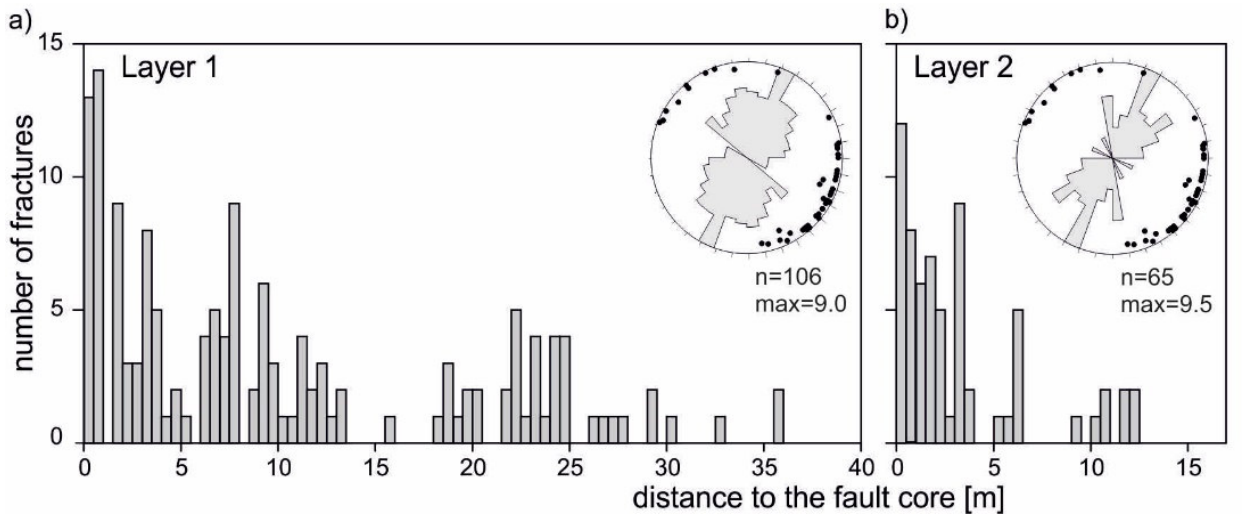

c)

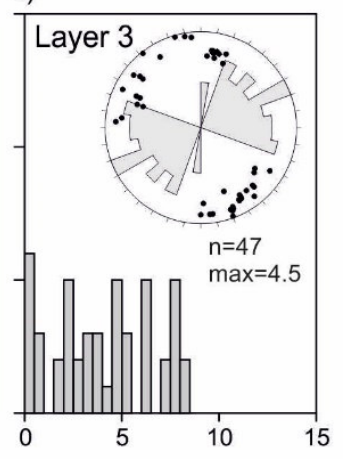

Figure 6.7: Fracture orientation and intensity in Cleebourg, shown for three individual layers. In layers 1 and 2, the fracture orientations are comparable and the fracture intensity increases towards the fault core. In layer 3 , fracture orientation and intensity show a different pattern. Rose diagrams with equal area scaling and $10^{\circ}$ bin size and equal area pole point plots on the lower hemisphere.

For Cleebourg, background parameters of the fracture system cannot be provided, due to the limited extent of the outcrop. However, in the outcrops without fault zone exposure, larger blocks that are almost fracture free occur, in contrast to the Cleebourg outcrop (Table 6.2).

Table 6.2: Summary of fracture intensity, mineralization, and connectivity for the outcrops studied.

\begin{tabular}{|c|c|c|c|c|c|c|c|}
\hline \multirow{2}{*}{ outcrop } & \multicolumn{3}{|c|}{ fracture intensity $\left[\mathrm{m}^{-1}\right]$} & \multicolumn{3}{|c|}{ amount of mineralization [\%] } & \multirow{2}{*}{ connectivity [\%] } \\
\hline & mean & $\min$ & $\max$ & none & partial open & full & \\
\hline Cleebourg & 3.3 & 0 & 27 & 87 & 6 & 7 & 49 \\
\hline Leistadt & 1.2 & 0 & 5 & 89 & 7 & 4 & 40 \\
\hline Kammerforster & 0.7 & 0 & 3 & 100 & 0 & 0 & 35 \\
\hline Riesenstein & 0.8 & 0 & 3 & 100 & 0 & 0 & 20 \\
\hline
\end{tabular}

The highest fracture connectivity occurs within the fault zone in Cleebourg, where $49 \%$ of all measured fractures are interconnected. In the proximity of the fault core, i.e. within $5 \mathrm{~m}$ distance, the amount of connected fractures rises to $66 \%$. In contrast, in outcrops without fault zone exposure, only $20-40 \%$ of the fractures are interconnected (Table 6.2).

The vast majority of the observed fractures were not affected by mineralization. We observed $7 \%$ mineralized fractures only in the western outcrops (Table 6.2; Fig. 6.8). This mineralization comprise mostly quartz and baryte.

The mean fracture aperture in Cleebourg is about $0.8 \mathrm{~mm}$, and therefore lower than in Leistadt at $1.0 \mathrm{~mm}$. In Leistadt, the widest fracture apertures occur in fractures classified as partially open. They reach a maximum aperture of $14 \mathrm{~mm}$ and belong to the NW- to SE-striking set. In Cleebourg, the maximum fracture aperture is $7 \mathrm{~mm}$ and was observed in the $\mathrm{N}$ - to S-striking fracture set, close to the fault plane (Fig. 6.8). 


\subsubsection{Permeability data}
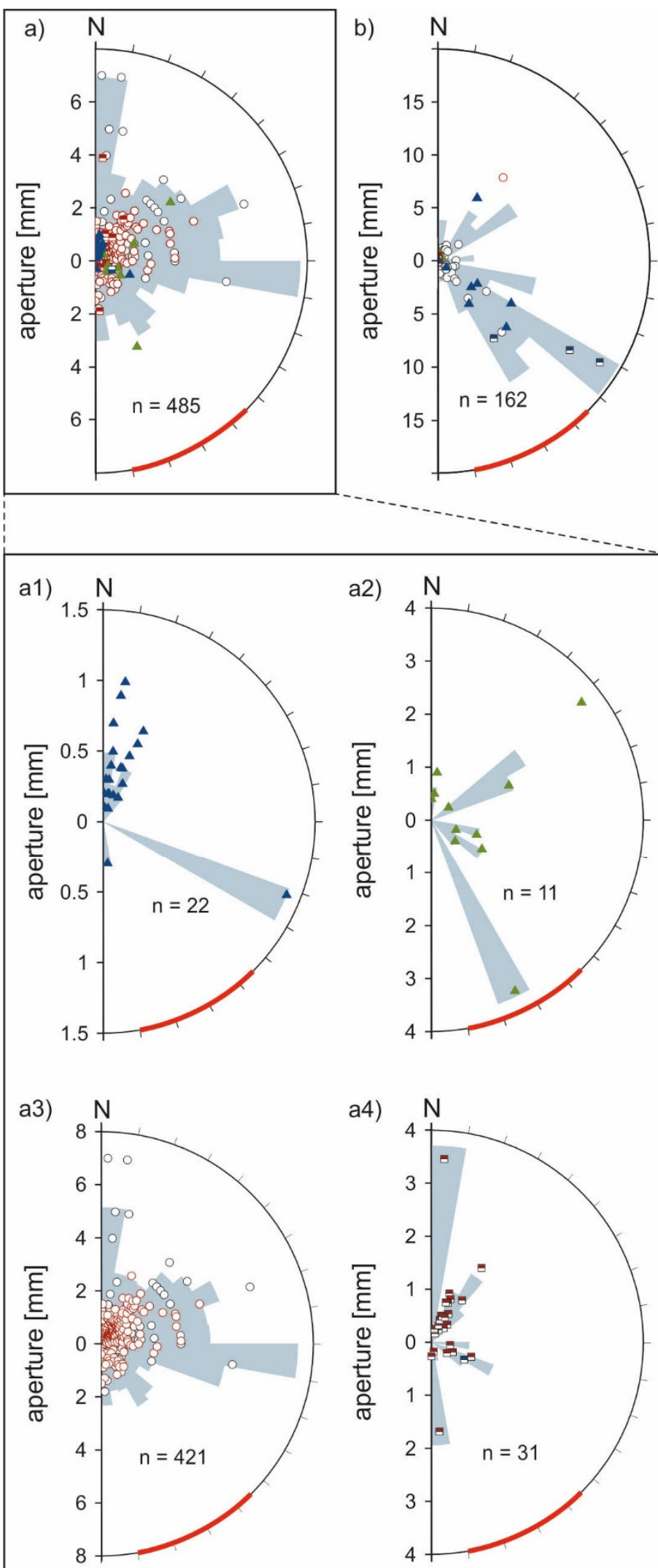

Matrix permeabilities of the outcrops, calculated using Eq. 6.1, range between $2 \cdot 10^{-13} \mathrm{~m}^{2}$ and $8 \cdot 10^{-13} \mathrm{~m}^{2}$ for the western outcrops, with the highest values determined for the Leistadt samples, followed by St and $\mathrm{SI}$ samples from Cleebourg (see Section 6.3.1). The matrix permeabilities at the eastern outcrops are about one order of magnitude lower (Fig. 6.9).

Structural permeabilities, derived using Eq. 6.2 , range between $10^{-10}$ and $10^{-13} \mathrm{~m}^{2}$ for Cleebourg and from $10^{-9}$ to $10^{-15} \mathrm{~m}^{2}$ in Leistadt, for the different fracture sets. Since fracture intensity and apertures in Cleebourg increase towards the fault plane, calculated fracture permeabilities follow this same trend. Main orientations of enhanced fracture permeabilities in Cleebourg change from N-S close to the fault core to NE-SW in the damage zone. In Leistadt, the estimated maximum fracture permeability was determined for the NW- SE-oriented fracture set and reaches values about one order of magnitude higher with respect to Cleebourg.

Figure 6.8: Half-circular diagrams showing the relation between fracture strike and apertures or thickness of fill, respectively. a) Cleebourg, a1) - a4) fracture data from the Cleebourg outcrop with adjusted scale for improved readability and b) Leistadt. Apertures from the eastern outcrops of Kammerforster and Riesenstein are not available. Rose diagrams scaled for mean aperture in $10^{\circ}$ bins. The bold red lines show the direction of the regional maximum horizontal compressive stress (NW-SE to NNW-SSE; Heidbach et al., 2008).

\begin{tabular}{lll} 
open & partial open & closed \\
\hline$\circ$ open & a quarz bridges & $\Delta$ mineralized \\
$\circ$ coloured/ bleached & $\approx$ Fe-Mn-coating & $\Delta$ debris/ clay
\end{tabular}




\subsection{Reservoir properties}

\subsubsection{Rock properties}

For depths between 3150 and $3282 \mathrm{~m}$ (MD), which covers almost the complete vertical extent of the reservoir, drill cuttings are available. From the cuttings, the rocks encountered in the well were classi-

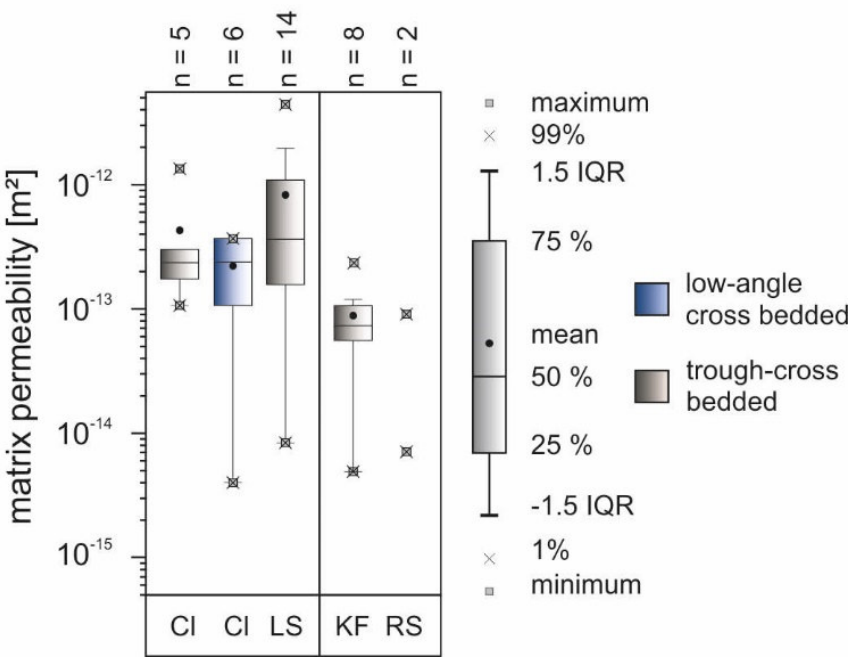

Figure 6.10: Box-whisker plot of the calculated matrix permeabilities. Outcrops ordered according to their location, from west to east, and colour coded according to fabric type. fied as light red to red-brownish sandstones, with grain sizes that reach from silt to coarsegrained sand which is well to poorly sorted. The mineralogical composition of the cuttings is predominantly subarkosic with low to tight porosity and high cementation (Reinecker et al., 2015). Typical sedimentary fabric types from FMI image logs comprise an alternation of horizontally and cross-bedded sandstone beds, interbedded by thin silty claystones (Reinecker et al., 2015).

The values of the gamma-ray log range between 20 and $104 \mathrm{API}$. Most values lie in a range between 35 and $83 \mathrm{API}$ (mean $60 \mathrm{API}$ ), with the lowest values in the middle of the reservoir. The strongest variations in the gamma-ray log occur at about 3270 to $3280 \mathrm{~m}$ and in the uppermost $20 \mathrm{~m}$ of the reservoir. There are two intervals with considerably higher API: $3180-3200 \mathrm{~m}$ and $3240-3270 \mathrm{~m}$ (Fig. 6.10a).

The recorded $v_{p} / v_{s}$ ratios range from 1.0 to 2.9 (Fig. 6.10b). The majority of the formation has $v_{p} / v_{s}$ ratios between 1.6 and 1.8, which are typical values for clean sandstone, whereas higher ratios may indicate higher clay content (Pickett, 1963). Equivalent to the gamma-ray log, the $v_{p} / v_{s}$ ratio shows strong variation at about $3200 \mathrm{~m}$, between 3270 and $3280 \mathrm{~m}$, and in the top $20 \mathrm{~m}$ of the well log (Fig. 6.10).

The log data presented in Figs. 6.11 and 6.12 are complete datasets. Data found to be unreliable are indicated as dashed lines (see Section 6.2.3) and were not included in further evaluation. 


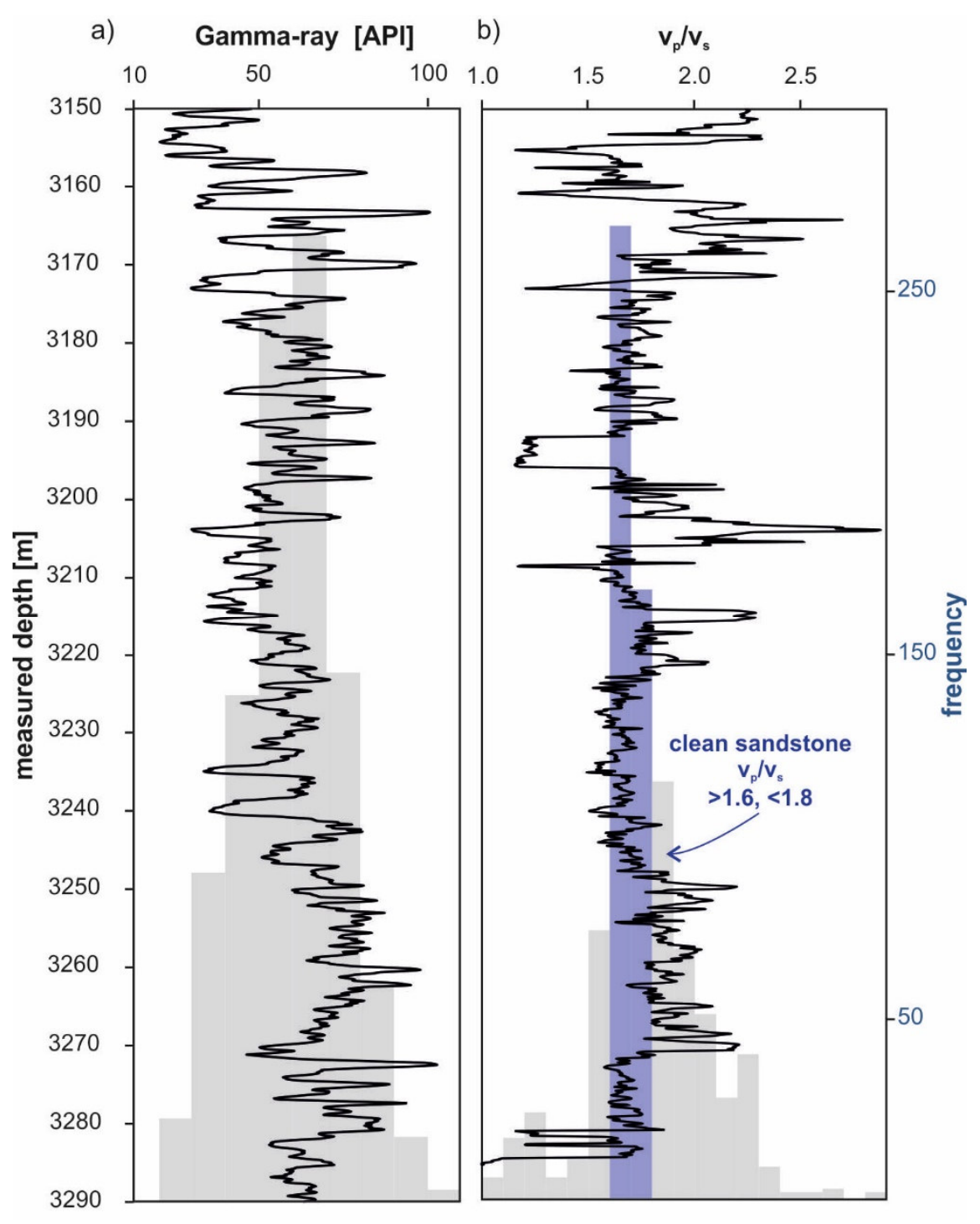

Figure 6.11: Vertical bore logs of lithological and mineralogical properties and corresponding histograms. a) Results from LDS gamma-ray log, implying reduced API values in the middle of the reservoir. b) Ratio of $\boldsymbol{v}_{\boldsymbol{s}}$ and $\boldsymbol{v}_{\boldsymbol{p}}$ wave velocities, used to determine the purity of the reservoir sandstone. Typical values for sandstone are marked in blue.

The calculated bulk densities under dry conditions in the reservoir lie between 1143 and $2648 \mathrm{~kg} \mathrm{~m}^{-3}$ (mean $2323 \mathrm{~kg} \mathrm{~m}^{-3}$ ), with the majority of data falling in the range between 2070 and $2534 \mathrm{~kg} \mathrm{~m}^{-3}$ (Fig. 6.11a). The bulk porosity, calculated according to Eq. 6.3, varies from 0 to $58 \%$ (mean about 13\%). Most of the determined porosity data lie between 5 and $22 \%$. There is a slight tendency towards higher bulk porosities with increasing depth until about $3240 \mathrm{~m}$, below which the porosity decreases. Matrix porosity (Eq. 6.4) varies in the range of 0 to $48 \%$ (mean 16\%). Common values lie between 3 and $27 \%$. The bulk porosities document a higher variability with depth, compared to the matrix porosity. Over large parts of the reservoir formation, however, the calculated bulk porosity is lower than the matrix porosity (Fig. 6.11b, d). 


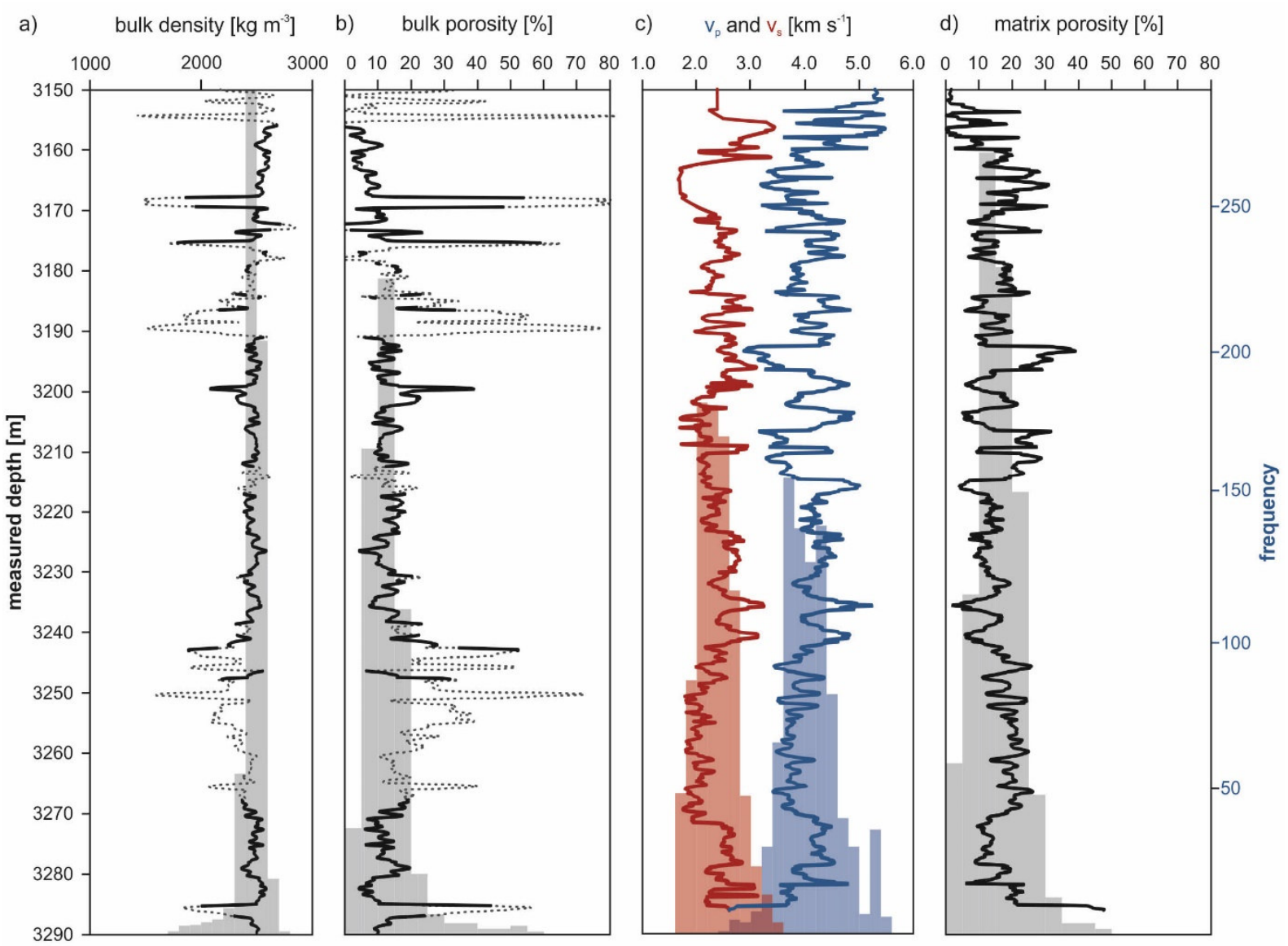

Figure 6.12: Vertical bore logs of rock properties and corresponding histograms. a) The bulk density as calculation basis for b) the bulk porosity. c) The compressional wave velocities (and additionally the shear-wave velocities) as calculation basis for d) the matrix porosity. The grey dotted lines show data rejected due to bad hole conditions.

The dynamic Young's Modulus of the reservoir formation was derived from DSI and LDS logs (Eq. 6.5). Even after removing unreliable data (see Section 6.2.3), the determined Young's Modulus covers a wide range of $2-71 \mathrm{GPa}$, where the majority of data lie between 20 and $46 \mathrm{GPa}$ and have a mean value of $34 \mathrm{GPa}$ (Fig. 6.12).

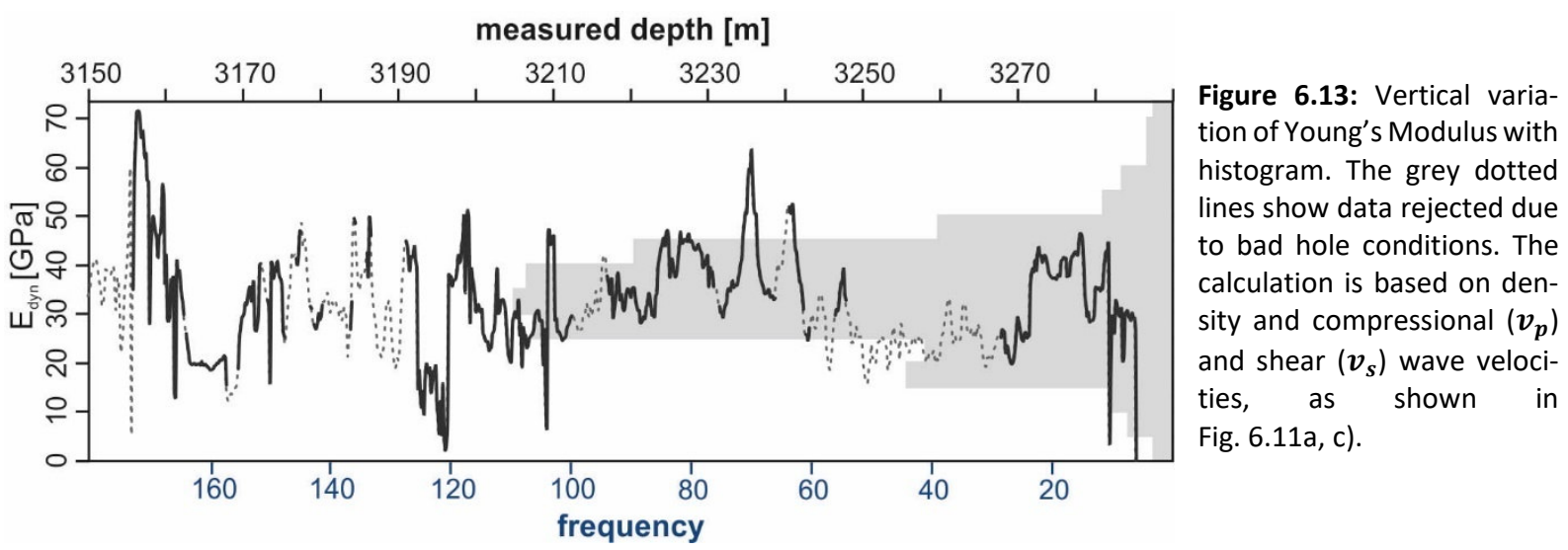




\subsubsection{Fracture-system parameters}

Fracture properties measured based on FMI logs comprise orientation, intensity, aperture, and mineralization (analysed and provided by J. Reinecker). Two different fracture systems, separated at a depth of $3270 \mathrm{~m}$, were identified.

Above $3270 \mathrm{~m}$, the main fracture set strikes NW-SE and NNW-SSE and may constitute a conjugate fracture set. Most of the fractures dip sub-vertically, and only a small amount dip less than $80^{\circ}$. Below $3270 \mathrm{~m}$, the fractures are differently oriented. Although the fractures probably also form a conjugate set, the strike of the fractures is rotated clockwise to a $\mathrm{N}$ - to NNE-direction. The dip component is considerably shallower, i.e. less than $80^{\circ}$, compared to the set above $3270 \mathrm{~m}$ (Fig. 6.13).

a)

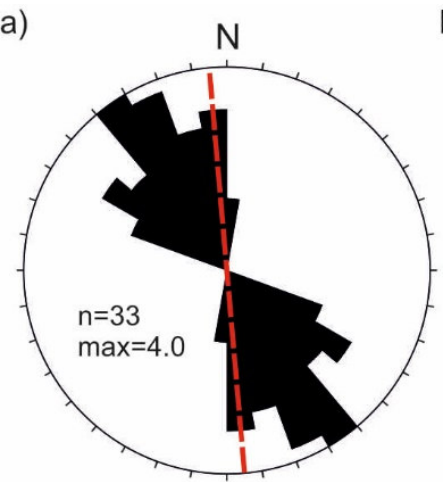

C)

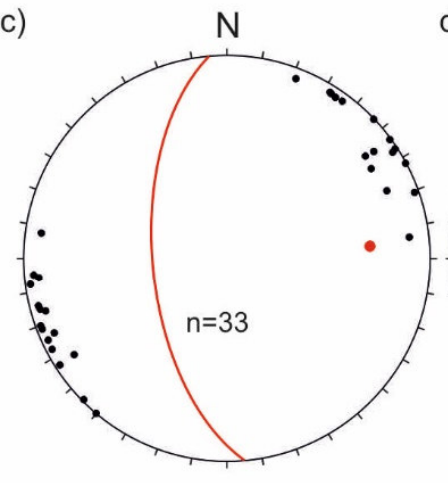

e)

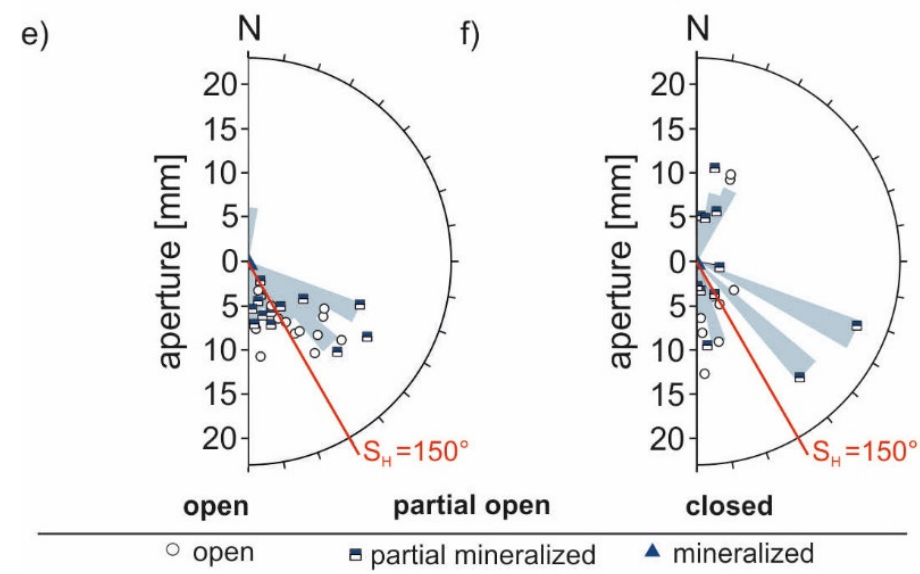

b)

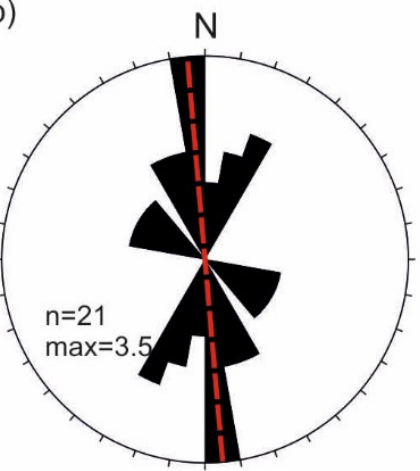

d)

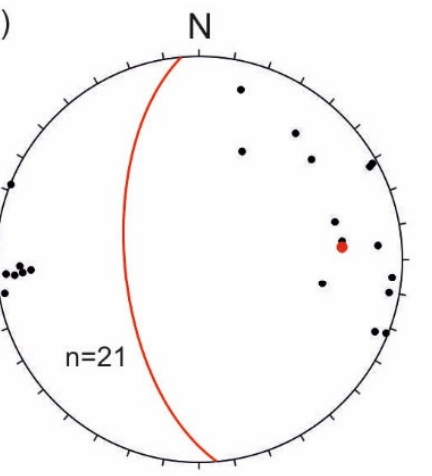

Figure 6.14: Fracture properties derived from the FMI log (analysed and provided by J. Reinecker). a), b) the fracture orientations, above and below $3270 \mathrm{~m}$ depth, respectively, in equal area-scaled rose diagrams with $10^{\circ}$ bin size. The dashed red line shows the strike of the fault that cuts through the reservoir. c) and d) Show the corresponding pole point plots (equal area, lower hemisphere) with the great circle showing the fault orientation. e), f) Half-circular diagrams showing the relation between fracture strike, with respect to aperture and fracture filling. Rose diagrams scaled for mean aperture for $10^{\circ}$ bins. The red lines indicate the local maximum horizontal stress direction from the well (Reinecker et al., 2015).

A large amount of the fractures are partially mineralized $(46 \%)$ or completely closed by mineralization (13\%). The observed fracture apertures span 3-22 mm (mean $8.5 \mathrm{~mm}$ ). The largest apertures were detected for partly-mineralized fractures, which deviate, in terms of orientation, by about $20^{\circ}$ anticlockwise from the main fracture set above and by $40-50^{\circ}$ below $3270 \mathrm{~m}$ (Fig. 6.12e, f). The maximum horizontal stress direction in the reservoir is about $\mathrm{N} 150^{\circ}$ (Reinecker et al., 2015). This means fractures striking $30^{\circ}$ counter clockwise from the main horizontal stress direction show the largest apertures.

The vertical fracture intensity varies between 0 and $6 \mathrm{~m}^{-1}$ (mean about $0.3 \mathrm{~m}^{-1}$ ).

Fractures seem to concentrate in four intervals, i.e. there are depth intervals that differ considerably with respect to fracture intensity (Fig. 6.14a). Decreasing fracture aperture with increasing depth, i.e. due to increasing confining pressure, is not observed. 
a) fracture aperture $[\mathrm{mm}] \quad$ fracture porosity SPI [\%]

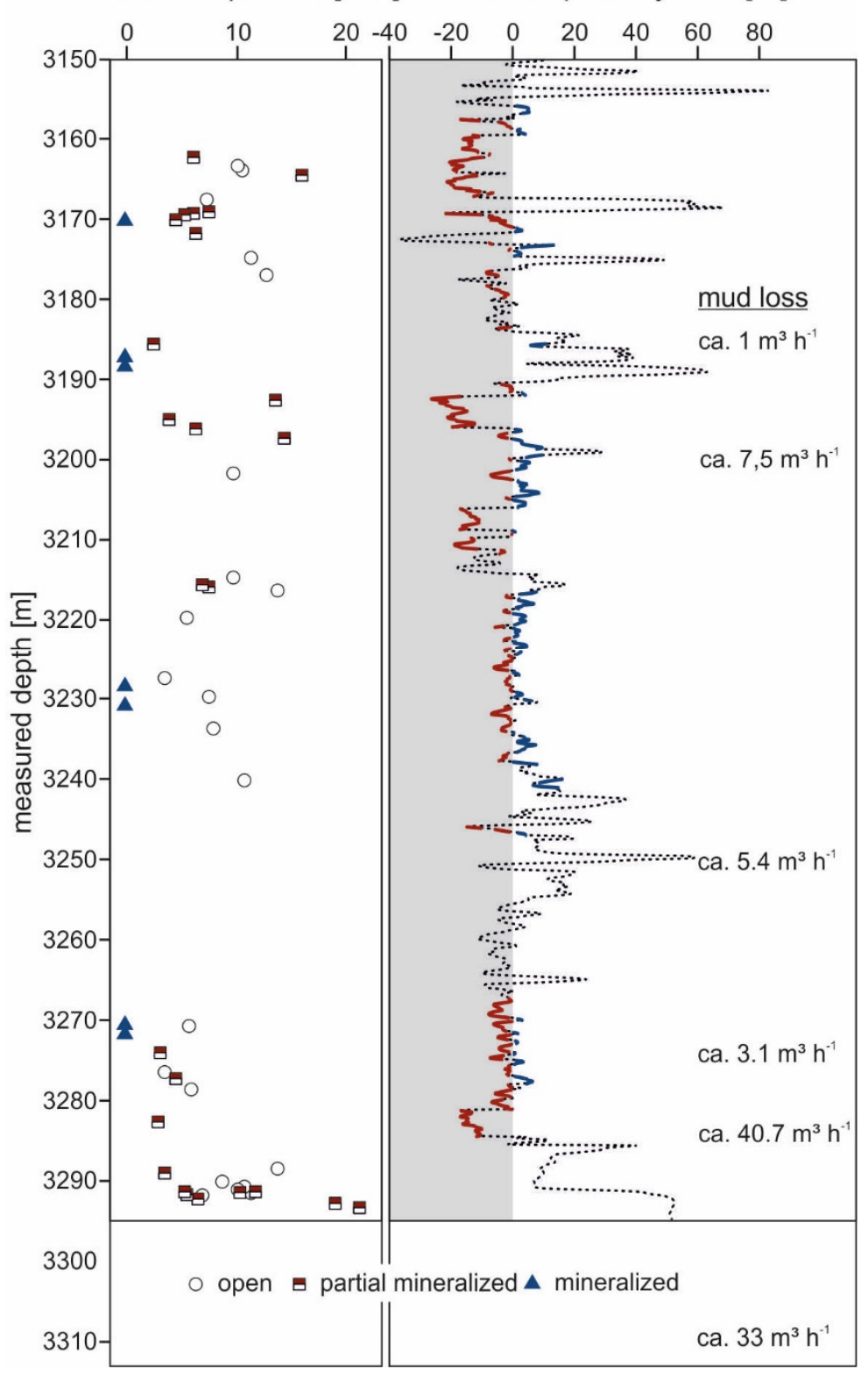

Figure 6.15: Plots showing the vertical variation of a) fracture aperture and b) the calculated fracture porosity (secondary porosity index), and observed mud loss during the drilling operation, as a proxy for the structural permeability. The grey dotted lines show rejected data, e.g. data found to be biased by bad hole conditions, red bold lines negative and blue bold lines positive fracture porosities.
Fracture porosity, as determined using the secondary porosity index (see Section 6.2.3), lies in a range between -26 and $43 \%$ with a mean of $3 \%$ (Fig. 6.14b), even if data classified as unreliable are excluded. However, excluding negative fracture porosity, the mean fracture porosity is $5 \%$.

Comparison of fracture apertures from FMI with the secondary porosity index (SPI) shows that high SPI values do not correspond to the higher amounts of detected fractures or vice versa (Fig. 6.14).

\subsubsection{Reservoir permeability}

Increased mud loss between 3200 and $3282 \mathrm{~m}$ depth and total mud loss below $3282 \mathrm{~m}$ depth indicates drastically increased permeability at this depth (Reinecker et al., 2015, Fig. 6.14). The high permeability was confirmed and quantified by injection and production tests.

In the production test, $1000 \mathrm{~m}^{3}$ thermal water was produced in $15,480 \mathrm{~s}$ ( $4 \mathrm{~h}$ and $18 \mathrm{~min}$ ), which corresponds to an average production rate (Q) of $65 \mathrm{I} \mathrm{s}^{-1}$. At the maximum production rate of $70 \mathrm{I} \mathrm{s}^{-1}$, the pressure drop was $0.28 \mathrm{MPa}$, equivalent to a productivity index of $29 / \mathrm{s}^{-1} \mathrm{bar}^{-1}$. During the injection test, $3084 \mathrm{~m}^{3}$ water was injected at $2.6 \mathrm{MPa}$ within $61,920 \mathrm{~s}(17 \mathrm{~h}$ and $12 \mathrm{~min})$, i.e. with a mean rate of $50 \mathrm{~s}^{-1}$. The maximum injection rate was $90 \mathrm{I} \mathrm{s}^{-1}$, which resulted in an injectivity index of $3.6 \mathrm{I} \mathrm{s}^{-1} \mathrm{bar}^{-1}$. The skin effect of the borehole is estimated from the difference between the pressure in the well before and directly after shut-in and amounts to $2.3 \mathrm{MPa}$. If the skin effect of the well is neglected, the injectivity index is $30 \mathrm{~s}^{-1}$ bar $^{-1}$. In consequence, the reservoir transmissivity (Eq. 6.6) reaches values of about $4.6 \cdot 10^{-4} \mathrm{~m}^{2} \mathrm{~s}^{-1}$, whereas the mean integrated reservoir permeability is about $7.2 \cdot 10^{-14} \mathrm{~m}^{2}$, according to Eq. 6.7. 


\subsection{Discussion}

The aim of this study was to evaluate to what extent the concept of outcrop analogue studies, as commonly applied in hydrocarbon exploration (Budding and Inglin, 1981; Keogh et al., 2007), could be used to improve predictions about the quality of geothermal reservoirs, with focus on permeability.

\subsubsection{Lithology}

The comparison of outcrop and well data show that rock properties that determine lithology, such as mineralogical composition and grain size, are in good agreement, despite some uncertainties in stratigraphic correlation. All rocks analysed fall into the fields of subarkose and lithic subarkose (Fig. 6.3), with medium to fine grain size, and a tendency for finer grain size towards the east (Fig. 6.4d), as previously reported by Reinecker et al. (2015) and Soyk (2015). The rocks in the reservoir cover a somewhat wider range of grain size and are less well sorted (Reinecker et al., 2015). The similar API values for the outcrops (77-97 API) and the reservoir rocks (35-85 API; Reinecker et al., 2015) show that the clay contents are comparable. Also, the rock facies, as confirmed by fabric types, are comparable between surface and sub-surface (Reinecker et al., 2015).

\subsubsection{Cementation and porosity}

Quartz cementation, which has a direct effect on rock properties, such as density, porosity, and strength, has a trend at the surface which increases from west ( $3-7 \%$ ) to east ( $3-23 \%$; Fig. 6.5b). These findings agree with observations made by Soyk (2015) and with the observations in the reservoir, where the quartz cementation of cuttings is described as high (Reinecker et al., 2015). However, the highly variable quartz cementation in the eastern outcrops does not cause high variability in porosity $(3-8 \%)$ and density $\left(2117-2592 \mathrm{~kg} \mathrm{~m}^{-3} ; \mathrm{Fig} .6 .4 \mathrm{a}, \mathrm{b}\right)$. In the west a wide range in porosity is observed $(2-22 \%)$, where the quartz cementation is well defined in a narrow range (Fig. 6.4). In the reservoir, "high" quartz cementation is accompanied by a highly variable matrix porosity ( $0-27 \%$; Fig. 6.11d). Thus, even though direct correlation between porosity and cementation is impossible for the reservoir, since cementation has only been reported from drill cuttings, the cementation to porosity ratio appears to be inconsistent with that observed at the surface. Rock density seems to be comparable between reservoir and the eastern outcrops. The fact that strong variation in cementation does not cause strong variation in porosity might be due to the fact that during diagenesis, the rocks were subjected to different conditions. While early cementation may initially reduce the matrix porosity, during burial it may also counteract further porosity loss due to compaction. Consequently, late cementation may cause high cementation rates in rocks that already have been compacted, i.e. that already have low porosity (e.g., Ehrenberg, 1989; Ramm and Bjorlykke, 1994; Molenaar et al., 2007).

Differences in the burial and thermal history of the Buntsandstein (e.g., Steingötter, 2005; Clauer et al., 2008; Rupf and Nitsch, 2008; Soyk, 2015) and thus regional diagenesis have been described for the URG. Furthermore, the complex structural geology has likely caused strong heterogeneities, e.g. along deep-seated faults that may provide preferred pathways for fluids and thus have locally strong effects on cementation and porosity. Thus the prediction of porosity and cementation, in a lateral and vertical sense, is difficult for the Buntsandstein of the URG. However, in a less complex structural situation, with knowledge of original rock composition, thermal, and diagenetic history, it may be possible to better predict porosity. 


\subsubsection{Rock mechanical properties}

The values determined for tensile and compressive strength from the outcrop samples follow a trend that is consistent with increasing quartz cementation and decreasing porosity from east to west (Figs. 6.4 and 6.5). Average dynamic Young's Moduli determined for the outcrops span from $35 \mathrm{GPa}$ in the west to $64 \mathrm{GPa}$ in the east (Figs. 6.4 and 6.5). In the reservoir, the determined average dynamic Young's Modulus is $34 \mathrm{GPa}$ (Fig. 6.12). This means the outcrops closest to the reservoir have dynamic Young's Moduli almost twice as high as those obtained from the reservoir. Since dynamic as well as static Young's Moduli increase with depth (e.g., Carlson and Gangi, 1985; Holt et al., 2005), Young's Modulus at reservoir depth should therefore be higher than at the surface. Thus, Young's Modulus at reservoir depth has been highly underestimated. This agrees with the high porosity (e.g., Dunn et al., 1973; Palchik, 1999; Palchik and Hatzor, 2004), as reported from the well logs, but not with the high quartz cementation reported from the drill cuttings. The other rock mechanical parameters cannot be compared since measurements of tensile-, and compressive strength are not feasible in the well. However, based on the poor correlation of porosity, cementation, and density, one can expect that they are also highly variable in the reservoir.

Variable mechanical rock properties also influence the development of fracture systems (Narr and Suppe, 1991; Gross et al., 1995; Odling et al., 1999; Gross and Eyal, 2007; Laubach et al., 2009). Since fracture systems, besides matrix permeability, are most essential in geothermal energy, because they provide a large part of the permeability (e.g., Snow, 1965; Witherspoon et al., 1980; Nelson, 1985; Hestir and Long, 1990; Bear, 1993), detailed knowledge of fractures in the reservoir is desirable.

\subsubsection{Fracture-system parameter and permeability}

The fracture orientations derived from the outcrops in this study show a degree of similarity; for instance, a common NE-SW set exists, and in three of the four outcrops a second NW-SE group occurs (Fig. 6.6). However, other studies carried out in this region (e.g., Peters, 2007; Dezayes et al., 2015; Meier et al., 2015) show that a wider range of fracture patterns have been observed in this area. In addition, we found that in the Cleebourg outcrop with fault zone exposure, individual layers host different fracture systems (Fig. 6.7). Both observations suggest that the permeability-controlling fracture patterns are difficult to predict in the study area. This assumption is further supported by the two fracture patterns that were identified in the well, based on FMI data (Fig. 6.13; Reinecker et al., 2015). None of these fracture patterns coincides with those observed at the surface. At a depth of about $3275 \mathrm{~m}$, i.e. the depth at which the total mud loss occurred, and where the API values are increased (Fig. 6.10a), a fault is expected based on the seismics (Lotz, 2014a). We propose that it is likely that this fracture system belongs to the damage zone of the fault, rather than reflecting the regional trend.

The fracture intensity is comparable among the outcrops, but significantly increases in Cleebourg where a fault is exposed. The same holds for the fracture connectivity, which is highest in Cleebourg. In the Brühl GT1 well, the upper fracture system appears to be dominated by a conjugate sub-vertical fracture set, and is thus likely to be poorly connected. This assumption is supported by the low to moderate mud loss in this section. In the lower fracture system, in contrast, the fractures dip shallower and have a higher variability in strike, which favours better connectivity (Fig. 6.13), supported by the increasing mud loss at this depth (Fig. 6.14b). However, from the FMI log, as well as from the secondary porosity index (fracture porosity), increased fracture intensity, at the depth where the fault is expected, cannot be confirmed (Fig. 614b). 
The average fracture apertures observed at the surface range from $0.8 \mathrm{~mm}$ in Cleebourg (range: $0.1-7 \mathrm{~mm}$ ), to $1.0 \mathrm{~mm}$ in Leistadt (range: $0.1-14 \mathrm{~mm}$ ), whereas the apertures derived from the FMI are, on average, $8.5 \mathrm{~mm}$ (range: $3-22 \mathrm{~mm}$; Figs. 6.8, 6.13, and 6.14a). Thus, the apertures at depth are reported to be about one magnitude of order larger, despite the higher confining pressure. When utilizing these data, and using the cubic law (Eq. 6.2) to roughly estimate and compare structural permeabilities between outcrop and reservoir conditions, we show that the structural permeability for the different fracture orientations in the outcrops lies between $10^{-9}$ and $10^{-15} \mathrm{~m}^{2}$ (Leistadt), and $10^{-10}$ and $10^{-13} \mathrm{~m}^{2}$ (Cleebourg). In the reservoir, based on $\mathrm{FMI}$, it is in the range of $10^{-9}-10^{-11} \mathrm{~m}^{2}$. The bulk permeability of the reservoir determined by the pumping tests is $10^{-14} \mathrm{~m}^{2}$, and thus estimates of the structural permeability, only based on $\mathrm{FMI}$, are three to five orders too high, but close to outcrop data. This apparent overestimation of bulk permeability by FMI might, for example, result from excessive tool standoffs due to bad hole conditions or to the common enlargement of fractures close to the well (Luthi and Souhaité, 1990). Notably, also the fracture porosity of about $5 \%$ determined with the SPI is about three orders higher than typical values (e.g., Snow, 1968; van Golf-Racht, 1982). This and the fact that SPI values and FMI fracture locations do not correspond are strong indicators for technical problems and/or bad hole conditions during logging.

Bulk permeability can be controlled by few fractures with considerably larger apertures (e.g., Snow, 1965, 1969; Witherspoon et al., 1980; Nelson, 1985; De Marsily, 1986; Hestir and Long, 1990; Bear, 1993). These may be at least to a certain degree provided by partly mineralized fractures, or by fractures favourably oriented to the present-day stress field. Partially mineralized fractures and fractures sub-parallel to the recent major stress direction are both reported to provide larger apertures (e.g., Teufel et al., 1991; Heffer and Lean, 1993; Laubach et al., 2004; Marrett et al., 2007; Singhal and Gupta, 2010, Figs. 6.8 and 6.13). The observations in the outcrop Leistadt and in the reservoir confirmed that partly mineralized apertures are wider compared to barren fractures. However, aperture and the main horizontal stress direction do not correlate in general. For instance, the widest fracture apertures in the Leistadt outcrop are sub-parallel to the regional maximum horizontal stress direction, while they deviate in Cleebourg by about $45^{\circ}$ and in the well by about $30^{\circ}$ counter clockwise from the maximum horizontal stress direction. Reasons for the observed mismatch at the surface could be disturbances in the local stress field caused by topography or faults (Barton and Zoback, 1994). The mismatch in the reservoir, where the present-day stress orientation was determined by borehole breakouts, shows that the concept, even under perfect conditions, is not generally applicable and should thus be applied with caution. Fractures that have an acute angle of about $20-30^{\circ}$ to the maximum horizontal stress direction, as observed in the well, are subject to a high shear component. It has been shown, for example, by Barton et al. (1995) and Rogers (2003) that such fractures can constitute preferable pathways for fluid flow. Noteworthy, also fracture sets normal to the maximum compressive stress were reported by Laubach et al. (2016) to provide high permeabilities over long time spans.

\subsection{Summary and conclusions}

It is commonly thought that, if an outcrop is of the same formation and depositional facies, it may serve as an analogue to derive in-depth knowledge about the conditions in the envisaged reservoir. However, this statement on outcrop analogue studies constitutes the "classic chicken and egg problem", because the appropriateness of any given outcrop is unknown until the reservoir itself has been analysed. This requires that the cost-intensive drilling process is at least advanced before analogue outcrops are sought out. 
In the example presented here, the comparison of the data derived from outcrop and well logs shows that, in particular, the most relevant parameters for geothermal energy exploitation, i.e. the fracture system and porosity, show notable differences and cannot be extrapolated from the surface to reservoir depth. We conclude that the concept of outcrop analogue studies, based on standard methods, has, in this case, limited potential to minimize exploration risk for this fault-related geothermal reservoir.

The main reasons for the differences in observations are attributed to two facts. Firstly, the URG is a complex geological area, i.e. the area underwent a multiphase deformation history, and is characterized by sedimentary rocks that show strong facies changes at a small scale. Given, however, a less complex setting, knowledge of original rock composition, thermal history, and fracture timing should improve comparison and prediction of cementation (Lander et al., 2008; Lander and Laubach, 2015) and thus allow mechanical rock properties to be better determined.

Secondly, the fact that the reservoir is fault controlled introduces an extra amount of uncertainty, since fault and fracture architecture and therefore the hydraulic characteristics can undergo significant changes that depend on a variety of different factors and their interplay, e.g. host rock lithology, displacement, pre-existing structures, temperature, depth, time, and stress conditions (e.g., Caine et al., 1996; Schulz and Evans, 2000; Shipton and Cowie, 2001; Lunn et al., 2008; Faulkner et al., 2010; Bense et al., 2013).

We conclude that in our study area the outcrops are simply unfavourable as a reservoir analogue. Aiming for fault-related fractured reservoirs can, under the right circumstances, promise increased structural permeability, but at the same time this significantly lowers the chance to predict the reservoir conditions from surface outcrops. Conversely, outcrop analogue studies have a higher potential to produce meaningful results in homogenous areas such as large basins that do not have complex internal structures.

To further improve the concept of analogue studies, the next step must be to identify ranges within which essential parameters must be determined, to allow for an early evaluation of the quality of a reservoir.

\section{Acknowledgments}

The authors appreciate the support of the German Federal Ministry for Economic Affairs and Energy (BMWi) and previously the German Federal Ministry for the Environment, Nature Conservation, and Nuclear Safety (BMU), as part of the Research and Development Project AuGE (Outcrop Analogue Studies in Geothermal Exploration) within the framework of the 5th Energy Research Program (FKZ 0325302). Our thanks to Prof. Dr. S. Siegesmund for permission to use the tectonic laboratory and to Dr. John Reinecker for providing well data. 


\section{Numerical sensitivity study of parameters that control the quality of geo- thermal reservoirs}

\subsection{Introduction}

In the last chapter, I showed that many of the parameters that control the quality of a geothermal reservoir (e.g., porosity, permeability, permeability's anisotropy) are difficult to predict and often only a wide range of parameter values can be provided. Therefore, it is desirable to investigate which of the parameters exert the major control on the reservoir's performance over time and with which accuracy they must be predicted to allow for a reasonable estimate of the geothermal reservoir's quality. This is of importance since the exploitation of geothermal reservoirs is not only subject to high exploration risks, but also to high initial costs (Paschen et al., 2003; URL3: Bundesverband Geothermie). In consequence, a geothermal reservoir must operate over a minimum time period, typically several decades, to reach the break-even point. The end of the performance of a geothermal reservoir is commonly reached, if at a given flowrate, the production temperature falls below a certain threshold, i.e. the amount of energy produced per unit time becomes too low (Paschen et al., 2003; Schulz, 2011). The uncertainties of these predictions have been underlined by several examples of initially-successful deep geothermal projects that suddenly were subject to an unexpected drop in temperature (e.g., Bödvarsson and Tsang, 1982; Horne, 1982a, b; MacDonald et al., 1992; Beall et al., 1994; Parini et al., 1996; Ocampol et al., 1998; Tenma et al., 2008) and in consequence never reached a profitable life span.

The most important parameters in exploration for geothermics comprise temperature and permeability, as well as a number of rock physical parameters (e.g., porosity, petrography), and fluid properties (e.g., viscosity, and chemical composition). Based on this information, predictions on a reservoir's performance over time are commonly carried out using analytical and numerical models (e.g., Gringarten and Sauty, 1975; Gringarten et al., 1975; Bödvarsson and Tsang, 1982; Bakhsh et al., 2016; Gan and Elsworth, 2016; Li et al., 2016).

In modern geothermal facilities, the geothermal waste water is reinjected. This is mandatory due to environmental concerns regarding toxic components of the fluid (e.g., fluorine (F); cadmium (Cd); boron (B), arsenic (As), radioactive minerals) and to maintain reservoir pressure (e.g., Bödvarsson and Tsang, 1982; Horne, 1982a; Shook, 2001). However, reinjecting cold waste water can result in a complex interplay between the natural flow field and the circulation induced by production and reinjection of the geothermal fluid (Bense et al., 2013). Thus, negative effects on the thermal development of the reservoir can be expected that have the potential to reduce the reservoir's performance. These effects might be expressed either as generally lower temperatures of the produced geothermal water and/or in a reduced time to thermal breakthrough (Bödvarsson and Tsang, 1982; Horne, 1982a).

In the following I present a 4D numerical sensitivity study carried out using the software package COMSOL Multiphysics. The main objective of this study is to evaluate, using simplified models, how varying lithological- and structural parameters affect the fluid circulation between hydrogeothermal doublets (i.e. the convective fluid transport) and thus the thermal development of a reservoir. This sensitivity study aims 1 ) to determine the most important parameters needed to evaluate geothermal exploration, 2) to estimate ranges of accuracy for these parameters that should serve as reliable input parameters for modelling, and 3 ) to provide a ranking of the most promising reservoir configurations. 
I inspect the thermal breakthrough times, geometry, and size of the heat transfer volume. The range of input parameters I used in the models for e.g. porosities, permeabilities, and permeability anisotropies were obtained from outcrop and wellbore data in the lower Triassic (Buntsandstein) of the Upper Rhine Graben (URG). I decide to set the thermal breakthrough temperature to $100^{\circ} \mathrm{C}$, because this is the minimum temperature binary cycles can use to produce economically electricity (e.g., DiPippo, 2005; PK-Geothermie et al., 2007; Schulz et al., 2009; Schulz, 2011).

\subsection{Justification of Model parameters}

My sensitivity study comprises a large suite of numerical models, in which I successively varied the hydraulic gradient direction and height (see Section 3.4.3), material, and structural parameters to identify their importance, interplay, and in consequence their effect on the thermal development of geo-

Table 7.1: Material properties used for all models

\begin{tabular}{|c|c|c|c|}
\hline parameter & symbol & values & unit \\
\hline \multicolumn{4}{|l|}{ fluid properties } \\
\hline density & $\rho$ & 1100 & $\mathrm{~kg} \mathrm{~m}^{-3}$ \\
\hline heat capacity & $c_{p}$ & 4200 & $\mathrm{~J} \mathrm{~kg}^{1} \mathrm{~K}^{-1}$ \\
\hline thermal conductivity & $k$ & 0.6 & $W m^{-1} K^{-1}$ \\
\hline viscosity & $\mu$ & 280 & Pa s \\
\hline \multicolumn{4}{|l|}{ rock properties } \\
\hline density & $\rho$ & 2400 & $\mathrm{~kg} \mathrm{~m}^{-3}$ \\
\hline heat capacity & $c_{p}$ & 670 & $\mathrm{~J} \mathrm{~kg}^{1} \mathrm{~K}^{-1}$ \\
\hline thermal conductivity & $k$ & 2.6 & $W m^{-1} K^{-1}$ \\
\hline
\end{tabular}

Table 7.2: Default values for porosity and permeability and corresponding model codes used in the different scenarios. From left to right increasing permeability $(\kappa)$ and from top to bottom increasing porosity $(\boldsymbol{\theta})$.

\begin{tabular}{c|c|c}
\hline M1: & M2: & M3: \\
$\kappa=10^{-15} \mathrm{~m}^{2} ;$ & $\kappa=10^{-13} \mathrm{~m}^{2} ;$ & $\kappa=10^{-11} \mathrm{~m}^{2} ;$ \\
$\theta=0.03$ & $\theta=0.03$ & $\theta=0.03$ \\
\hline M4: & M5: & M6 \\
$\kappa=10^{-15} \mathrm{~m}^{2} ;$ & $\kappa=10^{-13} \mathrm{~m}^{2} ;$ & $\kappa=10^{-11} \mathrm{~m}^{2} ;$ \\
$\theta=0.14$ & $\theta=0.14$ & $\theta=0.14$ \\
\hline M7: & M8: & M9: \\
$\kappa=10^{-15} \mathrm{~m}^{2} ;$ & $\kappa=10^{-13} \mathrm{~m}^{2} ;$ & $\kappa=10^{-11} \mathrm{~m}^{2} ;$ \\
$\theta=0.25$ & $\theta=0.25$ & $\theta=0.25$ \\
\hline
\end{tabular}
thermal reservoirs. For a detailed scenario description, see Section 3.4.2. The necessary material parameters for the coupled heat- and fluid transport (Eqs. 3.6, 3.9, and 3.10) are: The heat capacity $\left(c_{p}\right)$, the thermal conductivity $(k)$, the density $(\rho)$, the fluid viscosity $(\mu)$, the porosity $(\theta)$, and the permeability $(\kappa)$.

The heat capacity of rocks is considerably lower than that of fluids. The thermal conductivity of rocks on the contrary is significantly higher than that of fluids (Sydney and Clark, 1966). Both parameters are strongly coupled due to the rock's pore space which at depth is commonly fluidsaturated, and are thus calculated as a balanced composition in COMSOL (Eqs. 3.7 and 3.8). Since, $k \quad\left(2.5-2.8 \quad\left[\mathrm{~W} \mathrm{~m}^{-1} \mathrm{~K}^{-1}\right]\right)$ and $c_{p}$ $\left(650-720\left[\mathrm{~J} \mathrm{~kg}^{1} \mathrm{~K}^{-1}\right]\right)$ of dry sandstones only vary over a small range (PK-Geothermie et al., 2007; Stober et al., 2011; Bär, 2012) and have only minor relevance in hydrogeothermal facilities (PK-Geothermie et al., 2007; Schulz et al., 2009; Stober et al., 2011), I do not specified them separately throughout the model suite. and 3.4.3; Table 7.1). Therefore, my numerical models focus on permeability and porosity variations (Table 7.2; Fig. 7.1). The range of variations I applied is typical for the study area (Fig. 7.1) and thus used throughout the model suite. 
permeability $\left[\mathrm{m}^{2}\right]$
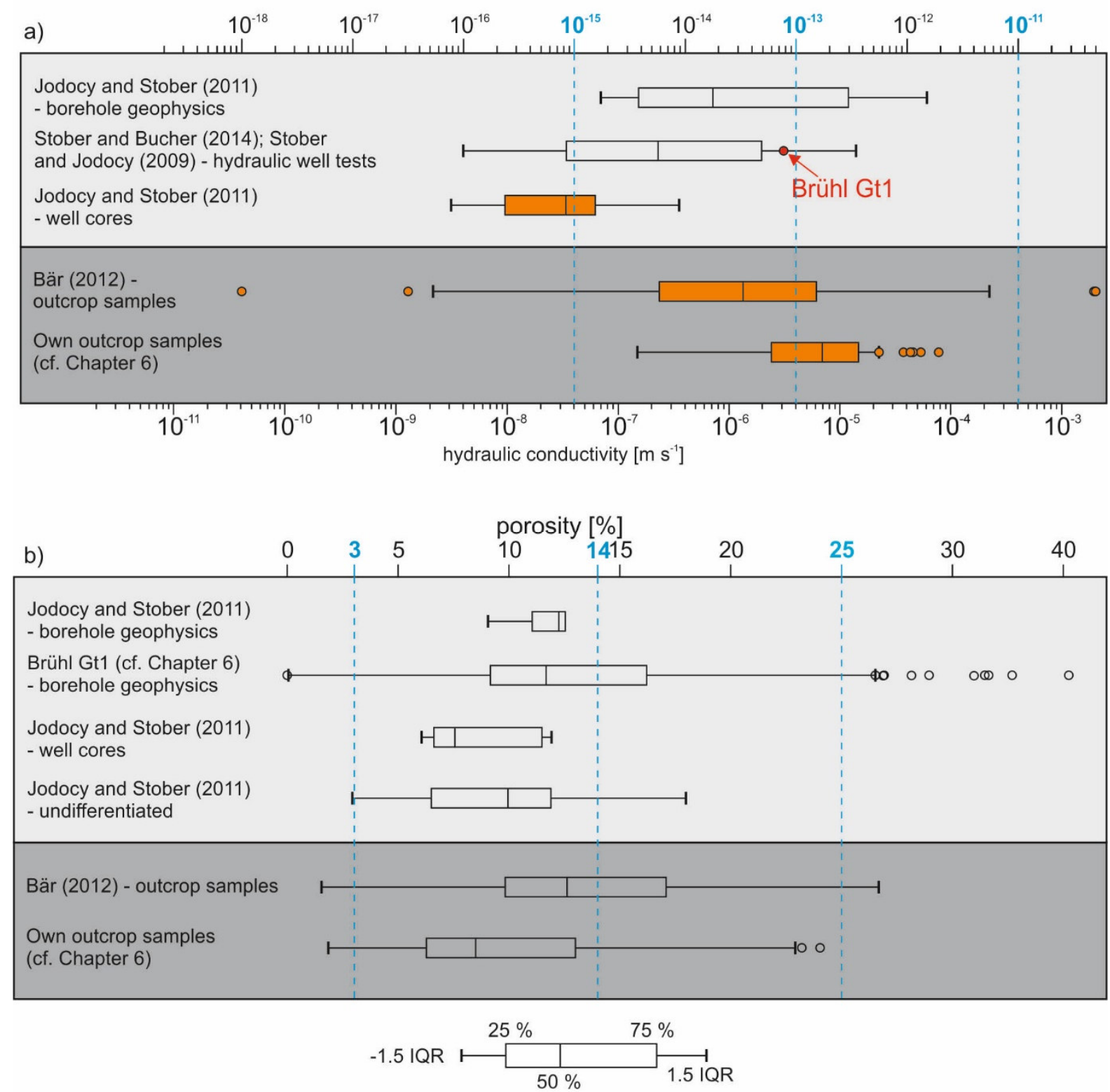

Figure 7.1: Permeability and porosity values listed by method, and sub-surface (light grey) and surface (dark grey) data from Buntsandstein rocks of the URG and adjacent areas. a) Permeability and corresponding hydraulic conductivity. Orange and grey bars represent pore permeability and bulk permeability values, respectively. b) Porosity [\%]. The default parameters I used in this study are shown in blue.

The model M5 (Table 7.2), with medium permeability and porosity, represents the benchmark parameters needed for geothermal electricity generation, according to e.g., Jung et al. (2002), and URL3: Bundesverband Geothermie. The model suite comprises five basic scenarios. In scenario 1, I investigate the general effect of changing porosity and permeability in a homogenous rock volume. In the scenarios 2 to 5 , I successively increase the model's complexity by introducing sedimentary layers, fractureinduced permeability anisotropy, and fault zones. Reservoir-confining layers (referred as claystone layers) are assigned with permeability values of 1 to 4 orders of magnitude lower than that of the reservoir layers (referred to as sandstone layers). Fracture anisotropy was simulated by values that are 1 to 3 orders of magnitude higher in different directions. The default parameter I use for the fault core permeability is $10^{-18} \mathrm{~m}^{2}$, while damage zone(s) have values 1 to 4 orders of magnitude higher than the host rock. 


\subsection{Results of the sensitivity study}

\subsubsection{Scenario 1 (S1): Homogeneous reservoir volume}

In scenario 1, I test, using homogeneous and isotropic models, the influence of permeability and porosity, under hydraulic gradients of varying height and direction, on the propagation of the thermal front in a geothermal reservoir. My aim here was to initially identify their interplay and their influence on structure-independent temperature development.

In models with low permeability (M1, M4, M7; Table 7.2; Fig. 7.2a, d), only the porosity influences the propagation of the $100^{\circ} \mathrm{C}$ isothermal (HIT). However, with increasing permeability the hydraulic gradient gains influence on the reservoir's performance, while the relative impact of porosity ceases (Fig. 7.2b-c, e-f).
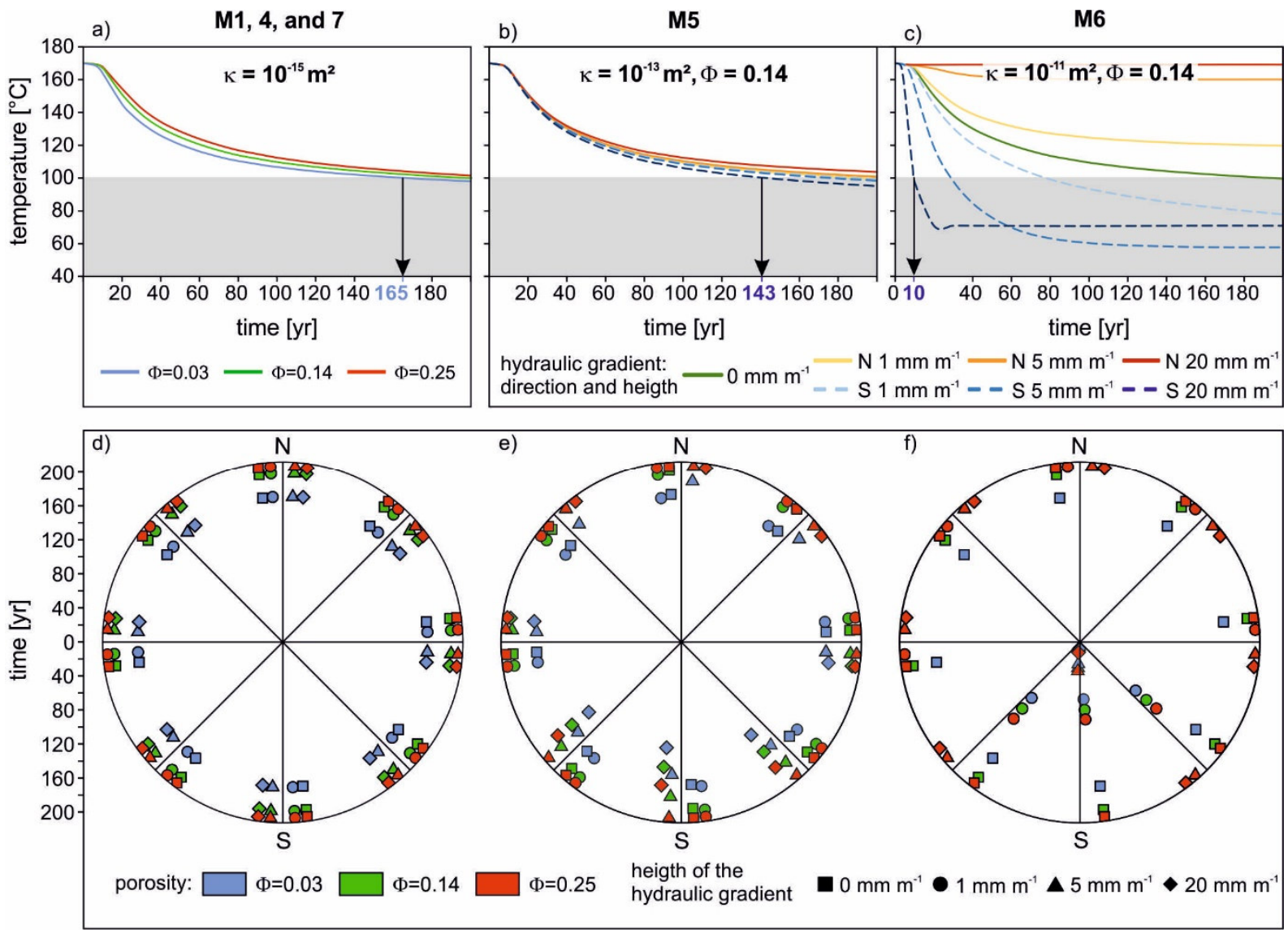

Figure 7.2: Temperature development and breakthrough times of homogeneous reservoir volume, depending on the permeability, porosity, and hydraulic gradient configuration. a to c) show the temperature development of the produced fluid over time. The reservoir's permeability increases from left to right. Only north- and southward-directed gradients are shown. In a) the temperature development depending on the porosity value is presented. The influence of the hydraulic gradient is not noticeable. In b) and c) the porosity is set to 0.14 the influence of the height of the hydraulic gradient increases with permeability. $\mathbf{d}$ to $\mathbf{f}$ ) show polar plots of the breakthrough times for all model configurations with increasing reservoir permeability from left to right. The segment of the circle indicates the direction of the hydraulic gradient. The distance from the centre indicates the time to thermal breakthrough. The individual temperature development of the nine basic models are shown in Appendix 2.2 - Fig. A3.

Depending on the height and direction of the hydraulic gradient, I observed in this model suite breakthrough times from $8 \mathrm{yr}$ to infinite $(>200 \mathrm{yr}$ ). With the shortest breakthrough times observed in the high permeability and low porosity model (M3; Table 7.2), for the case of a southward directed hydraulic gradient of $20 \mathrm{~mm} \mathrm{~m}^{-1}$ (Fig. 7c, f; Appendix 2.2 - Fig. A3c). 
In cases with no assigned hydraulic gradient (green lines in Fig. 7.2a-c) or when the required pumping pressure to achieve flow rates of $75 \mathrm{I} \mathrm{s}^{-1}$ exceeds the natural hydraulic gradient (low permeable models), the induced pressure difference in the wells controls the fluid flow regime. The result is that the HIT forms a spherical body (Fig. 7.3a). In consequence, I deduce that the expansion of the HIT is independent of permeability and only controlled by porosity; higher porosities result in a higher lifetime of the reservoir (Fig. 7.2a, d). With increasing hydraulic gradient height, assigned to the medium and high permeability models, the shape of the exploited reservoir volume becomes ellipsoidal, i.e. the exploited reservoir volume becomes smaller (Fig. 7.3b, c; Appendix 2.2 - Fig. A4). This effect becomes stronger with increasing permeability and lead to an increasing effect of the hydraulic gradient direction and height.

In the simulations with southward directed gradient i.e. natural fluid flow direction is oriented from the injection to the production well, the HIT very quickly reached the production well (Fig. 7.3b). Northward directed hydraulic gradients, however, hindered the HIT reaching the production well (Fig. 7.3c).

a)

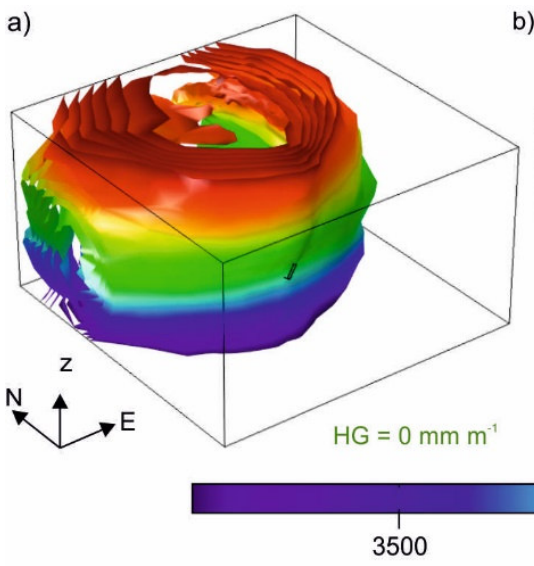

b)

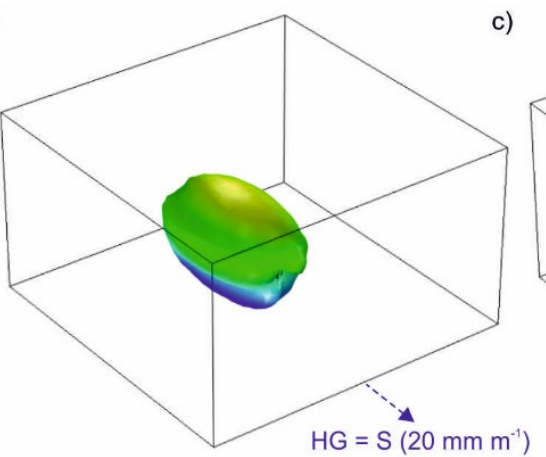

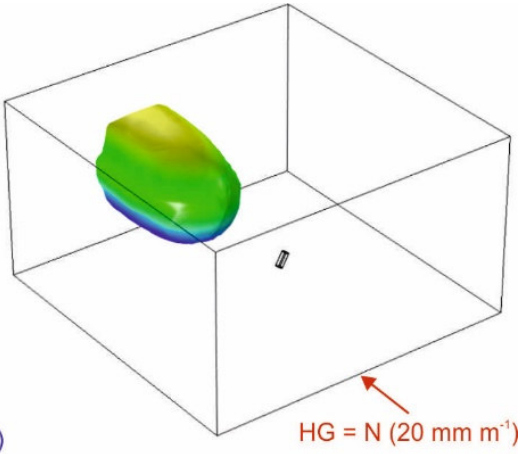

Figure 7.3: Effect of variable hydraulic gradient (HG) directions on the reservoir shape in homogeneous reservoir models. Figures show the HIT for the medium porosity and high permeability model (M6) after $160 \mathrm{yr}$ of heat production. In a) no hydraulic gradient, b) southward-directed hydraulic gradient with a height of $20 \mathrm{~mm} \mathrm{~m}^{-1}$, and c) a northward-directed hydraulic gradient with a height of $20 \mathrm{~mm} \mathrm{~m}^{-1}$. The complete sequence of figures for the $\mathrm{M} 6$ model of all hydraulic gradient configurations is shown in Appendix 2.2- Fig. A4. The HIT is colour-coded for depth.

Notably, the hydraulic gradient's importance is stronger when the reservoir permeability reaches values that are recommended for economical electricity production (i.e. $>10^{-13} \mathrm{~m}^{2}$; Jung et al., 2002; URL3: Bundesverband Geothermie; medium permeability models: $M 2,5,8)$.

\subsubsection{Scenario $2(\mathrm{~S} 2)$ : Layered reservoir volume}

In the second scenario, I introduced layers into the model setup that constitute permeability contrasts, i.e. I confined the sandstone layers within layers of lower permeability, as typically observed in the URG Buntsandstein, caused by clay layers or variations in the sandstone layers themselves (Figs. 7.1 and 6.9; Jodocy and Stober, 2011; Sass and Hoppe, 2011; Bär, 2012; Reinecker et al., 2015). The default input parameters of the sandstone layers, i.e. reservoir layers, correspond to the medium porosity models (M4, M5, and M6; Table 7.2).

In detail, I observe the best-performing reservoir configuration to be when the layered succession comprises permeability contrasts of $10^{1}$. In this case, the time for the HIT to reach the production well is increased, with respect to scenario 1 (compare Figs. 7.2 and 7.4). Higher permeability contrasts, however, cause notably faster cooling of the reservoir (Fig. 7.4). 


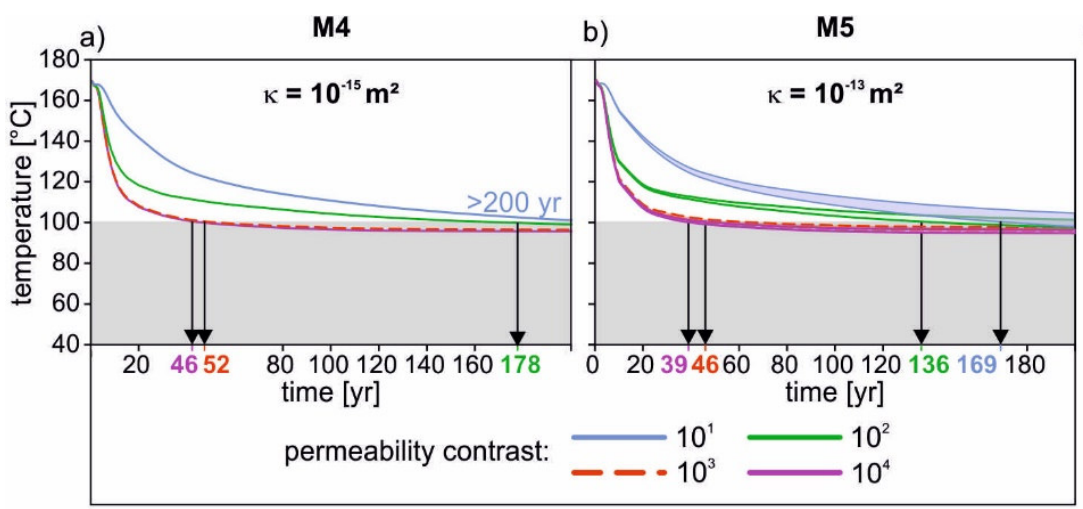

c)

M6

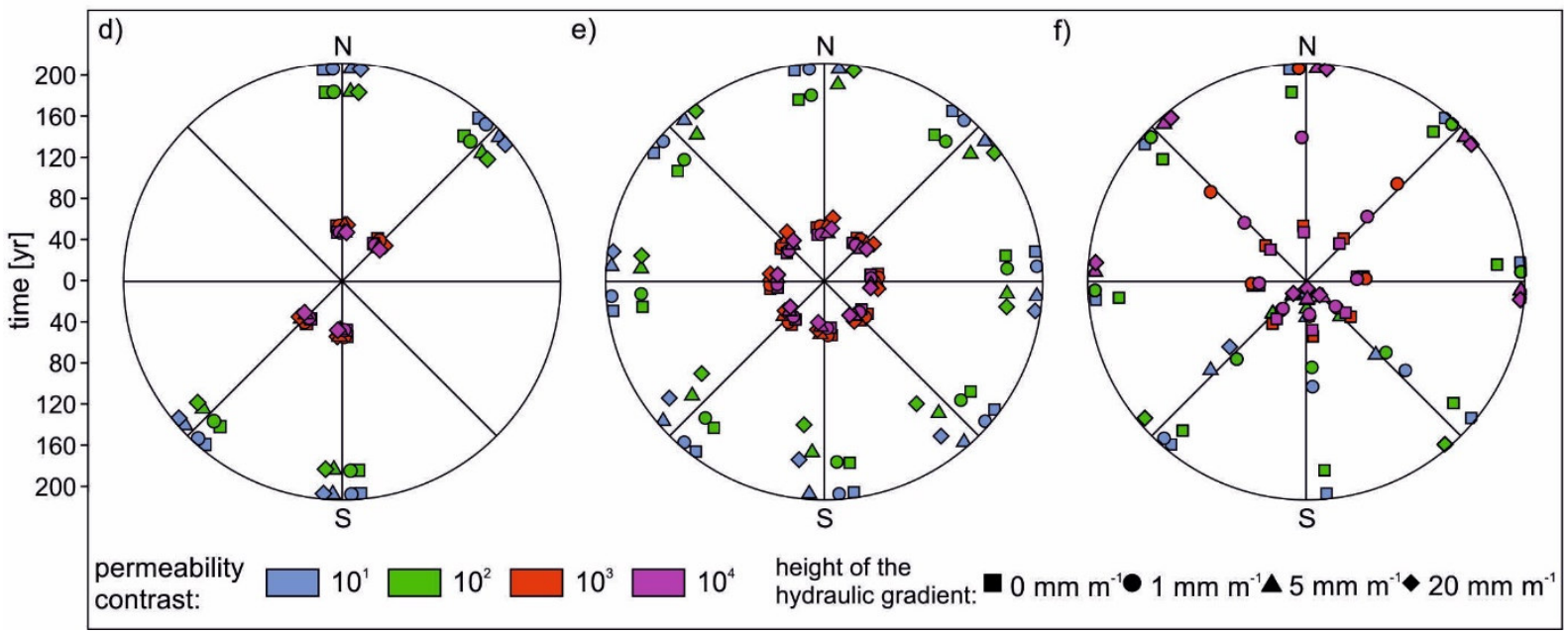

Figure 7.4: Temperature development and breakthrough times of layered reservoir volumes depending on the permeability contrast, sandstone permeability, and hydraulic gradient configuration. a to $\mathrm{c}$ ) the temperature development of the produced fluid over time. Only north- and southward-directed gradients are shown. The sandstone permeability increases from left to right. In a) and b) permeability of the confining layers is varied. The influence of the hydraulic gradient is small. In c) only the permeability contrast of $10^{4}$ is presented. $\mathbf{d}$ to f) Polar plots of the breakthrough times for all model configurations, with increasing reservoir permeability from left to right. The segment of the circle indicates the direction of the hydraulic gradient. The distance from the centre indicates the time to thermal breakthrough. The individual temperature developments of the 12 basic models are shown in Appendix 2.3 - Fig. A5.

In the layered reservoir models, I observed, depending on permeability contrasts and hydraulic gradient configurations, breakthrough times from 7 yrs to infinite (Fig. 7.4). The slightly-decreased permeability in the confining layers causes a step-like pattern in the HIT, however it is still spherical in shape, which results in an increased surface to volume ratio (Fig. 7.5a), and leads to later thermal breakthrough times compared to the homogenous models (Figs. 7.2, 7.4; Appendix 2.3 - Figs. A3 and A5).

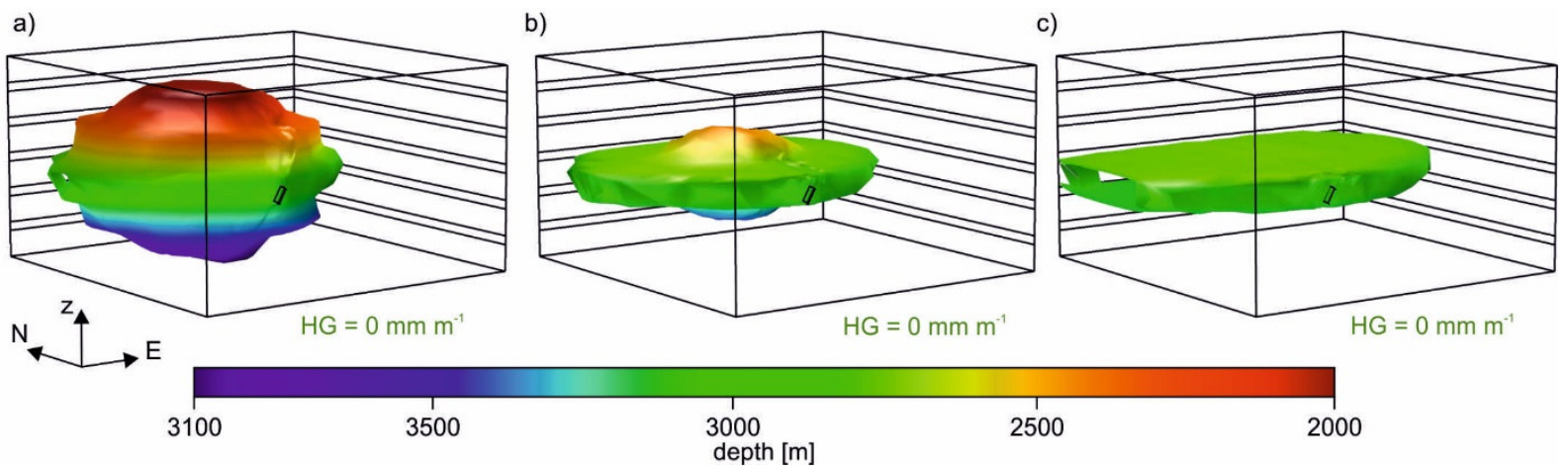

Figure 7.5: Effect of increasing permeability contrast on the reservoir shape in layered reservoir models. Figures show the HIT for the medium porosity and medium permeability model (M5) after $60 \mathrm{yr}$ of heat production, simulated for a hydraulic gradient (HG) of $0 \mathrm{~mm} \mathrm{~m}^{-1}$. The applied permeability contrasts are a) $\left.10^{1}, \mathbf{b}\right) 10^{2}$, and c) $10^{4}$. The HIT is colour-coded by depth. 
Higher permeability contrasts reduce the hydraulic interconnection between the different layers and thus the exploitable part of the reservoir becomes increasingly restricted to only the production and injection layer (Fig. 7.5). In consequence, the re-injected cold-water lead to a premature cooling of the production area. The restriction in exploitable volume can however be counteracted by a northwarddirected hydraulic gradient of sufficient height $\left(>1 \mathrm{~mm} \mathrm{~m}^{-1}\right)$ that hinders the HIT in reaching the production well. In contrast, unfavourably-oriented hydraulic gradients can cause very short lifetimes of the reservoir (Fig. 7.4). In conclusion, high permeability contrasts in layered reservoirs increase the possibility that the HIT reaches the production well faster than in homogeneous models.

\subsubsection{Scenario 3 (S3): Fractured reservoirs}

In this step, I introduce fracture-induced permeability anisotropy into the model setup. The default model parameters correspond to the medium porosity and permeability model (M5) and the anisotropy factor (permeability parallel/vertical to the fractures) is varied from $10^{1}$ to $10^{3}$, as typical for porous fractured rocks (e.g., Caine and Forster, 1999; Jourde et al., 2002; Flodin and Aydin, 2004; Bense and Person, 2006).

My models show that the best reservoir configuration depends on the interplay between the hydraulic gradient configuration, and the height and orientation of the permeability anisotropy (Fig. 7.6). In general, under hydraulic gradients of zero height, increasing N-S-directed permeability anisotropy lead to premature cooling of the reservoir (green lines in Fig. 7.6a - c), compared to homogeneous models in scenario 1 (Fig. 7.2).
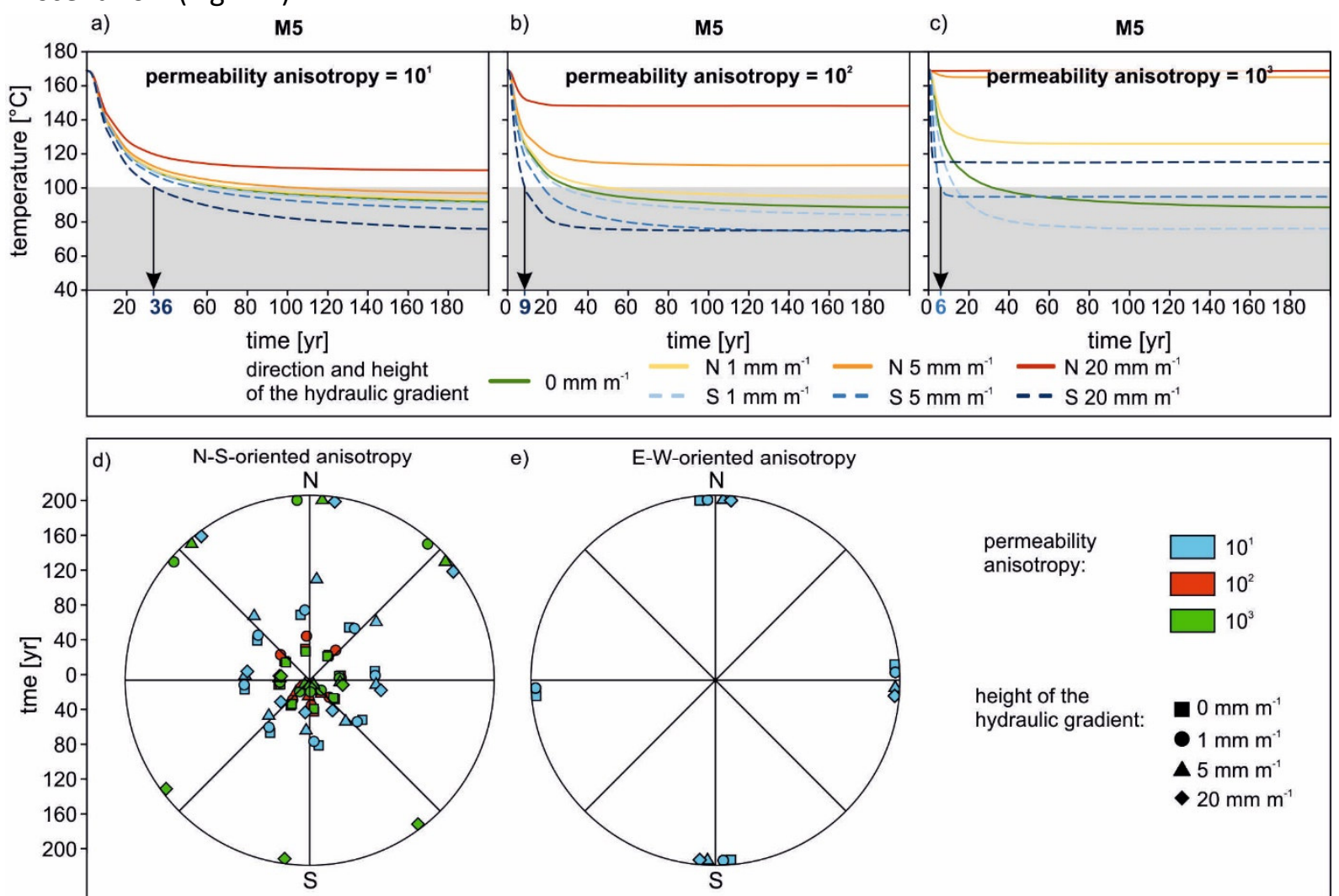

Figure 7.6: Temperature development and breakthrough times of fractured reservoir volumes depending on the fracture induced permeability anisotropy and hydraulic gradient configuration. a to $\mathbf{c}$ ) the temperature development of the produced fluid over time for the medium permeability and medium porosity model (M5). The N-S-oriented permeability anisotropy increases from left to right. Only north- and southward directed gradients are shown. Polar plots show the breakthrough times for all model configurations for d) N-S-oriented and e) E-W-oriented permeability anisotropy. The segment of the circle indicates the direction of the hydraulic gradient. The distance from the centre indicates the time to thermal breakthrough. 
a) permeability anisotropy $=10^{1}$
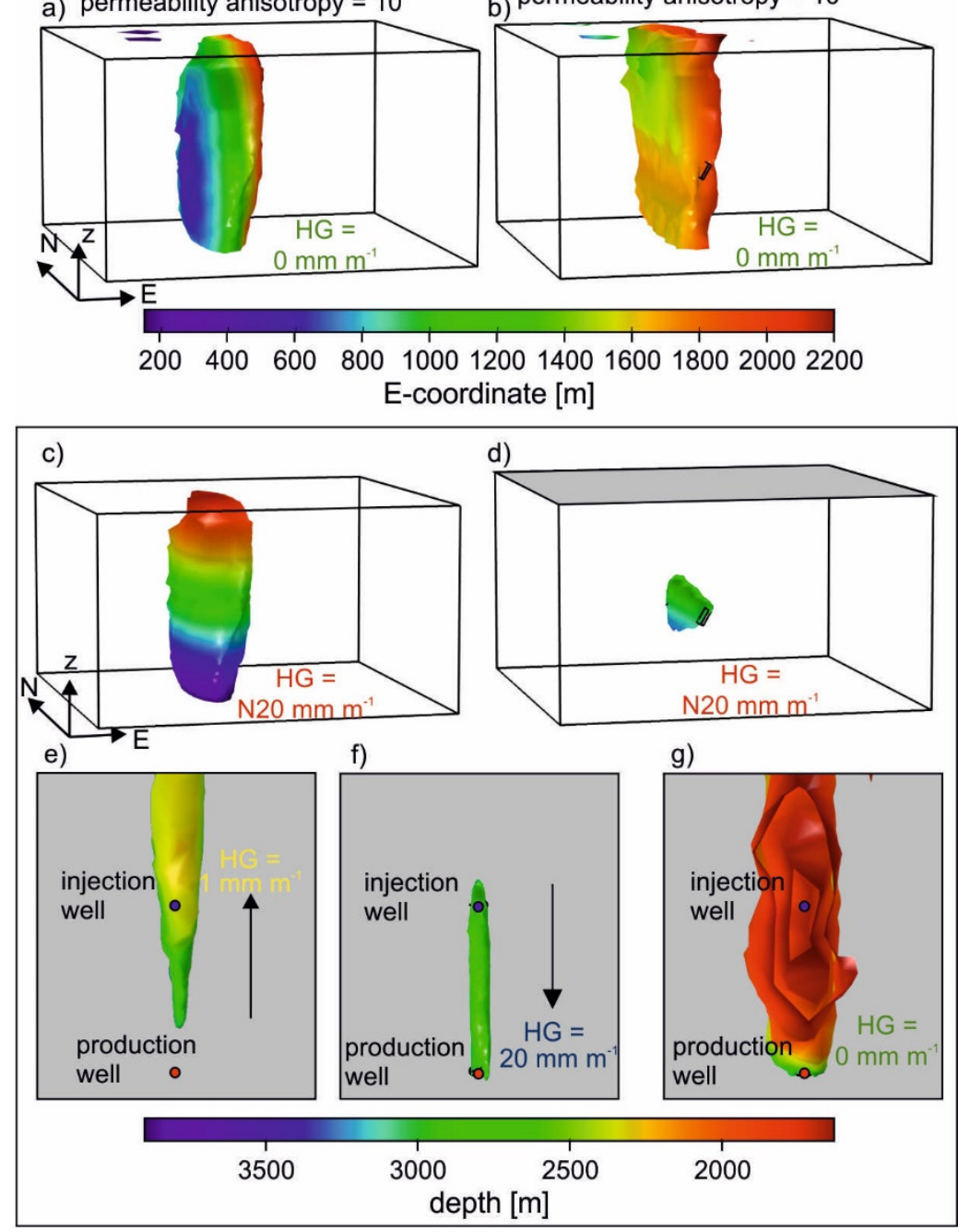

Figure 7.7: Effect of increasing N-S-directed permeability anisotropy on the reservoir shape in fractured reservoir models. Figures show the HIT for the medium porosity and medium permeability model (M5) after $20 \mathrm{yr}$ of heat production with variable hydraulic gradient (HG) configurations and increasing permeability anisotropy from left to right. a, b) No hydraulic gradient and c, d) high southwarddirected gradients of $20 \mathrm{~mm} \mathrm{~m}^{-1}$. e to f) Top view of models with high permeability anisotropy under varying hydraulic gradient configuration. e) Northward-directed gradient of $1 \mathrm{~mm} \mathrm{~m}^{-1}, \mathbf{f}$ ) southward-directed hydraulic gradient of $20 \mathrm{~mm} \mathrm{~m}^{-1}, \mathbf{g}$ ) no hydraulic gradient. In Appendix 2.4 - Fig. A7, the effect of all hydraulic gradient configurations on the HIT for models with high anisotropies are presented.
Changing the height and direction of the hydraulic gradient and the permeability anisotropy, I observed breakthrough times from 6 yr to infinite (Fig. 7.6). Already low fracture anisotropy inhibits the development of a spherical HIT, as observed in the homogeneous models (Fig. 7.3a), but favour an oblately-shaped HIT, with decreased reservoir volume (Fig. 7.7). The width of the oblate-shaped HIT is oriented parallel to the anisotropy and becomes narrower with increasing anisotropy (Fig. 7.7a, b). As previous observed, northward-directed gradients suppress the HIT reaching the production well, while southward-oriented hydraulic gradients can cause extremely short breakthrough times due to the limited reservoir volume (Fig. 7.6).

According to my model, the HIT will not reach the production well if the anisotropies are high enough and nonparallel to the well alignment (Fig. 7.6e; Appendix 2.4 - Fig. A6).

In cases where high hydraulic gradients and high anisotropies are in-line, thermal expansion in the z-direction is additionally hampered, forming a HIT that is limited to a small channel (Fig. 7.7d). The width of the cooled volume is so narrow that it does not cool down the complete thermal catchment area of the production well (Fig. 7.7f). As a consequence, the reservoir cools down extremely fast during the first years, but the production temperature never reaches the cut-off temperature of $100^{\circ} \mathrm{C}$, (Fig. 7.6c; dark blue dashed line). If the height of southward-directed gradient is $<20 \mathrm{~mm} \mathrm{~m}^{-1}$, or no hydraulic gradient is applied (Fig. $7.7 \mathrm{~g}$ ), the width of the HIT is wider, and the reservoir cools down (Figs. 7.6c; green line; Fig. 7.7g; Appendix 2.5 - Fig. A7). For the lowest northward-directed gradients, the production temperature is only slightly influenced by the re-injection of geothermal water and stays at a constant high temperature level (Figs. 7.7e and Fig. 7.6c). As a consequence, long lifetimes become more likely with increasing N-S-directed anisotropy, but at the same time the risk of rapid cooling increases (Fig. 7.6). 


\subsubsection{Scenario 4 (S4): Fractured and layered reservoirs}

In this section, I investigate the combined effect of layering and fracturing on reservoir performance. The basic setup, i.e. porosity and permeability, is based on model M5, with a permeability contrast of $10^{1}$ to $10^{3}$. Within the model series the only modification I applied is that I successively increased the permeability anisotropy in the confining layers from zero to a value equalling that of the reservoir layers. Initially only the sandstone layers are assigned with a permeability anisotropy. I only present results for the extreme case of the anisotropy being parallel to the well alignment, i.e. in the $\mathrm{N}-\mathrm{z}$ plane.

As previously observed in Section 7.3.2 (layered reservoirs), increasing permeability contrasts between different horizontal layers increasingly prevents the propagation of the HIT in z-direction (Fig. 7.5). In contrast, increasing fracture-induced permeability anisotropy prevents the propagation of the HIT in x-direction and in z-direction if the high anisotropies are in-line with high hydraulic gradients (Fig. 7.7; Appendix 2.5 - Fig. A7). In combination, both effects lead to decreased reservoir performance compared to reservoirs modelled as either layered or fractured (Figs. 7.4, 7.6 and 7.8).

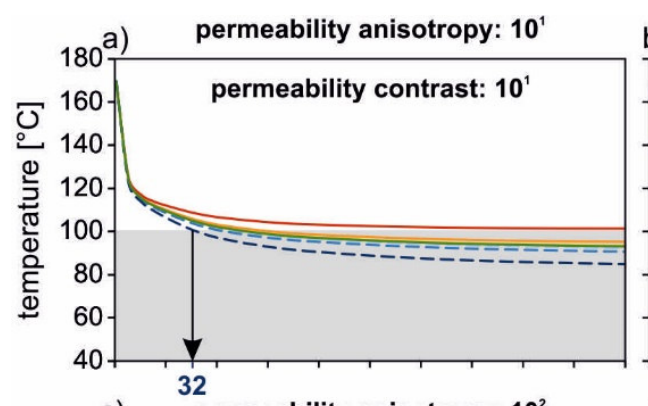

b) permeability anisotropy: 10
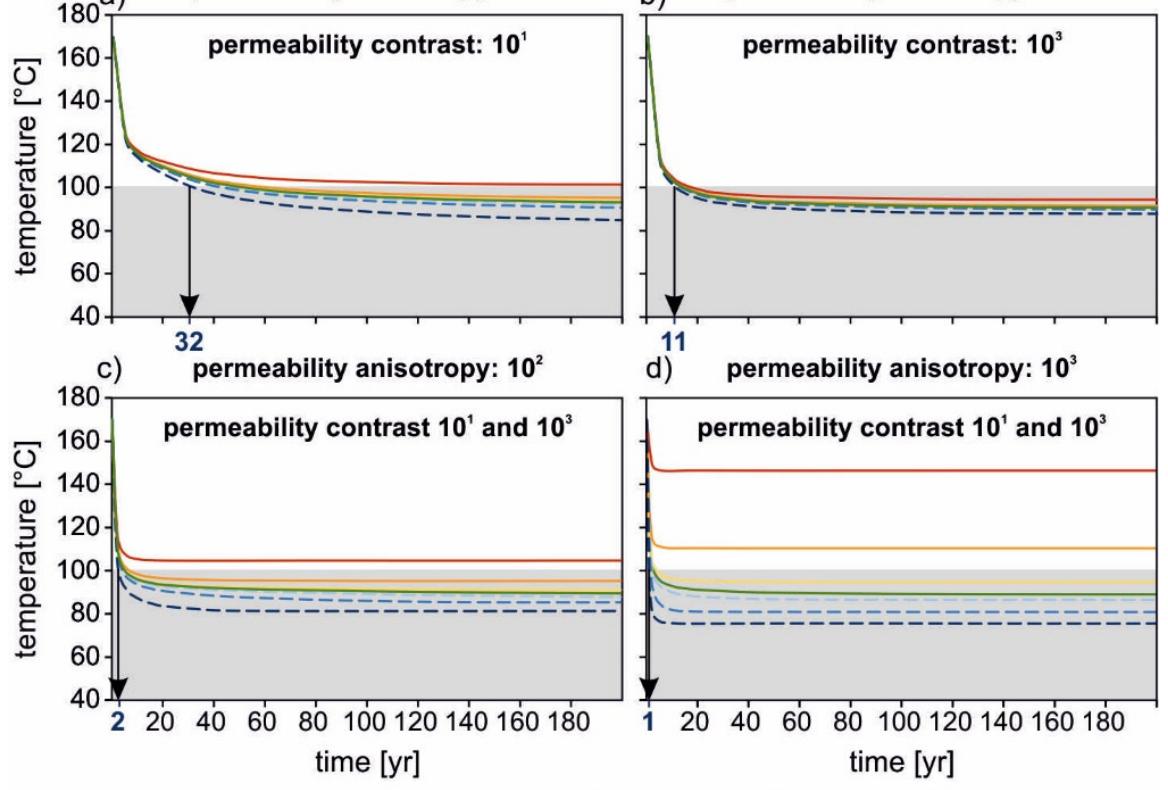

d) permeability anisotropy: $10^{3}$

$\begin{aligned} & \text { hydraulic gradient: } \\ & \text { direction and heigth }\end{aligned}-\mathrm{mm} / \mathrm{m} 1 \mathrm{~mm} \mathrm{~m}^{-1}-\mathrm{N} 5 \mathrm{~mm} \mathrm{~m}^{-1}-\mathrm{N} 20 \mathrm{~mm} \mathrm{~m}^{-1}$
$-\mathrm{S} 1 \mathrm{~mm} \mathrm{~m}^{-1}-\mathrm{S} 5 \mathrm{~mm} \mathrm{~m}^{-1}-\mathrm{S} 20 \mathrm{~mm} \mathrm{~m}^{-1}$

Figure 7.8: Temperature development and breakthrough times for layered and fractured reservoir volumes depending on the permeability contrast, fracture-induced permeability anisotropy, and hydraulic gradient configuration. Figures show the temperature development of the produced fluid over time for the medium permeability and medium porosity model (M5) for north- and southward directed hydraulic gradients: a, b) Permeability anisotropy of $10^{1}$ and increasing permeability contrast from left to right, and c, d) Increasing permeability anisotropy from left to right. In this case, the height of the permeability contrast does not influence the temperature development.

Depending on the configuration between height and direction of the hydraulic gradient, the permeability anisotropy, and the permeability contrast, the breakthrough times range from $1 \mathrm{yr}$ to infinite (Fig. 7.8).I observe that a slight permeability contrast $\left(10^{1}\right)$ in combination with fracture-induced anisotropy in the sandstone layers, restricts the propagation of the HIT in the vertical and horizontal direction efficiently and leads to a strong decrease in exploitable reservoir volume and consequently earlier breakthrough times compared to the layered succession model and fractured model (Figs. 7.4a, 7.6a, and 7.8a, b). Increasing permeability contrast, exaggerates this effect remarkably (Fig. 7.8c, d). Notably, already a low fracture induced permeability anisotropy in the sandstone layers impedes the positive effect observed in the layered succession models with a permeability contrast of $10^{1}$ (Figs. 7.4a and $7.8 \mathrm{a}, \mathrm{c})$. 
A permeability anisotropy $\geq 10^{2}$ alone prohibits connection between reservoir and its confining layers, i.e. independently of the permeability contrast of the layered succession, propagation of the HIT in z-direction is inhibited. As a consequence, for models with a permeability anisotropy $\geq 10^{2}$, the height of the permeability contrast does not influence the thermal development (Figs. 7.8c, $d$ and $7.9 c, d)$.

a)

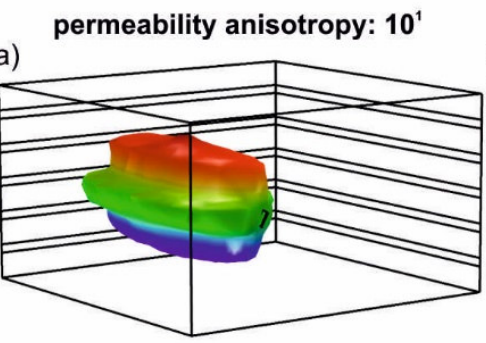

b)

permeability anisotropy: $10^{3}$

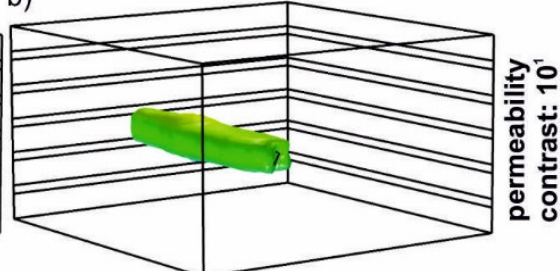

c)

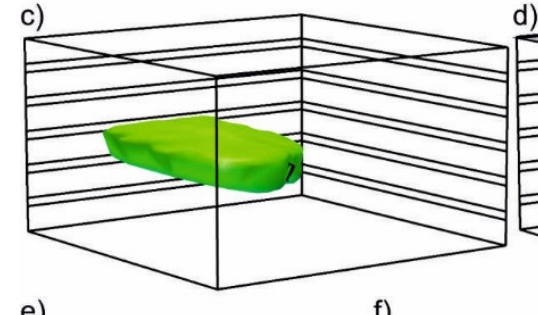

d)

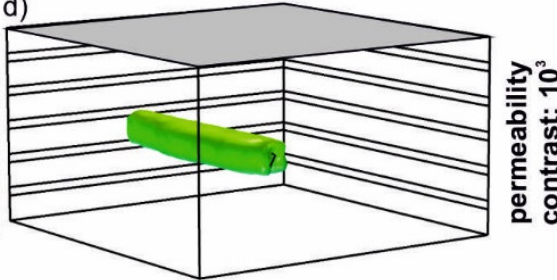

e)

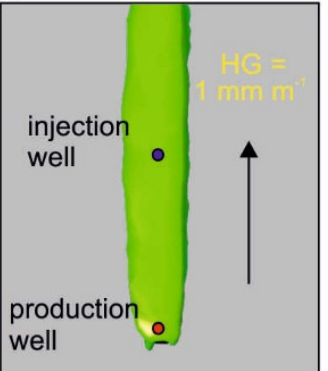

f)

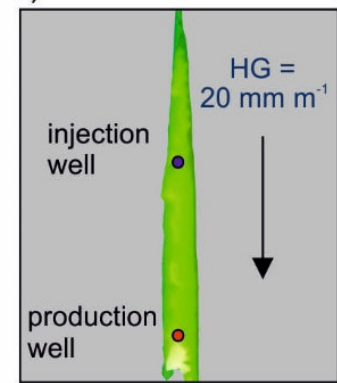

g)

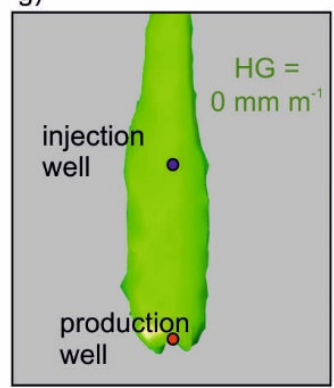

Figure 7.9: Effect of increasing N-Soriented permeability anisotropy and contrast on the reservoir shape in fractured and layered reservoir models. Figures show the HIT for the medium porosity and medium permeability model (M5) after $60 \mathrm{yr}$ of heat production with variable hydraulic gradient configurations. a to d) Permeability anisotropy increases from left to right, the permeability contrast increases from top to bottom. No hydraulic gradient is assigned. e-f) top view of models with high permeability anisotropy and a high permeability contrast with varying hydraulic gradient configuration. e) Northwarddirected gradient of $1 \mathrm{~mm} \mathrm{~m}^{-1}, \mathbf{f}$ ) Southward-directed hydraulic gradient of $\left.20 \mathrm{~mm} \mathrm{~m}^{-1}, \mathbf{g}\right)$ No hydraulic gradient.

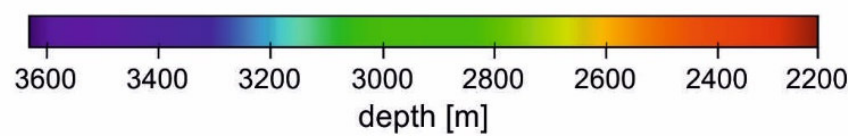

In general, the utilized reservoir volumes are comparatively small. The suppressed propagation of the HIT in z-direction due to sedimentary layering or high anisotropy yields not only wider lateral extent of the HIT (Fig. 7.9), but also its faster propagation towards the production well. This holds for all modelled hydraulic gradients, except for high, northward-directed gradients (Fig. 7.8; Appendix 2.6Fig. A8). Notably, the highest southward-directed gradient does not lead to unlimited reservoir performance as observed in the model suit S3 (fractured models without layering), since the cooling front surrounds the production well and causes rapid cooling by itself (Fig. 7.7f, Fig. 7.9f, Appendix 2.6 - Fig. A8).

Models with stepwise-decreasing anisotropy contrast, i.e. fractures have propagated through the confining layers, show that the production temperature cools down slower. Depending on the hydraulic gradient, the possibility to achieve unlimited usability also increases. In cases where fracture-system parameter are identical in the different layers, i.e. permeability anisotropy contrast is 0 , the temperature development in the reservoir is identical to the homogeneous and anisotropic models (cf. Fig. 7.6; Appendix 2.6 - Fig. A8f). 


\subsubsection{Scenario 5 (S5): Fault-related reservoir}

In this scenario, I include a fault or fault zone into the medium porosity and permeability model (M5). The fault is either defined as low permeable fault core with or without a conductive damage zone or as a highly conductive damage zone without fault core. Thus, I simulate barrier-, conduit faults, and combined conduit-barrier systems. The individual parts of the fault (zone) are modelled first as homogenous bodies and in a second step, with permeability anisotropy in the damage zone parallel to the fault orientation and sedimentary layering within the host rock.

In my models in which the fault core acts as barrier, the fault permeability was $\leq 10^{-16} \mathrm{~m}^{2}$. Therefore, the fault core restricts the usable reservoir volume, since fluids cannot pass through it. In consequence, the thermal breakthrough times were reached much faster compared to the homogeneous models (Figs. 7.10a, d and Fig. 7.2b; Appendix 2.7 - Fig. A9). My models also show that breakthrough times further decreases for conduit- or combined conduit-barrier faults (Fig. 7.10b, c). I observed the shortest breakthrough times for conduit-barrier systems.

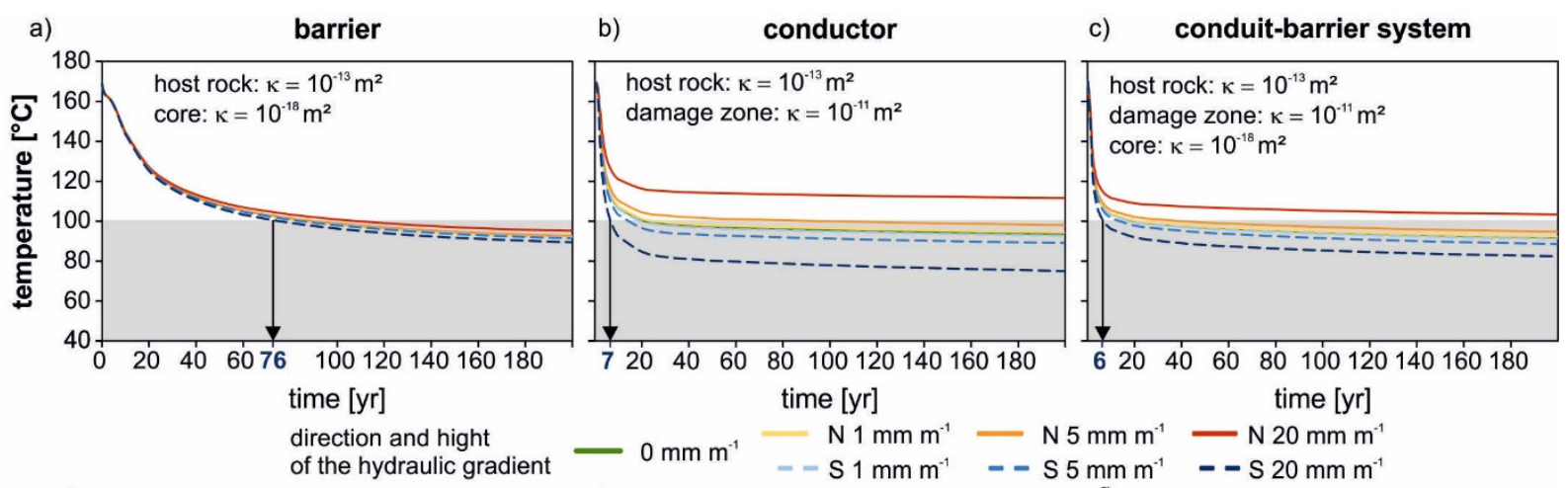

d)

e) f)

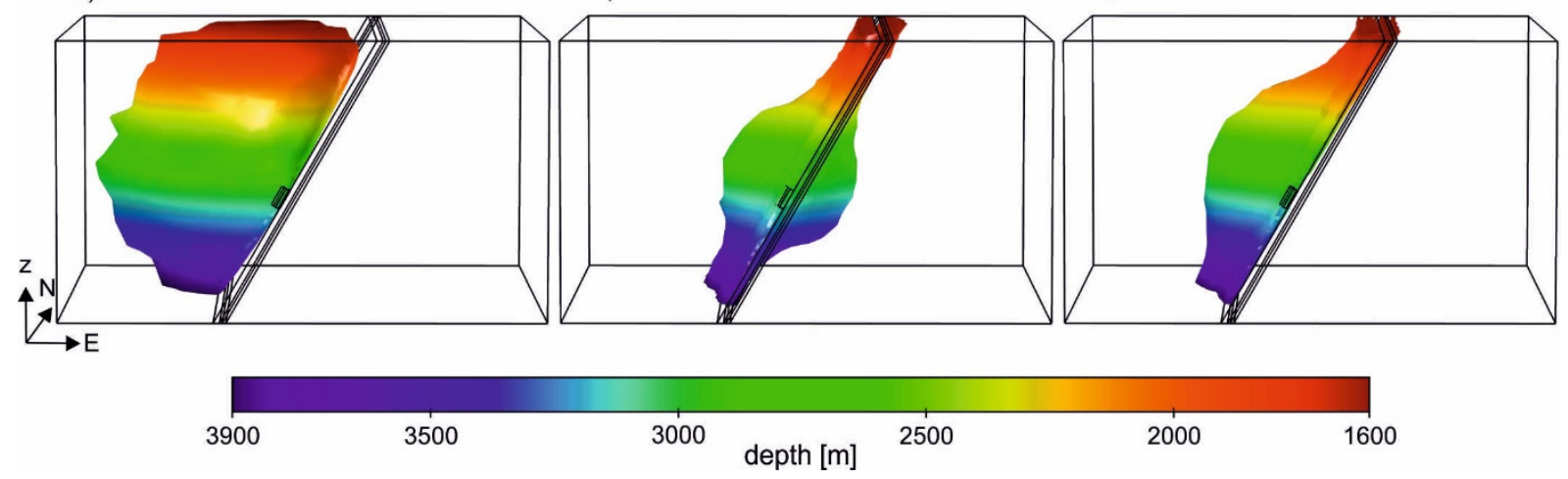

Figure 7.10: Temperature development, breakthrough times, and reservoir shape of fault-related reservoir volumes depending on fault zone structure and hydraulic gradient configuration. a to c) the temperature development of the produced fluid over time for the medium permeability and medium porosity model (M5) for north- and southward directed hydraulic gradients. Models are crosscut by a fault simulated as a) a barrier fault zone with a core zone permeability of $\left.10^{-18} \mathrm{~m}^{2}, \mathbf{b}\right)$ a conductive fault with a damage zone permeability of $10^{-11} \mathrm{~m}^{2}$, and, c) a conduit-barrier system with a core zone permeability of $10^{-18}$ and a damage zone permeability of $10^{-11} \mathrm{~m}^{2}$. $\mathbf{d}$ to $\mathrm{f}$ ) the corresponding shape of the HIT after $40 \mathrm{yr}$ of heat production, simulated for a hydraulic gradient of $0 \mathrm{~mm} \mathrm{~m}^{-1}$. Temperature development and reservoir shape of fault models with variable damage- and core zone permeability are shown in Appendix 2.7 - Figs. A9 to A11.

Depending on the hydraulic gradient, the modelled breakthrough times range from $6 \mathrm{yr}$ to unlimited (Fig. 7.10a-c). The extreme short lifetimes, are observed for faults that act as conductor and conduitbarrier system and result from the effect that the usable reservoir volume becomes restricted to the higher permeable damage zone (Fig. 7.10e, f), i.e. the fluid propagates preferably in the damage zone. With increasing damage zone permeability, the propagation of the HIT into the host rock is further 
supressed. In consequence, increasing damage zone permeability leads to decreasing reservoir performances (Appendix 2.7 - Fig. A10). Further I observed that for conduit-barrier system, the core zone permeability has only minor influence on the thermal development (Appendix 2.7-Fig. A11) of the reservoir. However, due to the reduced damage zone thickness, i.e. only one part of the damage zone is utilized, the reservoir cools down faster compared with faults that constitute a purely conductive system (Fig. 7.10b, c; Appendix 2.7 - Fig. A11).

Since the modelled thermal development between conducting faults and conduit-barrier systems is rather similar (Fig. 7.10b, c), I present the effects of fracture-induced permeability anisotropy within the damage zone only for conducting faults. Default material parameters are similar to the medium porosity and permeability model (M5; Table 7.1), with a permeability contrast for the host rock of $10^{1}$ and $10^{3}$. Since I assume a non-stratabound fracture system with anisotropy values of $10^{1}$ and $10^{3}$ in the damage zone, permeability contrast can be neglected, as shown in Section 7.3.4 and Appendix 2.6 - Fig. A8. The fracture-induced permeability anisotropy is modelled to be parallel to the fault, as often reported (Caine et al., 1996; Shipton and Cowie, 2003; Berg and Skar, 2005; Fossen et al., 2007; Faulkner et al., 2010; Bense et al., 2013).

I observed that the thermal development of reservoirs utilising conducting faults, with an anisotropic damage zone, mostly depends on the degree of the fracture-induced anisotropy and the hydraulic gradient configuration, while the influence of host rock layering is less important. With increasing anisotropy, the importance of the hydraulic gradient increases, and the thermal development becomes (almost) independent of the permeability contrast within the host rock (Fig. 7.11a - d).

In models with no assigned hydraulic gradients, reservoir performance decreases with increasing permeability anisotropy (Fig. 7.11), while at the same time the possibility to achieve unlimited reservoir performance increases for northward-directed gradients. Equally for scenario 3 (Section 7.3.3), the highest southward-directed gradient also results in unlimited reservoir lifetime; however, the production temperature is only slightly above the $100^{\circ} \mathrm{C}$ (Fig. 7.11b, d). 

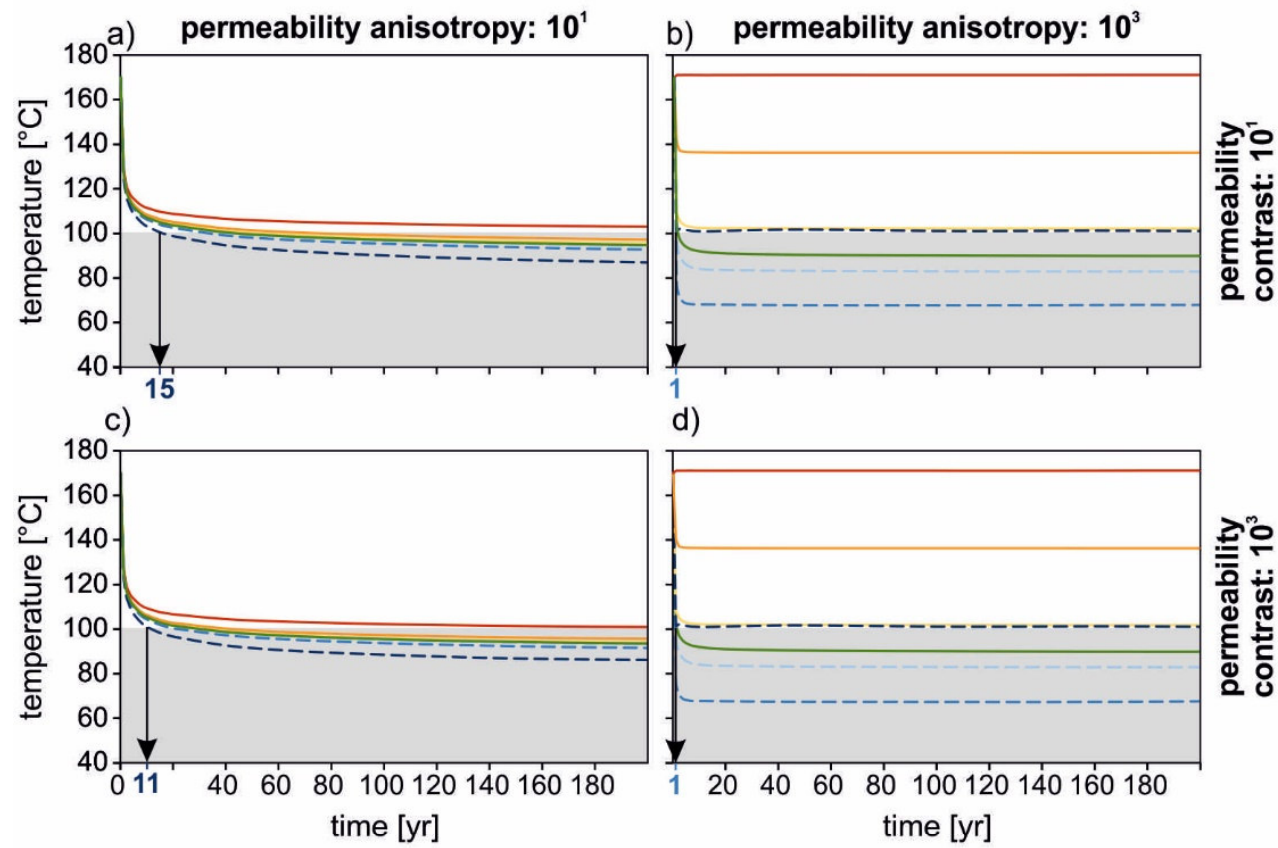

d)

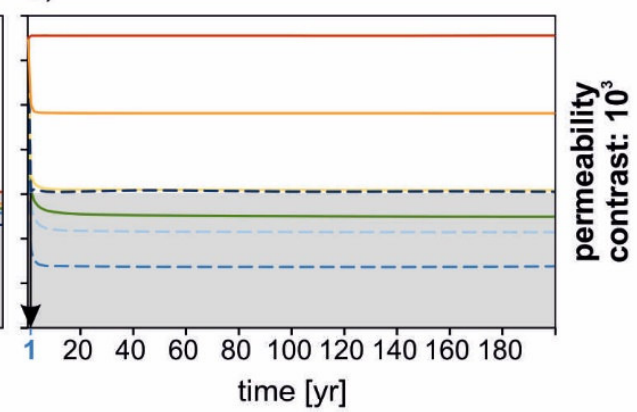

hydraulic gradient: direction and heigth $0 \mathrm{~mm} \mathrm{~m}^{-1}-\mathrm{S} 1 \mathrm{~mm} \mathrm{~m}^{-1}--\mathrm{S} 5 \mathrm{~mm} \mathrm{~m}^{-1}--\mathrm{S} 20 \mathrm{~mm} \mathrm{~m}^{-1}$

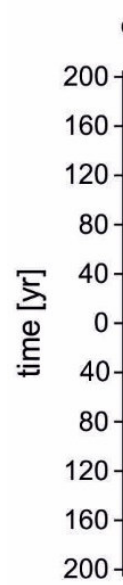

e)

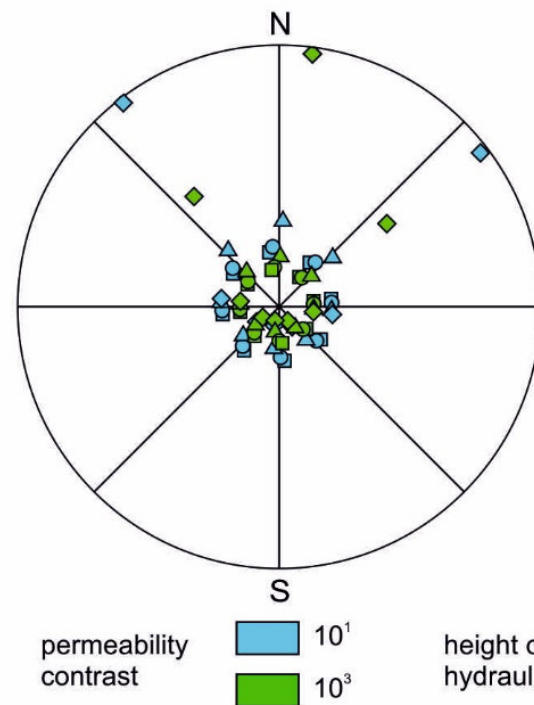

f)
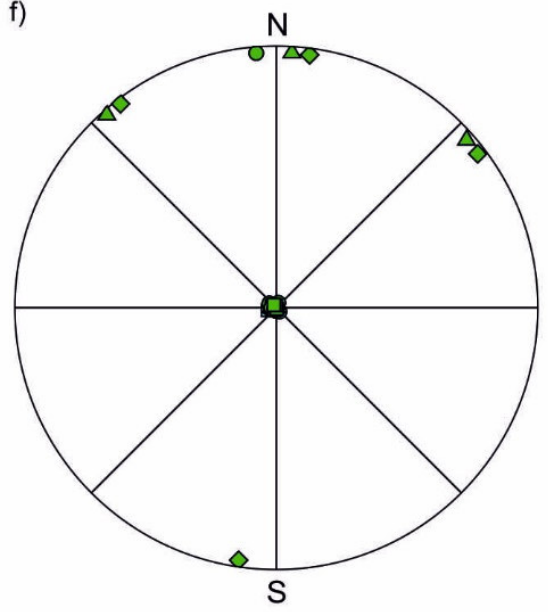

permeability

hydraulic gradient:

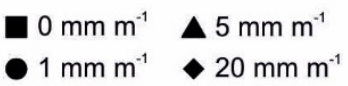

Figure 7.11: Temperature development and breakthrough times of reservoirs utilising conductive faults, depending on permeability anisotropy in the damage zone, permeability contrasts in the host rock, and the hydraulic gradient configuration. a to d) the temperature development of the produced fluid over time. The permeability anisotropy increases from left to right and the permeability contrast increases from top to bottom. Only north- and southward-directed gradients are shown. e to f) polar plots of the breakthrough times for all model configurations with increasing permeability anisotropy from left to right. The segment of the circle indicates the direction of the hydraulic gradient. The distance from the centre indicates the time to thermal breakthrough.

Depending on the height and direction of the hydraulic gradient and the anisotropy factor, breakthrough times range between $1 \mathrm{yr}$ and infinite (Fig. 7.11a - d). The span in breakthrough times and the reduced reservoir performance, compared to homogeneous fault zones, results from the effect that increasing permeability anisotropies within the damage zone strongly prevents the propagation of the HIT into the host rock (Fig. 7.12). Additionally, the vertical propagation of fluids in the fault(zone), as previous observed in scenario 3 (Figs. 7.7), becomes restricted. 
a)

permeability anisotropy: $10^{1}$ permeability contrast: $10^{1}$

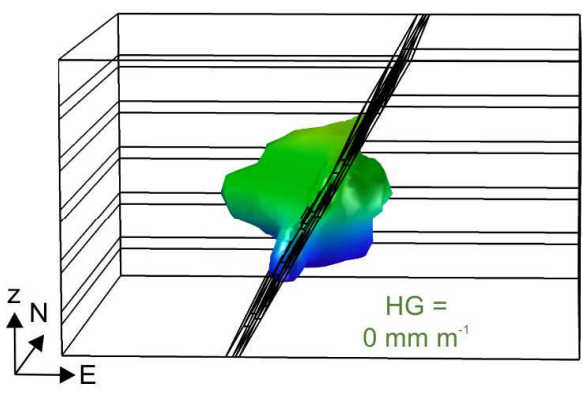

b) permeability anisotropy: $10^{3}$ permeability contrast: $10^{3}$

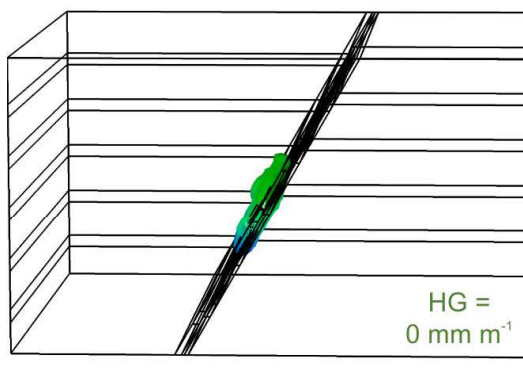

Figure 7.12: Effect of increased permeability anisotropy in the fault damage zone on the reservoir shape for conductive faults. Figures show the HIT for the medium porosity and medium permeability model (M5) after $40 \mathrm{yr}$ of heat production, simulated for a hydraulic gradient of $0 \mathrm{~mm} \mathrm{~m}^{-1}$. a) the permeability contrast in the host rock and the fracture-induced permeability anisotropy of the damage zone is $10^{1}$, b) the permeability contrast in the host rock and the fracture-induced permeability anisotropy of the damage zone is $10^{3}$.

Thus, for high permeability anisotropies, the propagation of the geothermal water is restricted within the damage zone with a small vertical extent, and thus the exploitable volume becomes very small (Fig. 7.12b). To prevent rapid reservoir cooling, it is mandatory to have northward-directed gradients, or high southward-directed gradients that counteract the low reservoir volume and lead to unlimited performances (Fig. 7.11f). If the fluid flow is controlled by the production and injection pressure alone, or low to medium southward-oriented hydraulic gradients act on the system, thermal breakthrough times are reached already after 1 year.

\subsection{Summary}

My numerical sensitivity study uses conceptual models to examine the thermal development of hydrogeothermal reservoirs. My models show first that height and direction of hydraulic gradients have strong influence on the thermal development of geothermal reservoirs. Thus they demonstrate the importance of including the hydraulic gradient when making an estimate of reservoir cooling during production. The impact of the hydraulic gradient increases with increasing reservoir permeability and if structural inhomogeneities are included into the simulation (e.g., sedimentary layering, fractures, faults). Thus, the hydraulic gradient constitutes a crucial factor whether or not a reservoir can be exploited over a long-time span (Fig. 7.13).

In the model suite of homogeneous reservoirs, I observed that higher porosity models, due to the increased heat capacity of the rocks, lead to longer reservoir performances. However, with increasing permeability, the impact of porosity on the thermal development becomes less important, while the importance of the hydraulic gradient increases. However, the threshold at which point the hydraulic gradient gains in influence, depends not only on the permeability value, but rather on the applied pumping and injection pressure. This means that in cases when the hydraulic gradient exceeds the induced pressure difference between the wells (which primarily depends on the pumping rate), the appropriate wellbore locations need to be considered carefully. In general, hydraulic gradient configurations that support fast fluid flow from the injection to the production well (i.e. southward directed gradients in the models, compare Fig. 3.6) shorten thermal breakthrough times. In contrast, hydraulic gradients that prevent the cold reinjected fluid to propagate towards the production well (i.e. southwards directed gradients in the models) expand the thermal lifetime of a reservoir. However, in homogeneous model suits, most reservoir configurations are promising and have therefore the potential for long usability. The only exceptions are high permeability models with high southward-directed hydraulic gradients (Fig. 7.13a). 
Including sedimentary layering, that constitutes a permeability contrast into the model setup, results in clearly earlier breakthrough times when the permeability contrast is $\geq 10^{2}$. This is the threshold at which the fluid circulation becomes restricted to the production layer. Notably a smaller permeability contrast of $10^{1}$ increases the thermal performance of the reservoir. The quality of layered successions is thus controlled by the height of the permeability contrast, the default permeability of the higher permeable layers, and, in cases of high permeability models, by the direction of the hydraulic gradient. The overall reservoir quality is reduced compared to the homogeneous model suite, since the risk to achieve short production times is clearly increased for layered succession constituting permeability contrasts $\geq 10^{2}$ (Fig. 7.13b).

Fracture induced permeability anisotropy, leads to clearly reduced reservoir volumes, since the fluid is preferably transported along them. The higher the anisotropy the stronger the channelling effect becomes. In extreme cases, with the fracture anisotropy parallel to the well alignment, they remarkably shorten the thermal breakthrough time. On the contrary, perpendicular-oriented anisotropies have the potential to hinder fluids to reach the production well, independent of the hydraulic gradient direction and height. Thus, in extreme cases, fractured reservoirs can clearly not only reduce the geothermal reservoir quality, when compared to layered and homogeneous reservoirs (Fig. 7.12c), but also can improve it. To prevent rapid reservoir cooling, these observations demonstrate the importance to know:

1. fracture orientation and their anisotropy,

2. the natural hydraulic gradient direction and height,

and adjust:

3. the well locations,

4. and the production and injection pressures.

The combination of fracture-induced permeability anisotropy and layering, i.e. reduced interconnection between different layers due to permeability contrasts, and channelling along fractures, additionally complicates the system and its predictability. Dependent on the height of the permeability contrast, the anisotropy value, the hydraulic gradient configuration and whether the fractures are stratabound or not, the thermal development of the reservoir can vary significantly. In general, in models with a permeability anisotropy of $10^{1}$ in the sandstone layers, increasing permeability contrasts lower the reservoir performance (Fig. 7.8a, b). For fracture-induced permeability anisotropies $\geq 10^{2}$, however, layering does not influence the thermal development of the reservoir, and makes it possible to achieve long lifetimes for positive-oriented hydraulic gradients (Fig. 7.8c, d). However, high fracture NS-directed anisotropy $\left(10^{3}\right)$, in combination with high gradients oriented between the injection and the production well, only result in unlimited reservoir performances in a non-stratabound fracture system. If this is not the case, it cools down extremely fast. Also, the positive effect of a layered succession with a permeability contrast of $10^{1}$ is counteracted by fractures.

In the homogeneous fault zone models, I observed that faults, independent of their internal structure, decrease the reservoir performance significantly, compared to homogeneous models (Fig. 7.10a - c). Notably, conductive faults lead to a more rapid reservoir cooling compared with barrier faults, due to the channelling of fluids within the limited volume of the damage zones. The exploitable reservoir volume and also the breakthrough times of conducting faults further decreases when sedimentary layers and fractures are added to the model setup. In consequence, for fault-related reservoirs it is mandatory to know a number of parameters (damage zone thickness, layering, fracture anisotropy, 
hydraulic gradient) and their precise combination to make reliable estimates on the reservoir performance. Nonetheless, not only faults acting as barrier but also conducting fault zones clearly reduce the probability to receive high production temperatures over a long-time span (Fig. 7.13d). This holds especially true for the often-observed cases that fractures hosted in a damage zone are aligned parallel to the fault.
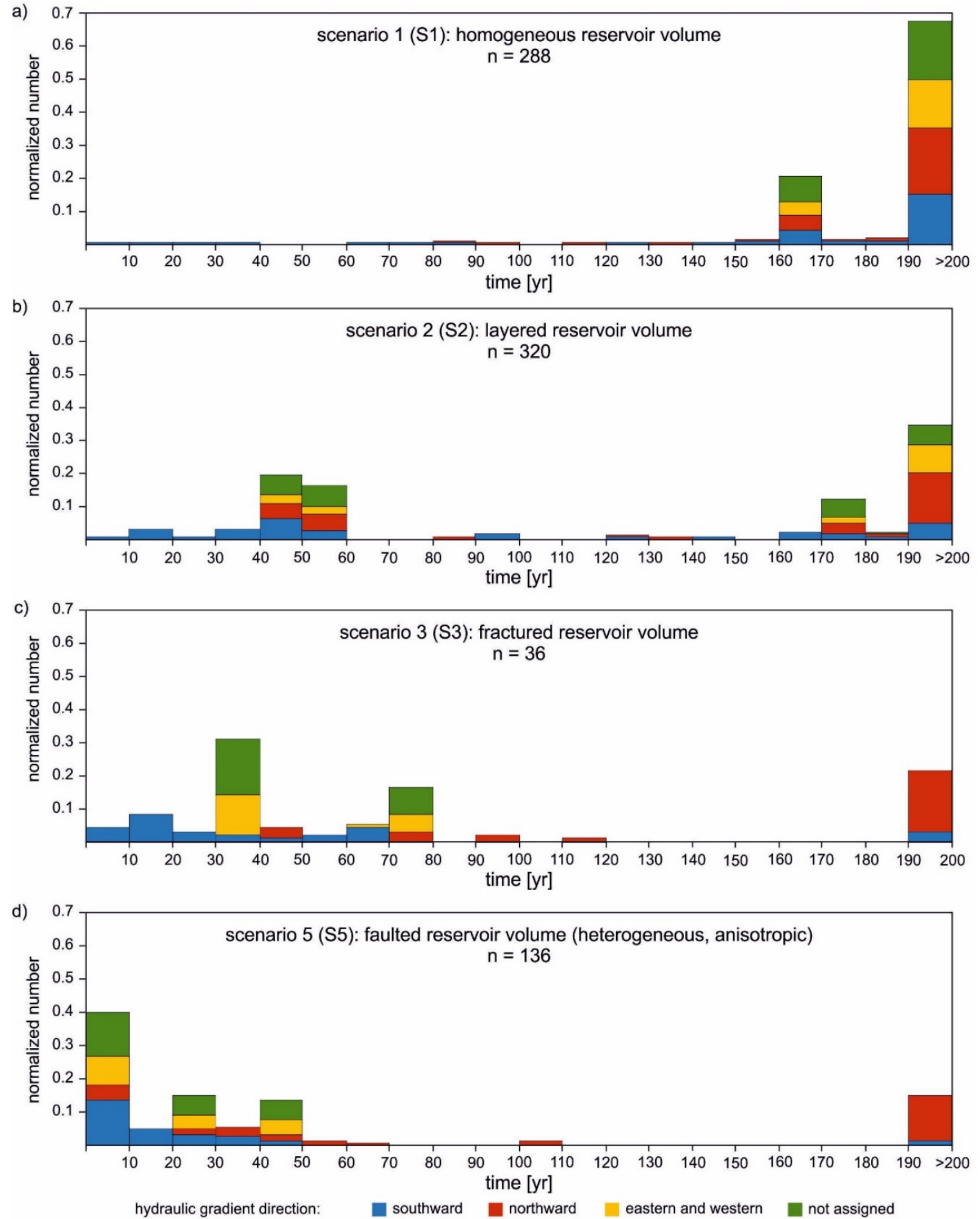

Figure 7.13: Normalized number of thermal breakthrough times depending on the hydraulic gradient direction. a) for homogeneous reservoir models (scenario $1: n=288$ ), b) layered reservoir models (scenario $2 ; n=320$ ), c) fractured reservoir models (scenarios $3, n=36$ ), and $\mathbf{d}$ ) heterogeneous and anisotropic fault zone models (scenario $5 ; n=136$ ). With increasing structural complexity (top to bottom), the probability for short reservoir lifetimes increases. Scenario 4 (fractured and layered reservoir) is not shown due to the small number $(n=24)$ of experiments. 


\section{Discussion}

My thesis evaluates rock- and fracture-system parameters of fault zones and their predictability, with the aim to increase the success rate of fault-related hydrogeothermal projects. Attributes of fracture systems, petrological, and lithological parameters were determined using outcrop analogue studies in the Upper Rhine Graben (URG). The extrapolation of outcrop findings to depth was tested using a comparative study of outcrop and borehole data. Finally, the impact of the determined geological parameter ranges on thermal depletion of a hydrogeothermal doublet was tested using a comprehensive numerical sensitivity study.

In this discussion, I firstly give a short overview of operating geothermal projects worldwide and their different geological settings. Secondly, I discuss findings of our outcrop analogue studies and, based on this, the suitability of fault zones as targets for geothermal energy. Thirdly, I discuss the current exploration methods in geothermics and the contribution that outcrop analogue studies can make. I also discuss possible approaches that may help to improve the predictability of fault zone features that are important from the hydraulical point of view. Fourthly, I discuss the possible impacts of different reservoir structures and their properties on the fluid and heat transport, based on the results of the numerical modelling. Lastly, I discuss the effects of model simplification and possible improvements that would allow a more accurate depiction of the reservoir system, and to which degree improved model accuracy is useful.

\subsection{Geothermal projects worldwide and their geological setting}

Analysis of the distribution of successful geothermal projects worldwide shows that they are basically established in areas with active volcanism or in tectonically-active settings (Barbier et al., 2012; Glassley, 2014; Moeck, 2014; URL4:Thinkgeoenergy; Fig. 8.1), and were explored often directly from surface expressions, such as hot springs or fumaroles (Barbier, 2002; Bruhn et al., 2010). Typical geological settings that provide geothermal resources, according to Glassley (2014) and Moeck (2014), can be subdivided into:

1) Compressional geological settings, i.e. orogenic belts, or foreland basins (Japan, Russia, New Zealand, Philippines, Central- and South America), where most geothermal facilities are installed.

2) Strike-slip geological settings as in North America along the San Andreas Fault or the Anatolian Fault in north Turkey.

3) Extensional geological settings, e.g. along mid oceanic ridges, such as the Mid-Atlantic Ridge, in Iceland and the Azores. Other examples are back-arc spreading centres, such as in northern New Zealand. Further extensional environments that provide geothermal resources are intracontinental rift settings. Examples are the Imperial Valley in the USA, the East Pacific Rise in Mexico, and the East-African Rift in Ethiopian and Kenya. 

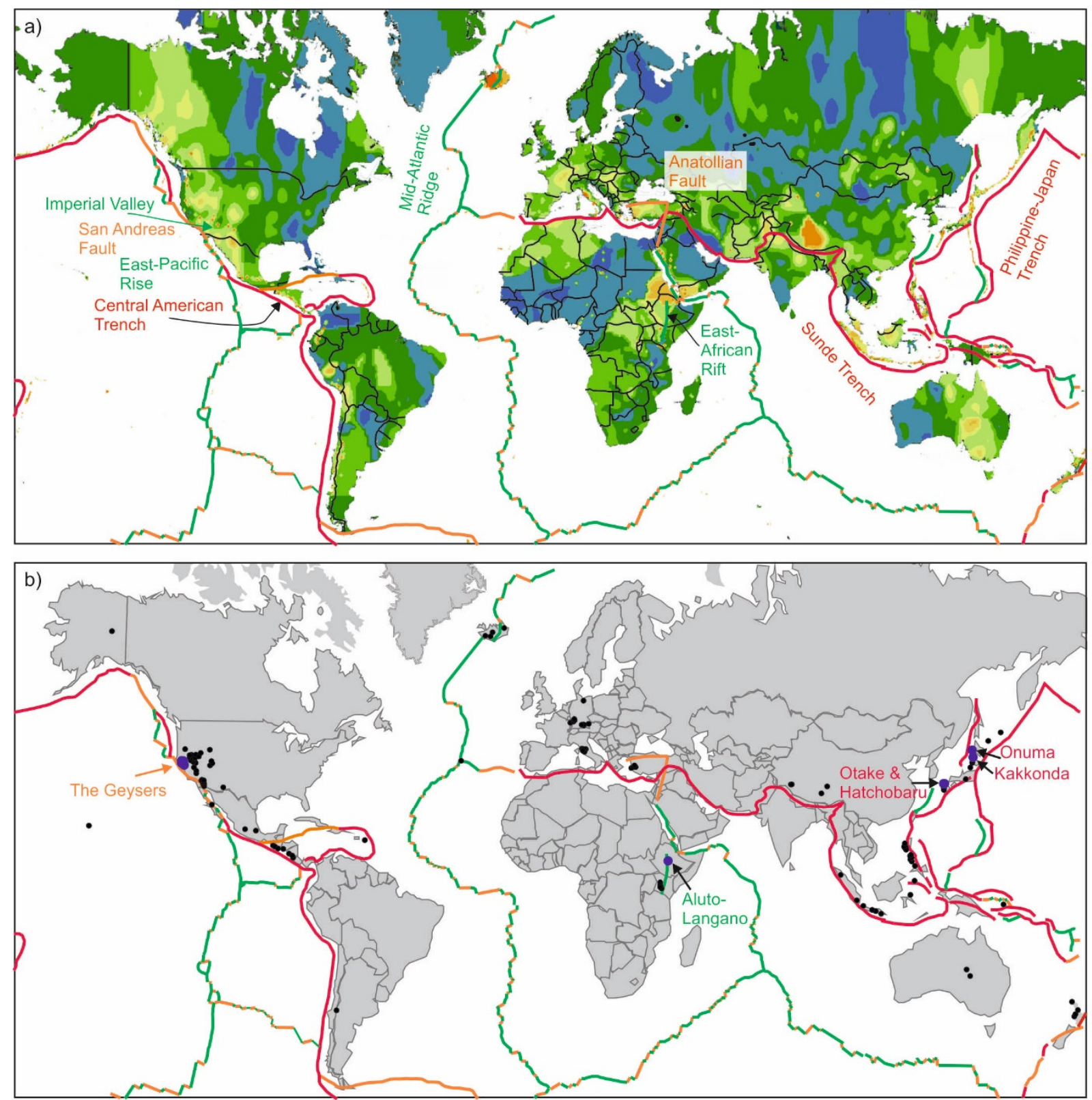

$<15$

$15-30 \square 30-45$

$45-60$ heat flow $\left[\mathrm{mW} \mathrm{m}^{-2}\right]$

convergent plate boundaries divergent plate boundaries

Figure 8.1: Heat flow map (a) and geothermal energy producing projects (b) worldwide according to tectonic setting. Most geothermal facilities are in active tectonic settings that constitute high enthalpy regions. Heat flow map from URL10:ThermoGIS, tectonic settings based on Simkin et al., 2006, and locations of geothermal projects after URL4 : Thinkgeoenergy.

All these geological environments benefit from various processes, but have in common very high geothermal heat flows at the surface ( $150 \mathrm{~mW} \mathrm{~m}^{-2}$; Fig. 8.1a; URL11: IHFC) and are mostly tectonic active (Barbier, 2002; Glassley, 2014; Moeck, 2014). Compressional regions, i.e. subduction zones, are characterized by rising melts and thus they comprise hot volcanic systems that provide shallow, longlasting heat sources (e.g., Iwamori, 1997; Stein, 2003; Glassley, 2014). On the other hand, transitional systems, often provide major rupture zones that allow fluids to circulate from great depth (e.g., Kennedy et al., 1997; Glassley, 2014). Extensional settings benefit from an uprising mantle, which forms young, fractured, and thus hot and permeable crust (Flóvenz and Saemundsson, 1993; Glassley, 2014). 
In Germany, utilization of deep geothermal energy takes place in three settings; within an intracratonic basin (North German Basin - extensional type), a foreland basin (Molasse Basin - compressional type), and in the URG, as part of an intracontinental rift system (European Cenozoic Rift System - extensional type; Fig. 1.2; URL3: Bundesverband Geothermie; Stober et al., 2011). In contrary to e.g. geothermal power plants established in extensional settings as in the north of New Zealand, where rifting is still active and characterised by recent volcanic activity (Glassley, 2014; Moeck, 2014), the tectonic activity of the URG (studied here), the Molasse Basin, and the North German Basin is considerably lower and no recent volcanic activity has taken place (Simkin et al., 2006). As a consequence, all three regions of geothermal interest in Germany are characterised by relatively low geothermal heat flow (average $65 \mathrm{~mW} \mathrm{~m}^{-2}$; Stober et al., 2011) near the global average (70 $\mathrm{mW} \mathrm{m}^{-2}$, Li et al., 2017), with the highest values observed in the URG at $60-140 \mathrm{~mW} \mathrm{~m}^{-2}$ (Haenel and Staroste, 1988). In consequence, all three regions are of low enthalpy type, which only allows the utilization of geothermal power using binary cycles. Thus, the generation of geothermal power in Germany can be currently considered to be at an early state.

To date, exploitation of low enthalpy, hydrogeothermal sedimentary reservoirs for power generation is rare and most realisations can be found in Germany, Austria, and China (URL4: Thinkgeoenergy). In the North China Basin and in the Molasse Basin (Germany), mostly karstified and fractured limestone reservoirs are explored (Jung et al., 2002; Paschen et al., 2003; Masum, 2015). In these regions, however, the risk of dry wells seems to be lower than in the URG, where fractured clastic rocks are utilized (Jung et al., 2002; Paschen et al., 2003). In the Molasse Basin, only two from eight electricity-producing projects failed in recent years, in contrast to six from nine in the URG (Section 1.2; URL: $6-8$ ). These projects failed mostly due to insufficient reservoir permeability (URL: $6-8$ ). In consequence, the combination of deep-seated reservoirs and the difficulties in exploring heterogeneous sedimentary successions requires detailed and advanced exploration methods to exploit the geothermal potential in Germany that doubtlessly exists.

\subsection{Should fault zones be a target for geothermal energy?}

As stated above, most geothermal projects in Germany that failed, encountered insufficient permeability in the envisaged reservoir volume. While insufficient permeability may also be technically improved by stimulation methods, for instance by widening existing or by creating new fractures, it remains an unsure venture (DiPippo, 2016) and increases the risk of induced seismicity (Baisch et al., 2009; Cladouhos et al., 2010; Häring et al., 2008). Thus, it is desirable to improve the success rate by finding initially sufficient permeable reservoirs.

In this context, faults and fault zones are more and more often proposed as potential reservoir formations (Paschen et al., 2003; Jung, 2007; Agemar et al., 2016; Meier, 2016; Stober et al., 2016). A vast number of studies have shown that faults have a large impact on fluid flow conditions in the Earth's crust and have the potential to greatly improve permeability (e.g., Sibson, 1977; Byerlee, 1993; Caine et al., 1996; Caine and Forster, 1999; Haneberg et al., 1999; Micarelli et al., 2006a; Kurz et al., 2008; Caine et al., 2010; Faulkner et al., 2010; Wibberley et al., 2010; Bense et al., 2013). However, many processes during fault zone evolution can either decrease permeability e.g. particulate flow (e.g., Heynekamp et al., 1999; Rawling and Goodwin, 2006; Caine and Minor, 2009), cementation (e.g., Bruhn et al., 1994; Bastesen and Braathen, 2010; Caine et al., 2010), and cataclasis (e.g., Aydin and Johnson, 1978; Antonellini and Aydin, 1994, 1995; Gibson, 1998), or increase permeability e.g. fracturing (e.g., Agosta and Kirschner, 2003; Balsamo et al., 2010; Caine et al., 2010), brecciation (e.g., Bruhn et al., 1994; Caine and Minor, 2009; Caine et al., 2010; Walker et al., 2013), and dissolution (e.g., 
Micarelli et al., 2006a, Bruhn et al., 1994; Bastesen and Braathen, 2010; Caine et al., 2010). The range of interaction and linkage between direct controlling factors such as clay smear (Sperrevik et al., 2002; Yielding, 2002), bed thicknesses (Hobbs, 1967; Narr and Suppe, 1991; Gross et al., 1995; Van der Pluijm and Marshak, 2004), mechanical rock properties (Faulkner et al., 2010), and external factors, such as depth of formation (Twiss and Moores, 2007; Ishii et al., 2010), geological setting, water-rock interactions (Bruhn et al., 1994; Haneberg et al., 1999; Molli et al., 2010), displacement (Knott, 1994; Manzocchi et al., 1999; Sperrevik et al., 2002; Mitchell and Faulkner, 2009) determine the mode of rock failure and thus the permeability of faults. Fault zone structures are consequently of a heterogeneous, anisotropic, and discontinuous nature (Shipton and Cowie, 2003; Mitchell and Faulkner, 2009; Faulkner et al., 2010). Thus, the impact of faults on fluid flow must also be considered as highly complex, and to vary significantly even on small scales.

As many other authors before, we observed the tendency for fracture density to be inversely proportional to the distance to the fault (Chapters 4 and 5), and that fault-related fractures tend to align subparallel to the main fault (Caine et al., 1996; Shipton and Cowie, 2003; Berg and Skar, 2005; Fossen et al., 2007; Faulkner et al., 2010; Bense et al., 2013). We also observed that fracture system properties (density, orientation, dimension, interconnectedness, and the amount of stratabound- and non-stratabound fractures) in general, can greatly vary, not only between the foot- and hanging-wall (Aydin and Johnson, 1978; Antonellini and Aydin, 1995; Clausen et al., 2003; Berg and Skar, 2005), and between different outcrops, but also within the same outcrop in different layers (Chapters 4, 5, and 6). The consequence of this is that the impact of fault zones on fluid flow, within a certain rock volume, is difficult to predict.

The data recorded in our outcrop studies from the URG (Fig. 2.1) did not allow to identify a relationship between e.g. fault zone thicknesses and properties such as displacement (Knott, 1994; Manzocchi et al., 1999; Sperrevik et al., 2002; Mitchell and Faulkner, 2009), or fault geometry (Rotevatn et al., 2009; Huenges, 2010; Faulds and Hinz, 2015). One important reason for these negative results must be attributed to the poor outcrop conditions (size and amount) in the study area and the consequently limited amount of fault zones that could be studied in detail. In most outcrops, it was a problem to distinguish the true extent of the damage zone. Possible reasons for these observations are: that the extent of the outcrops was too small, that in outcrops with a number of faults different damage zones intersected, or that a damage zone simply does not exist.

However, in mechanically more homogeneous lithologies, i.e. such with high layer thicknesses (Buntsandstein: Cl; Sections 4.4.5 and 6.3.2; Upper Muschelkalk mo1: NL; Section 5.4), the density of fractures clearly increases within the damage zones towards the fault, and a higher amount of nonstratabound fractures and a higher fracture connectivity could be observed compared to faults hosted in the Triassic Nodosus Beds (mo2; NL; Section 5.4). This observation shows the inextricable connection between structural characteristics, lithological and mechanical aspects, and therefore their impact on the hydraulic properties of faults. However, the complex interaction of different processes and parameters that influence fault zones characteristics (e.g., fracture orientation and density) likely precludes the ability to predict fault zone structures, even from one outcrop to another. Therefore, it is not surprising that no general trend for fracture-system parameter could be observed in our outcrop studies. Further complexity in extrapolation from outcrop data to reservoir depth is introduced by differences in diagenetic and geological history (uplift and erosion on the graben shoulders vs. subsidence and sedimentation at the graben centre), increasing confining pressures with depth, and changes in stress field and stress state. 
At least qualitatively, we could observe that faults can form promising geothermal reservoirs in terms of improved structural permeability (Chapters 4 and 5). The benefit of such point observations, however, has to be balanced against the heterogeneity of faults and fault zones (Faulkner et al., 2010; Mitchell and Faulkner, 2009; Shipton and Cowie, 2003). A few examples of this are: the observation that $\mathrm{CO}_{2}$-leakage along faults in the Paradox Basin (Utah - USA; Dockrill and Shipton, 2010) occurs only in few locations, which, in addition, change over time, or by the observation that neighbouring springs along the Borax Lake Fault in Oregon (USA) have extremely different temperatures (Fairley and Hinds, 2004). In conclusion, faults and fault zones can affect the geothermal potential in both a positive and a negative fashion, or possibly in some cases, not at all. While the densely faulted system of the URG is a promising area for fault-related geothermal energy, the risk of dry wells is significantly increased due to the complex und often unknown impacts of faults on rock permeability in an already complex geological setting.

\subsection{Exploration methods in geothermics}

The current exploration strategy for geothermal energy includes four different stages:

1) selection of reconnaissance regions,

2) selection of prospect areas,

3) selection of drill sites,

4) drilling and reservoir testing (Barbier, 2002).

Detailed knowledge about the spatial distribution of structural, lithological, and diagenetic parameters to characterize reservoirs is essential, but sub-surface data are commonly rare. To fill these gaps outcrop analogue studies have been recently used in Germany to identify promising locations for geothermal energy production (e.g., Sass and Hoppe, 2011; Bär, 2012; GeORG-Projektteam, 2013; Rohrer, 2015; Soyk, 2015; Aretz et al., 2016; Meier, 2016; Stober et al., 2016).

For example, the project "Hessen $3 D^{\prime}$ " analysed the matrix permeability, porosity, heat conductivity, and heat capacity of different rocks in the northern URG to identify suitable lithologies and facies types for deep geothermal reservoirs and implemented the results in a 3-D structural model (Sass and Hoppe, 2011; Bär, 2012). However, based on the results, faults and fault zones were declared the greatest uncertainty factor. In consequence, the hydraulic behaviour of the faults was not separately specified and no general assumptions about the geothermal potential of fault-related reservoirs was made. It was concluded, similar to other projects, such as e.g. TAB (Paschen et al., 2003), StörTief (Agemar et al., 2016), GeORG (GeORG-Projektteam, 2013), and GeoTIS (Schulz et al., 2009), that faults and fault zones need to be considered site specific, but have the potential to considerably improve reservoir quality in terms of permeability. The StörTief project further noted that, on a large scale, the probability of meeting permeable faults appears to be higher when young and active faults are targeted that have an appropriate geometry (crossing normal faults, horsetail structures, relay ramps), are hosted in rigid and homogeneous rocks, and are favourably oriented to the local stress field (Stober et al., 2016). However, since there are many other factors, including e.g. fault displacement, depth of formation, but also stress states, and diagenetic conditions over time that need to be considered when deciphering fault zone structures and their hydraulic behaviour in the sub-surface, these factors can only be used for the selection of prospect areas worthy of further examination. That the projects at Geretsried, Mauerstetten (Molasse-Basin), and Trebur (URG), which targeted fault-related reservoirs, failed due to insufficient permeability, is likely to be a manifestation of this difficulty to predict faultzone structures, despite promising prospective conditions, as listed above (URL8: iTG). 
We also found for the study area in the URG that our observed surface trends of e.g. porosity and permeability of Buntsandstein rocks could not be transferred to depth (Chapter 6). The common approach of outcrop analogue studies in geothermics of extrapolating these crucial parameters to reservoir depth is thus fundamentally challenged. These difficulties must be explained at least partly by differences in the scale of observation, and different measuring methods in the sub-surface and at the surface. Most problematic is, however, the heterogeneity of rock properties at larger scales and specifically those of faults. In many cases, one cannot decide whether an outcrop can serve as analogue before the cost intensive drilling process.

Especially in areas like Germany, exploration is difficult, since easily recognizable surface manifestations of hot and permeable sub-surface structures, such as hot springs, are mostly absent, and outcrop conditions are unfavourable in many areas. Further complications arise due to non-thermal groundwater horizons that additionally hinder or falsify surface observation (Barbier, 2002). Thus, exploration risk is comparatively high and demonstrates the need to develop new or to improve existing prospection methods. These improvements must specifically aim for a better spatial resolution when evaluating the distribution of permeability that dominantly control the thermal- and hydraulic conditions in the subsurface.

Some of these geophysical prospecting methods are, for example:

1. aeromagnetic surveys, which can be used to detect anomalies of low magnetic susceptibility that can indicate hydrothermal alteration (Bruhn et al., 2010; Riveros et al., 2014),

2. electrical resistivity measurements that can detect regions of low resistivity, which is an indication of hot water-filled and highly porous rocks (Llera et al., 1990; Bruhn et al., 2010), and

3. seismic measurements that can give insight into structural parameters of the subsurface (Lüschen et al., 2011), but also can provide evidence of fluid-filled fractures due to an increased $v_{p} / v_{s}$ ratio (Bauer et al., 2010).

Other promising techniques that can be used in early stage of exploration include, for example, the analysis of ${ }^{4} \mathrm{He},{ }^{3} \mathrm{He}$, and $\mathrm{N}_{2}$ anomalies, $\mathrm{C}_{14}$ concentrations and tracer tests. ${ }^{4} \mathrm{He}$ and $\mathrm{N}_{2}$ are indicators of fluids originating from the deep crust (Kennedy et al., 1997), and, together with mantle ${ }^{3} \mathrm{He}$, they provide evidence of deep-seated faults (Kennedy et al., 1997). $C_{14}$ concentrations, in addition, can serve as a measure of hydraulic residence time (Barbier, 2002). These chemical isotope methods can thus provide important insights into the origin, evolution, and location of geothermal water and therefore likely geothermal recourses (Haneberg et al., 1999; Barbier, 2002). These techniques, as well as tracer tests (Adams, 2001), have a large potential to provide deep insights into the movement of subsurface water and the impact of injection and production activity on fluid flow. However, in many cases, the prerequisite for such analysis is the existence of prospecting wells. 


\subsection{Numerical sensitivity study}

The exploration of geothermal reservoirs, however, does not only include identification of zones with sufficient temperature and permeability, but also the question for how long the resource can be utilized. This is commonly estimated using numerical experiments. However, until realisation of the timeand cost-intensive exploration methods, as described above, the structural, hydrological, and lithological parameters in the target reservoir are insufficiently constrained. In consequence, the significance of preliminary numerical models based on them is unknown. For my numerical models, I thus used data from my outcrop studies to narrow down ranges within which I tested geological parameters and their impact on reservoirs.

I intentionally developed a simple numerical model setup to estimate the impact of different structures, rock characteristics, and hydraulic gradient configurations on the fluid- and heat transport (i.e. the reservoir capacity) and to analyse which parameters need to be known and to which accuracy. I tested permeability and porosity inhomogeneities (e.g., layering) and permeability anisotropies (e.g., fractures and faults) to quantify their effect on reservoir lifetimes. My results provide important information about these parameters and their effect on the longevity of geothermal reservoirs.

I show that with increasing permeability (Fig. 7.2) and permeability heterogeneity (Fig. 7.4), the impact of the hydraulic gradient on the fluid- and heat transport increases. The threshold at which the natural hydraulic gradient needs to be considered is reached when its influence on the flow field outperforms the gradient induced by the well pressure. Since the required pumping pressure decreases with increasing permeability the hydraulic gradient gains importance at higher permeabilities. Introducing sedimentary layering (permeability contrasts) in geothermal systems reduces the usable reservoir volume. Permeability contrasts become significant if they reach about two orders of magnitude. The consequence is that in unfavourable cases (i.e. a highly permeable reservoir layer is confined by lower permeable layers and the hydraulic gradient has the same orientation as the induced flow field), the reservoir potentially depletes very fast. Therefore, when a notable hydraulic gradient is expected, knowledge of its height and direction is essential in choosing the appropriate well configuration.

In contradiction to, for example, Bär (2012) and Stober et al. (2011), but in agreement with Aliyu and Chen (2017), porosity was found to have one of the lowest impacts on the reservoir performance (Figs.7.2; Appendix 2.2 - Fig. A3), among the parameters tested. In detail, my models show that the significance of porosity decreases dramatically when the permeability value reaches $10^{-13} \mathrm{~m}^{2}$, as recommended for geothermal reservoirs (Jung et al., 2002). Thus, in porous reservoirs, in order of priority, the main factors that control reservoir quality are: permeability, the hydraulic gradient properties, permeability contrasts, porosity.

In the case of a fractured reservoir, the impact of the permeability-anisotropy direction with respect to the doublet's spatial configuration is most important. When the anisotropy direction is in-line with the doublet location, the reservoir cools down very quickly, caused by the impeded peripheral fluid flow, which restricts the fluid access to a larger rock volume (Fig. 7.7). This observation holds for almost all hydraulic gradient configurations. In general, the reinjected fluid preferably follows the trend of permeability anisotropy. These observations are in agreement with previous studies by Bakhsh et al. (2016), Bense and Person (2006), Biemans (2014), and Fu et al. (2016). Premature cooling of the extremely channelled fluid flow can only be counteracted by high hydraulic gradients that hinder the reinjected cold fluid to reach the production well. However, permeability anisotropies not in-line with the production- and injection wells, promise longer reservoir lifetimes, since the cold re-injected fluid is unlikely to reach the production well. 
Comparable observations have been made by Bakhsh et al. (2016), who used a discrete single fracture model, designed with Comsol Multiphysics. They showed that the presence of only one fracture, which connected production and injection well, reduces the thermal breakthrough time significantly. They also showed that matrix permeability and porosity of the host rock only marginally influences the temperature development, when permeability is dominantly provided by fractures. Biemans (2014) further showed, based on DFN models of different fracture networks, that increasing fracture density also reduces thermal breakthrough times. This is because accessible heat capacity is reduced to small volumes in the close vicinity of thermally interacting fractures, i.e. heat transport is less supported by the rock matrix.

In consequence, and supported by my models, I predict that geothermal reservoirs that utilize conducting faults with a high fracture-induced permeability and anisotropy parallel to the fault, have the high potential to channel the re-injected fluid to the production well, in most hydraulic gradient configurations (Sections 7.3.5 and 7.4). This results in fast depletion of the reservoir. The successful exploitation of fault-related reservoirs, requires thus detailed knowledge of fracture orientation, fracture-permeability anisotropy, the amount of non-stratabound and stratabound fractures, as well as the permeability contrast of different layers, damage zone thickness, and most important the hydraulic gradient to choose appropriate well locations to prevent fast thermal breakthrough.

Based on my modelling study and the findings of the comparative outcrop analogue study at Brühl (Chapter 6), I propose that fault zones as potential geothermal reservoirs must be considered critically. I conclude that exploitation of less structurally-complex reservoirs is not only less risky, but promises also improved reservoir lifetimes.

That my simplified models give results that are, at least qualitatively, comparable to real geological reservoirs is shown by several examples of geothermal projects worldwide. For instance, rapid temperature drops (within 3 years) of individual wells in four of the five geothermal facilities using multiple wells in Japan in the 70's (Otake, Onuma, Onikobe, Hotchobaru, and Kakkonda - see Fig. 8.1; Bödvarsson and Tsang, 1982; Horne, 1982b; DiPippo, 2005) were observed. In the Hotchobaru field, for example, the location of the injection and production wells were initially chosen to prevent early thermal breakthrough caused by an unfavourable oriented hydraulic gradient. The observed fast decrease in temperature was later found to be caused by altered pressure conditions in the reservoir due to reinjection and production, i.e. the flow field within the reservoir was reversed due to the pumping activity. The reason was that the cold re-injected fluid circulated within the spatially-restricted damage zone from the injection to the production well (Bödvarsson and Tsang, 1982; Horne, 1982b; DiPippo, 2005).

With respect to the geothermal site Brühl, I surmise that, even after gaining more details from the well logs from the geothermal reservoir, estimates of the reservoir performance are still highly speculative. From the well measurements, it is known that the integrated overall rock permeability is about $10^{-13} \mathrm{~m}^{2}$. Based on the borehole geophysics, and the known high heterogeneity of the Buntsandstein Formation, a succession of high and low permeable beds must be considered. According to my numerical models, it is very likely that this configuration will restrict the vertical extent, and therefore the volume, of the reservoir. Based on the FMI data, the fracture system, which is likely part of a damage zone, is roughly parallel to the NNW-SSE-oriented fault, and highly conductive (Chapter 6).It was planned to place both the production- and the injection well in this damage zone, i.e. in a zone of high permeability anisotropy (Reinecker et al., 2015; Fig. 8.2b). I suggest that it is likely that this highly conductive fracture system would form a direct flow pathway between the doublets; this was also envisaged during prospection (Reinecker et al., 2015). The expected low E-W-directed hydraulic gradient, 
derived from the hydraulic gradient map (Fig. 3.6), is unlikely to disturb the direct flow path between the planned wells, as shown in my models in Figs. 7.11f and 7.12. Under these conditions, I consider that there would have been a high risk that the reservoir depletes thermally within a very short time. However, between the originally-planned well locations, an E-W-directed fault has been identified in the 3-D seismics (Fig. 8.2a). The hydraulic effect of this fault (i.e. whether positive, negative or not relevant), can only be speculated, since no details about the fault are available. It is possible that this fault compartmentalizes the whole reservoir, i.e. it constitutes a barrier to fluid flow and hinders the injected cold fluid reaching the production well. It is also possible that this fault does not affect the fluid path. A third option could be that if the fault is conducting that it drains the injected cold fluid either completely or partly in E-W-direction and so eventually it improves the reservoir's performance over time.

My findings indicate that, especially in faulted reservoirs, where direct circulation between the wells is aimed at, a number of alternative borehole configurations should be considered to impede early thermal depletion. One possible configuration, as proposed by Fu et al. (2016), could be to place an injection well in the centre of a number of production wells to increase so the exploitable reservoir volume.
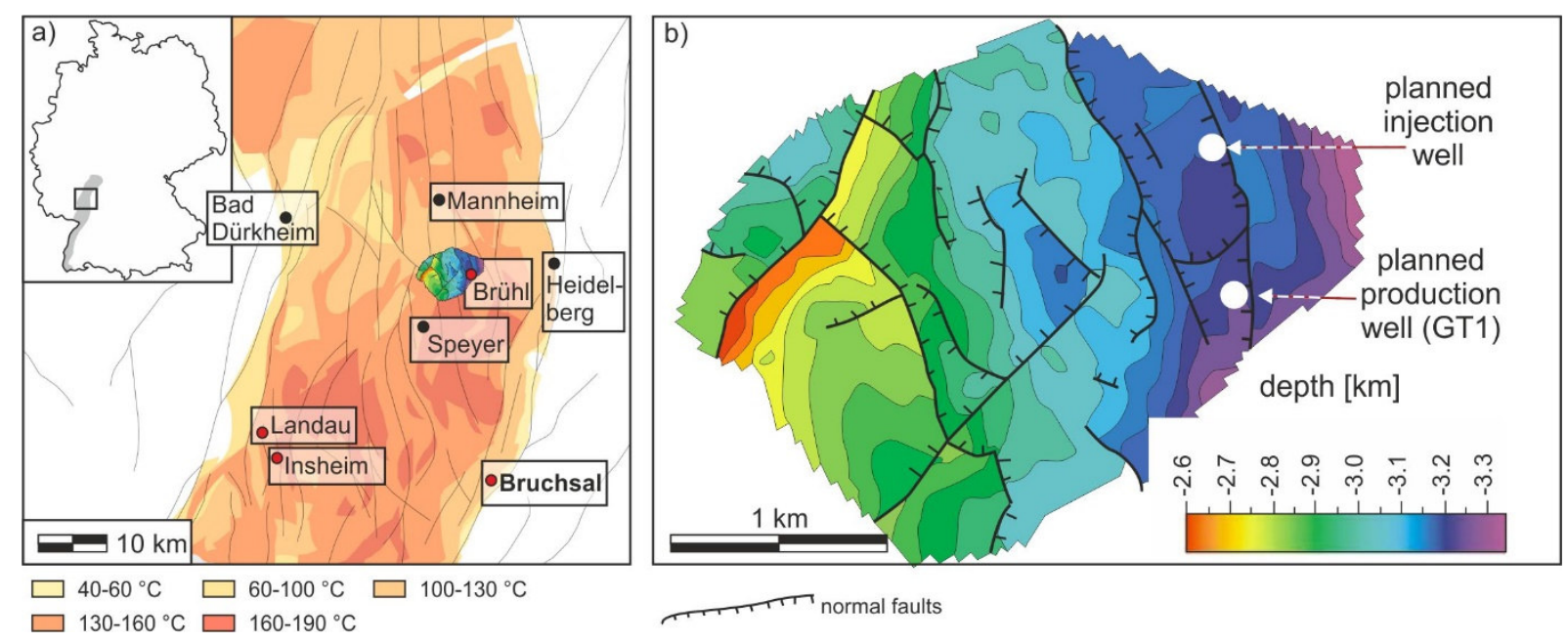

Figure 8.2: Overview of the planned geothermal site location - Brühl. a) Location and temperature distribution in 3 km depth of the study area (URL6: GeotIS). b) Isopach map of the top of Middle Buntsandstein with fault traces, the well Brühl GT1, and the initial planned location for the injection well (figures modified after Lotz, 2014a, b).

In general, high structural complexity, which commonly includes permeability anisotropy due to variations in fracture systems, layer-induced heterogeneities at different scales, or the highly variable permeability structures of faults, together with the often-unknown hydraulic gradient, make it extremely challenging, if not impossible, to reliably determine the capacity of a geothermal project from reservoir parameters that were derived from classical exploration. Reasonable estimates on reservoir performance require data from a sufficient number of prospecting wells, subsequent tracer tests, and detailed analysis of rock heterogeneities and anisotropies. The latter should preferably be known to the highest possible degree for the whole reservoir volume. 


\subsection{Possible improvements of numerical models of geothermal reservoirs}

My sensitivity study aims to improve the understanding of the role and interplay of prime parameters e.g. porosity, permeability, and structural framework, on reservoir quality. To focus on these parameters, I made a number of simplifications regarding e.g. geometry, and the use of continuum models (Section 3.3.4). In the following, I discuss these simplifications and give advice on improvements that may in the future allow for more accurate models and in consequence more meaningful predictions of reservoir quality.

Continuum models, as applied in this study, are known to underestimate the tendency for flow channelling in individual fractures and within fracture networks (Li et al., 2016). Discrete fracture models (DFN) in contrast, do not have this tendency, and instead provide the opportunity to analyse precisely the effect of diverse fracture patterns. However, it is only possible to take benefit from this approach if the fracture patterns are known in detail. This is commonly not the case, since fracture patterns are mostly only known in two dimensions. Thus, the advantages of the DFN approach cannot, at least in most cases, be realized, due to the lack of input parameters (Chapter 6). In contrary, fracture system idealization in DFN modelling and the uncertainty in the fracture characteristics, has the potential to increase the error remarkably. However, if I compare my sensitivity study with those of, e.g., Biemans (2014), Fu et al. (2016), and Bakhsh et al. (2016), the general conclusions drawn from all these studies are comparable. Thus, in most cases, I consider that the continuum approach is sufficient.

A similar statement applies to simplifications made in terms of permeability and porosity properties of different layers and for the idealized fault zone structures, as I applied in my models. The main reason why this simplification is justified is because internal inhomogeneities are commonly unknown. To generate a site-specific model setup, with near real-life conditions, findings from direct sub-surface measurements i.e. from drill cores, would be necessary in unrealistically high spatial resolution. In addition, using data from outcrops, where properties can be observed in a high spatial resolution, can also be misleading, since we showed for the case of the Brühl GT1 borehole that these data could not be transferred to depth with the required accuracy. Nevertheless, outcrop data are still of prime importance to e.g. constrain permeability contrasts that may remarkably change reservoir performance.

I recommend that further sensitivity studies are carried out that not only include the effects of such changes in rock properties at a smaller scale, but also evaluate different reservoir configurations in more detail, e.g. they include small-scale changes in fault characteristics or vary the well configurations.

In my sensitivity study, I included neither the effect of variable rock storage capacity i.e. the ability of a rock to take in or to release fluid under varying pressure conditions, nor the effect of heterogeneity in heat conductivity and heat capacity. All three parameters largely depend on the rock's porosity (Kolditz, 1997; Stober et al., 2011). Since I used open model boundaries that allow a continuous inflow of hot thermal water, changes in the storage capacity do not influence my model results. To which degree the storage capacity influences the reservoir performance must be tested separately, but it can be considered less important, since in most geothermal facilities, production does not take place without re-injection, i.e. the water supply can be considered sufficient. To which extent heterogeneity in the heat capacity and heat conductivity influence the temperature development, i.e. due to preferred discharge of heat in rock volumes with high heat conductivity, is another topic worthy of further examination. 
Some simplifications of my models were made with regards the underlying physics in the model set up. For example, I decoupled the fluid viscosity and density from temperature and thus inhibited density-driven convection. This simplification can be assumed to have only a minor influence on the models since density-driven convection cells require a combination of high rock permeability $\left(>10^{-14} \mathrm{~m}^{2}\right)$, high geothermal gradients, and large homogenous rock volumes (Hochstein, 1988). Since less permeable beds in Triassic Buntsandstein and Muschelkalk rocks are common (e.g., Bär, 2012; Jodocy and Stober, 2011; Reinecker et al., 2015; Sass and Hoppe, 2011), and I found that permeability contrasts of $10^{2}$ between different layers are sufficient to supress hydraulic connection; I consider this simplification valid. In addition, the decoupling of temperature and fluid properties resulted in a decrease in computational time by a factor of about 100 in the cases of the homogenous reservoir models.

Nevertheless, I also tested a fully coupled model (fluid properties dependent on temperature, Appendix 2.1 - Fig. A2), and found that convection does not alter the general temperature development of the simulated geothermal system. The only difference I observed was a lower cooling rate in the homogeneous models (scenario 1 - homogeneous reservoir models). Thus, density-driven fluid convection, at least in my models, in which fluid flow in heterogeneous rocks is mainly forced by high pressure differences, should be negligible, as also proposed by Kaiser et al. (2011).

Another important physical factor that can affect the reservoir quality, but was not part of this study, is the chemical composition of aqueous fluids. As a result, scaling and corrosion of geothermal wells is often (e.g., Genesys, Soultz-sous-Forêts), but not always observed, and constitutes a not yet completely understood phenomena (Mundhenk et al., 2013). 


\section{Main findings and conclusions}

\subsection{Main findings to key questions}

Here I summarize the main findings of my thesis, based on the aims and questions outlined in Section 1.5 (Fig. 1.3).

\section{1) Are fault zones suitable reservoirs for geothermal energy production in terms of permeability?}

Based on our outcrop analogue studies, faults in formations with thick layers and weakly-pronounced mechanical contrasts among the layers (Trochitenkalk-mo1, Buntsandstein-sm), form damage zones that have a higher fracture connectivity and a higher amount of non-stratabound fractures compared to damage zones that are hosted in thinly-bedded layers with high mechanical contrast (e.g., the Triassic "Nodosus Beds"-mo2). Also, fracture apertures were often found to be enhanced for fractures oriented sub-parallel to analysed faults and to the strike of prominent URG faults. A general pattern for fracture-system parameter could not be observed. This holds for the background fracture patterns as well as for fracture patterns in damage zones. In addition, no preferred orientation or systematic could be found for sealing structures that was valid over a large area. Nevertheless, we conclude that fault damage zones, especially in lithologies with higher bed thicknesses, constitute structures of enhanced permeability.

\section{2) Can outcrop studies improve knowledge of the subsurface?}

My main findings regarding this question are twofold. First outcrop studies are the only way to study properties of the reservoir rocks and fracture-system parameter in detail before the cost intense drilling process. In addition, if a sufficient number of outcrops exists, studying them may provide some trends and scaling laws for the analysed parameters. Therefore, outcrop analogue studies will always remain an important part of subsurface exploration.

However, at least for my study area, I show that several parameters that are relevant for the quality of geothermal reservoirs (e.g. fracture-system parameter), could not be predicted from one outcrop to another. Other parameters, such as porosity and permeability correlate in the study area, but still with a high variability in parameter values, which, according to my modelling experiment, is too high to make reliable predictions about the reservoir. Moreover, when comparing the results from the outcrop analogue studies with that derived from the envisaged reservoir, most parameters were not comparable, did not followed trends observed at the surface, and could not have been predicted. This shows that the commonly-proposed high potential of outcrop analogue studies must be seen more critically, at least in structural complex areas. This conclusion holds especially true for fault-related geothermal reservoirs, in which an extra amount of uncertainty is introduced by the heterogeneous nature of faults and their damage zones.

However, after detailed knowledge of the reservoir system has been gained, an appropriate outcrop analogue can be chosen and used to improve understanding of the reservoir system by using better geological parameters in the numerical model.

3) What is the potential of fault-related geothermal reservoirs and what are the most promising reservoir conditions?

Faults and their damage zones promise high permeabilities and are thus in the focus of exploration. The evaluation of the local potential of a faulted reservoir however necessitates cost- and time-consuming methods and is subject to a high degree of uncertainty. When the desired conditions in a faulted reservoir are encountered, at the same time the high permeability has the large potential to 
restrict the amount of energy available. This is especially the case for the often-favoured doublet configuration, with production- and injection well placed in the high permeable damage zone. This is because the usable reservoir volume becomes restricted to the highly permeable damage zone, i.e. to a comparatively small volume, and in consequence a significantly reduced reservoir lifetime must be considered. For modelling the lifetime of such reservoir structures, I therefore recommend choosing the maximum values for permeability. Nevertheless, the findings of my sensitivity study, given that reservoir parameters are properly known, can be used to maximize reservoir performance by choosing appropriate well locations.

Based on the manifold problems in exploration and exploitation of fault-related reservoirs, I suggest shifting the focus in the future on reservoirs of less structural complexity in order to increase the success rate in exploration.

\subsection{Conclusions and outlook}

Many studies based on outcrop analogues, including this thesis, show that fault zones have the potential to either increase, or decrease permeability. However, fault zone attributes that control permeability, as well as other basic parameters that determine reservoir quality, cannot be prospected with the required accuracy using outcrop surveys alone. Additionally, fault zones with their heterogenous nature, increase the uncertainties in the prediction of reservoir-quality significantly.

I found that qualitative structural and sedimentary heterogeneities tend to reduce the usable reservoir volume, and so the lifetime of the reservoir. When aiming to explore fault-related reservoirs, it must be considered that both reduced reservoir permeability as well as high damage zone permeability and anisotropy are likely to have negative impacts on the reservoir performance. The latter is due to the possible restriction of the usable reservoir volume to the damage zone, which in consequence increases the possibility of fast thermal depletion.

I propose that the doubtless given, but also difficult to exploit potential of fault-related reservoirs for geothermal energy production should be critically re-evaluated. Reported difficulties in exploration and exploitation of faulted reservoirs lead me to the conclusion that the usable potential of fault zones is overstated. Thus, I conclude that geothermal prospection should focus more on structurally-less complex reservoirs that are easier to explore, easier to exploit, and promise longer reservoir lifetimes.

Another important implication of my thesis is that a geothermal resource should be carefully monitored during exploitation to improve the understanding of the specific reservoir conditions. Findings of these observations could then be used to plan further suitable well configurations at the same site to increase the amount of exploitable geothermal energy, and also to learn for future projects.

With respect to the development of better exploration methods, it would be valuable to carefully reevaluate failed and successful geothermal projects. It would be helpful at such locations to use a suite of new and classical exploration methods, and test whether they would have delivered the reservoir parameters that were later observed.

In summary, the focus in future research must shift more towards studies that analyse the influence of heterogeneities e.g. faults, layers, etc. on the quality of geothermal reservoirs. In addition, the oftenunconsidered effect of the hydraulic gradient must be analysed in more detail, especially its impact on structurally-complex reservoirs. This knowledge must then be combined with reliable data from pilot boreholes, including core analysis, geophysical data, tracer test, and surface-related geophysical methods to improve predictions of geothermal reservoirs. Only a responsible combination of all the available methods has the potential to increase significantly the success rate in finding and exploiting longlasting geothermal reservoirs. 


\section{References}

Adams, M.C., 2001. Preface. Geothermics 30 (6), 571-572. http://dx.doi.org/10.1016/\$0375-6505(01)00029-3.

Adler, P.M., Thovert, J.-F., Mourzenko, V.V., 2013. Fractured porous media. Oxford University Press. http://dx.doi.org/10.1093/acprof:oso/9780199666515.001.0001.

Afşar, F., Westphal, H., Philipp, S. L., 2014. How facies and diagenesis affect fracturing of limestone beds and reservoir permeability in limestone-marl alternations. Marine and Petroleum Geology 57, 418-432. http://dx.doi.org/10.1016/j.marpetgeo.2014.05.024.

Agemar, T., Alten, J.A., Gorling, L., Gramenz, J., Kuder, J., Suchi, E., Moeck, Inga S., Weber, J., v. Hartmann, H., Stober, I., Hese, F., Thomsen, C., 2016. Die Rolle von tiefreichenden Störungszonen bei der geothermischen Energienutzung: Teilprojekt A: Verbundvorhaben "StörTief" Endbericht, Leibniz-Institut für Angewandte Geophysik, 0325623A, 01144290 https://www.tib.eu/de/suchen/id/TIBKAT\%3A878209506/Die-Rolle-vontiefreichenden-St\%C3\%B6rungszonen-bei/?tx_tibsearch_search\%5Bsearchspace\%5D=tn.

Agemar, T., Schellschmidt, R., Schulz, R., 2012. Subsurface temperature distribution in Germany. Geothermics 44, 65-77. http://dx.doi.org/10.1016/j.geothermics.2012.07.002.

Agosta, F., Alessandroni, M., Antonellini, M., Tondi, E., Giorgioni, M., 2010. From fractures to flow: A field-based quantitative analysis of an outcropping carbonate reservoir. Tectonophysics 490 (3-4), 197-213. http://dx.doi.org/10.1016/j.tecto.2010.05.005.

Agosta, F., Kirschner, D.L., 2003. Fluid conduits in carbonate-hosted seismogenic normal faults of central Italy. Solid Earth 108 (B4). http://dx.doi.org/10.1029/2002jb002013.

Agosta, F., Prasad, M., Aydin, A., 2007. Physical properties of carbonate fault rocks, Fucino Basin (central Italy): Implications for fault seal in platform carbonates. Geofluids 7 (1), 19-32. http://dx.doi.org/10.1111/j.14688123.2006.00158.x.

Agosta, F., Ruano, P., Rustichelli, A., Tondi, E., Galindo-Zaldívar, J., Sanz de Galdeano, C., 2012. Inner structure and deformation mechanisms of normal faults in conglomerates and carbonate grainstones (Granada Basin, Betic Cordillera, Spain): Inferences on fault permeability. Journal of Structural Geology 45, 4-20. http://dx.doi.org/10.1016/j.jsg.2012.04.003.

Aliyu, M.D., Chen, H.P., 2017. Sensitivity analysis of deep geothermal reservoir: Effect of reservoir parameters on production temperature. Energy 129, 101-113. http://dx.doi.org/10.1016/j.energy.2017.04.091.

Andreae, A., Benecke, E.W., Schumacher, E., Van Werveke, L., 1892. Abhandlungen zur geologischen Specialkarte von Elsass-Lothringen: Erläuterungen zu Blatt Weissenburg. Strassburger Druckerei und Verlagsanstalt, Strassburg.

Antonellini, M., Aydin, A., 1994. Effect of faulting on fluid flow in porous sandstones: Petrophysical properties. AAPG Bulletin 78 (3), 355-377.

Antonellini, M., Aydin, A., 1995. Effect of faulting on fluid flow in porous sandstones: Geometry and spatial distribution. AAPG Bulletin 79 (5), 642-670.

Aretz, A., Bär, K., Götz, A.E., Sass, I., 2016. Outcrop analogue study of Permocarboniferous geothermal sandstone reservoir formations (northern Upper Rhine Graben, Germany): impact of mineral content, depositional environment and diagenesis on petrophysical properties. International Journal of Earth Sciences 105 (5), 1431-1452. http://dx.doi.org/10.1007/s00531-015-1263-2.

Aydin, A., 1978. Small faults formed as deformation bands in sandstone. Pure and Applied Geophysics 116 (4-5), 913-930. http://dx.doi.org/10.1007/BF00876546.

Aydin, A., Basu, A., 2005. The Schmidt hammer in rock material characterization. Engineering Geology 81 (1), 114. http://dx.doi.org/10.1016/j.enggeo.2005.06.006.

Aydin, A., Johnson, A.M., 1978. Development of faults as zones of deformation bands and as slip surfaces in sandstone. Pure and Applied Geophysics 116 (4-5), 931-942. http://dx.doi.org/10.1007/BF00876547.

Bachmann, G.H., Beutler, G., Hagdorn, H., Hauschke, N., 1999. Stratigraphie der Germanischen Trias, in: Hauschke, N., Wilde, V. (Eds.), Trias, eine ganz andere Welt: Mitteleuropa im frühen Erdmittelalter. Pfeil, München, pp. 81-104.

Backhaus, E., 1974. Limnische und fluviatile Sedimentation im südwestdeutschen Buntsandstein. Geologische Rundschau 63 (3), 925-942. http://dx.doi.org/10.1007/bf01821318.

Baisch, S., Carbon, D., Dannwolf, U., Delacou, B., Devaux, M., Dunand, F., Jung, R., Koller, M., Martin, C., Sartori, R.S., Vörös, R., 2009. Deep heat mining basel: Seismic risk analysis - SERIANEX. Schlussbericht, Bundesamt für 


\subsection{Conclusions and outlook}

Energie BFE, 153'682 / 102' 869 .

www.bfe.admin.ch/php/modules/enet/streamfile.php?file=000000010350.pdf.

Bakhsh, K.J., Nakagawa, M., Arshad, M., Dunnington, L., 2016. Modelling thermal breakthroughtimes in sedimentary geothermal systems, using Comsol Multiphysics. Proceedings, 41st Workshop on Geothermal Reservoir Engineering, Stanford, California, p. 11, February 22-24.

Balsamo, F., Storti, F., Salvini, F., Silva, A.T., Lima, C.C., 2010. Structural and petrophysical evolution of extensional fault zones in low-porosity, poorly lithified sandstones of the Barreiras Formation, NE Brazil. Journal of Structural Geology 32 (11), 1806-1826. http://dx.doi.org/10.1016/j.jsg.2009.10.010.

Bär, K., 2012. Untersuchung der tiefengeothermischen Potenziale von Hessen. PhD Thesis, Technische Universität Darmstadt. urn:nbn:de:tuda-tuprints-30671.

Barbier, E., 2002. Geothermal energy technology and current status: an overview. Renewable and Sustainable Energy Reviews 6 (1), 3-65. http://dx.doi.org/10.1016/S1364-0321(02)00002-3.

Barbier, M., Hamon, Y., Callot, J.-P., Floquet, M., Daniel, J.-M., 2012. Sedimentary and diagenetic controls on the multiscale fracturing pattern of a carbonate reservoir: The Madison Formation (Sheep Mountain, Wyoming, USA). Marine and Petroleum Geology 29 (1), 50-67.

Barton, C.A., Zoback, M.D., 1994. Stress perturbations associated with active faults penetrated by boreholes: Possible evidence for near-complete stress drop and a new technique for stress magnitude measurement. Journal of Geophysical Research: Solid Earth 99 (B5), 9373-9390. http://dx.doi.org/10.1029/93jb03359.

Barton, Colleen A., Zoback, Mark D., Moos, Daniel, 1995. Fluid flow along potentially active faults in crystalline rock. Geology 23 (8), 683-686. http://dx.doi.org/10.1130/0091-7613(1995)023<0683:ffapaf>2.3.co;2.

Barton, N., Choubey, V., 1977. The shear strength of rock joints in theory and practice. Rock Mechanics 10 (1-2), 1-54. http://dx.doi.org/10.1007/BF01261801.

Bartz, J., 1974. Die Mächtigkeit des Quartärs im Oberrheingraben, in: Ilies, J.H., Fuchs, K. (Eds.), Approaches to taphrogenesis. Schweizerbart, Stuttgart, pp. 78-87.

Bastesen, E., Braathen, A., 2010. Extensional faults in fine grained carbonates - analysis of fault core lithology and thickness-displacement relationships. Journal of Structural Geology 32 (11), 1609-1628. http://dx.doi.org/10.1016/j.jsg.2010.09.008.

Bastesen, E., Braathen, A., Nøttveit, H., Gabrielsen, R.H., Skar, T., 2009. Extensional fault cores in micritic carbonate - Case studies from the Gulf of Corinth, Greece. Journal of Structural Geology 31 (4), 403-420. http://dx.doi.org/10.1016/j.jsg.2009.01.005.

Bastesen, E., Braathen, A., Skar, T., 2013. Comparison of scaling relationships of extensional fault cores in tight carbonate and porous sandstone reservoirs. Petroleum Geoscience 19 (4), 385-398. http://dx.doi.org/10.1144/petgeo2011-020.

Bauer, K., Moeck, I., Norden, B., Schulze, A., Weber, M., Wirth, H., 2010. Tomographic P wave velocity and vertical velocity gradient structure across the geothermal site Groß Schönebeck (NE German Basin): Relationship to lithology, salt tectonics, and thermal regime. Journal of Geophysical Research: Solid Earth 115 (B8), n/a-n/a. http://dx.doi.org/10.1029/2009jb006895.

BDEW, 2016. Erneuerbare Energien und das EEG: Zahlen, Fakten, Grafiken (2016): Anlagen, installierte Leistung, Stromerzeugung, EEG-Auszahlungen, Marktintegration der Erneuerbaren Energien und regionale Verteilung der EEG-

Anlagen, https://www.bdew.de/internet.nsf/res/7BD63123F7C9A76BC1257F61005AA45F/\$file/160218_En ergie-Info_Erneuerbare\%20Energien\%20und\%20das\%20EEG_2016_final.pdf, p. 85.

Beall, J.J., Adams, M.C., Hirtz, P.N., 1994. R-13 tracing of injection in The Geysers. Geothermal Resources Council Transactions 18, 151-159.

Bear, J., 1993. Modelling flow and contaminant transport in fractured rocks, in: Bear, J., Tsang, C.F., De Marsily, G. (Eds.), Flow and contaminant transport in fractured rock. Academic Press, New York, pp. 1-37.

Becker, A., Paladini, S., 1990. In situ-Spannungen in Nord- und Mitteleuropa. Schriftenreihe Angewandte Geologie, Karlsruhe.

Bense, V.F., Gleeson, T., Loveless, S.E., Bour, O., Scibek, J., 2013. Fault zone hydrogeology. Earth-Science Reviews 127, 171-192. http://dx.doi.org/10.1016/j.earscirev.2013.09.008.

Bense, V.F., Person, M.A., 2006. Faults as conduit-barrier systems to fluid flow in siliciclastic sedimentary aquifers. Water Resources Research 42 (5). http://dx.doi.org/10.1029/2005wr004480. 
Berg, S. E., Troll, V. R., Deegan, F. M., Burchardt, S., Krumbholz, M., Mancini, L., Polacci, M., Carracedo, J. C., Soler, V., Arzilli, F., Brun, F., 2016. Heterogeneous vesiculation of 2011 El Hierro xeno-pumice revealed by X-ray computed microtomography. Bulletin of Volcanology 78 (12), 85. http://dx.doi.org/10.1007/s00445-0161080-x.

Berg, S.S., Skar, T., 2005. Controls on damage zone asymmetry of a normal fault zone: Outcrop analyses of a segment of the Moab fault, SE Utah. Journal of Structural Geology 27 (10), 1803-1822. http://dx.doi.org/10.1016/j.jsg.2005.04.012.

Bergerat, F., 1987. Stress fields in the European platform at the time of Africa-Eurasia collision. Tectonics 6 (2), 99-132. http://dx.doi.org/10.1029/TC006i002p00099.

Bergman, T.L., Lavine, A.S., Incropera, F.P., Dewitt, D.P., 2011. Introduction to heat transfer, 6 ed. John Wiley \& Sons, INC.

Berkowitz, B., Bear, J., Braester, C., 1988. Continuum models for contaminant transport in fractured porous formations. Water Resources Research 24 (8), 1225-1236. http://dx.doi.org/10.1029/WR024i008p01225.

Biemans, B.C.B., 2014. The influence of fractures on geothermal heat production in the Roer Valley Graben. Master Thesis, Delft University of Technology. https://repository.tudelft.nl/islandora/object/uuid\%3Ac616f3da-5ae9-4a92-b9d7-c435d3ad81b0.

Billi, A., Salvini, F., Storti, F., 2003. The damage zone-fault core transition in carbonate rocks: Implications for fault growth, structure and permeability. Journal of Structural Geology 25 (11), 1779-1794. http://dx.doi.org/10.1016/S0191-8141(03)00037-3.

Bödvarsson, G.S., Tsang, C.F., 1982. Injection and thermal breakthrough in fractured geothermal reservoirs. Solid Earth 87 (B2), 1031-1048. http://dx.doi.org/10.1029/JB087iB02p01031.

Boigk, H., Schöneich, H., 1970. Die Tiefenlage der Permbasis im nördlichen Teil des Oberrheingrabens, in: Illies, J.H., Mueller, S. (Eds.), Graben Problems: Proceedings of an International Rift Symposium held in Karlsruhe 1968. Schweizerbart, Stuttgart, pp. 45-55.

Boro, H., Bertotti, G., Hardebol, N.J., 2013. Distributed fracturing affecting isolated carbonate platforms, the Latemar Platform Natural Laboratory (Dolomites, North Italy). Marine and Petroleum Geology 40, 69-84. http://dx.doi.org/10.1016/j.marpetgeo.2012.09.012.

Bourquin, Sylvie, Peron, Samuel, Durand, Marc, 2006. Lower Triassic sequence stratigraphy of the western part of the Germanic Basin (west of Black Forest): Fluvial system evolution through time and space. Sedimentary Geology 186 (3-4), 187-211. http://dx.doi.org/10.1016/j.sedgeo.2005.11.018.

Braathen, A., Tveranger, J., Fossen, H., Skar, T., Cardozo, N., Semshaug, S.E., Bastesen, E., Sverdrup, E., 2009. Fault facies and its application to sandstonereservoirs. AAPG Bulletin - The American Association of Petroleum Geologists 93 (7), 891-917. http://dx.doi.org/10.1306/03230908116.

Brown, E.T., 1981. Rock characterisation testing and monitoring: ISRM suggested methods, Oxford: Pergamon for the Commission on Testing Methods, International Society for Rock Mechanics.

Bruhn, D., Manzella, A., Vuataz, F., Faulds, J., Moeck, I., Erbas, K., 2010. Exploration methods, in: Huenges, E. (Ed.), Geothermal energy systems - exploration, development, and utilization. WILEY-VCH, pp. 37-112. http://dx.doi.org/10.1002/9783527630479.ch2.

Bruhn, R.L., Parry, W.T., Yonkee, W.A., Thompson, T., 1994. Fracturing and hydrothermal alteration in normalfault zones. Pure and Applied Geophysics 142 (3), 609-644. http://dx.doi.org/10.1007/BF00876057.

Brun, J.P., Gutscher, M.A., ECORS-DEKORP-Team, 1992. Deep crustal structure of the Rhine Graben from ECORSDEKORP seismic reflection data: A summary. Tectonophysics 208 (1-3), 139-147. http://dx.doi.org/10.1016/0040-1951(92)90340-C.

Brun, J.P., Wenzel, F., ECORS-DEKORP-Team, 1991. Crustal-scale structure of the southern Rhinegraben from ECORS-DEKORP seismic reflection data. Geology 19 (7), 758-762. http://dx.doi.org/10.1130/00917613(1991)019<0758:cssots>2.3.co;2.

Budding, M.C., Inglin, H.F., 1981. A reservoir geological model of the Brent Sands in southern Cormorant, in: Illing, L.V., Hobson, G.D. (Eds.), Petroleum Geology of the Continental Shelf of Northwestern Europe. John Wiley and Sons, Institute of Petroleum, London, pp. 326-334.

Byerlee, J., 1978. Friction of rocks. Pure and Applied Geophysics 116 (4-5), 615-626. http://dx.doi.org/10.1007/BF00876528.

Byerlee, J., 1993. Model for episodic flow of high-pressure water in fault zones before earthquakes. Geology 21 (4), 303-306. http://dx.doi.org/10.1130/0091-7613(1993)021<0303:MFEFOH>2.3.CO;2. 


\subsection{Conclusions and outlook}

Caine, J.S., Bruhn, R.L., Forster, C.B., 2010. Internal structure, fault rocks, and inferences regarding deformation, fluid flow, and mineralization in the seismogenic Stillwater normal fault, Dixie Valley, Nevada. Journal of Structural Geology 32 (11), 1576-1589. http://dx.doi.org/10.1016/j.jsg.2010.03.004.

Caine, J.S., Evans, J.P., Forster, C.B., 1996. Fault zone architecture and permeability structure. Geology 24 (11), 1025-1028. http://dx.doi.org/10.1130/0091-7613(1996)024<1025:FZAAPS>2.3.CO;2.

Caine, J.S., Forster, C.B., 1999. Fault zone architecture and fluid flow: Insights from field data and numerical modeling, in: Haneberg, W.C., Mozley, P.S., Moore, J.C., Goodwin, L.B. (Eds.), Faults and subsurface fluid flow in the shallow crust. American Geophysical Union, Washington DC, pp. 101-127. http://dx.doi.org/10.1029/GM113p0101.

Caine, J.S., Minor, S.A., 2009. Structural and geochemical characteristics of faulted sediments and inferences on the role of water in deformation, Rio Grande Rift, New Mexico. GSA Bulletin 121 (9-10). http://dx.doi.org/10.1130/b26164.1.

Caine, J.S., Tomusiak, S.R.A., 2003. Brittle structures and their role in controlling porosity and permeability in a complex Precambrian crystalline-rock aquifer system in the Colorado Rocky Mountain Front Range. GSA Bulletin 115 (11), 1410-1424. http://dx.doi.org/10.1130/B25088.1.

Cargill, J.S., Shakoor, A., 1990. Evaluation of empirical-methods for measuring the uniaxial compressive strength of rock. International Journal of Rock Mechanics and Mining Sciences \& Geomechanics Abstracts 27 (6), 495 503. http://dx.doi.org/10.1016/0148-9062(90)91001-N.

Carlson, R.L., Gangi, A.F., 1985. Effect of cracks on the pressure dependence of $P$ wave velocities in crystalline rocks. Solid Earth 90 (B10), 8675-8684. http://dx.doi.org/10.1029/JB090iB10p08675.

Chang, C.D., Zoback, M.D., Khaksar, A., 2006. Empirical relations between rock strength and physical properties in sedimentary rocks. Journal of Petroleum Science and Engineering 51 (3-4), 223-237. http://dx.doi.org/10.1016/j.petrol.2006.01.003.

Chesnaux, R., Allen, D.M., Jenni, S., 2009. Regional fracture network permeability using outcrop scale measurements. Engineering Geology 108 (3-4), 259-271. http://dx.doi.org/10.1016/j.enggeo.2009.06.024.

Chester, F.M., Logan, J.M., 1986. Implications for mechanical properties of brittle faults from observations of the Punchbowl fault zone, California. Pure and Applied Geophysics 124 (1-2), 79-106. http://dx.doi.org/10.1007/BF00875720.

Childs, C., Manzocchi, T., Walsh, J.J., Bonson, C.G., Nicol, A., Schopfer, M.P.J., 2009. A geometric model of fault zone and fault rock thickness variations. Journal of Structural Geology 31 (2), 117-127. http://dx.doi.org/10.1016/j.jsg.2008.08.009.

Childs, C., Watterson, J., Walsh, J.J., 1996. A model for the structure and development of fault zones. Journal of the Geological Society 153 (3), 337-340. http://dx.doi.org/10.1144/gsjgs.153.3.0337.

Cladouhos, T., Petty, S., Foulger, G., Julian, B., Mike Fehler, M., 2010. Injection induced seismicity and geothermal energy. GRC Transactions 34, 1213-1220.

Clauer, N., Liewig, N., Ledesert, B., Zwingmann, H., 2008. Thermal history of Triassic sandstones from the Vosges Mountains-Rhine Graben rifting area, NE France, based on K-Ar illite dating. Clay Minerals 43 (3), 363-379. http://dx.doi.org/10.1180/claymin.2008.043.3.03.

Clausen, J.A., Gabrielsen, R.H., Johnsen, E., Korstgard, J.A., 2003. Fault architecture and clay smear distribution. Examples from field studies and drained ring-shear experiments. Norwegian Journal of Geology 83 (2), 131146.

Dachroth, W., 1985. Fluvial sedimentary styles and associated depositional environments in the Buntsandstein west of river rhine in Saar Area and Pfalz (F.R. Germany) and Vosges (France), in: Mader, D. (Ed.), Aspects of fluvial sedimentation in the Lower Triassic Buntsandstein of Europe. Springer, Berlin, pp. 197-248. http://dx.doi.org/10.1007/BFb0010521.

Dawers, N.H., Anders, M.H., 1995. Displacement-length scaling and fault linkage. Journal of Structural Geology 17 (5), 607-614. http://dx.doi.org/10.1016/0191-8141(94)00091-D.

De Dreuzy, J.R., Davy, P., Bour, O., 2001. Hydraulic properties of two-dimensional random fracture networks following a power law length distribution: 1. Effective connectivity. Water Resources Research 37 (8), 2065 2078. http://dx.doi.org/10.1029/2001WR900011.

De Marsily, G., 1986. Quantitative hydrogeology: Groundwater hydrology for engineers, 1 ed. Academic Press, New York. 
Deere, D.U., Miller, R.P., 1966. Engineering classification and index properties for intact rock. Air Force Weapons Laboratory, New Mexico.

Delouis, B., Haessler, H., Cisternas, A., Rivera, L., 1993. Stress tensor determination in France and neighbouring regions. Tectonophysics 221 (3-4), 413-438. http://dx.doi.org/10.1016/0040-1951(93)90171-F.

Dezayes, C., Lerouge, C., Sanjuan, B., Ramboz, C., Brach, M., 2015. Toward a better understanding of the fluid circulation in the Rhine Graben for a better geothermal exploration of the deep basins. Proceedings World Geothermal Congress 2015 Melbourne, Australia, p. 13,

Dèzes, P., Schmid, S.M., Ziegler, P.A., 2004. Evolution of the European Cenozoic Rift System: Interaction of the Alpine and Pyrenean orogens with their foreland lithosphere. Tectonophysics 389 (1-2), 1-33. http://dx.doi.org/10.1016/j.tecto.2004.06.011.

DIN-22024, 1989. Rohstoffuntersuchungen im Steinkohlenbergbau; Bestimmung der Spaltzugfestigkeit von Festgesteinen. Deutsches Institut für Normung. Beuth Verlag $\mathrm{GmbH}$, Berlin.

DIN-EN-1926, 2007. Prüfverfahren für Naturstein - Bestimmung der einachsigen Druckfestigkeit; Deutsche Fassung EN 1926:2006. Deutsches Institut für Normung. Beuth Verlag GmbH, Berlin.

DiPippo, R., 2005. Geothermal power plants: Principles, applications and case studies, 1st ed. Elsevier Science, Oxford.

DiPippo, R., 2016. Geothermal power generation: Developments and innovation. Woodhead Publishing.

Dockrill, B., Shipton, Z.K., 2010. Structural controls on leakage from a natural $\mathrm{CO}_{2}$ geologic storage site: Central Utah, U.S.A. Journal of Structural Geology 32 (11), 1768-1782. http://dx.doi.org/10.1016/j.jsg.2010.01.007.

Doebl, F., 1967. The Tertiary and Pleistocene sediments of the northern and central part of the Upper Rhinegraben, in: Rothe, J.P., Sauer, K. (Eds.), The Rhinegraben progress report 1967. Abhandlungen des Geologischen Landesamtes Baden-Württemberg, Schweizerbart, Stuttgart, Germany, pp. 48-54.

Doebl, F., Olbrecht, W., 1974. An isobath map of the Tertiary base in the Rhinegraben, in: Illies, J.H., Fuchs, K. (Eds.), Approaches to Taphrogenesis. Schweizerbart, Stuttgart, pp. 71-72.

Doebl, F., Teichmüller, R., 1979. Zur Geologie und heutigen Geothermik im mittleren Oberrhein-Graben. Fortschritte in der Geologie von Rheinland und Westfalen 27, 1-17.

Domenico, P.A., Palciauskas, V.V., 1973. Theoretical analysis of forced convective heat transfer in regional ground-water flow. GSA Bulletin 84 (12), 3803-3814. http://dx.doi.org/10.1130/00167606(1973)84<3803:taofch>2.0.c0;2.

Dunn, D.E., LaFountain, . J., Jackson, R.E., 1973. Porosity dependence and mechanism of brittle fracture in $\begin{array}{lllll}\text { sandstones. Journal of } & \text { 2403-2417. }\end{array}$ http://dx.doi.org/10.1029/JB078i014p02403.

Durst, H., 1991. Aspects of exploration history and structural styles in the Rhine Graben area, in: Spencer, A.M. (Ed.), Generation, accumulation, and production of Europe's hydrocarbons. Oxford University Press, New York, pp. 247-261.

Economides, M.J., Nolte, K.G, 2000. Reservoir stimulation, 3rd ed. Wiley, New York.

Edel, J.B., Schulmann, K., Rotstein, Y., 2007. The Variscan tectonic inheritance of the Upper Rhine Graben: Evidence of reactivations in the Lias, Late Eocene-Oligocene up to the recent. International Journal of Earth Sciences 96 (2), 305-325. http://dx.doi.org/10.1007/s00531-006-0092-8.

Ehrenberg, S.N., 1989. Assessing the relative importance of compaction processes and cementation to reduction of porosity in sandstones; discussion; compaction and porosity evolution of Pliocene sandstones, Ventura Basin, California: Discussion. AAPG Bulletin 73 (10), 1274-1276.

Eisbacher, G.H., Fielitz, W., 2010. Karlsruhe und seine Region Nordschwarzwald: Kraichgau, Neckartal, südlicher Odenwald, Oberrhein-Graben, Pfälzerwald und westliche Schwäbische Alb. Gebrüder Bornträger, BerlinStuttgart.

Engesser, W., Leiber, J., 1991. Geologischer Bau und Landschaftsgeschichte, in: Schütz, J. (Ed.), Der Rhein-NeckarKreis. Theiss, Stuttgart, pp. 17-49.

England, W.A., Townsend, C., 1998: The Effects of faulting on production form a shallow marine reservoir - A study of the relative importance of fault parameters. in: Society of Petroleum Engineers, Petroleum Engineers Annual Technical Conference and Exhibition, New Orleans, Louisiana, USA., 27-30 September. 


\subsection{Conclusions and outlook}

Evans, J.P., Forster, C.B., Goddard, J.V., 1997. Permeability of fault-related rocks, and implications for hydraulic structure of fault zones. Journal of Structural Geology 19 (11), 1393-1404. http://dx.doi.org/10.1016/S01918141(97)00057-6.

Fairhurst, C.E., Hudson, J.A., 1989. International society for rock mechanics commission on testing methods. International Journal of Rock Mechanics and Mining Sciences \& Geomechanics Abstracts 26 (5), 427-434. http://dx.doi.org/10.1016/0148-9062(89)90938-8.

Fairhurst, C.E., Hudson, J.A., 1999. Draft ISRM suggested method for the complete stress-strain curve for intact rock in uniaxial compression. International Journal of Rock Mechanics and Mining Sciences 36 (3), 281-289. http://dx.doi.org/10.1016/S0148-9062(99)00006-6.

Fairley, J.P., Hinds, J.J., 2004. Field observation of fluid circulation patterns in a normal fault system. Geophysical Research Letters 31 (19). http://dx.doi.org/10.1029/2004gl020812.

Fan, Y., Li, H., Miguez-Macho, G., 2013. Global patterns of groundwater table depth. Science 339 (6122), 940943. http://dx.doi.org/10.1126/science.1229881.

Farrell, N. J. C., Healy, D., Taylor, C. W., 2014. Anisotropy of permeability in faulted porous sandstones. Journal of Structural Geology 63 (Supplement C), 50-67. http://dx.doi.org/doi.org/10.1016/j.jsg.2014.02.008.

Faulds, J.E., Hinz, H., 2015. Favorable tectonic and structural settings of geothermal systems in the Great Basin region, Western USA: Proxies for discovering blind geothermal systems. Proceedings World Geothermal Congress 2015, Melbourne, Australia, p. 6, 19-25 April 2015.

Faulkner, D. R., Mitchell, T. M., Jensen, E., Cembrano, J., 2011. Scaling of fault damage zones with displacement and the implications for fault growth processes. Journal of Geophysical Research: Solid Earth 116 (B5). http://dx.doi.org/10.1029/2010jb007788.

Faulkner, D.R., Jackson, C.A.L., Lunn, R.J., Schlische, R.W., Shipton, Z.K., Wibberley, C.A.J., Withjack, M.O., 2010. A review of recent developments concerning the structure, mechanics and fluid flow properties of fault zones. Journal of Structural Geology 32 (11), 1557-1575. http://dx.doi.org/10.1016/j.jsg.2010.06.009.

Faulkner, D.R., Lewis, A.C., Rutter, E.H., 2003. On the internal structure and mechanics of large strike-slip fault zones: Field observations of the Carboneras fault in southeastern Spain. Tectonophysics 367 (3-4), $235-251$. http://dx.doi.org/10.1016/S0040-1951(03)00134-3.

Feist-Burkhardt, S., Götz, A.E., Szulc, J., Borkhataria, R., Geluk, M., Haas, J., Hornung, J., Jordan, P., Kempf, O., Michalik, J., Nawrocki, J., Reinhardt, L., Ricken, W., Röhling, H.-G., Rüffer, T., Török, A., Zühlke, R., 2008. Triassic, in: McCann, T. (Ed.), The geology of central Europe Volume 2: Mesozoic and Cenozoic. Geological Society, London, pp. 749-821.

Fitch, Peter J. R., Lovell, Mike A., Davies, Sarah J., Pritchard, Tim, Harvey, Peter K., 2015. An integrated and quantitative approach to petrophysical heterogeneity. Marine and Petroleum Geology 63 (Supplement C), 82-96. http://dx.doi.org/10.1016/j.marpetgeo.2015.02.014.

Flodin, E., Aydin, A., 2004. Faults with asymmetric damage zones in sandstone, Valley of Fire State Park, southern Nevada. Journal of Structural Geology 26 (5), 983-988. http://dx.doi.org/10.1016/j.jsg.2003.07.009.

Flóvenz, O.G., Saemundsson, K., 1993. Heat-flow and geothermal processes in Iceland. Tectonophysics 225 (1-2), 123-138. http://dx.doi.org/10.1016/0040-1951(93)90253-G.

Folk, R.L., Ward, W.C., 1957. Brazos River bar [Texas]; a study in the significance of grain size parameters. Journal of Sedimentary Research 27 (1), 3-26. http://dx.doi.org/10.1306/74D70646-2B21-11D7-8648000102C1865D

Fossen, H., 2010. Structural geology, 2end ed. Cambridge University Press, New York.

Fossen, H., Schultz, R.A., Shipton, Z.K., Mair, K., 2007. Deformation bands in sandstone: A review. Journal of the Geological Society 164 (4), 755-769. http://dx.doi.org/10.1144/0016-76492006-036.

Foxford, K.A., Walsh, J.J., Watterson, J., Garden, I.R., Guscott, S.C., Burley, S.D., 1998. Structure and content of the Moab Fault Zone, Utah, USA, and its implications for fault seal prediction. Geological Society, London, Special Publications 147, 87-103. http://dx.doi.org/10.1144/gsl.sp.1998.147.01.06.

Franco, Alessandro, Villani, Marco, 2009. Optimal design of binary cycle power plants for water-dominated, medium-temperature geothermal fields. Geothermics 38 (4), 379-391. http://dx.doi.org/10.1016/j.geothermics.2009.08.001.

Freeze, R.A., Cherry, J.A., 1979. Groundwater, 1st ed. Prentice-Hall. Englewood Cliffs, USA.

Fu, P., Hao, Y., Walsh, S.D.C., Carrigan, C.R., 2016. Thermal drawdown-induced flow channeling in fractured geothermal reservoirs. Rock Mechanics and Rock Engineering 49 (3), 1001-1024. http://dx.doi.org/10.1007/s00603-015-0776-0. 
Gan, Q., Elsworth, D., 2016. Production optimization in fractured geothermal reservoirs by coupled discrete fracture network modeling. Geothermics 62, 131-142. http://doi.org/10.1016/j.geothermics.2016.04.009.

GeORG-Projektteam, 2013. Geopotenziale des tieferen Untergrundes im Oberrheingraben. Abschlussbericht des Interreg-Projekts GeORG, https://produkte.Igrb-bw.de/cms/c373_data.pdf.

Gibson, R.G., 1998. Physical character and fluid-flow properties of sandstone-derived fault zones, in: Coward, M.P., Daltaban, T.S., Johnson, H. (Eds.), Structural geology in reservoir characterization, pp. 83-97.

Glassley, W.E., 2014. Geothermal energy: Renewable energy and the environment, 2end ed. CRC Press, Taylor \& Francis Group.

Gleeson, T., Befus, K.M., Jasechko, S., Luijendijk, E., Cardenas, M.B., 2016. The global volume and distribution of modern groundwater. Nature Geoscience 9 (2), 161-167. http://dx.doi.org/10.1038/ngeo2590.

GMTED, 2010. Global multi-resolution terrain elevation data 2010 (GMTED2010). https://topotools.cr.usgs.gov/GMTED_viewer/.

Gringarten, A.C., Sauty, J.P, 1975. A theoretical study of heat extraction from aquifers with uniform regional flow. Journal of Geophysical Research 80 (35), 4956-4962. http://doi.org/10.1029/JB080i035p04956.

Gringarten, A.C., Witherspoon, P.A., Ohnishi, Y., 1975. Theory of heat extraction from fractured hot dry rock. Journal of Geophysical Research 80 (8), 1120-1124. http://doi.org/10.1029/JB080i008p01120.

Groshong, R.H., 1996. Construction and validation of extensional cross sections using lost area and strain, with application to the Rhine Graben. Geological Society, London, Special Publications 99 (1), 79-87. http://dx.doi.org/10.1144/gsl.sp.1996.099.01.07.

Gross, M.R., Eyal, Y., 2007. Throughgoing fractures in layered carbonate rocks. GSA Bulletin 119 (11-12), 13871404. http://dx.doi.org/10.1130/0016-7606(2007)119[1387:TFILCR]2.0.CO;2.

Gross, M.R., Fischer, M.P., Engelder, T., Greenfield, R.J., 1995. Factors controlling joint spacing in interbedded sedimentary rocks: Integrating numerical models with field observations from the Monterey Formation, USA. Geological Society, London, Special Publications $92 \quad$ (1), 215-233. http://dx.doi.org/10.1144/GSL.SP.1995.092.01.12.

Gudmundsson, A, Simmenes, T.H., Larsen, B., Philipp, S.L., 2010. Effects of internal structure and local stresses on fracture propagation, deflection, and arrest in fault zones. Journal of Structural Geology 32 (11), 16431655. http://dx.doi.org/10.1016/j.jsg.2009.08.013.

Gudmundsson, A., 2011. Rock fractures in geological processes, 1st ed. Cambridge University Press, New York.

Haenel, R., Staroste, E., 1988. Atlas of geothermal resources in the European Community, Austria and Switzerland. Th. Schaefer.

Hagdorn, H., Nitsch, E., 2009. The Germanic Triassic in its southwest german type area in: Hagdorn, H., Nitsch, E., Aigner, T., Simon, T. (Eds.), 6th International Triassic Field Workshop (Pan-European Correlation of the Triassic) Triassic of Southwest Germany 175th. Anniversary of the Foundation of the Triassic System, http://www.stratigraphie.de/perm-trias/trias_workshops.htm.

Hagdorn, H., Simon, T., 2005. Der Muschelkalk in der Stratigraphischen Tabelle von Deutschland 2002. Newsletters on Stratigraphy 41 (1-3), 143-158. http://dx.doi.org/10.1127/0078-0421/2005/0041-0143.

Haneberg, W.C., Mozley, P.S., Moore, J.C., Goodwin, L.B., 1999. Faults and subsurface fluid flow in the shallow crust. American Geophysical Union, Washington DC.

Häring, M.O., 2007. Geothermische Stromproduktion aus Enhanced Geothermal Systems (EGS): Stand der Technik. Report, Geothermal Explorers Ltd, Pratteln, CH-4133. http://www.geoex.ch/assets/uploads/publikationen/egs061207.pdf.

Häring, M.O., Schanz, U., Ladner, F., Dyer, B.C., 2008. Characterisation of the Basel 1 enhanced geothermal system. Geothermics 37 (5), 469-495. http://dx.doi.org/10.1016/j.geothermics.2008.06.002.

Heffer, K.J., Lean, J., 1993. Earth stress orientation - a control on, and a guide to, flooding directionality in a majority of reservoirs, in: Linville, W. (Ed.), Reservoir characterization III. PennWell Books, Tulsa, pp. 799-822.

Heidbach, O., Tingay, M., Barth, A., Reinecker, J., Kurfeß, D., Müller, B., 2008. The World Stress Map Database Release 2008. http://dx.doi.org/10.1594/GFZ.WSM.Rel2008.

Hestir, K., Long, J.C.S., 1990. Analytical expressions for the permeability of random two-dimensional Poisson fracture networks based on regular lattice percolation and equivalent media theories. Solid Earth 95 (B13), 21565-21581. http://dx.doi.org/10.1029/JB095iB13p21565. 


\subsection{Conclusions and outlook}

Heynekamp, M.R., Goodwin, L.B., Mozley, P.S., Haneberg, W.C., 1999. Controls on faultzone architecture in poorly lithified sediments, Rio Grande Rift, New Mexico: Implications for fault-zone permeability and fluid flow, in: Haneberg, W.C., Mozley, P.S., Casey Moore, J., Goodwin, L.B. (Eds.), Faults and subsurface fluid flow in the shallow crust, AGU Geophysical Monograph, pp. 27-51. http://dx.doi.org/10.1029/GM113p0027.

Hobbs, D.W., 1967. The formation of tension joints in sedimentary rocks: An explanation. Geological Magazine 104 (6), 550-556. http://dx.doi.org/10.1017/S0016756800050226.

Hochstein, M.P., 1988. Assessment and modelling of geothermal reservoirs (small utilization schemes). Geothermics 17 (1), 15-49. http://dx.doi.org/10.1016/0375-6505(88)90004-1.

Hoek, E., Brown, E.T., 1997. Practical estimates of rock mass strength. International Journal of Rock Mechanics and Mining Sciences 34 (8), 1165-1186. http://dx.doi.org/10.1016/S1365-1609(97)80069-X.

Holt, R.M., Nes, O.-M., Fjaer, E., 2005. In-situ stress dependence of wave velocities in reservoir and overburden rocks. The Leading Edge 24 (12), 1268-1274. http://dx.doi.org/10.1190/1.2149650.

Horne, R.N., 1982a. Effects of water injection into fractured geothermal reservoirs: A summary of experience worldwide. Report, Stanford Geothermal Program, Interdisciplinary Research in Engineering and Earth Sciences, Stanford University, Stanford, California, SGP-TR-57 https://pangea.stanford.edu/ERE/research/geoth/publications/techreports/SGP-TR-057.pdf.

Horne, R.N., 1982b. Geothermal reinjection experience in Japan. Journal of Petroleum Technology 34 (3). http://dx.doi.org/10.2118/9925-PA.

Howell, J.A., Martinius, A.W., Good, T.R., 2014. The application of outcrop analogues in geological modelling: A review, present status and future outlook. Geological Society, London, Special Publications 387 (1). http://dx.doi.org/10.1144/sp387.12.

Huenges, E., 2010. Geothermal energy systems: Exploration, development, and utilization, 1st ed. Wiley-VCH Verlag $\mathrm{GmbH} \& \mathrm{Co} . \mathrm{KGaA}$, Weinheim.

Huenges, E., Hoth, P., Scheytt, T., 1999. Technisch nutzbare Erdwärmevorkommen, in: Kaltschmitt, M., Huenges, E., Wolf, H. (Eds.), Energie aus Erdwärme. Deutscher Verlag für Grundstoffindustrie, Stuttgart, pp. 40-59.

Hull, J., 1988. Thickness displacement relationships for deformation zones. Journal of Structural Geology 10 (4), 431-435. http://dx.doi.org/10.1016/0191-8141(88)90020-X.

Illies, J.H., 1972. The Rhine Graben rift system-plate tectonics and transform faulting. Geophysical surveys 1 (1), 27-60. http://dx.doi.org/10.1007/BF01449550.

Illies, J.H., 1975. Intraplate tectonics in stable Europe as related to plate tectonics in the Alpine system. Geologische Rundschau 64 (1), 677-699. http://dx.doi.org/10.1007/bf01820690.

Illies, J.H., 1977. Ancient and recent rifting in the Rhinegraben. Geologie En Mijnbouw 56 (4), 329-350.

Illies, J.H., Greiner, G., 1978. Rhinegraben and Alpine system. GSA Bulletin 89 (5), 770-782. http://dx.doi.org/10.1130/0016-7606(1978)89<770:RATAS>2.0.CO;2.

Illies, J.H., Greiner, G., 1979. Holocene movements and state of stress in the Rhinegraben rift system. Tectonophysics 52 (1-4), 349-359. http://dx.doi.org/10.1016/0040-1951(79)90245-2.

Ishii, E., Funaki, H., Tokiwa, T., Ota, K., 2010. Relationship between fault growth mechanism and permeability variations with depth of siliceous mudstones in northern Hokkaido, Japan. Journal of Structural Geology 32 (11), 1792-1805. http://dx.doi.org/10.1016/j.jsg.2009.10.012.

Iwamori, H., 1997. Heat sources and melting in subduction zones. Solid Earth 102 (B7), 14803-14820. http://dx.doi.org/10.1029/97jb01036.

Jodocy, M., Stober, I., 2011. Porositäten und Permeabilitäten im Oberrheingraben und südwestdeutschen Molassebecken. Erdöl, Erdgas, Kohle 127 (1), 20-28.

Jolie, Egbert, Klinkmueller, Matthias, Moeck, Inga, 2015. Diffuse surface emanations as indicator of structural permeability in fault-controlled geothermal systems. Journal of Volcanology and Geothermal Research 290 (Supplement C), 97-113. http://dx.doi.org/10.1016/j.jvolgeores.2014.11.003.

Jourde, H., Flodin, E.A., Aydin, A., Durlofsky, L.J., Wen, X.H., 2002. Computing permeability of fault zones in eolian sandstone from outcrop measurements. AAPG Bulletin 86 (7), 1187-1200.

Jung, R., 2007. Stand und Aussichten der Tiefengeothermie in Deutschland. Erdöl, Erdgas, Kohle 123 (2).

Jung, R., Röhling, S., Ochmann, N., Rogge, S., Schellschmidt, R., Schulz, R., Thielmann, T., 2002. Abschätzung des technischen Potenzials der geothermischen Stromerzeugung und der geothermischen Kraft-WärmeKopplung (KWK) in Deutschland. Report, Institut für Geowissenschaftliche Gemeinschaftsaufgaben 
(Hannover, BGR), Insitut für Energiewirtschaft und Rationelle Energieanwendung (IER) der Universität Stuttgart, Archiv-Nr. 122458.

Junghans, W.D., 2003. Fazies, Zyklizität, Petrophysik und Paläomagnetik im Buntsandstein der Bohrung Kraichgau 1002 (SW-Deutschland). PhD Thesis, Eberhard Karls Universaität Tübingen. Thüringer geowissenschaftliche Arbeiten: Reihe A-69.

Kaiser, B.O., Cacace, M., Scheck-Wenderoth, M., Lewerenz, B., 2011. Characterization of main heat transport processes in the northeast German Basin: Constraints from 3-D numerical models. Geochemistry, Geophysics, Geosystems 12 (7). http://dx.doi.org/10.1029/2011gc003535.

Katz, Y., Weinberger, R., Aydin, A., 2004. Geometry and kinematic evolution of Riedel shear structures, Capitol Reef National Park, Utah. Journal of Structural Geology 26 (3), 491-501. http://dx.doi.org/10.1016/j.jsg.2003.08.003.

Kemeny, J., Cook, N.G.W., 1986. Effective moduli, nonlinear deformation and strength of cracked elastic solid. International Journal of Rock Mechanics and Mining Sciences 23 (2), 107-118. http://dx.doi.org/10.1016/0148-9062(86)90337-2.

Kennedy, B.M., Kharaka, Y.K., Evans, W.C., Ellwood, A., DePaolo, D.J., Thordsen, J., Ambats, G., Mariner, R.H., 1997. Mantle fluids in the San Andreas Fault system, California. Science 278 (5341), 1278-1281. http://dx.doi.org/10.1126/science.278.5341.1278.

Keogh, K.J., Martinius, A.W., Osland, R., 2007. The development of fluvial stochastic modelling in the Norwegian oil industry: A historical review, subsurface implementation and future directions. Sedimentary Geology 202 (1-2), 249-268. http://dx.doi.org/10.1016/j.sedgeo.2007.05.009.

Kleinschnitz, M., Engesser, W., 2009. Erläuterungen zu Blatt L 6718 Heidelberg-Süd. In: Regierungspräsidium Freiburg, Landesamt für Geologie, Rohstoffe und Bergbau (Eds.), Karte der mineralischen Rohstoffe von Baden-Württemberg, 1:50 000 (Freiburg i. Br). p. 242.

Kley, J., Voigt, T., 2008. Late Cretaceous intraplate thrusting in central Europe: Effect of Africa-Iberia-Europe convergence, not Alpine collision. Geology 36 (11), 839-842. http://dx.doi.org/10.1130/g24930a.1.

Knipe, R.J., 1993. The influence of fault-zone processes and diagenesis on fluid flow, in: Horbury, A.D., Robinson, A. (Eds.), Diagenesis and basin development. American Association of Petroleum Geologists, pp. 135-151.

Knott, S.D., 1994. Fault zone thickness versus displacement in the Permo-Triassic sandstones of NW England. Journal of the Geological Society 151 (1), 17-25. http://dx.doi.org/10.1144/gsjgs.151.1.0017.

Kolditz, O., 1997. Strömung, Stoff- und Wärmetransport im Kluftgestein. Gebrüder Bornträger, Berlin, Stuttgart.

Krumbholz, M., Hieronymus, C.F., Burchardt, S., Troll, V. R., Tanner, D.C., Friese, N., 2014a. Weibull-distributed dyke thickness reflects probabilistic character of host-rock strength. Nature Communications 5. http://dx.doi.org/10.1038/ncomms4272.

Krumbholz, M., Vollbrecht, A., Aschoff, M., 2014b. Recent horizontal stress directions in basement rocks of southern Sweden deduced from open microcracks. Journal of Structural Geology 65, 33-43. http://dx.doi.org/10.1016/j.jsg.2014.03.006.

Kruseman, G.P., Ridder, N.A., 1992. Analysis and evaluation of pumping test data 2end ed. International Institute for Land Reclamation and Improvement, Netherlands.

Kurz, W., Imber, J., Wibberley, C.A.J., 2008. The internal structure of fault zones: Fluid flow and mechanical properties. Geological Society, London, Special Publications 299 (1-3). http://dx.doi.org/10.1144/SP299.1.

Lander, R. H., Laubach, S. E., 2015. Insights into rates of fracture growth and sealing from a model for quartz cementation in fractured sandstones. GSA Bulletin 127 (3-4), 516-538. http://dx.doi.org/10.1130/b31092.1.

Lander, Robert H., Larese, Richard E., Bonnell, Linda M., 2008. Toward more accurate quartz cement models: The importance of euhedral versus noneuhedral growth rates. AAPG Bulletin 92 (11), 1537-1563. http://dx.doi.org/10.1306/07160808037.

Larroque, J.M., Etchecopar, A., Philip, H., 1987. Evidence for the permutation of stresses $\sigma 1$ and $\sigma 2$ in the Alpine foreland: the example of the Rhine Graben. Tectonophysics 144 (4), 315-322. http://dx.doi.org/10.1016/0040-1951(87)90299-X.

Larroque, J.M., Laurent, Ph, 1988. Evolution of the stress field pattern in the south of the Rhine Graben from the Eocene to the present. Tectonophysics 148 (1-2), 41-58. http://dx.doi.org/10.1016/0040-1951(88)90159-X.

Larsen, B., Grunnaleite, I., Gudmundsson, A., 2010. How fracture systems affect permeability development in shallow-water carbonate rocks: An example from the Gargano Peninsula, Italy. Journal of Structural Geology 32 (9), 1212-1230. http://dx.doi.org/10.1016/j.jsg.2009.05.009. 


\subsection{Conclusions and outlook}

Laubach, S.E., Eichhubl, P., Hargrove, P., Ellis, M.A., Hooker, J.N., 2014. Fault core and damage zone fracture attributes vary along strike owing to interaction of fracture growth, quartz accumulation, and differing sandstone composition. Journal of Structural Geology 68 (Part A), 207-226. http://dx.doi.org/10.1016/j.jsg.2014.08.007.

Laubach, S.E., Fall, A.S., Copley, L.K., Marrett, R., Wilkins, S.J., 2016. Fracture porosity creation and persistence in a basement-involved Laramide fold, Upper Cretaceous Frontier Formation, Green River Basin, USA. Geological Magazine 153 (5-6), 887-910. http://dx.doi.org/10.1017/s0016756816000157.

Laubach, S.E., Olson, J.E., Gale, J.F.W., 2004. Are open fractures necessarily aligned with maximum horizontal stress? Earth and Planetary Science Letters 222 (1), 191-195. http://dx.doi.org/10.1016/j.epsl.2004.02.019.

Laubach, S.E., Olson, J.E., Gross, M.R., 2009. Mechanical and fracture stratigraphy. AAPG Bulletin 93 (11), 14131426. http://dx.doi.org/10.1306/07270909094.

Lee, C.H., Farmer, I., 1993. Fluid flow in discontinuous rocks. Chapman and Hall, London.

Lege, T., Kolditz, O., Zielke, W., 1996. Handbuch zur Erkundung des Untergrundes von Deponien und Altlasten: Band 2: Strömungs- und Transportmodellierung, 2end ed. Springer, Hamburg.

Lepper, J., Rambow, D., Röhling, H.-G., 2006. Der Buntsandstein in der Stratigraphischen Tabelle von Deutschland 2002. Newsletters on Stratigraphy 41 (1-3), 129-142. http://dx.doi.org/10.1127/0078-0421/2005/0041-0129.

Li, C.-F., Lu, Y., Wang, J., 2017. A global reference model of Curie-point depths based on EMAG2. Scientific Reports 7. http://dx.doi.org/10.1038/srep45129.

Li, T., Shiozawa, S., McClure, M.W., 2016. Thermal breakthrough calculations to optimize design of a multiplestage Enhanced Geothermal System. Geothermics 64, 455-465. http://dx.doi.org/10.1016/j.geothermics.2016.06.015.

Lindanger, M., Gabrielsen, R.H., Braathen, A., 2007. Analysis of rock lenses in extensional faults. Norwegian Journal of Geology 87 (4), 361-372.

Littke, R., Bayer, U., Gajewski, D., 2005. Dynamics of sedimentary basins: the example of the Central European Basin system. International Journal of Earth Sciences 94 (5-6), 779-781. http://doi.org/10.1007/s00531-0050036-8.

Llera, F.J., Sato, M., Nakatsuka, K., Yokoyama, H., 1990. Temperature dependence of the electrical resistivity of water-saturated rocks. Geophysics 55 (5), 576-585. http://dx.doi.org/10.1190/1.1442869.

Lotz, U., 2014a. Geothermie - Potentiale im Oberrheintal und Chancen für die kommunale Energieversorgung, Alternative Energieversorgungssysteme, http://docplayer.org/12998886-Geothermie-potentiale-imoberrheintal-und-chancen-fuer-die-kommunale-energieversorgung-dr-ulrich-lotz-leiter-explorationgeoenergy-gmbh.html.

Lotz, U., 2014b. Geothermieprojekt Brühl - Tiefengeothermie in Baden-Württemberg unter schwierigen Rahmenbedingungen. GoeTherm 2014, Offenburg, 21.02.2014.

Loveless, S.E., Bense, V., Turner, J., 2011. Fault architecture and deformation processes within poorly lithified rift sediments, Central Greece. Journal of Structural Geology 33 (11), 1554-1568. http://dx.doi.org/10.1016/j.jsg.2011.09.008.

Lunn, R.J., Shipton, Z.K., Bright, A.M., 2008. How can we improve estimates of bulk fault zone hydraulic properties? Geological Society, London, Special Publications $299 \quad$ (1), 231-237. http://dx.doi.org/10.1144/SP299.14.

Lüschen, E., Dussel, M., Thomas, R., Schulz, R., 2011. 3D seismic survey for geothermal exploration at Unterhaching, Munich, Germany. First Break 29 (1), 45-54. http://dx.doi.org/10.3997/1365-2397.2011002

Luthi, S.M. , Souhaité, P., 1990. Fracture apertures from electrical borehole scans. Geophysics 55 (7), $821-833$. http://dx.doi.org/10.1190/1.1442896.

MacDonald, P., Stedman, A., Symons , G., 1992. The UK geothermal hot dry rock R\&D programme. Proceedings, Seventeenth Workshop on Geothermal Reservoir Engineering, Stanford, California, p. 7.

Manzocchi, T., Carter, J.N., Skorstad, A., Fjellvoll, B., Stephen, K.D., Howell, J.A., Matthews, J.D., Walsh, J.J., Nepveu, M., Bos, C., Cole, J., Egberts, P., Flint, S., Hern, C., Holden, L., Hovland, H., Jackson, H., Kolbjørnsen, O., MacDonald, A., Nell, P.A.R., Onyeagoro, K., Strand, J., Syversveen, A.R., Tchistiakov, A., Yang, C., Yielding, G., Zimmerman, R.W., 2008. Sensitivity of the impact of geological uncertainty on production from faulted and unfaulted shallow-marine oil reservoirs: Objectives and methods. Petroleum Geoscience 14 (1), 3-15. http://dx.doi.org/10.1144/1354-079307-790. 
Manzocchi, T., Walsh, J.J., Nell, P., Yielding, G., 1999. Fault transmissibility multipliers for flow simulation models. Petroleum Geoscience 5 (1), 53-63. http://dx.doi.org/10.1144/petgeo.5.1.53.

Marrett, R., Laubach, S.E., Olson, J.E., 2007. Anisotropy and beyond: Geologic perspectives on geophysical prospecting for natural fractures. The Leading Edge 26 (9), 1106-1111. http://dx.doi.org/10.1190/1.2780778.

Masum, M., 2015. Low-Temperature Geothermal Systems in Sedimentary Basin and Their Prospect in Bangladesh Proceedings World Geothermal Congress 2015, Melbourne, Australia, p. 10, 19-25 April 2015.

McBride, E.F., 1963. A classification of common sandstones. Journal of Sedimentary Research 33 (3), 664-669. http://dx.doi.org/10.1306/74d70ee8-2b21-11d7-8648000102c1865d.

Medeiros, W.E., do Nascimento, A.F., Alves da Silva, F.C., Destro, N., Demetrio, J.G.A., 2010. Evidence of hydraulic connectivity across deformation bands from field pumping tests: Two examples from Tucano Basin, NE Brazil. Journal of Structural Geology 32 (11), 1783-1791. http://dx.doi.org/10.1016/j.jsg.2009.08.019.

Meier, L., Eisbacher, G.H., 1991. Crustal kinematics and deep structure of the northern Rhine Graben. Tectonics 10 (3), 621-630. http://dx.doi.org/10.1029/91TC00142.

Meier, S., 2016. Fault zones in potential geothermal reservoir rocks in the Upper Rhine Graben: Characteristics, permeability implications, and numerical stress field models. PhD Thesis, Georg-August-Universität Göttingen. http://hdl.handle.net/11858/00-1735-0000-0028-87D5-5.

Meier, S., Bauer, J F., Philipp, S.L., 2015. Fault zone characteristics, fracture systems and permeability implications of Middle Triassic Muschelkalk in Southwest Germany. Journal of Structural Geology 70, 170-189. http://dx.doi.org/10.1016/j.jsg.2014.12.005.

Meixner, J., Schill, E., Grimmer, J.C., Gaucher, E., Kohl, T., Klingler, P., 2016. Structural control of geothermal reservoirs in extensional tectonic settings: An example from the Upper Rhine Graben. Journal of Structural Geology 82, 1-15. http://dx.doi.org/10.1016/j.jsg.2015.11.003.

Ménillet, F., Benecke, E.W., Schumacher, E., 1989. Carte géologique de la France à 1:50 000, Lembach: Document cartographique, Orléans.

Miall, A.D., 1978. Lithofacies types and vertical profile models in braided river deposits: a summary, in: Miall, A.D. (Ed.), Fluvial Sedimentology, Memoir 5, Canadian Society of Petroleum Geologists, Calgary, Alberta, Canada, pp. 597-604.

Micarelli, L., Benedicto, A., Wibberley, C.A.J., 2006a. Structural evolution and permeability of normal fault zones in highly porous carbonate rocks. Journal of Structural Geology 28 (7), 1214-1227. http://dx.doi.org/10.1016/j.jsg.2006.03.036.

Micarelli, L., Moretti, I., Jaubert, M., Moulouel, H., 2006b. Fracture analysis in the south-western Corinth rift (Greece) and implications on fault hydraulic behavior. Tectonophysics 426 (1-2), 31-59. http://dx.doi.org/10.1016/j.tecto.2006.02.022.

Minor, S.A., Hudson, M.R., 2006. Regional Survey of Structural Properties and Cementation Patterns of Fault Zones in the Northern Part of the Albuquerque Basin, New Mexico - Implications for Ground-Water Flow. Report, U.S. Geological Survey Professional 1719. https://pubs.usgs.gov/pp/1719/pdf/P1719_508.pdf.

Mitchell, T.M., Faulkner, D.R., 2009. The nature and origin of off-fault damage surrounding strike-slip fault zones with a wide range of displacements: A field study from the Atacama fault system, northern Chile. Journal of Structural Geology 31 (8), 802-816. http://dx.doi.org/10.1016/j.jsg.2009.05.002.

Moeck, I.S., 2014. Catalog of geothermal play types based on geologic controls. Renewable and Sustainable Energy Reviews 37, 867-882. http://dx.doi.org/10.1016/j.rser.2014.05.032.

Molenaar, N., Cyziene, J., Sliaupa, S., 2007. Quartz cementation mechanisms and porosity variation in Baltic $\begin{array}{lllll}\text { Cambrian } \quad \text { sandstones. } & \text { Sedimentary } & \text { Geology } & 195 & \text { (3-4), }\end{array}$ http://doi.org/10.1016/j.sedgeo.2006.07.009.

Molli, G., Cortecci, G., Vaselli, L., Ottria, G., Cortopassi, A., Dinelli, E., Mussi, M., Barbieri, M., 2010. Fault zone structure and fluid-rock interaction of a high angle normal fault in Carrara marble (NW Tuscany, Italy). Journal of Structural Geology 32 (9), 1334-1348. http://dx.doi.org/10.1016/j.jsg.2009.04.021.

Morad, S, Al-Ramadan, K, Ketzer, J M, De Ros, L F, 2010. The impact of diagenesis on the heterogeneity of sandston reservoirs: A review of the role of depositional facies and sequence stratigraphy. AAPG BulletinAmerican Association of Petroleum Geologists 94 (8), 1267-1309. http://dx.doi.org/10.1306/04211009178.

Müller, C., Siegesmund, S., Blum, P., 2010. Evaluation of the representative elementary volume (REV) of a fractured geothermal sandstone reservoir. Environmental Earth Science 61, 1713-1724. http://dx.doi.org/10.1007/s12665-010-0485-7. 


\subsection{Conclusions and outlook}

Mundhenk, N., Huttenloch, P., Sanjuan, B., Kohl, T., Steger, H., Zorn, R., 2013. Corrosion and scaling as interrelated phenomena in an operating geothermal power plant. Corrosion Science 70, 17-28. http://dx.doi.org/10.1016/j.corsci.2013.01.003.

Mutschler, T., 2004. Einaxiale Druckversuche an zylindrischen Gesteinsprüfkörpern. Bautechnik 81 (10), 825-834. http://dx.doi.org/10.1002/bate.200490194.

Narr, W., Suppe, J., 1991. Joint Spacing in Sedimentary-Rocks. Journal of Structural Geology 13 (9), 1037-1048. http://dx.doi.org/10.1016/0191-8141(91)90055-N.

Nelson, R.A., 1985. Geologic Analysis of Naturally Fractured Reservoirs, 1st ed. Gulf Publishing, Houston, Texas.

Oberdorfer, P., 2014. Heat Transport Phenomena in Shallow Geothermal Boreholes. PhD Thesis, Georg-AugustUniversität Göttingen. http://hdl.handle.net/11858/00-1735-0000-0022-5E40-0.

Ocampol, J., Pelayo, A., De Leon, J., Goyal, K., Box, T., 1998. Reservoir characteristic obtained from steam decline trends in the Cerro Prieto geothermal field. Proceedings of the 23rd Workshop on Geothermal Reservoir Engineering, Stanford, California, pp. 27-32, 26-28 January.

Odling, N.E., Gillespie, P., Bourgine, B., Castaing, C., Chiles, J.P., Christensen, N.P., Fillion, E., Genter, A., Olsen, C., Thrane, L., Trice, R., Aarseth, E., Walsh, J.J., Watterson, J., 1999. Variations in fracture system geometry and their implications for fluid flow in fractured hydrocarbon reservoirs. Petroleum Geoscience 5 (4), 373-384. http://dx.doi.org/10.1144/petgeo.5.4.373.

Odling, N.E., Roden, J.E., 1997. Contaminant Transport in Fractured Rocks with Significant Matrix Permeability, Using Natural Fracture Geometries. Applied Journal of Contaminant Hydrology 27 (3-4), 263-283. http://dx.doi.org/10.1016/S0169-7722(96)00096-4.

Ortega, O., Marrett, R., 2000. Prediction of macrofracture properties using microfracture information, Mesaverde Group sandstones, San Juan basin, New Mexico. Journal of Structural Geology 22 (5), 571-588. http://dx.doi.org/10.1016/S0191-8141(99)00186-8.

Palchik, V., 1999. Influence of Porosity and Elastic Modulus on Uniaxial Compressive Strength in Soft Brittle Porous Sandstones. Rock Mechanics and Rock Engineering 32 (4), 303-309. http://dx.doi.org/10.1007/s006030050050.

Palchik, V., Hatzor, Y.H., 2004. The influence of porosity on tensile and compressive strength of porous chalks. Rock Mechanics and Rock Engineering 37 (4), 331-341. http://dx.doi.org/10.1007/s00603-003-0020-1.

Parini, M., Acuna, J.A., Laudiano, M., 1996. Reinjected water return at Miravalles geothermal reservoir, Costa Rica: numerical modelling and observations. Proceedings of the 21st Workshop on Geothermal Reservoir Engineering, Stanford, California, pp. 127-134, 22-24 January.

Paschen, H., Oertel, D., Grünwald, R., 2003. Möglichkeiten geothermischer Stromerzeugung in Deutschland. Sachstandbericht, TAB-Büro für Technikfolgen-Abschätzung beim Deutschen Bundestag, Nr. 84. https://www.tab-beim-bundestag.de/de/pdf/publikationen/berichte/TAB-Arbeitsbericht-ab084.pdf.

Paul, J., 1982. The Lower Buntsandstein of the Germanic Basin. Geologische Rundschau 71 (3), 795-811.

Peters, G., 2007. Active Tectonics in the Upper Rhine Graben: Integration of paleoseismology, geomorphology and geomechanical modeling. PhD Thesis, Vrije University, Amsterdam. urn:NBN:nl:ui:31-1871/10879.

Petit, J.P., 1987. Criteria for the sense of movement on fault surfaces in brittle rocks. Journal of Structural Geology 9 (5-6), 597-608. http://dx.doi.org/10.1016/0191-8141(87)90145-3

Pflug, R., 1982. Bau und Entwicklung des Oberrheingrabens. Wissenschaftliche Buchgesellschaft, Darmstadt.

Philipp, S.L., 2012. Fluid overpressure estimates from the aspect ratios of mineral veins. Tectonophysics 581, 3547. http://dx.doi.org/10.1016/j.tecto.2012.01.015.

Philipp, S.L., Afsar, F., Gudmundsson, A., 2013. Effects of mechanical layering on hydrofracture emplacement and fluid transport in reservoirs. Frontiers in Earth Science 1 (4), 19. http://dx.doi.org/10.3389/feart.2013.00004.

Philipp, S.L., Gudmundsson, A., Oelrich, A.R.I., 2007. How structural geology can contribute to make geothermal projects successful. Proceedings European Geothermal Congress 2007, Unterhaching, 30 May-1 June 2007.

Philipp, S.L., Reyer, D., Meier, S., 2010. Strukturgeologische Geländestudien in Aufschlussanaloga und Permeabilitätsentwicklung in potentiellen geothermischen Reservoiren. Zeitschrift für Geologische Wissenschaften 38 (1), 49-59.

Pickett, G.R., 1963. Acoustic Character Logs and Their Applications in Formation Evaluation. Journal of Petroleum Technology 15 (6), 659-667. http://dx.doi.org/10.2118/452-PA. 
Pinder, G.F., Gray, W.G., 1977. Finite Element Simulation in Surface and Subsurface Hydrology, 1st ed. Academic Press, New York.

PK-Geothermie, Blum, R., Fritsche, H.G., Fritzer, T., Göthel, M., Huckenriede, H., Iffland, J., Kärcher, T., Kracht, M., Kuhn, W., Pasternak, M., Pester, S., Rappsilber, I., Schellschmidt, R., Schulz, R., Stober, I., Thomsen, C., Walter, T., Wolf, P., Wrede, V., 2007. Nutzungen der geothermischen Energie aus dem tiefen Untergrund (Tiefe Geothermie) - Arbeitshilfe für Geologische Dienste -. http://www.infogeo.de/dokumente/download_pool/tiefe_geothermie_arbeitshilfe_08022007.pdf.

Plenefisch, T., Bonjer, K.P., 1997. The stress field in the Rhine Graben area inferred from earthquake focal mechanisms and estimation of frictional parameters. Tectonophysics 275 (1-3), 71-97. http://dx.doi.org/10.1016/S0040-1951(97)00016-4.

Plenefisch, T., Brückner, L., Ceranna, L., Gestermann, N., Houben, G., Tischner, T., Wegler, U., Wellbrink, M., Bönnemann, C., 2015. Tiefe Geothermie - mögliche Umweltauswirkungen infolge hydraulischer und chemischer Stimulationen. Enbericht, Umwelt Bundesamt, 37EV $16 \quad 135 \quad 1$. https://www.umweltbundesamt.de/publikationen/tiefe-geothermie-moegliche-umwelt-auswirkunge.

Pribnow, Daniel, Schellschmidt, Rüdiger, 2000. Thermal tracking of upper crustal fluid flow in the Rhine graben. Geophysical Research Letters 27 (13), 1957-1960. http://dx.doi.org/10.1029/2000gl008494.

Priest, S.D., 1993. Discontinuity Analysis for Rock Engineering, 1st ed. Chapman and Hall, London, p. 473.

Priest, S.D., Hudson, J.A., 1981. Estimation of discontinuity spacing and trace length using scanline surveys. International Journal of Rock Mechanics and Mining Sciences \& Geomechanics Abstracts 18 (3), $183-197$. http://dx.doi.org/10.1016/0148-9062(81)90973-6.

Ramm, M., Bjorlykke, K., 1994. Porosity/depth trends in reservoir sandstones; assessing the quantitative effects of varying pore-pressure, temperature history and mineralogy, Norwegian Shelf data. Clay Minerals 29 (4), 475-490.

Rasband, W., 2011. ImageJ, U. S. National Institutes of Health, Bethesda, Maryland, USA, http://imagej.nih.gov/ij/, 1997-2016.

Rawling, G.C., Goodwin, L.B., 2006. Structural record of the mechanical evolution of mixed zones in faulted poorly lithified sediments, Rio Grande rift, New Mexico, USA. Journal of Structural Geology 28 (9), 1623-1639. http://dx.doi.org/10.1016/j.jsg.2006.06.008.

Rawling, G.C., Goodwin, L.B., Wilson, J.L., 2001. Internal architecture, permeability structure, and hydrologic significance of contrasting fault-zone types. Geology 29 (1), 43-46. http://dx.doi.org/10.1130/00917613(2001)029<0043:IAPSAH>2.0.CO;2.

Reicherter, K., Froitzheim, N., Jarosinski, M., Badura, J., Franzke, H.-J., Hansen, M., Hübscher, C., Müller, R., Poprawa, P., Reinecker, J., Stackebrandt, W., Voigt, T., von Eynatten, H., Zuchiewicz, W., 2008. Alpine tectonics north of the Alps, in: McCann, T. (Ed.), The Geology of Central Europe Volume 2: Mesozoic and Cenozoic. The Geological Society, London, pp. 1233-1285.

Reinecker, J., Grobe, R., Hochschild, T., Bauer, J.F., Meier, S., Philipp, S.L., Filomena, M., Stollhofen, H., Bechstädt, T., Drews, T., Miernik, G., Soyk, D., Melchert, B, 2015. Verbundprojet AuGE: Aufschlussanalogstudien und ihre Anwendbarkeit in der geothermischen Exploration - Entwicklung von Methoden zur Ermittlung von Permeabilitäten und Transmissivitäten aus Reservoir-Informationen des Oberrheingrabens. Schlussbericht Teilprojekt A, GeoThermal Engineering GmbH, Karlsruhe, 0325302A, 01090425 http://dx.doi.org/10.2314/GBV:860785203.

Renshaw, C.E., 1996. Estimation of fracture zone geometry from steady-state hydraulic head data using iterative sequential cokriging. Geophysical Research Letters 23 (19), 2685-2688. http://dx.doi.org/10.1029/96GL02415.

Reyer, D., Bauer, J.F., Philipp, S.L., 2012. Fracture systems in normal fault zones crosscutting sedimentary rocks, Northwest German Basin. Journal of Structural Geology 45, 38-51. http://dx.doi.org/10.1016/j.jsg.2012.06.002.

Reyer, D., Philipp, S.L., 2014. Empirical relations of rock properties of outcrop and core samples from the Northwest German Basin for geothermal drilling. Geothermal Energy Science 2 (1), 21-37. http://dx.doi.org/10.5194/gtes-2-21-2014.

Richter-Bernburg, G., 1974. Stratigraphische Synopsis des deutschen Buntsandsteins. Geologisches Jahrbuch A 25, 27-132. 


\subsection{Conclusions and outlook}

Riveros, K., Veloso, E., Campos, E., Menzies, A., Véliz, W., 2014. Magnetic properties related to hydrothermal alteration processes at the Escondida porphyry copper deposit, northern Chile. Mineralium Deposita 49 (6), 693-707. http://dx.doi.org/10.1007/s00126-014-0514-7.

Rogers, Stephen F., 2003. Critical stress-related permeability in fractured rocks. Geological Society, London, Special Publications 209 (1), 7-16. http://dx.doi.org/10.1144/gsl.sp.2003.209.01.02.

Rohrer, L., 2015. Fazielle und thermohydraulische Modelle zur geothermischen Eignung des Permo-Karbons im nötrdlichen Oberrheingraben. PhD Thesis, Ruprecht-Karls-Universität Heidelberg.

Rotevatn, A., Tveranger, J., Howell, J.A., Fossen, H., 2009. Dynamic investigation of the effect of a relay ramp on simulated fluid flow: geocellular modelling of the Delicate Arch Ramp, Utah. Petroleum Geoscience 15 (1), 45-58. http://dx.doi.org/10.1144/1354-079309-779.

Rupf, I., Nitsch, E., 2008. Das geologische Landesmodell von Baden-Württemberg: Datengrundlagen, technische Umsetzung und erste geologische Ergebnisse. Landesamt für Geologie, Rohstoffe und Bergbau BadenWürttemberg.

Sahagian, Dork L., Proussevitch, Alexander A., 1998. 3D particle size distributions from 2D observations: stereology for natural applications. Journal of Volcanology and Geothermal Research 84 (3), 173-196. http://dx.doi.org/10.1016/S0377-0273(98)00043-2.

Sass, I., Hoppe, A., 2011. Forschungs- und Entwicklungsprojekt „3D-Modell der geothermischen Tiefenpotenziale von Hessen". Abschlussbericht, Technische Universität Darmstadt, https://www.energieland.hessen.de/pdf/3-D-Modell-Hessen-Endbericht_(PDF,_7.300_KB).pdf.

Sauer, K., Naegele, R., Tietze, R., Kreuzkamp, H., 1982. Geothermal Inventory of the Upper Rhinegraben between Karlsruhe and Mannheim (Situated in Baden-Wuerttemberg). Report, Commission of the European $\begin{array}{lll}\text { Communities, } \quad \text { Luxembourg, } & \text { EUR-7719/XAB; }\end{array}$ https://www.tib.eu/de/suchen/id/ntis\%3Asid oai\%253Ads2\%253Antis\%252F531a00b44fe2d5c13d103c37/Geothermische-Bestandsaufnahme-des-Oberrheingrabens/?tx_tibsearch_search\%5Bsearchspace\%5D=tn.

Scheck-Wenderoth, M., Krzywiec, R., Zühlke, R., Maystrenko, Y., Froitzheim, N., 2008. Permian to Cretaceous Tectonics, in: McCann, T. (Ed.), The Geology of Central Europe Volume 2: Mesozoic and Cenozoic. The Geological Society, London, pp. 923-999.

Schellschmidt, R., Clauser, R., 1996. The Thermal Regime of the Upper Rhine Graben and the Anomaly at Soultz. Zeitschrift für Angewandte Geologie 42 (1), 40-44.

Schlumberger, 1989. Log Interpretation Principles/Applications: Houston (Schlumberger Educ. Services), SMP7017.

Scholz, C.H., 1987. Wear and Gouge Formation in Brittle Faulting. Geology 15 (6), 493-495. http://dx.doi.org/10.1130/0091-7613(1987)15<493:WAGFIB>2.0.CO;2.

Schueller, S., Braathen, A., Fossen, H., Tveranger, J., 2013. Spatial distribution of deformation bands in damage zones of extensional faults in porous sandstones: Statistical analysis of field data. Journal of Structural Geology 52, 148-162. http://dx.doi.org/10.1016/j.jsg.2013.03.013.

Schultz, R. A., 2003. A method to relate initial elastic stress to fault population strains. Geophysical Research Letters 30 (11), 1593. http://dx.doi.org/10.1029/2002GL016681.

Schulz, R., 2011. Energie aus der Tiefe: Geothermie, in: Renn, J., Schrögl, R., Zenner, H.-P. (Eds.), Herausforderung Energie: ausgewählte Vorträge der 126. Versammlung der Gesellschaft Deutscher Naturforscher und Ärzte e.V. epubli $\mathrm{GmbH}$, Berlin, pp. 53-67.

Schulz, R., Agemar, T., Alten, J.A., Brunken, J., Heber, M., Kuder, J., Kühne, K., Maul, A.A., Pester, S., Schönhofen, K., Schulz, R., Fritzer, T., Birner, J., Schneider, M., Rauppach, K., Seibt, P., Wolfgramm, M., Brandes, J., Feldrappe, H., Obst, K., Jodocy, M., Stober, I., 2009. Aufbau eines geothermischen Informationssystems für Deutschland. Abschlussbericht, LIAG Hannover, 032754. http://www.geotis.de/homepage/Ergebnisse/GeotIS_Endbericht.pdf.

Schulz, S.E., Evans, J.P., 2000. Mesoscopic structure of the Punchbowl Fault, Southern California and the geologic and geophysical structure of active strike-slip faults. Journal of Structural Geology 22 (7), 913-930. http://dx.doi.org/10.1016/S0191-8141(00)00019-5.

Schumacher, M.E., 2002. Upper Rhine Graben: Role of preexisting structures during rift evolution. Tectonics 21 (1), 1-17. http://dx.doi.org/10.1029/2001TC900022. 
Schwarz, M., Henk, A., 2005. Evolution and structure of the Upper Rhine Graben: insights from three-dimensional thermomechanical modelling. International Journal of Earth Sciences 94 (4), 732-750. http://dx.doi.org/10.1007/s00531-004-0451-2.

Schweitzer, V., Kraatz, R., 1982. Kraichgau und südlicher Odenwald, in: Gwinner, M.P. (Ed.), Sammlung Geologischer Führer. Gebrüder Borntraeger, Berlin-Stuttgart.

Shipton, Z.K., Cowie, P.A., 2001. Damage Zone and slip-surface evolution over $\mu \mathrm{m}$ zo km scales in high-porosity Navajo sandstone, Utah. Journal of Structural Geology 23 (12), 1825-1844. http://dx.doi.org/10.1016/S01918141(01)00035-9.

Shipton, Z.K., Cowie, P.A., 2003. A conceptual model for the origin of fault damage zone structures in highporosity sandstone. Journal of Structural Geology 25 (3), 333-344. http://dx.doi.org/10.1016/S01918141(02)00037-8.

Shipton, Z.K., Soden, A.M., Kirkpatrick, J. D., Bright, A.M., Lunn, R.J., 2013. How Thick is a Fault? Fault Displacement-Thickness Scaling Revisited, in: Abercrombie, R., McGarr, A., Toro, G.D., Kanamori, H. (Eds.), Earthquakes: Radiated Energy and the Physics of Faulting. American Geophysical Union, pp. 193-198. http://dx.doi.org/10.1029/170gm19.

Shook, G.M., 2001. Predicting thermal breakthrough in heterogeneous media from tracer tests. Geothermics 30 (6), 573-589. http://doi.org/10.1016/S0375-6505(01)00015-3.

Sibson, R. H., 1996. Structural permeability of fluid-driven fault-fracture meshes. Journal of Structural Geology 18 (8), 1031-1042. http://dx.doi.org/10.1016/0191-8141(96)00032-6.

Sibson, R.H., 1977. Fault rocks and fault mechanisms. Journal of the Geological Society 133 (3), $191-213$. http://dx.doi.org/10.1144/gsjgs.133.3.0191.

Sibson, R.H., 1994. Crustal stress, faulting and fluid flow. Geological Society, London, Special Publications 78, 6984. http://dx.doi.org/10.1144/GSL.SP.1994.078.01.07

Simkin, T., Tilling, R.I., Vogt, P.R., Kirby, S.H., Kimberly, P., Stewart, D.B., 2006. This Dynamic Planet: World map of volcanoes, earthquakes, impact craters and plate tectonics. Report, https://pubs.er.usgs.gov/publication/i2800.

Singhal, B.B.S., Gupta, R.P., 2010. Applied Hydrogeology of Fractured Rocks, 2 ed. Springer, London. http://dx.doi.org/10.1007/978-90-481-8799-7.

Snow, D.T., 1965. A parallel plate model of fractured permeable media. PhD Thesis, University of California, Berkeley, USA.

Snow, D.T., 1968. Rock fracture spacings, openings, and porosities. Journal of the Soil Mechanics and Foundations Division 94 (1), 73-92.

Snow, D.T., 1969. Anisotropie Permeability of Fractured Media. Water Resources Research 5 (6), 1273-1289. http://dx.doi.org/10.1029/WR005i006p01273.

Soyk, D., 2015. Diagenesis and reservoir quality of the Lower and Middle Buntsandstein (Lower Triassic), SW Germany. PhD Thesis, Ruprecht-Karls-Universität Heidelberg. urn:nbn:de:bsz:16-heidok-188713.

Sperrevik, S., Gillespie, P.A., Fisher, Q.J., Halvorsen, T., Knipe, R.J., 2002. Empirical estimation of fault rock properties. Norwegian Petroleum Society Special Publications 11, 109-125. http://dx.doi.org/10.1016/S09288937(02)80010-8.

Stapf, K.R.G., 1988. Zur Tektonik des westlichen Rheingrabenrandes zwischen Nierstein am Rhein und Wissembourg (Elsaß). Jahresberichte und Mitteilungen / Oberrheinischer Geologischer Verein 70, 399-410.

Stapf, K.R.G., 1996. Neue Erkenntnisse zur Tektonik des pfälzischen Rheingrabenrandes, in: Geiger, M. (Ed.), Haardt und Weinstraße: Beitrage zur Landeskunde. Pfälzische Gesellschaft zur Förderung der Wissenschaften, pp. 60-96.

Stauffer, D., Aharony, A., 1994. Introduction to Percolation Theory 2nd ed. Taylor \& Francis, London.

Stein, CA., 2003. Heat flow and flexure at subduction zones. Geophysical Research Letters 30 (23). http://dx.doi.org/10.1029/2003gl018478.

Steingötter, K., 2005. Geologie von Rheinland-Pfalz. Landesamt für Geologie und Bergbau Rheinland Pfalz, Schweizerbart, Stuttgart.

Stober, I., Bucher, K., 2012. Geothermie, 1st ed. Springer, Heidelberg. http://dx.doi.org/10.1007/978-3-64241763-4. 


\subsection{Conclusions and outlook}

Stober, I., Bucher, K., 2014. Hydraulic and hydrochemical properties of deep sedimentary reservoirs of the Upper Rhine Graben, Europe. Geofluids 15 (3), 464-482. http://dx.doi.org/10.1111/gfl.12122.

Stober, I., Fritzer, T., Obst, K., Schulz, R., 2011. Tiefe Geothermie - Nutzungsmöglichkeiten in Deutschland, 3rd ed. Bundesministerium für Umwelt, Naturschutz und Reaktorsicherheit, Berlin.

Stober, I., Jodocy, M., 2009. Eigenschaften geothermischer Nutzhorizonte im baden-württembergischen und französischen Teil des Oberrheingrabens. Grundwasser 14 (2), 127-137. http://dx.doi.org/10.1007/s00767009-0103-3.

Stober, I., Schmidt, R., Seithel, R., 2016. Die Rolle von tiefreichenden Störungszonen bei der geothermischen Energienutzung: Teilprojekt C: Südwestdeutschland. Endbericht, Karlsruher Institut für Technologie (KIT), Institut für Angewandte Geowissenschaften, Abteilung Geothermie, 0325623C, 01144290 https://www.tib.eu/de/suchen/id/TIBKAT\%3A880979186/Verbundvorhaben-St\%C3\%B6rtief-die-Rolle-vontiefreichenden/?tx_tibsearch_search\%5Bsearchspace\%5D=tn.

Sydney, P., Clark, J.R., 1966. Handbook of Physical Constants. Geological Society of America. http://dx.doi.org/10.1130/MEM97.

Szurlies, M., 2007. Latest Permian to Middle Triassic cyclo-magnetostratigraphy from the Central European Basin, Germany: Implications for the geomagnetic polarity timescale. Earth and Planetary Science Letters 261 (3-4), 602-619. http://dx.doi.org/10.1016/j.epsl.2007.07.018.

Teichmüller, M., Teichmüller, R., 1979. Zur geothermischen Geschichte des Oberrhein-Grabens. Zusammenfassung und Auswertung eins Symposiums Fortschritte in der Geologie von Rheinland und Westfalen 27, 109-120.

Tenma, N., Yamaguchi, T., Zyvoloski, G., 2008. The Hijiori Hot Dry Rock test site, Japan: Evaluation and optimization of heat extraction from a two-layered reservoir. Geothermics 37 (1), 19-52. http://doi.org/10.1016/j.geothermics.2007.11.002.

Terzaghi, R.D. , 1965. Sources of Error in Joint Surveys. Géotechnique 15 (3), 287-304. http://dx.doi.org/10.1680/geot.1965.15.3.287.

Teufel, L.W., Rhett, D.W., Farrell, H.E., 1991: Effect of Reservoir Depletion And Pore Pressure Drawdown On In Situ Stress And Deformation In the Ekofisk Field, North Sea. in: American Rock Mechanics Association, Symposium on Rock Mechanics (USRMS), Norman, Oklahoma, p. 10, 10-12 July.

Thuro, K., Plinninger, R.J., Zäh, S., Schütz, S., 2001. Scale effects in rock strength properties. Part 1: Unconfined compressive test and Brazilian test, in: Särkkä, P., Eloranta, P. (Eds.), Rock mechanics - a challenge for society (ISRM Regional Symposium Eurock 2001). Taylor \& Francis, Espoo, Finland, pp. 169-174.

Tondi, E., Antonellini, M., Aydin, A., Marchegiani, L., Cello, G., 2006. The role of deformation bands, stylolites and sheared stylolites in fault development in carbonate grainstones of Majella Mountain, Italy. Journal of Structural Geology 28 (3), 376-391. http://dx.doi.org/10.1016/j.jsg.2005.12.001.

Torabi, S.R., Ataei, M., Javanshir, M., 2010. Application of Schmidt rebound number for estimating rock strength under specific geological conditions. Journal of Mining \& Environment 1 (2), $1-8$. http://dx.doi.org/10.22044/jme.2011.9.

Trunkó, L., 1984. Karlsruhe und Umgebung Nördlicher Schwarzwald, südlicher Kraichgau, Rheinebene, Ostrand des Pfälzer Waldes und der Nordvogesen, in: Gwinner, M.P. (Ed.), Sammlungen Geologischer Führer. Gebrüder Bornträger, Berlin, p. 227.

Twiss, R.J., Moores, E.M., 2007. Structural Geology, 2nd ed. W.H. Freeman, New York.

Ulusay, R., Hudson, J.A., 2007. The complete ISRM suggested methods for rock characterisation, Testing and Monitorin: 1974-2006, Suggested Methods Prepared by the Commission on Testing Methods, International Society for Rock Mechanics. Compilation ISRM Turkish National Group, Ankara, Turkey, p. 628.

Van der Pluijm, B.A., Marshak, S., 2004. Earth Structure, 2nd ed. McGraw Hill, New York.

van Golf-Racht, T.D., 1982. Fundamentals of Fractured Reservoir Engineering. Elsevier. http://dx.doi.org/10.1016/S0376-7361(08)70333-9.

Vidal, J., Genter, A., Chopin, F., Dalmais, E., 2016: Natural fractures and permeability at the geothermal site Rittershoffen, France. Proceed. 41st Workshop on Geothermal Reservoir Engineering, Stanford University,

Viles, H., Goudie, A., Grab, S., Lalley, J., 2010. The use of the Schmidt Hammer and Equotip for rock hardness assessment in geomorphology and heritage science: a comparative analysis. Earth Surface Processes and Landforms 36 (3), 320-333. http://dx.doi.org/10.1002/esp.2040. 
Villemin, T., Alvarez, F., Angelier, J., 1986. The Rhinegraben: Extension, subsidence and shoulder uplift. Tectonophysics 128 (1-2), 47-59. http://dx.doi.org/10.1016/0040-1951(86)90307-0.

Vollbrecht, A., Dürrast, H., Kraus, J., Weber, K., 1994. Paleostress directions deduced from microcrack fabrics in KTB core samples and granites from the surrounding field. Scientific Drilling 4, 233 - 241.

Walker, R.J., Holdsworth, R.E., Armitage, P.J., Faulkner, D.R., 2013. Fault zone permeability structure evolution in basalts. Geology 41 (1), 59-62. http://dx.doi.org/10.1130/g33508.1.

Walter, R., 2007. Geologie von Mitteleuropa, 7st ed. Schweizerbarth, Stuttgart.

Watkins, H., Bond, C.E., Healy, D., Butler, R.W.H., 2015. Appraisal of fracture sampling methods and a new workflow to characterise heterogeneous fracture networks at outcrop. Journal of Structural Geology 72, 6782. http://dx.doi.org/10.1016/j.jsg.2015.02.001.

Wentworth, C.K., 1922. A Scale of Grade and Class Terms for Clastic Sediments. The Journal of Geology 30 (5), 377-392.

Wenzel, F., Brun, J.P., group, ECORS-DEKORP working, 1991. A deep reflection seismic line across the Northern Rhine Graben. Earth and Planetary Science Letters 104 (2-4), 140-150. http://dx.doi.org/10.1016/0012821X(91)90200-2.

Wibberley, A.J., Christopher, Shipton, Z.K., 2010. Fault zones: A complex issue. Journal of Structural Geology 32 (11), 1554-1556. http://dx.doi.org/10.1016/j.jsg.2010.10.006.

Wibberley, C. A. J., Yielding, G., Di Toro, G., 2008. The Internal Structure of Fault Zones: Implications for Mechanical and Fluid-Flow Properties. Geological Society, London, Special Publications 299 (1-3), 5-33. http://dx.doi.org/10.1144/SP299.2.

Witherspoon, P.A., Wang, J.S.Y., Iwai, K., Gale, J.E., 1980. Validity of cubic law for fluid-flow in a deformable rock fracture. Water Resources Research 16 (6), 1016-1024. http://dx.doi.org/10.1029/WR016i006p01016.

Yagiz, S., 2009. Predicting uniaxial compressive strength, modulus of elasticity and index properties of rocks using the Schmidt hammer. Bulletin of Engineering Geology and the Environment 68 (1), 55-63. http://dx.doi.org/10.1007/s10064-008-0172-z.

Yielding, G., 2002. Shale Gouge Ratio - calibration by geohistory. Norwegian Petroleum Society Special Publications 11, 1-15. http://dx.doi.org/10.1016/S0928-8937(02)80003-0.

Zangerl, C., Evans, K.F., Eberhardt, E., Loew, S., 2008. Normal stiffness of fractures in granitic rock: A compilation of laboratory and in-situ experiments. International Journal of Rock Mechanics and Mining Sciences 45 (8), 1500-1507. http://dx.doi.org/10.1016/j.ijrmms.2008.02.001.

Ziegler, P.A., 1990. Geological Atlas of Western and Central Europe, 2 ed. Elsevier \& Shell Intern, Den Haag.

Ziegler, P.A., 1992. European Cenozoic rift system. Tectonophysics 208 (1-3), 91-111. http://dx.doi.org/10.1016/0040-1951(92)90338-7.

Ziegler, P.A., Cloetingh, S., 2004. Dynamic processes controlling evolution of rifted basins. Earth-Science Reviews 64 (1-2), 1-50. http://dx.doi.org/10.1016/S0012-8252(03)00041-2.

Ziegler, P.A., Dèzes, P., 2005. Evolution of the lithosphere in the area of the Rhine Rift System. International Journal of Earth Sciences 94 (4), 594-614. http://dx.doi.org/10.1007/s00531-005-0474-3.

Ziegler, P.A., Dèzes, P., 2006. Crustal evolution of Western and Central Europe. Geological Society, London, Memoirs 32, 43-56. http://dx.doi.org/10.1144/gsl.mem.2006.032.01.03.

Ziegler, P.A., Dèzes, P., 2007. Cenozoic uplift of Variscan Massifs in the Alpine foreland: Timing and controlling mechanisms. Global and Planetary Change 58 (1-4), 237-269. http://dx.doi.org/10.1016/j.gloplacha.2006.12.004.

Ziegler, P.A., Schumacher, M.E., Dèzes, P., Van Wees, J.-D., Cloetingh, S., 2006. Post-Variscan evolution of the lithosphere in the area of the European Cenozoic Rift System. Geological Society, London, Memoirs 32, 97112. http://dx.doi.org/10.1144/gsl.mem.2006.032.01.06.

Zielke, W., Helmig, R., Krohn, K. P., Shao, H., Wollrath, J., 1991: Discrete Modelling of Transport Processes In Fractured Porous Rock. in: International Society for Rock Mechanics, 7th ISRM Congress, Aachen, 16-20 September. 


\section{Websites}

URL1: EEG, 2014 - http://www.bmwi.de/Redaktion/DE/Downloads/G/gesetz-fuer-den-ausbauerneuerbarer-energien.html, last assessed 08.02.2017

URL2: U.S. Energy Information Administration, EIA - http://www.eia.gov, last assessed 08.02.2017

URL3: Bundesverband Geothermie - http://geothermie.de, last assessed 08.02.2017

URL4: Thinkgeoenergy - http://www.thinkgeoenergy.com, last accessed 14.07.2017

URL5: LIAG - https://www.liag-hannover.de/s/s4/online-dienste/temperaturfeld-im-untergrunddeutschlands/ergebnis.html, last assessed 08.02.2017

URL6: GeotIS - https://geotis.de, last assessed 08.02.2017

URL7: Trebur - https://www.geothermie-trebur-de, last accessed 08.02.2017

URL8: iTG - https://www.tiefegeothermie.de, last accessed 08.02.2017

URL9: proceq - https://www.proceq.com/uploads/tx_proceqproductcms/import_data/files/DigiSchmidt_Operating\%20Instructions_Multilingual_high.pdf, last assessed 08.02.2017

URL10: ThermoGIS - http://www.thermogis.nl/worldviewer/ThermoGISWorldEdition.html, last accessed 14.07.2017

URL11: IHFC - http://www.geophysik.rwth-aachen.de/IHFC/heatflow.html, last accessed 14.07.2017 


\section{Journal articles and author contributions}

Chapter 4

Chapter 5

Chapter 6

Chapter 7
Bauer, J.F., Meier, S., Philipp, S.L., 2015: Architecture, fracture system, mechanical properties and permeability structure of a fault zone in Lower Triassic sandstone, Upper Rhine Graben. Tectonophysics 647-648, 132-14.

- J.F.B. wrote the paper. J.F.B. and S.L.P. conceived the idea and designed the research. J.F.B and S.M. collected and J.F.B, S.M. and S.L.P. discussed the data. J.F.B. performed the laboratory experiments. All authors commented the Manuscript.

Meier, S., Bauer, J.F., Philipp, S.L., 2015: Fault zone characteristics, fracture systems and permeability implications of Middle Triassic Muschelkalk in Southwest Germany. Journal of Structural Geology 70, 170-189.

- $\quad$ S.M. wrote the paper. S.M. and S.L.P. conceived the idea and designed the research. J.F.B and S.M. collected and J.F.B, S.M. and S.L.P. discussed the data. S.M. performed the laboratory experiments. All authors commented the Manuscript.

Bauer, J.F., Krumbholz, M., Meier, S. Tanner D.C., 207: Predictability of properties of a fractured geothermal reservoir: The opportunities and limitations of an outcrop analogue study. Geothermal Energy 5 (1), 24. http://dx.doi.org/10.1186/s40517017-0081-0.

- $\quad$ The manuscript was written by J.F.B., M.K. and D.C.T., field work was carried out by J.F.B. and S.M., J.F.B carried out the laboratory experiments, discussion of data by J.F.K., M.K., S.M., and D.C.T., all authors commented on the manuscript.

\section{Publications in preparation}

Bauer, J.F., Krumbholz, M., Luijendijk, E., Tanner, D.C., in prep: Numerical sensitivity study of parameters that control geothermal reservoir quality. 


\section{Curriculum Vitae}

Personal Profile

\begin{tabular}{l||l} 
Name & $\begin{array}{l}\text { Johanna Frederike Bauer } \\
\text { Birth date and birthplace }\end{array}$ \\
11.02 .1984$, Konstanz
\end{tabular}

\section{Academic}

Education

since 10/2011

$10 / 2007-08 / 2010$

Graduation

08/2004-10/ 2007

Graduation

\section{PhD Thesis}

Georg-August-Universität Göttingen

\section{Dissertation:}

„On the significance and predictability of geological parameters in the exploration for geothermal energy"

\section{Geoscience}

Georg-August-Universität Göttingen

\section{Diploma-Geoscientist}

\section{Diploma Thesis:}

„Infrastruktur und Entwicklung ausgewählter Störungszonen im südlichen Norddeutschen Becken"

\section{Diploma mapping:}

"Geologische Kartierung im Bereich der westlichen Grabenrandstörung des Leinetalgrabens bei Esebeck"

\section{Geoscience}

Georg-August-Universität Göttingen

\section{Bachelor of Science}

\section{Bachelor Thesis:}

"Schadensanalyse an den Außenmauern des Schlosses von Buda" in Ungarn, Budapest 


\section{Danksagung}

Ich danke Sonja Philipp für die Vergabe dieser Doktorarbeit und die ursprüngliche Konzeptionierung des Themas. Ein großer Dank geht an Jonas Kley, David Tanner und Inga Moeck für die Übernahme des Referats. Erst die überaus konstruktiven, herzlichen und meinen Blick erweiternden Gespräche haben mir ermöglicht, diese Arbeit zu beenden. Ein besonders großer Dank geht hierbei an Dave: Dein jederzeit offenes Ohr, Deine Korrekturen und Vorschläge haben die Endphase meiner Doktorarbeit zu einer ganz besonderen und lehrreichen Erfahrung gemacht.

Ein weiteres Dankeschön geht an alle Kollegen des geologischen Institutes:

Zu allererst bedanke ich mich bei Klaus Wemmer und Hans Ruppert für die tatkräftige Unterstützung und Aufmunterungen, vor allem im Endstadium dieser Arbeit.

Danken möchte ich auch Michael Krumbholz für die Unterstützung und Zusammenarbeit. Auch wenn mich Deine andauernden Fragen - warum ist das denn so - oftmals in den Wahnsinn getrieben haben, waren es genau diese, welche bei mir so einige Knoten zum Platzen gebracht haben. Deine unermüdlichen Korrekturen und Vorschläge in den letzten Monaten haben meine Art zu denken maßgeblich geändert.

Ein großes Dankeschön geht an Elco Luijendijk, für die kritischen Kommentare und Anregungen bei meiner numerischen Studie. Ohne dich würde mein Computer vermutlich immer noch rechnen...

Von ganzem Herzen danke ich auch Silke Meier für die Zusammenarbeit, dafür dass Du einfach die beste Zimmernachbarin warst, die man sich nur wünschen kann, die hilfreichen Diskussionen und die aufmunternden Worte besonders in den letzten Wochen. Vor allem aber dafür, dass komplizierte Situationen und manchmal gegenläufige Meinungen keinen Einfluss auf unsere Freundschaft hatten und haben.

Gedankt sein muss auch Marie-France Hesse für die Beantwortung jeglicher organisatorischer Fragen. Ferner danke ich Jens Walter fürs Rumblödeln und auch Nicole Nolte, Franziska Wilsky und Filiz Afsar für so manche erheiternde Pause.

Zuletzt bedanke ich mich von ganzem Herzen bei meiner Familie und meinen Freunden. Ich könnte jedes Mal vor Freude weinen, wenn ich an Euren bedingungslosen Rückhalt denke. Ich bin Euch zutiefst dankbar für Eure aufmunternden Worte und Taten. Ein besonders großer Dank geht an meinen Bruder Ruben: Danke für Deine Unterstützung und ich meine es wortwörtlich, wenn ich Dir sage, dass die Fertigstellung dieser Arbeit ohne dich nur schwer möglich gewesen wäre. Ich hoffe wirklich, dass ich Dir dies irgendwann in angemessener Art zurückgeben kann!! Dir und Jonas danke ich auch für das Korrekturlesen der Arbeit. Besonderer Dank auch an meine Mutter Sisko: Ich bin Dir zutiefst dankbar, für Deine tatkräftige Unterstützung, das „Kopfwaschen“, das Aufmuntern und dass Du mir immer deine Zeit schenkst, wenn ich sie brauche, aber auch dass Du in den richtigen Momenten einfach nur schweigen kannst. Dank auch an meinen kleinen Neffen Samuel: Du bringst mich immer zum Lachen und erinnerst mich an die wunderbaren und aufregenden Dinge um uns herum, welche von den "großen“ Leuten nur zu leicht übersehen werden. Danke, dass Du mir immer wieder die kleinen und bitter nötigen Auszeiten geschenkt hast.

Vielen Dank auch an „Grossstadtgeflüster“, dass ich trotz allem immer wieder gut gelaunt in den Feierabend gehen konnte. 


\section{Appendix 1.Description of drill cuttings}

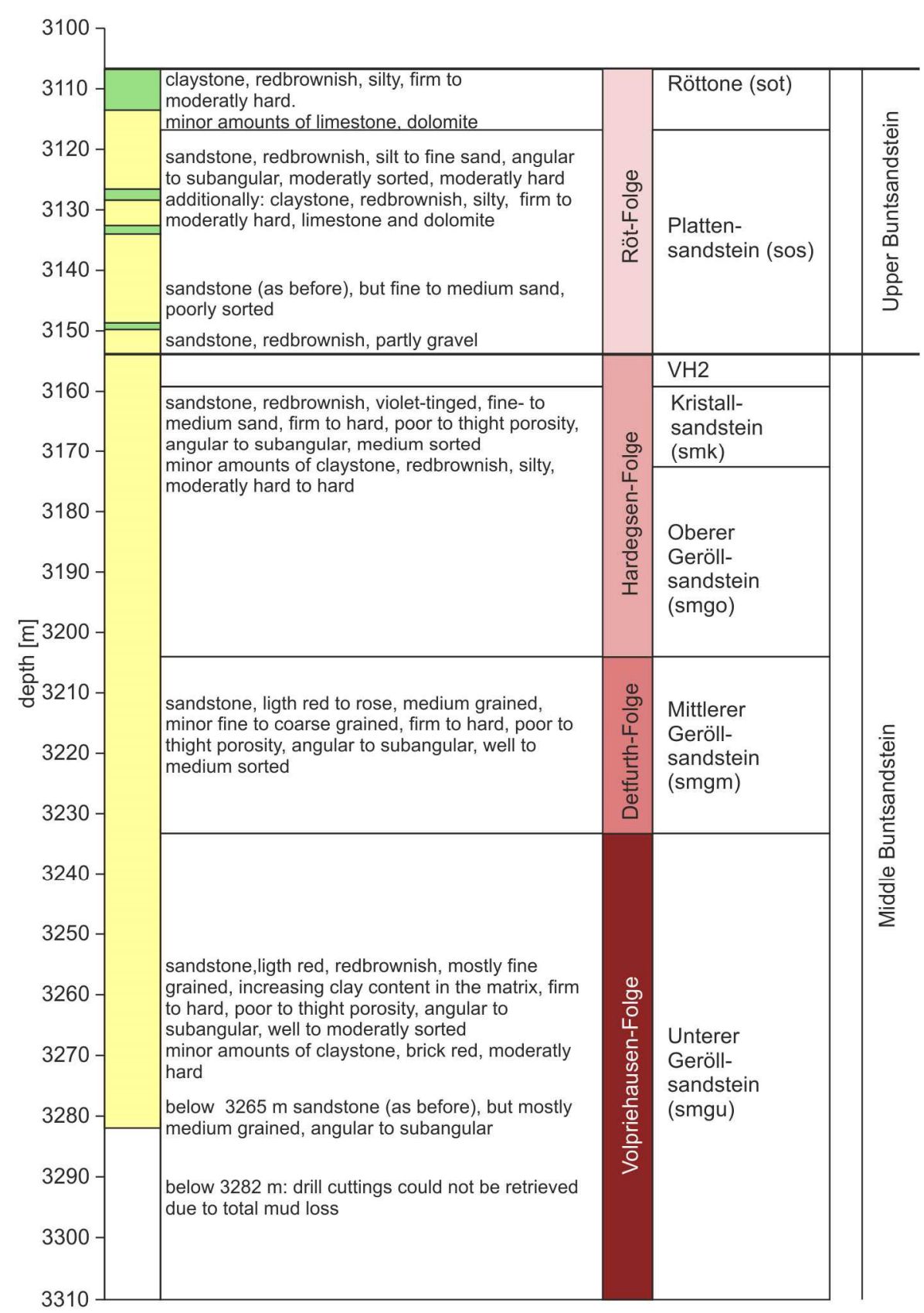

Fig. A1: Description of the drill cuttings and stratigraphic units encountered in the well Brühl (modified after Reinecker et al. (2015). 


\section{Appendix 2. Numerical model results}

\section{Appendix 2.1. Justification of unidirectional coupling}

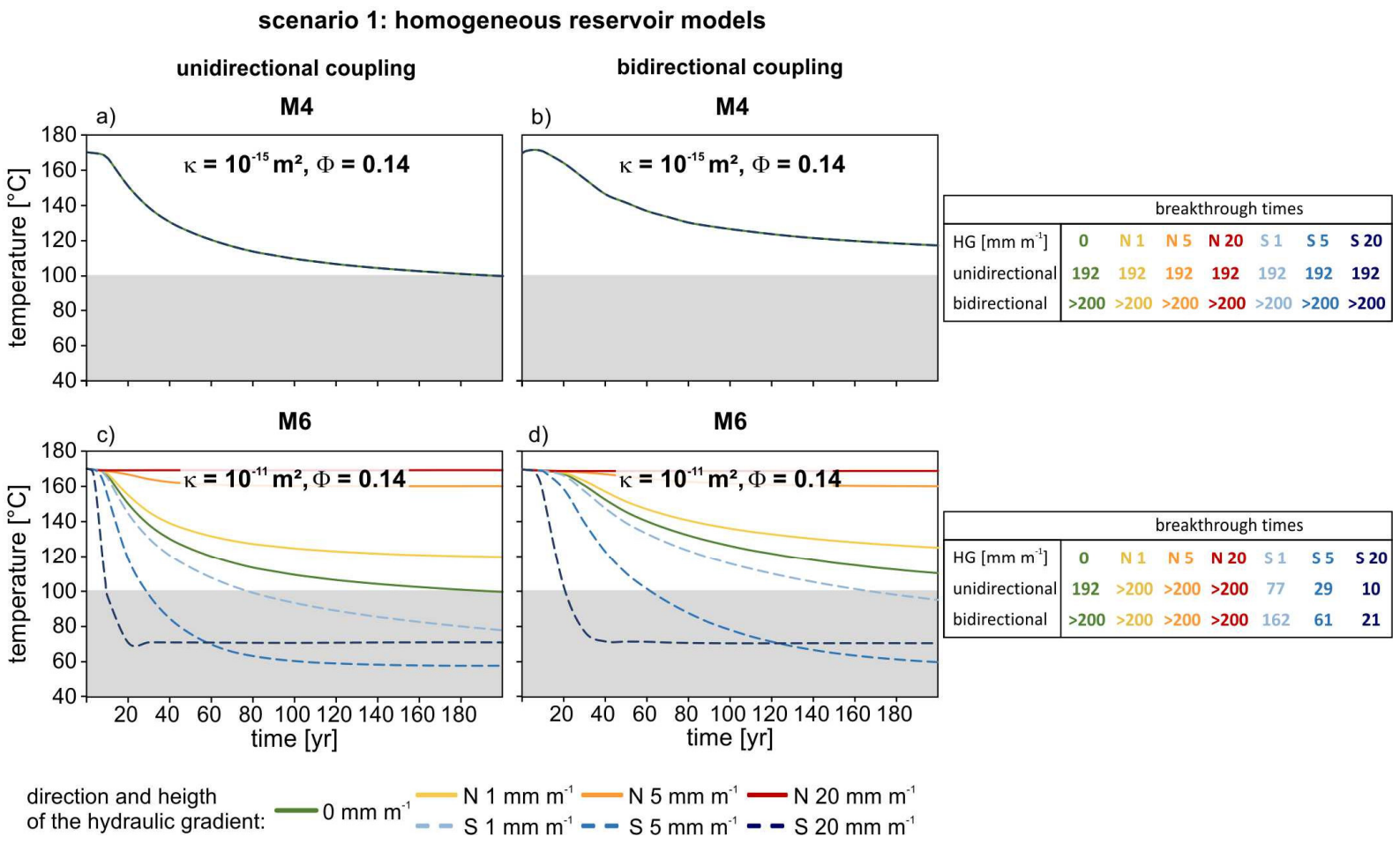

Fig. A2: Comparison of the temperature development and breakthrough times between unidirectional- and bidirectional coupled models. In general, the bidirectional coupling (i.e. the parameters $\boldsymbol{\rho}_{\boldsymbol{f}}$ and $\boldsymbol{\mu}$ in Darcy's law are temperature dependent) lead to increased reservoir lifetimes in homogeneous reservoir volumes, however the general trend of the modelled production temperature development does not change. Differences between unidirectional and bidirectional coupled models decreases with increasing permeability. 
Appendix 2.2. Scenario 1 (S1): Homogeneous reservoir models

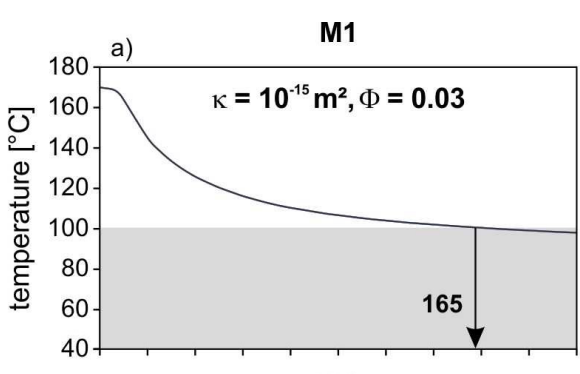

M4

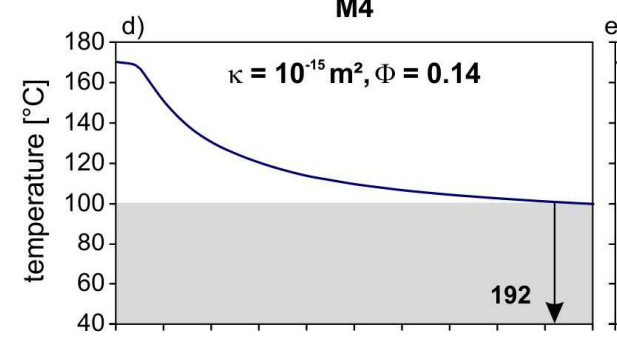

M7

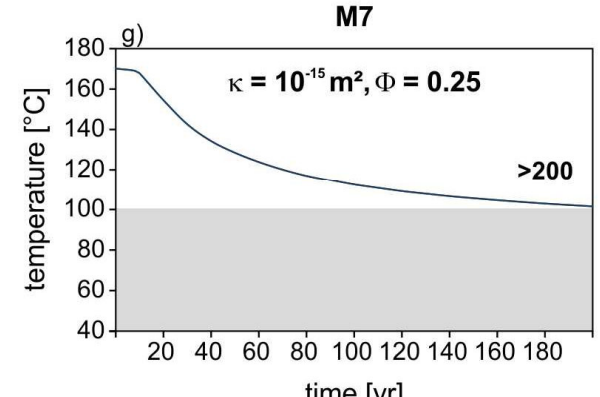

time [yr]

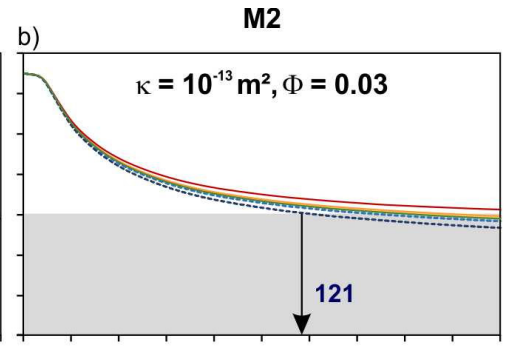

M5

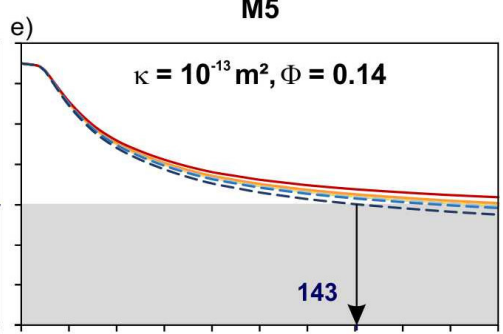

M8 h)

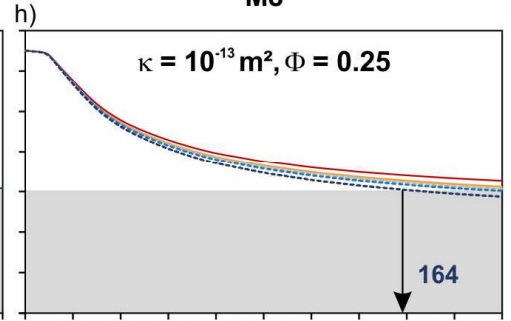

$20 \quad 40 \quad 6080 \quad 80100120140160180$ time [yr]

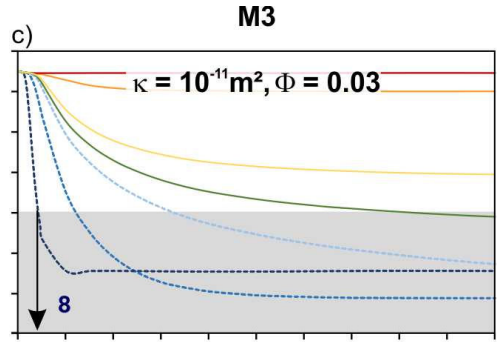

M6

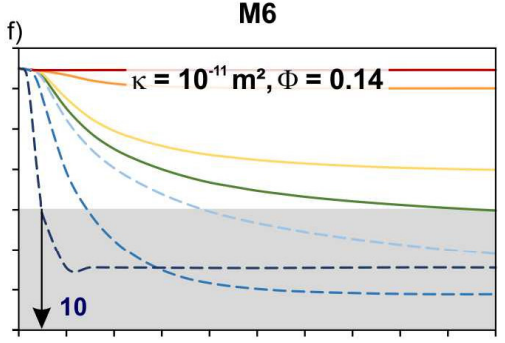

M9

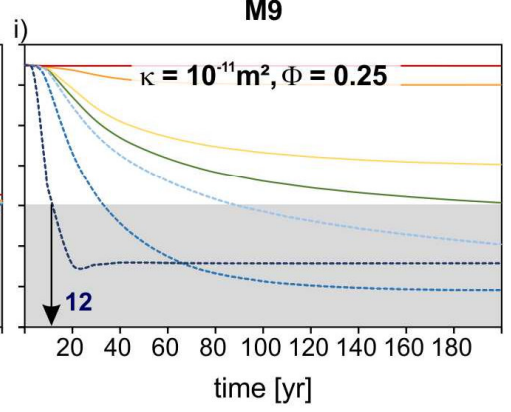

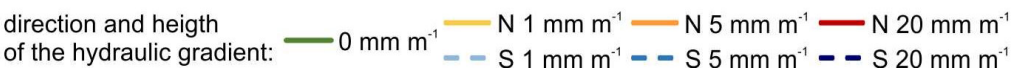

Fig. A3: Temperature development and breakthrough times of the nine basic homogeneous reservoir volumes, depending on the permeability, porosity, and the hydraulic gradient configuration. a to i) only north- and southward directed gradients are shown. The reservoir's permeability increases from left to right, the reservoir's porosity from top to bottom. Arrows indicates the shortest thermal breakthrough times. 


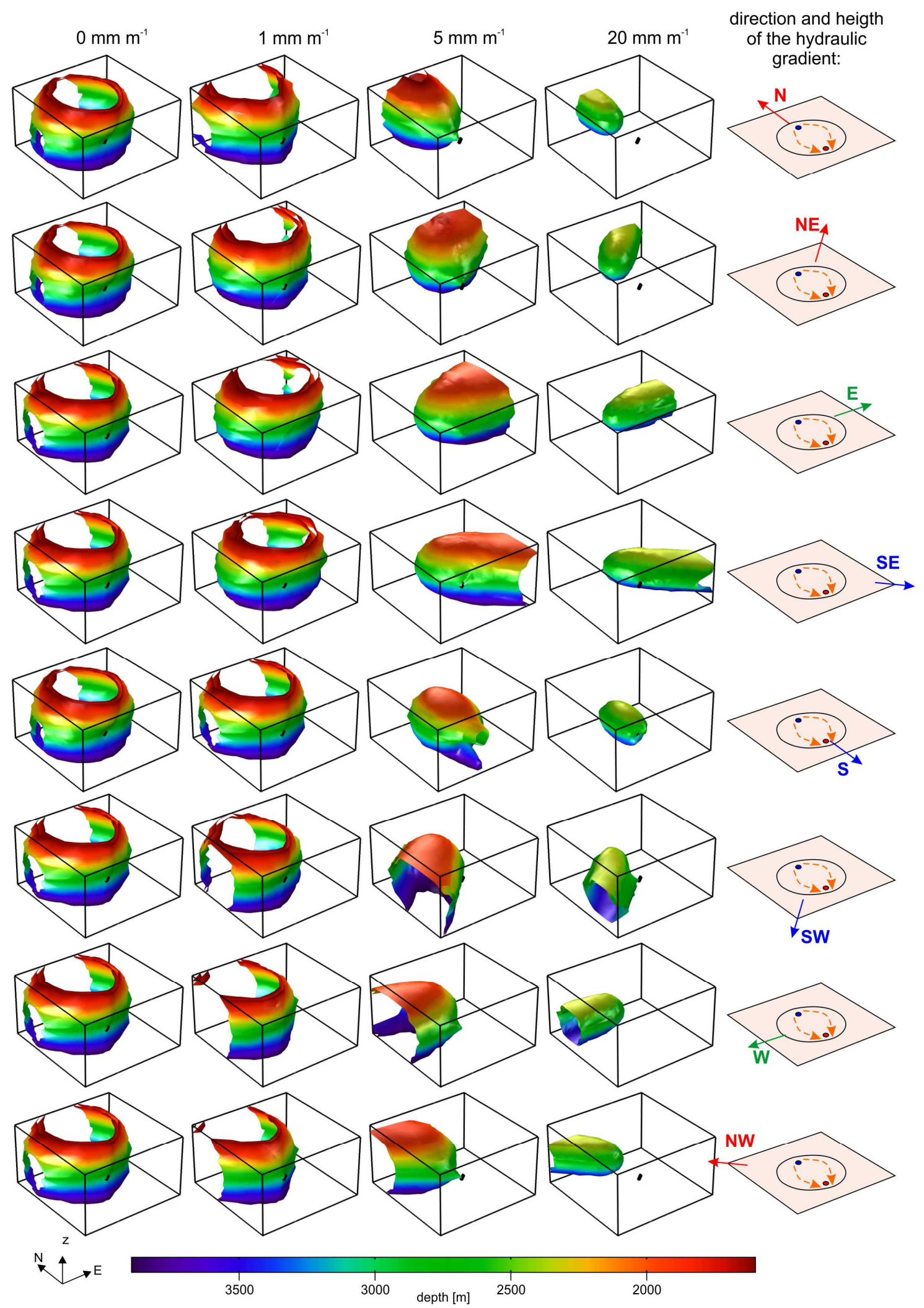

Fig. A4: Effect of variable hydraulic gradient directions and height on the reservoir shape in homogeneous reservoir volumes. Figures show the HIT for the high permeability and medium porosity model (M6) after $160 \mathrm{yr}$ of heat production. The height of the hydraulic gradient increases from left to right, the applied hydraulic gradient direction is varied from $\mathrm{N}$ to NW in $45^{\circ}$ steps from top to bottom as indicated by the sketch on the right side of the figure. The injection well is placed in the north (blue dot) and the production well is placed in the south (red dot). 


\subsection{Conclusions and outlook}

Appendix 2.3. Scenario 2 (S2): Layered reservoir models

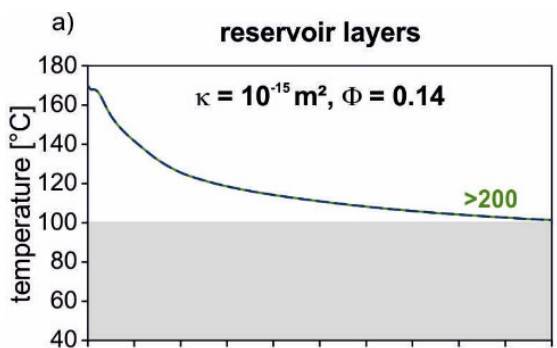

b) reservoir layers

c)

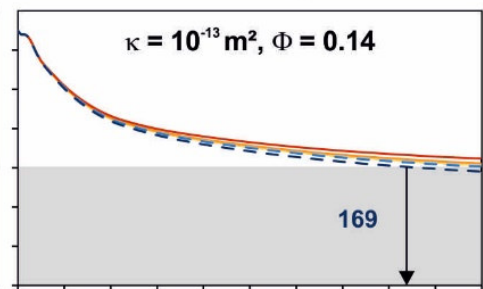

reservoir layers

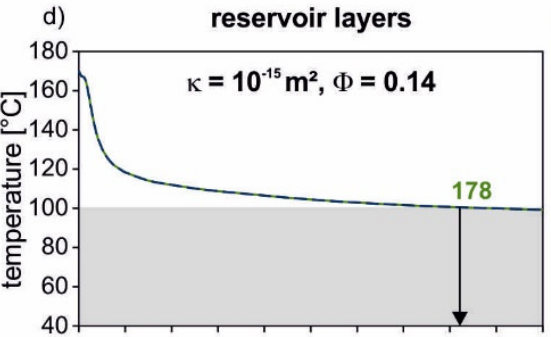

e) reservoir layers
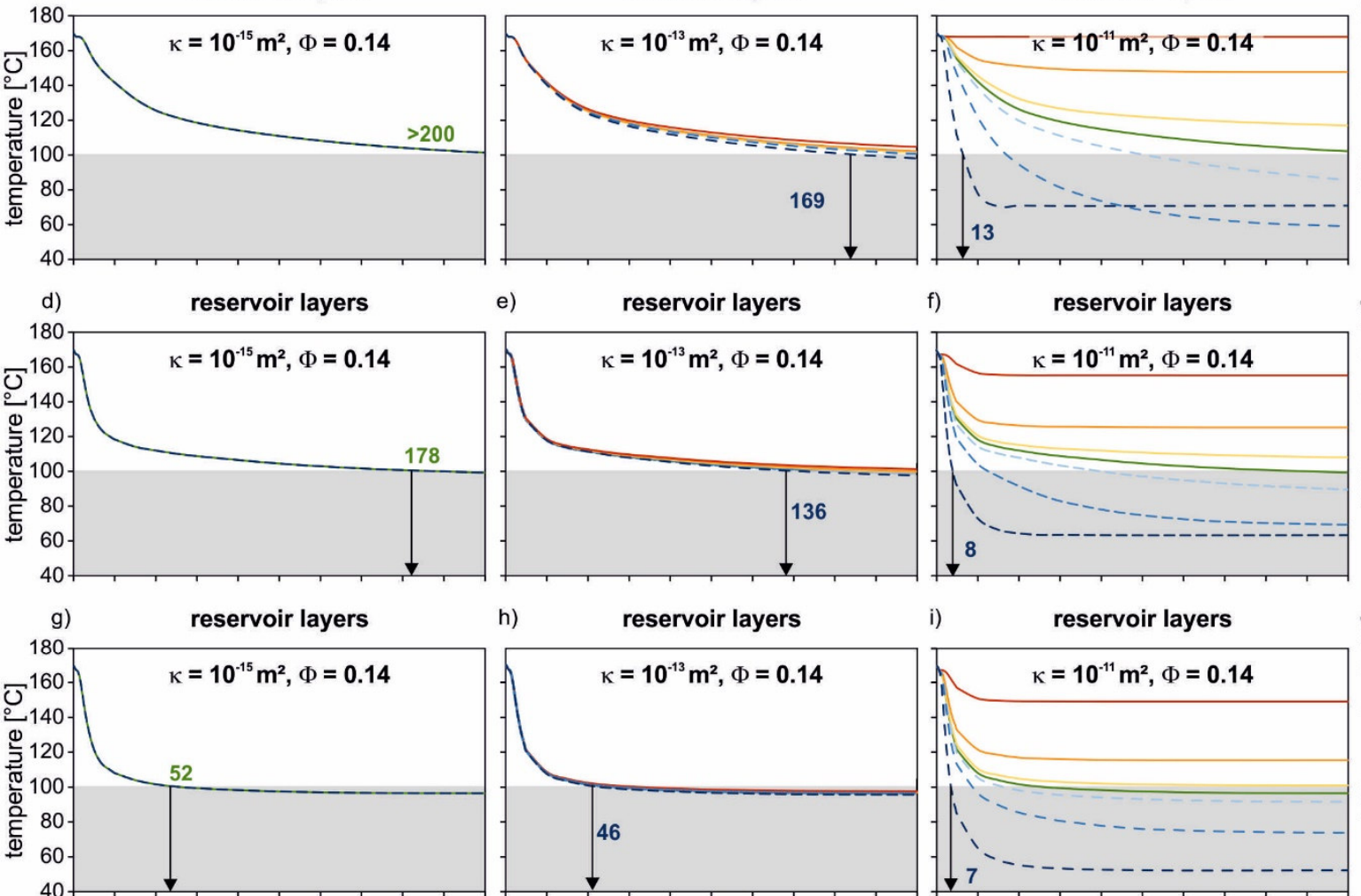

h)

i)
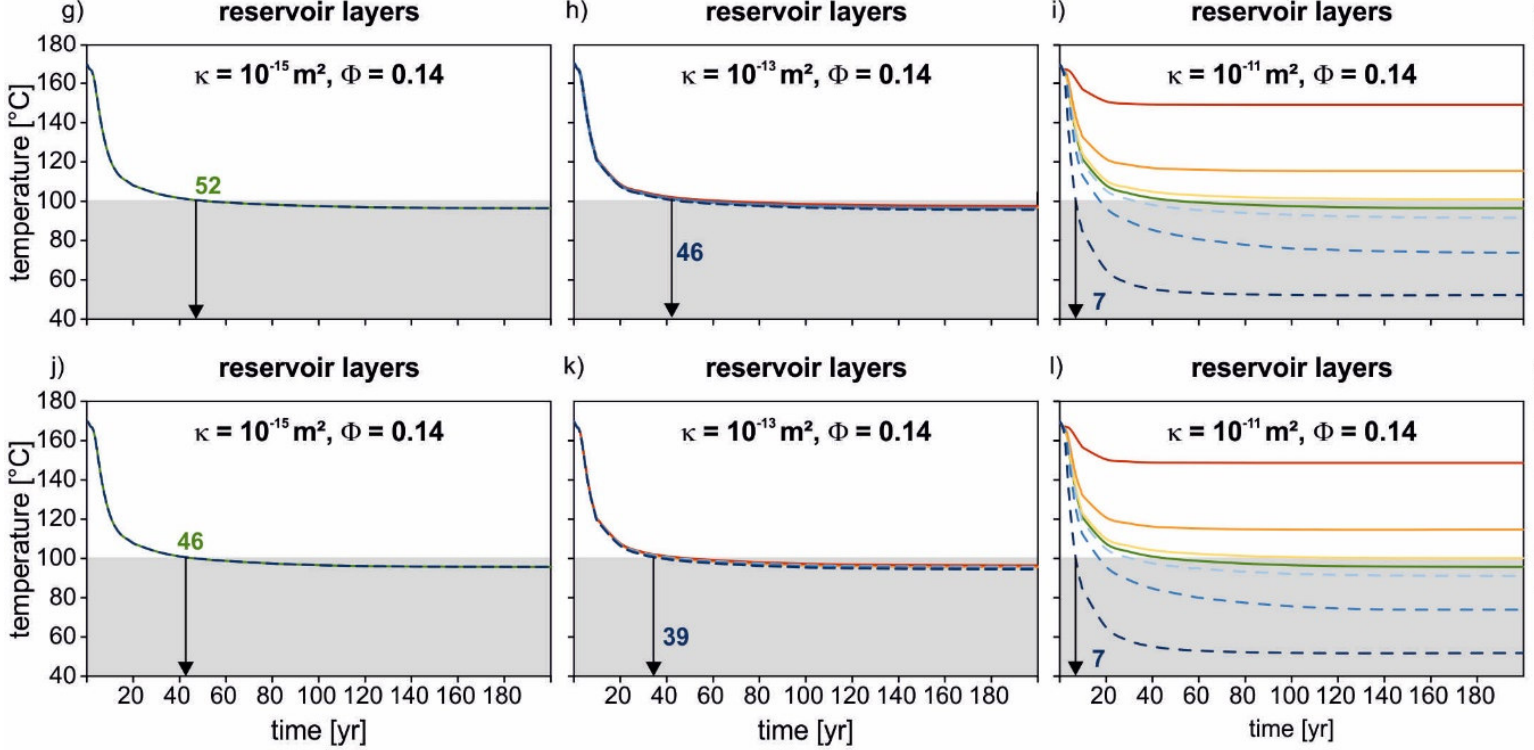

k) reservoir layers

I)
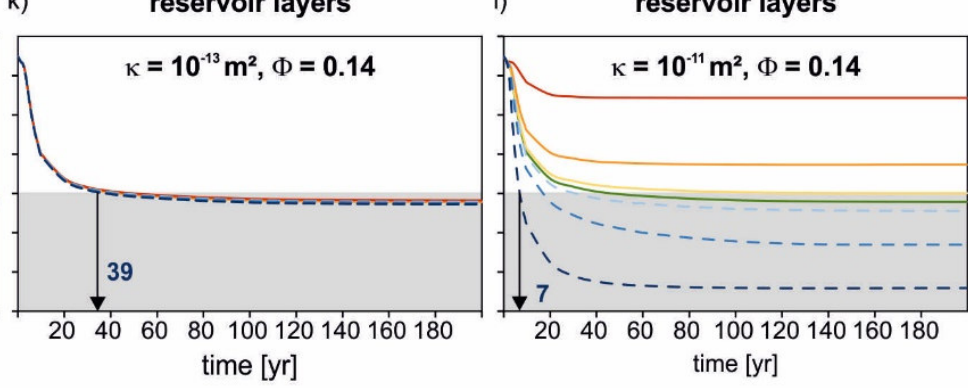

음

direction and heigth of the hydraulic gradient:

$-\mathrm{Nm} \mathrm{m} \mathrm{mm} \mathrm{m}^{-1}-\mathrm{N} \mathrm{mm} \mathrm{m}^{-1}-\mathrm{N} 5 \mathrm{~mm} \mathrm{~m}^{-1}-\mathrm{N} 20 \mathrm{~mm} \mathrm{~m}^{-1}-\mathrm{S} 5 \mathrm{~mm} \mathrm{~m}^{-1}-\mathrm{S} 20 \mathrm{~mm} \mathrm{~m}^{-1}$

Fig. A5: Temperature development and breakthrough times of layered reservoir volumes depending on the sandstone permeability, permeability contrast, and the hydraulic gradient configuration. a to I) Only north- and southward directed gradients are shown. The sandstone permeability increases from left to right, the permeability contrast increases from top to bottom. Arrows indicates the shortest thermal breakthrough times. 


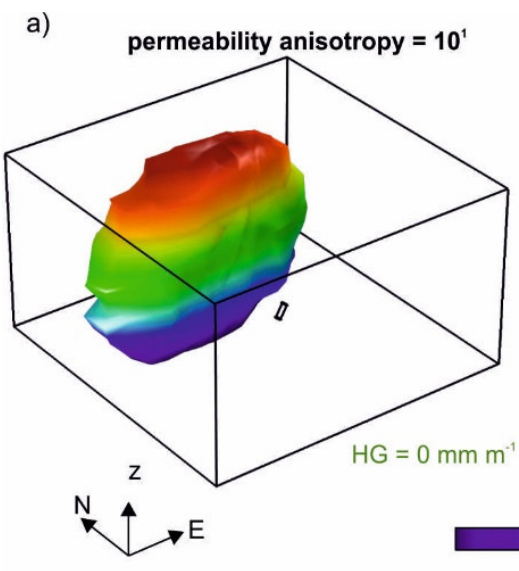

b)

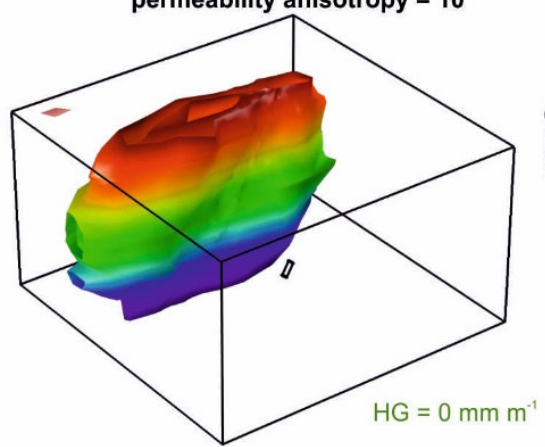

c)

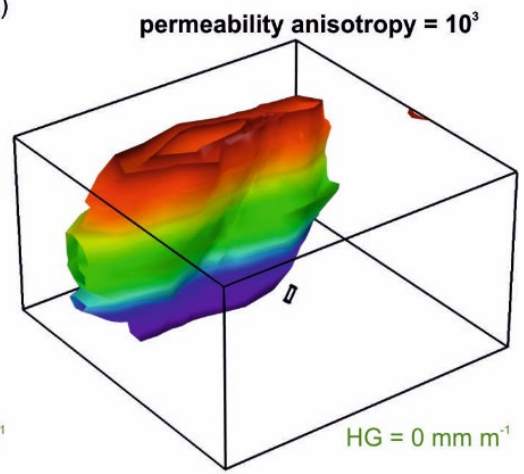

$$
2500
$$$$
2000
$$

Fig. A6: Effect of increasing E-W-directed permeability contrast on the reservoir shape in fractured reservoir volumes. Figures a to c) show the HIT for the medium porosity and medium permeability model (M5) after $20 \mathrm{yr}$ of heat production. No hydraulic gradient is applied. 


\subsection{Conclusions and outlook}

Appendix 2.5. Scenario 3 (S3): Fractured reservoirs with N-S- directed anisotropy

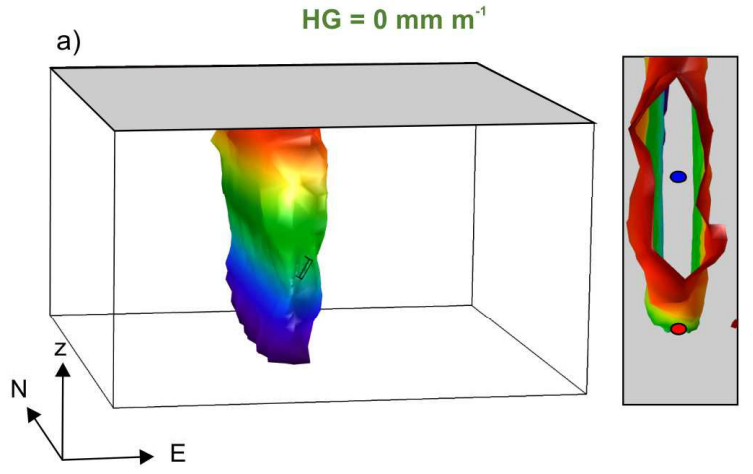

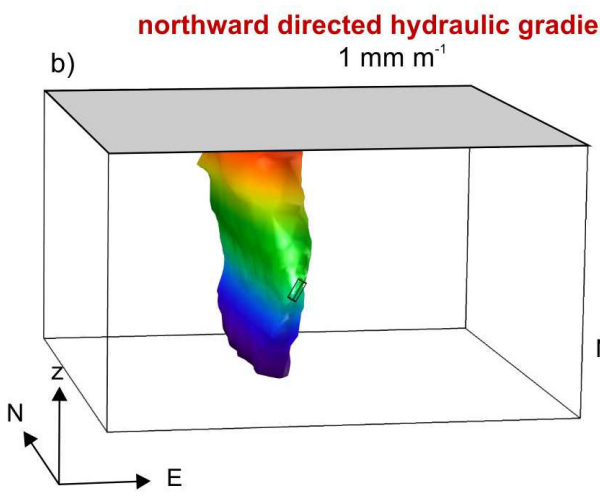

d)

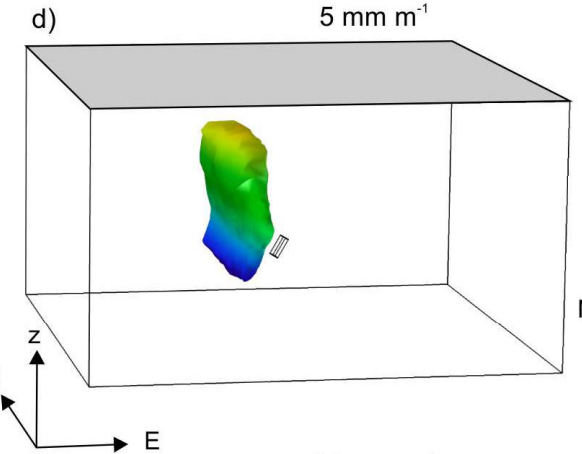

f)

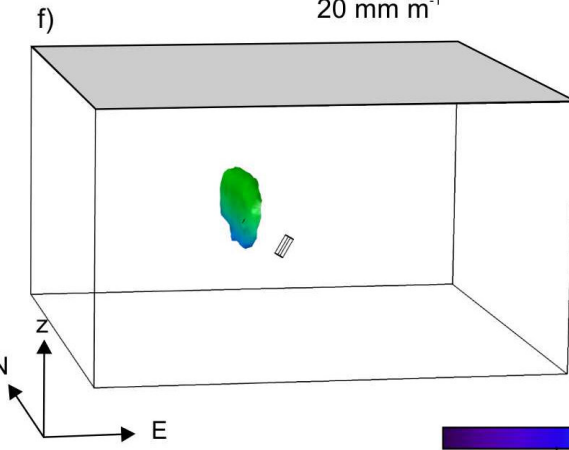

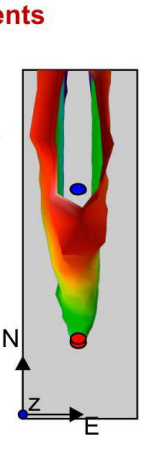
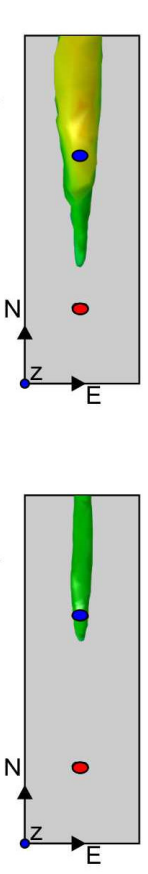

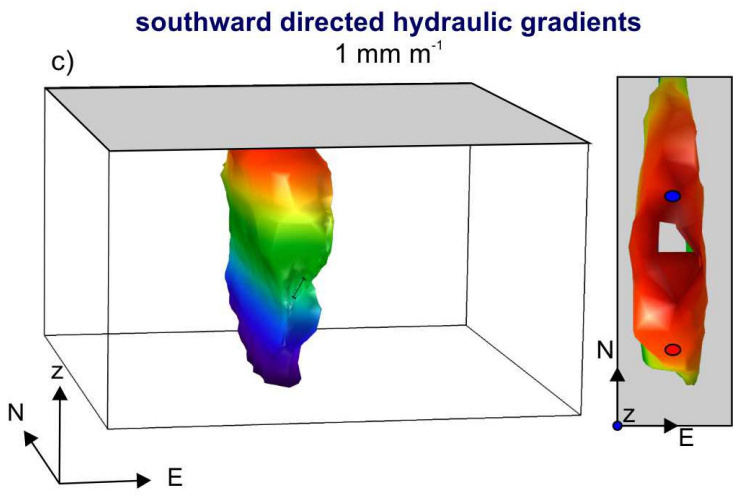

e)
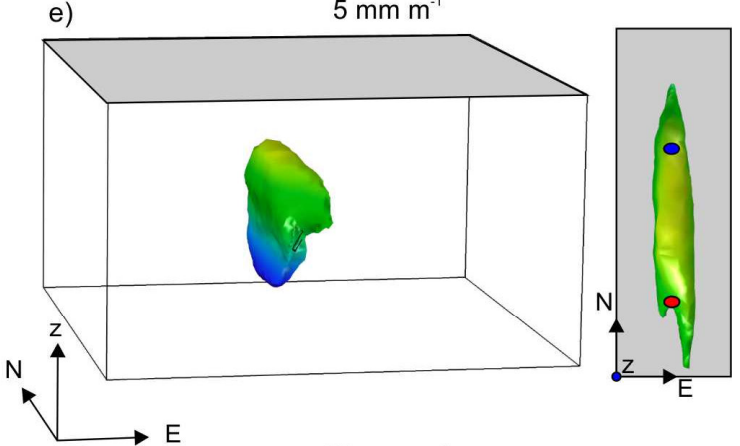

$20 \mathrm{~mm} \mathrm{~m}^{-1}$

g)

g)

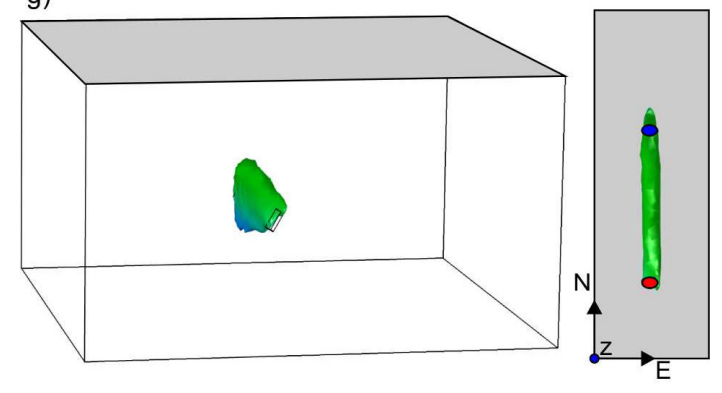

3500 $3000 \quad 2500$
depth $[\mathrm{m}]$

Fig. A7: Reservoir shape of fractured reservoir volumes with a N-S-directed fracture induced permeability anisotropy of $10^{3}$ depending on the hydraulic gradient direction and height. If high fracture induces anisotropies are in-line to the hydraulic gradient direction, hydraulic gradients $>1 \mathrm{~mm} \mathrm{~m}^{-1}$ prevent the propagation of the HIT in z-direction. In the case of high southward directed hydraulic gradients, the HIT reaches the production well very fast, but does not cool down the complete catchment area of the production well. The injection well is placed in the north (blue dot) and the production well is placed in the south (red dot). 


\section{Appendix 2.6. Scenario 4 (S4): Fractured and layered reservoir volumes}

a)

b)

c)

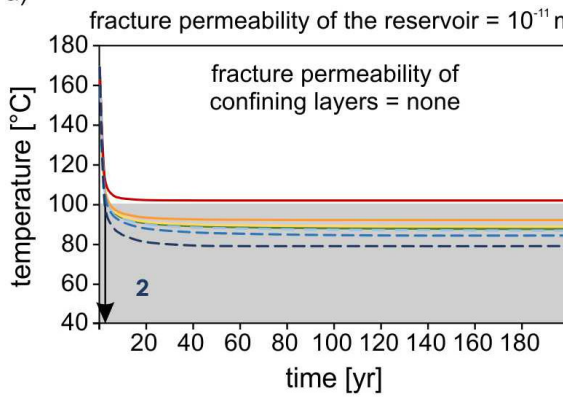

fracture permeability of the reservoir $=10^{-11} \mathrm{~m}^{2}$
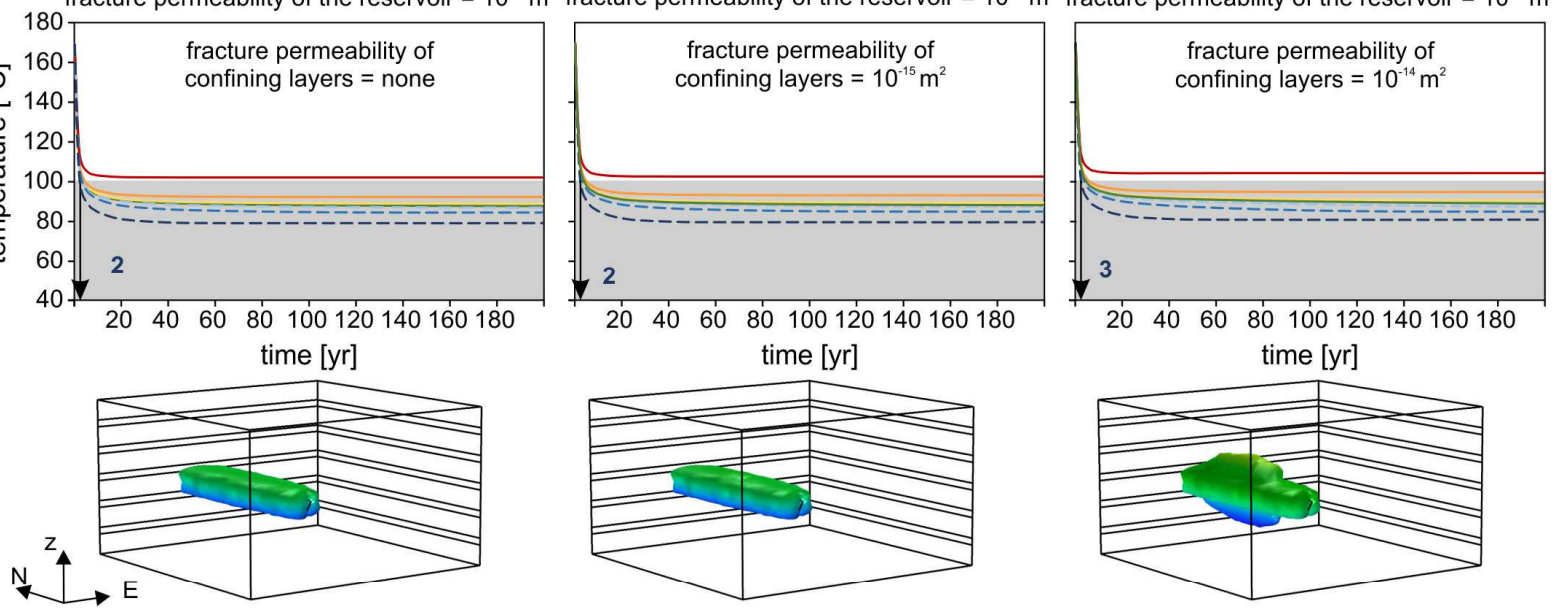

d)

e)

f)
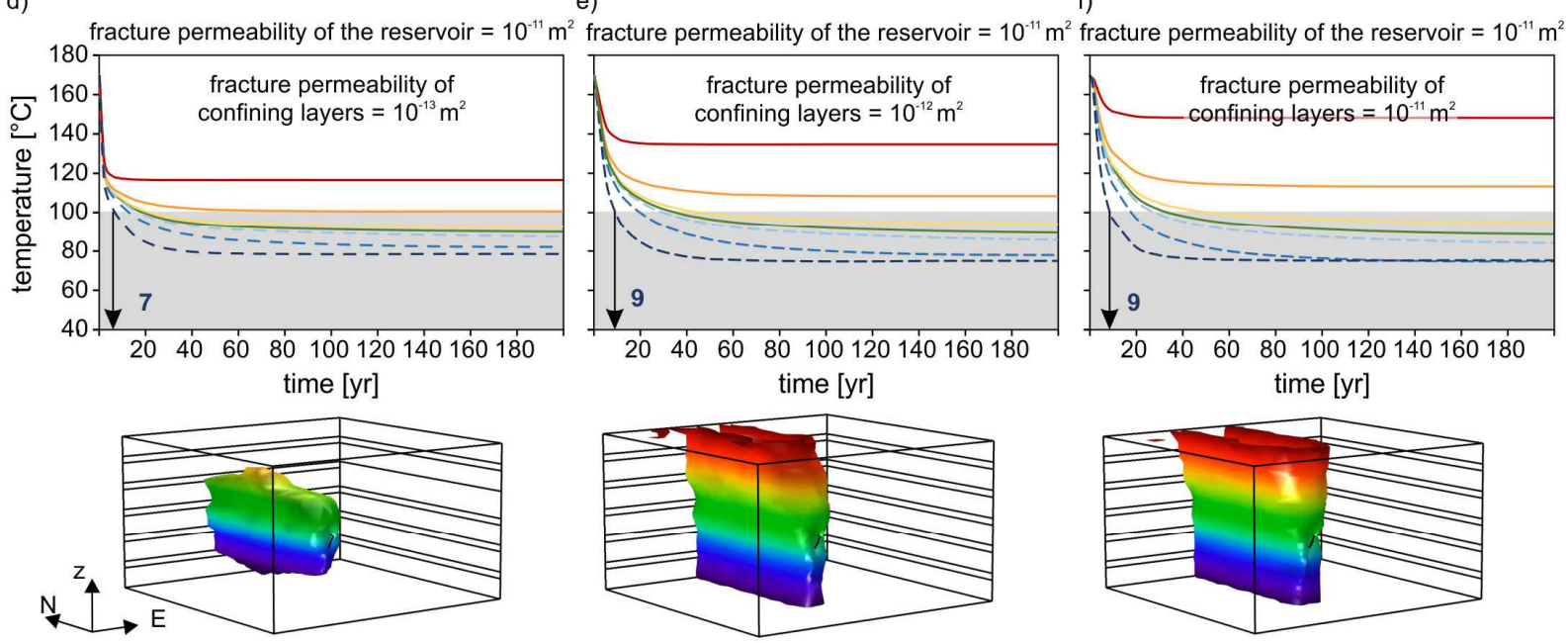

3500

$3000 \quad 2500$
depth $[\mathrm{m}]$

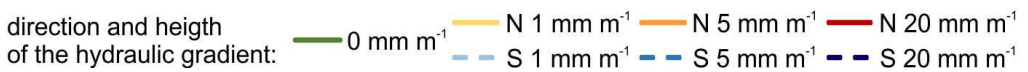

Fig. A8: Combined effect of layering and fracturing on the thermal development, breakthrough times, and reservoir shape. Only north- and southward directed gradients are shown. The permeability contrast of the layered succession is $10^{3}$, the permeability anisotropy of the sandstone layers is $10^{2}$. From a to f) the permeability anisotropy of the claystone layers increases from homogeneous to a value equal to the permeability anisotropy in the sandstone layers, i.e. the fractures are nonstratabound. In the last case (f), the temperature development in the reservoir is identical to the homogeneous and anisotropic model (Fig. 7.6b). Arrows indicates the shortest thermal breakthrough times. 


\subsection{Conclusions and outlook}

Appendix 2.7. Scenario 5 (S5): Fault-related reservoirs
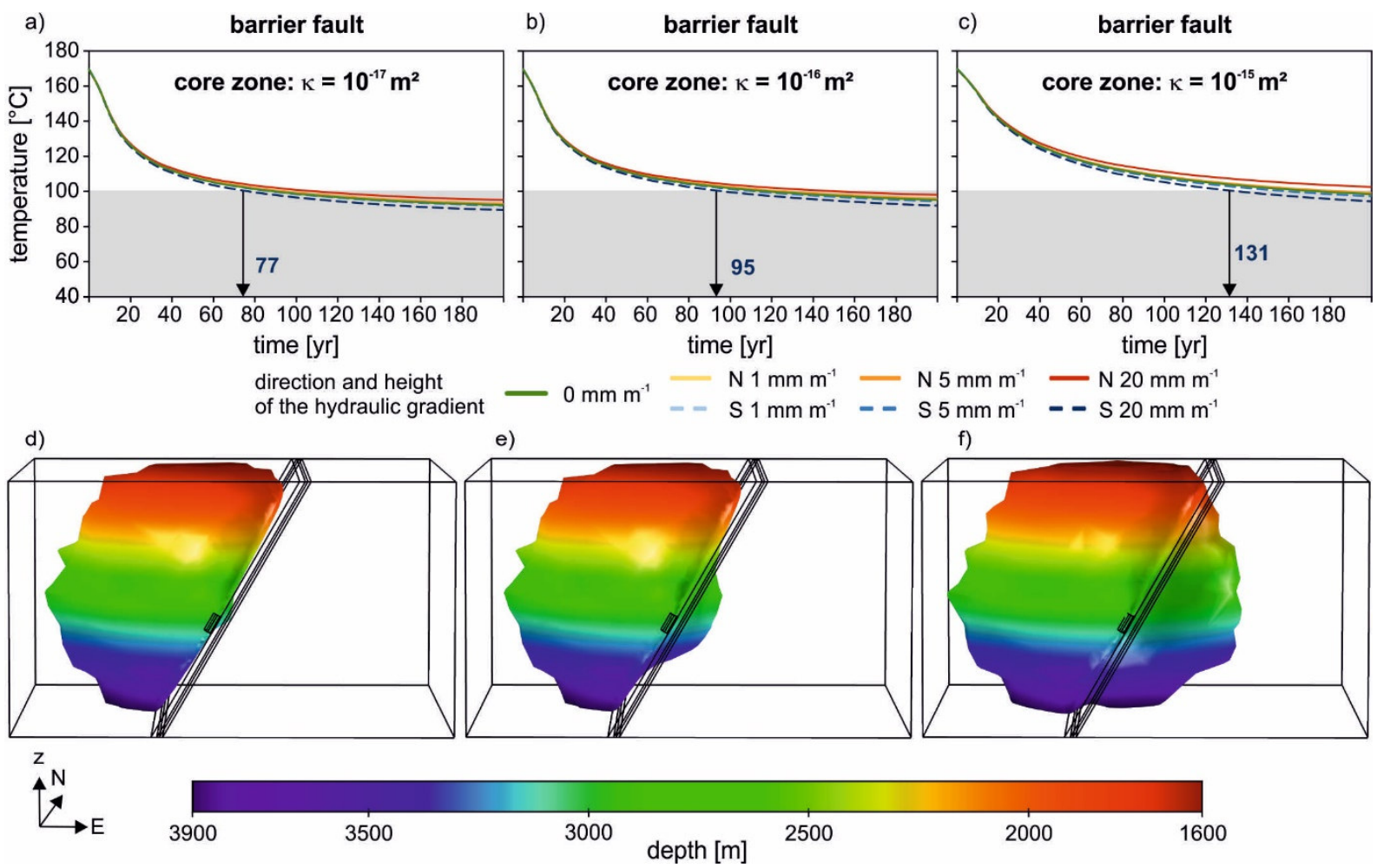

Fig. A9: Temperature development, breakthrough times, and reservoir shape of fault-related reservoir volumes acting as barrier depending on fault core permeability and hydraulic gradient configuration. The host rock properties are based on the medium permeability and medium porosity model (M5). a to c) the temperature development of the produced fluid over time for north- and southward directed hydraulic gradients. The fault core permeability increases from left to right. Arrows indicates the shortest thermal breakthrough times. $\mathbf{d}$ to $\mathbf{f}$ ) the corresponding shape of the HIT after $40 \mathrm{yr}$ of heat production, simulated for a hydraulic gradient of $0 \mathrm{~mm} \mathrm{~m}^{-1}$. Arrows indicates the shortest thermal breakthrough times. 
a)

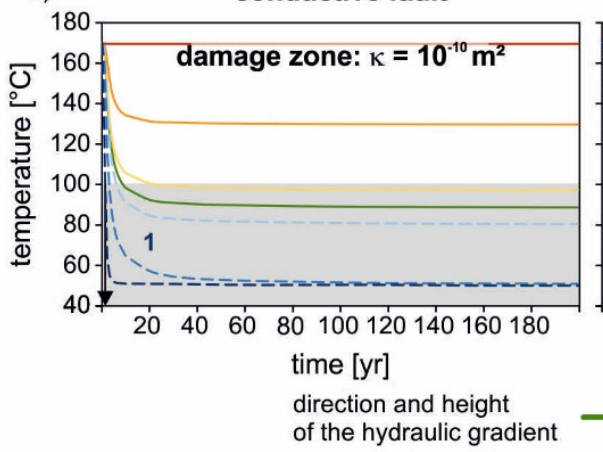

d)

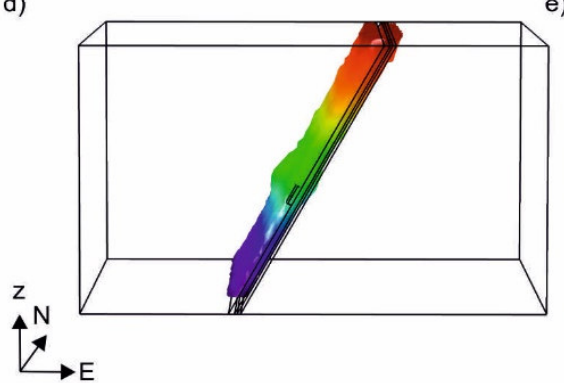

b)

conductive fault

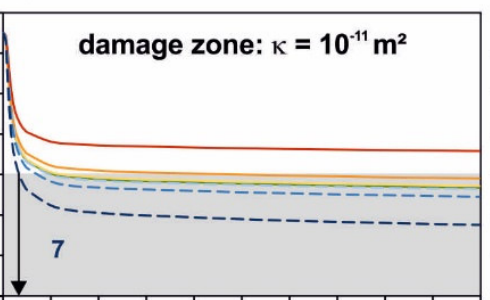

$20 \quad 40 \quad 60 \quad 80 \quad 100120140160180$ time [yr]

$\mathrm{N} 1 \mathrm{~mm} \mathrm{~m}^{-1}$

$0 \mathrm{~mm} \mathrm{~m}^{-1}$

- $\mathrm{s} 1 \mathrm{~mm} \mathrm{~m}^{-1}$
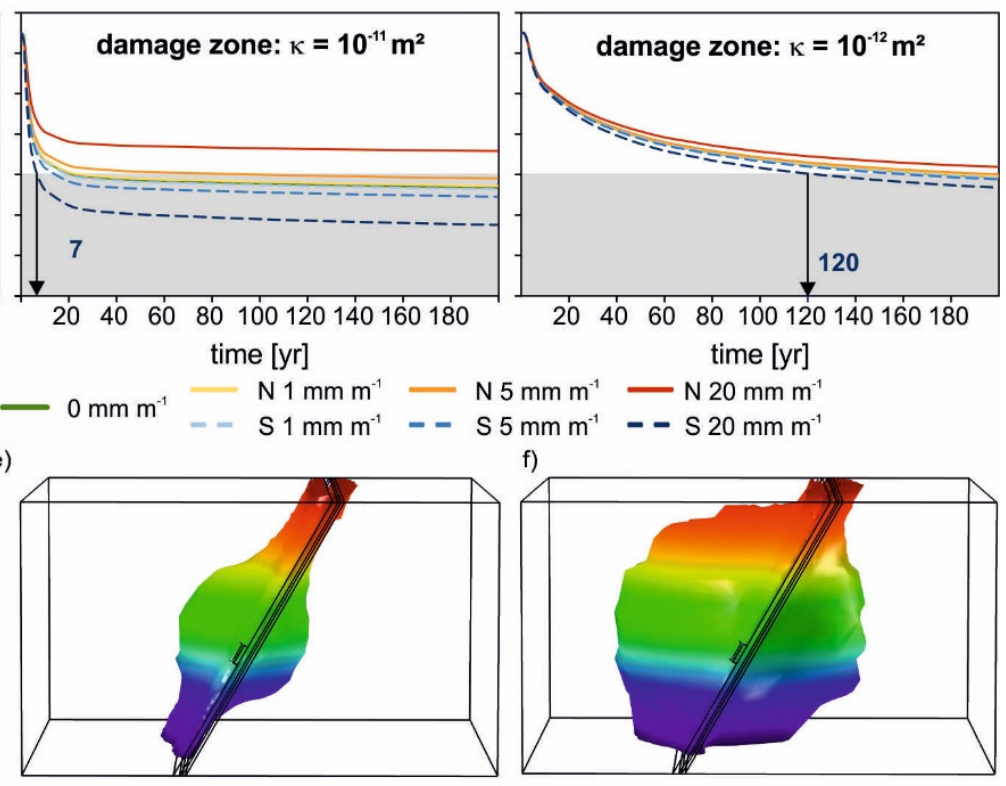

$20 \quad 40 \quad 60 \quad 80 \quad 100120140160180$ time [yr]

N $5 \mathrm{~mm} \mathrm{~m}^{-1}-\mathrm{N} 20 \mathrm{~mm} \mathrm{~m}^{-1}$
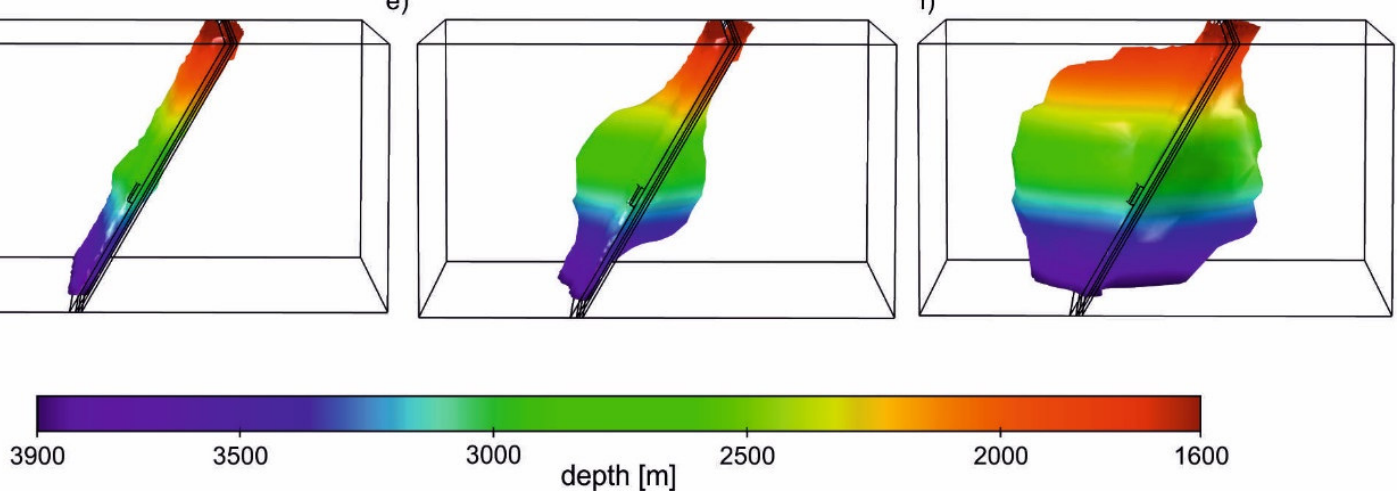

Fig. A10: Temperature development, breakthrough times, and reservoir shape of fault-related reservoir volumes acting as conductor depending on damage zone permeability and hydraulic gradient configuration. The host rock properties are based on the medium permeability and medium porosity model (M5). a to c) the temperature development of the produced fluid over time for north- and southward directed hydraulic gradients. The damage zone permeability increases from left to right. Arrows indicates the shortest thermal breakthrough times. $\mathbf{d}$ to $\mathbf{f}$ ) the corresponding shape of the HIT after 40 yr of heat production, simulated for a hydraulic gradient of $0 \mathrm{~mm} \mathrm{~m}^{-1}$. 


\subsection{Conclusions and outlook}

a)

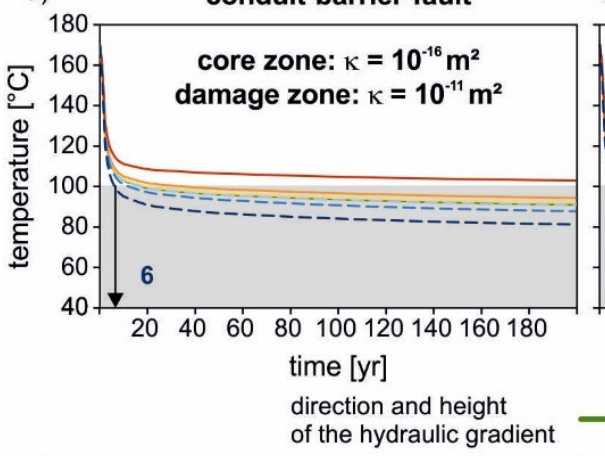

d)

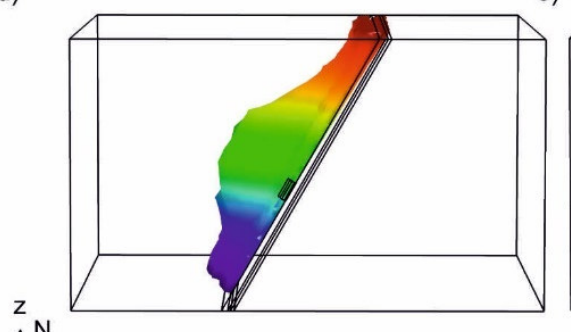

e) b) conduit-barrier-fault

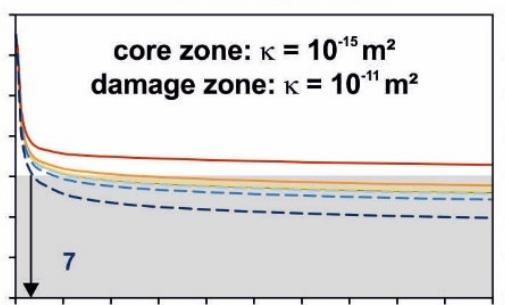

$20 \quad 40 \quad 60 \quad 80 \quad 100120140160180$ time [yr]

N $1 \mathrm{~mm} \mathrm{~m}^{-1}$ $0 \mathrm{~mm} \mathrm{~m}$

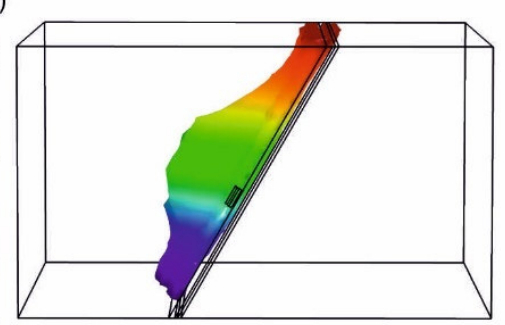

c) conduit-barrier-fault

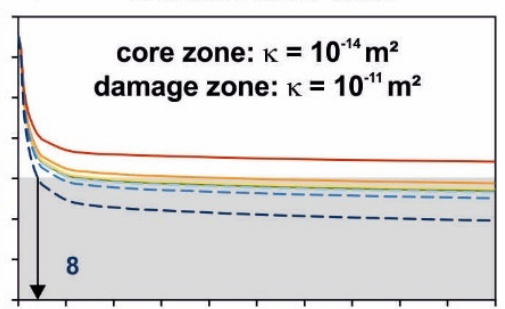

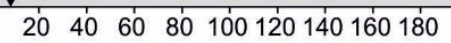
time [yr]<smiles>C[C@@H]1CN1</smiles>

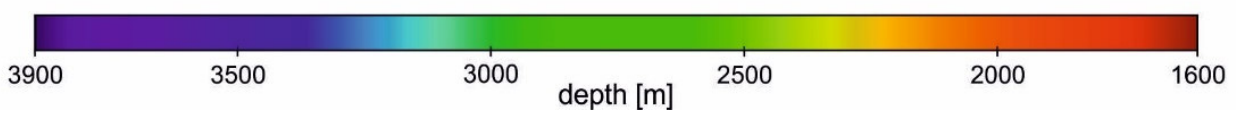

Fig. A11: Temperature development, breakthrough times, and reservoir shape of fault-related reservoir volumes acting as combined conduit-barrier system depending on fault core permeability and hydraulic gradient configuration. The host rock properties are based on the medium permeability and medium porosity model (M5). a to c) the temperature development of the produced fluid over time for north- and southward directed hydraulic gradients. The fault core permeability decreases from left to right. Arrows indicates the shortest thermal breakthrough times. $\mathbf{d}$ to e) the corresponding shape of the HIT after $40 \mathrm{yr}$ of heat production, simulated for a hydraulic gradient of $0 \mathrm{~mm} \mathrm{~m}^{-1}$. 